\title{
Transcriptional regulation of sex-dependently expressed renal organic anion transporter 1 and 3
}

\section{Doctoral Thesis}

In partial fulfillment of the requirements for the degree "Doctor rerum naturalium (Dr. rer. nat.)“

in the Molecular Medicine Study Program at the Georg-August University Göttingen

submitted by

Waja Wegner

born in Göttingen

Göttingen, November 2012 



\section{Members of the Thesis Committee:}

\section{Supervisor:}

Prof. Dr. Gerhard Burckhardt

Department of Systemic Physiology and Pathophysiology, University Medical Center, Georg-August University Göttingen

Second member of thesis committee:

Prof. Dr. Jürgen Brockmöller

Department of Clinical Pharmacology, University Medical Center, Georg-August University Göttingen

\section{Third member of thesis committee:}

Prof. Dr. Uwe Groß

Center for Hygiene and Human Genetics, University Medical Center, Georg-August University Göttingen

\section{Date of Disputation:}





\section{Affidavit}

Here I declare that my doctoral thesis entitled "Transcriptional regulation of sexdependently expressed renal organic anion transporter 1 and 3 " has been written independently with no other sources and aids than quoted.

Waja Wegner

Göttingen, November 2012 



\section{Related publications:}

Within this thesis, the following publication has been published. I want to thank all coauthors for their collaboration and assistance.

Wegner W, Burckhardt BC, Burckhardt G, and Henjakovic M.

Male-dominant activation of rat renal organic anion transporter 1 (Oat1) and 3 (Oat3) expression by transcription factor BCL6. PLoS One, published in 2012 (7:e35556)

\section{Parts of this thesis have been presented on meetings and conferences:}

June 2010

Talk, PhD-retreat molecular medicine, Göttingen: "Sex differences in the renal expression of organic anion transporters (OATs)"

September 2011 Talk, PhD-retreat molecular medicine, Braunlage: "Sex differences in the renal expression of organic anion transporters (Oats)"

September 2011 Poster, 3. Jahrestagung der Deutschen Gesellschaft für Nephrologie, Berlin: "Microarray analysis of gender-specific genes in proximal tubular cells of rat kidneys"

October 2011 Talk, Göttinger Transporttage, Göttingen: "Sex differences in the renal expression of rat organic anion transporters (Oats)"

March 2012 Talk, 91 ${ }^{\text {st }}$ Annual Meeting of the German Physiological Society, Dresden: "Male-dominant activation of rat organic anion transporter 1 (Oat1) and 3 (Oat3) by transcription factor BCL6"

April $2012 \quad$ Poster, Experimental Biology 2012, San Diego: "Male-dominant upregulation of organic anion transporter 1 (Oat1) and 3 (Oat3)"

October 2012 Poster, 4. Jahrestagung der Deutschen Gesellschaft für Nephrologie, Hamburg: "Activation of renal organic anion transporter 1 (Oat1 / OAT1) and 3 (Oat3 / OAT3) by BCL6"

October 2012 Talk, Göttinger Transporttage, Göttingen: “Activation of renal organic anion transporter 1 (Oat1/OAT1) and 3 (Oat3/OAT3) by BCL6" 



\section{Danksagung}

Ich bedanke mich bei

Herrn Prof. Dr. Gerhard Burckhardt, meinem Doktorvater, für das Vertrauen und die Möglichkeit meine Arbeit in der Abteilung vegetative Physiologie und Pathophysiologie durchführen zu können. Ihre Diskussionsbereitschaft und Ihr fachlicher Rat haben mit zum erfolgreichen Gellingen dieser Arbeit geführt.

Herrn Prof. Dr. Jürgen Brockmöller und Herrn Prof. Dr. Uwe Groß, für Ihr Interesse an meiner Arbeit und die damit verbundene Bereitschaft als Teil meines „thesis committees“ am Fortschritt meiner Arbeit teilzuhaben.

Frau Dr. Maja Henjakovic, für deine stetige Betreuung, deine Geduld, dein Engagement, deine unermüdliche Diskussionsbereitschaft, deine Korrekturen, sowie die vielen Anregungen während der letzten 3 Jahre. Ohne dies alles wäre meine Doktorarbeit nicht so, wie sie jetzt ist. Vielen Dank!

Frau Prof. Dr. Birgitta Burckhardt, für das aufmerksame Korrekturlesen unseres Papers.

allen Mitarbeitern des Zentrums für Physiologie und PortaCellTec, insbesondere Gesche Dallmayer, Sören Petzke, Dr. Nina Schnedler und Dr. Julia Grottker, für die zahlreichen Tipps und Anregungen während des Laboralltags und die schönen Mittagspausen $(;)$.

Jan Jäger, Marion Lösing, Franziska Hartung, Sebastian Meinhardt und Friederike Weinreich für die schönste Studienzeit meines Lebens (auch wenn ich nur eine hatte ()). Durch Euch und dich Dr. Silke Pauli, bin ich erst so weit gekommen, auch wenn ich zwischendurch nicht mehr so Recht wusste, ob dies der richtige Weg für mich ist. Danke, dass Ihr immer für mich da wart und mir geholfen habt!

allen, die mich während dieser 3 Jahre unterstütz und gefördert haben. Danke der Villa Kunterbunt und den Querschlägern für die tollen Spieleabende und die „fachlichen Diskussionen“. 
Ein ganz besonderer Dank gilt meiner Familie inklusive dir Uwe. Danke dass Ihr immer, Tag und Nacht für mich da wart und ich mich 120\% auf Euch verlassen konnte/kann. Danke Sister, für die länderübergreifenden Corel Nothilfen, ich werde dieses Programm nie ganz verstehen. Danke Daddy und Mama (die Betonung kennt ihr (-)), es ist einfach schön zu wissen, dass man solche Eltern seine nennen kann. Danke für Eure jahrelange Unterstützung! 


\section{Content}

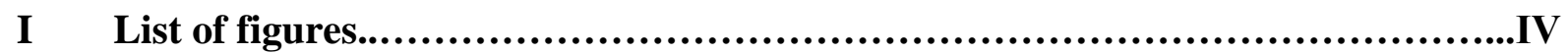

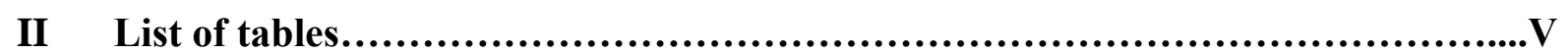

III List of abbreviations.................................................................

IV Abstract...................................................................................

1. Introduction .................................................................................................................................... 1

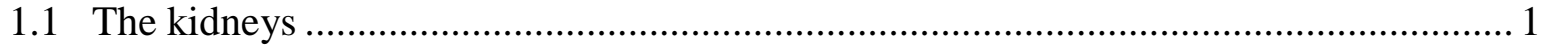

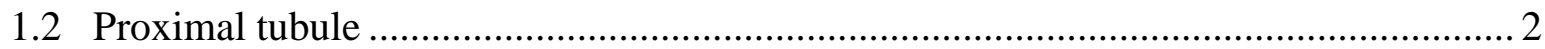

1.3 Organic anion transporter 1 (Oat1/OAT1) and 3 (Oat3/OAT3) …………………........ 3

1.3.1 Factors influencing rat and human Oat1/OAT1 and Oat3/OAT3 abundance and activity .................................................................................................. 4

1.3.2 Function of rat and human Oat1/OAT1 and Oat3/OAT3 ……………………...... 5

1.3.3 Substrates of rat and human Oat1/OAT1 and Oat3/OAT3 …………………….... 7

1.3.4 Adverse drug reactions (ADRs), a possible involvement of Oat1/OAT1 and

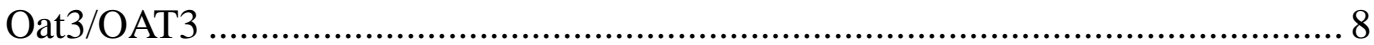

1.3.5 Sex-dependent expression of Oat1/OAT1 and Oat3/OAT3 and the impact of testosterone

1.4 Testosterone-dependent and androgen receptor mediated transcriptional activation of

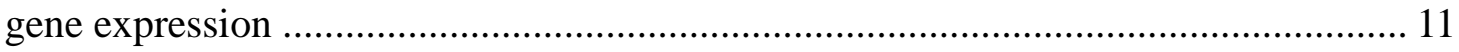

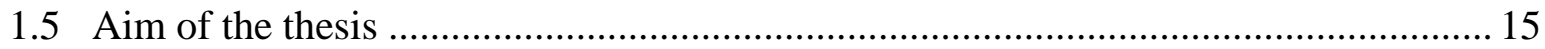

2. Material and Methods........................................................................................................ 16

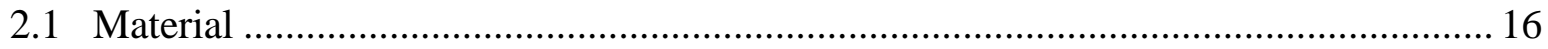

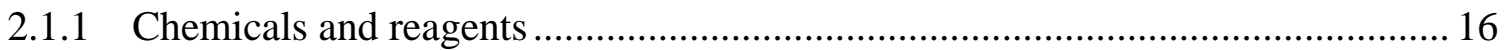

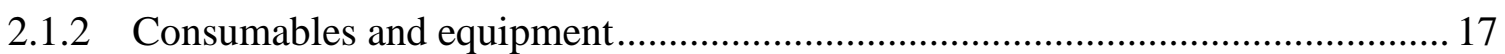

2.1.3 Reaction components and commercial kits ........................................................ 19

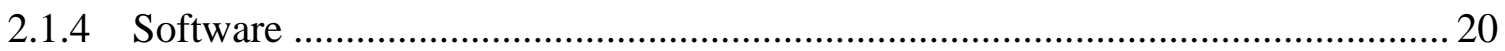

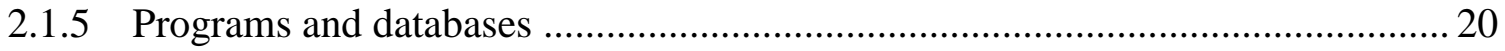

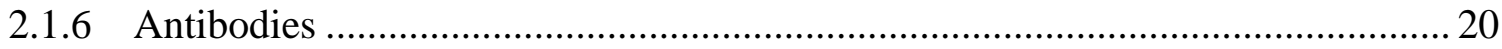

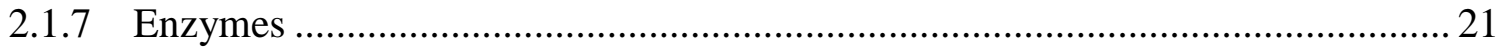

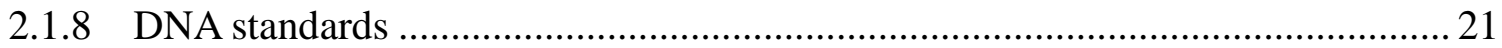

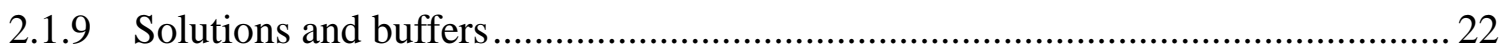

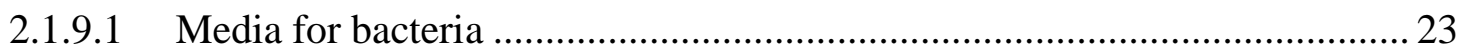




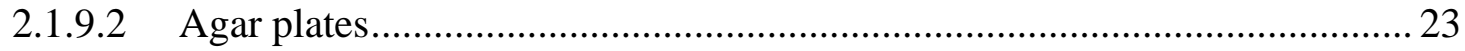

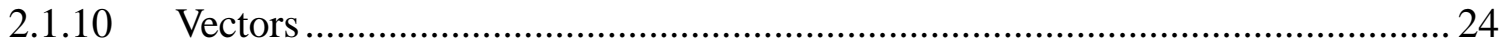

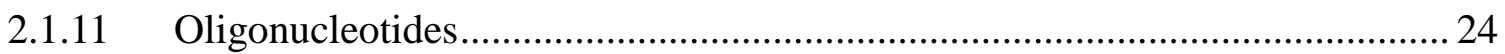

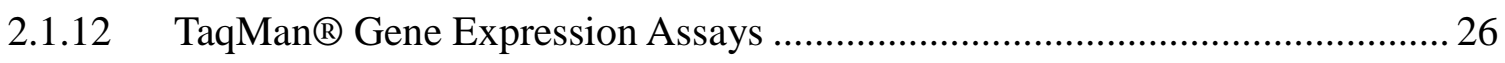

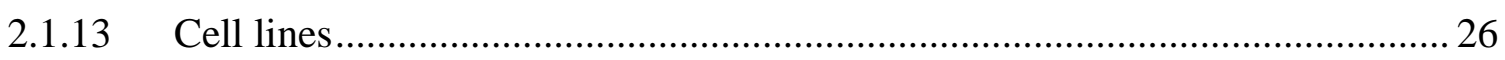

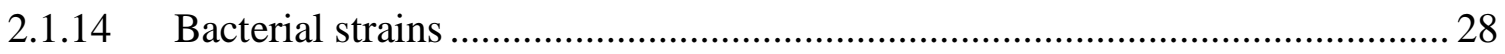

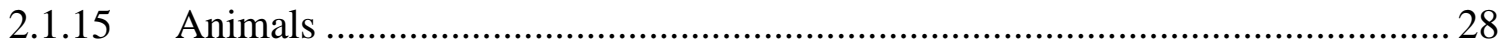

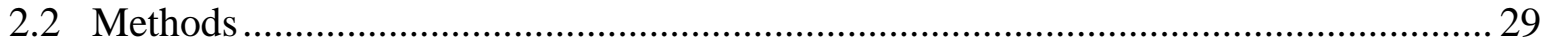

2.2.1 Methods required for promoter construct generation ........................................ 29

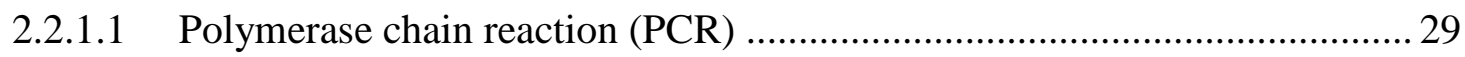

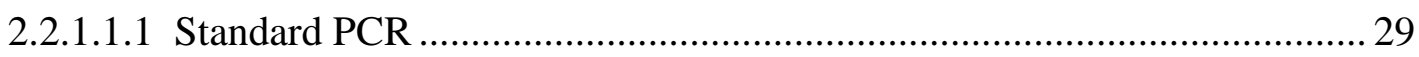

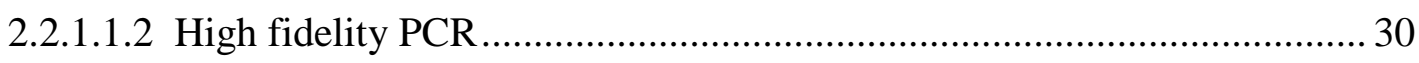

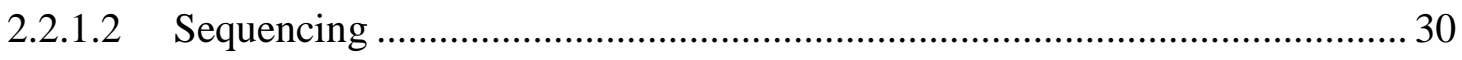

2.2.1.3 Concentration determination of DNA and RNA ….................................... 31

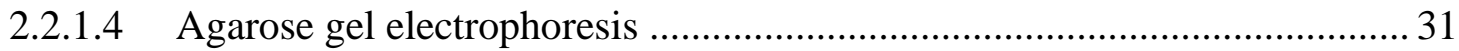

2.2.1.5 Isolation and purification of nucleic acids .............................................. 32

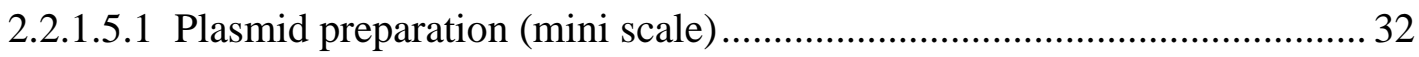

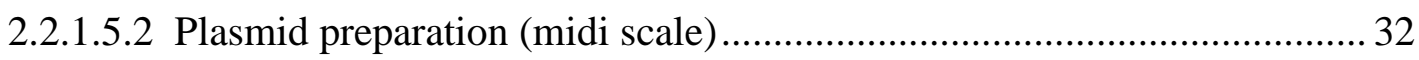

2.2.1.6 Purification of PCR products, restricted-, and dephosphorylated

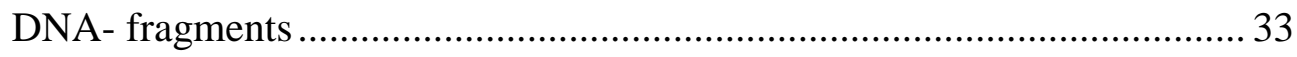

2.2.1.7 Digestion of DNA with restriction endonucleases ..................................... 33

2.2.1.8 Dephosphorylation of linearized vector .................................................... 33

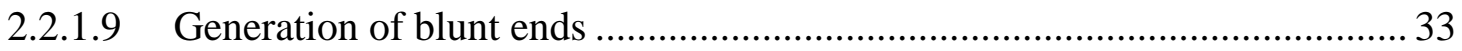

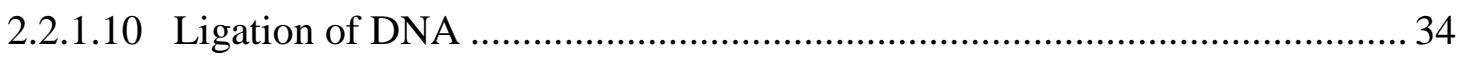

2.2.1.11 Transformation of competent bacteria with DNA ...................................... 34

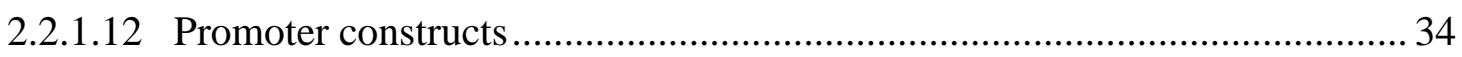

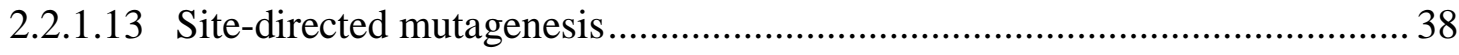

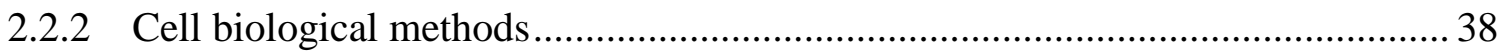

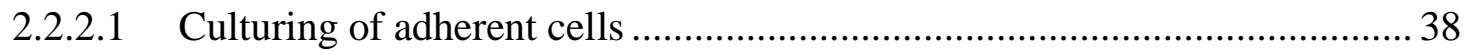

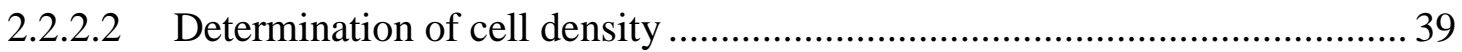

2.2.2.3 Transiently transfection of adherent cells.................................................. 40

2.2.2.3.1 Transiently transfection with pSG5-ratAr/AR ................................... 40

2.2.2.3.2 Transiently transfection with pcDNA3-BCL6 .................................... 40

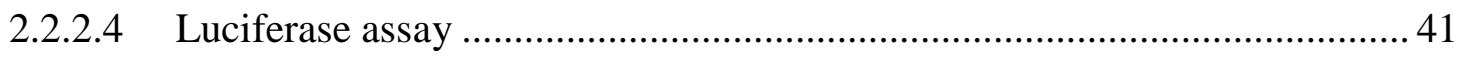


2.2.2.4.1 Immunostaining and evaluation of transfection efficiency 42

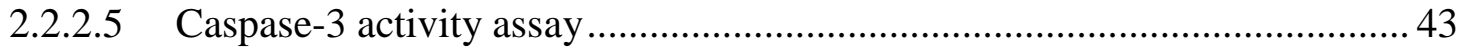

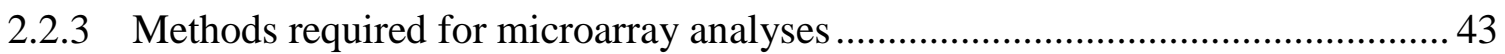

2.2.3.1 Preparation of rat cortical kidney slices ................................................... 43

2.2.3.2 Isolation and purification of total RNA.................................................... 44

2.2.3.2.1 Preparation of total RNA from rat cortical kidney slices ........................ 44

2.2.3.3 Sample preparation for microarray analyses ............................................. 45

2.2.3.4 Data analysis and adjustments of microarray data ..................................... 46

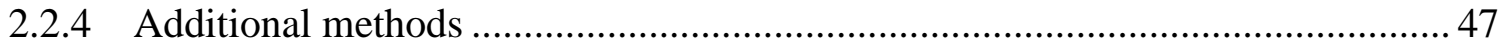

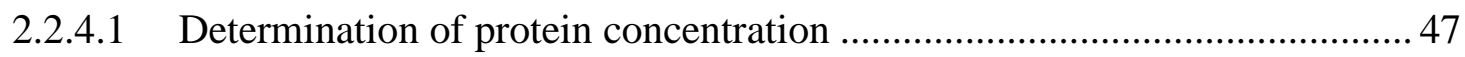

2.2.4.2 Preparation of RNA from adherent cells .................................................... 48

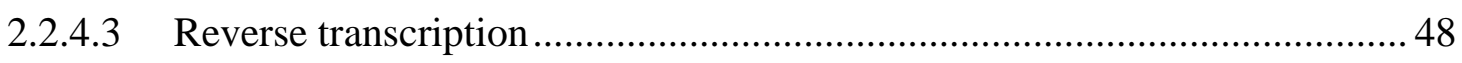

2.2.4.4 Real-time PCR with TaqMan® Gene Expression Assay ............................. 48

2.2.4.5 Statistic, non related to microarray ............................................................ 49

2.2.4.6 Determination of transcription start site .................................................. 50

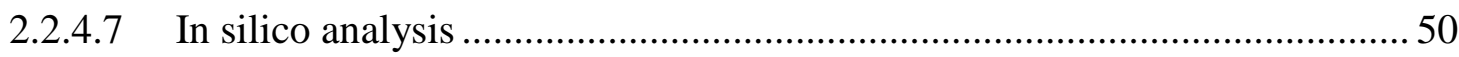

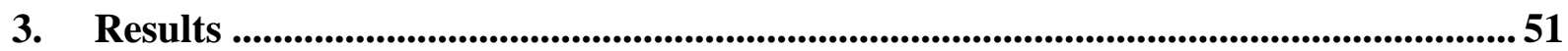

3.1 Impact of testosterone/androgen receptor complex on the regulation of organic anion

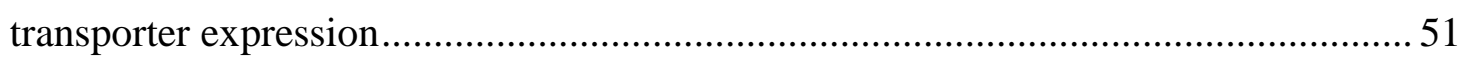

3.1.1 Localization of predicted androgen response elements (AREs) .........................51

3.1.2 Testosterone-dependent promoter activity in opossum kidney (OK) cells .......... 52

3.1.3 Effect of testosterone on promoter activity in the porcine kidney cell line

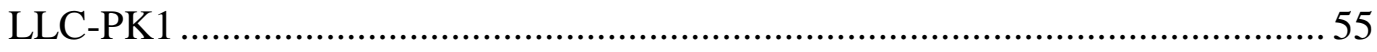

3.2 Sex-dependent expression of renal proximal tubular genes ....................................57

3.3 Involvement of transcription factor B-cell CLL/lymphoma 6 (BCL6) in the activation

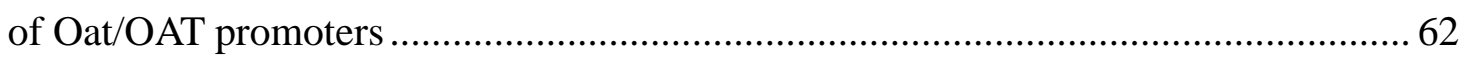

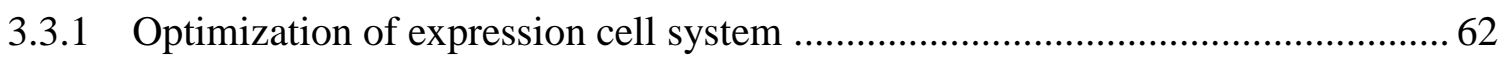

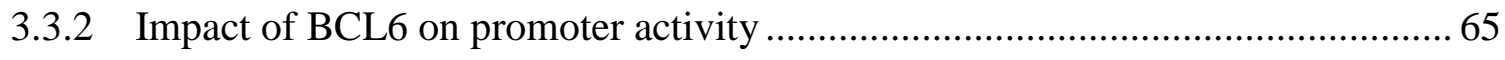

3.3.2.1 Influence of BCL6 on the regulation of rat Oat1 and Oat3 promoters......... 68

3.3.2.2 Effect of BCL6 on the promoter activity of human OAT1 and OAT3 .........73

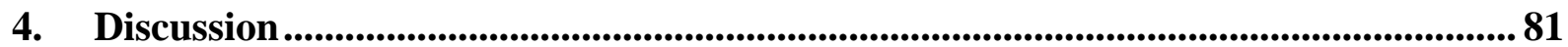

4.1 Involvement of testosterone in the regulation of rat and human Oat1/OAT1 and Oat3/OAT3 
Content

4.2 Identification of sex-dependently expressed genes in rat proximal tubule cells .......... 84

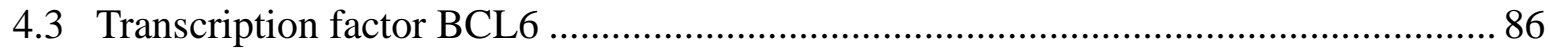

4.3.1 Establishment of a cell system for BCL6-dependent promoter regulation ........... 88

4.3.2 BCL6-dependent rat and human Oat1/OAT1 and Oat3/OAT3 promoter activation

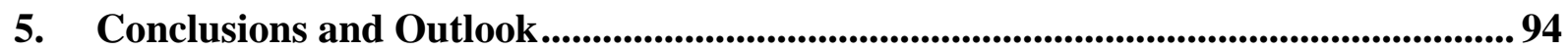

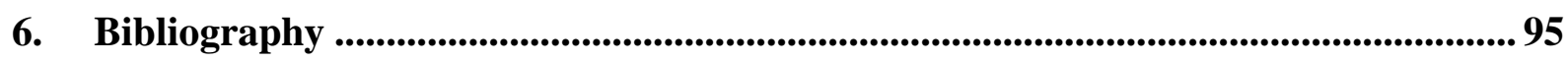

7. Appendix ........................................................................................................................................... 115

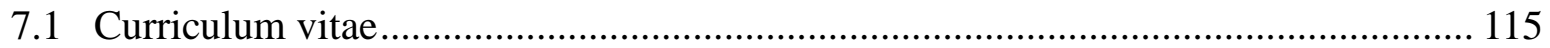

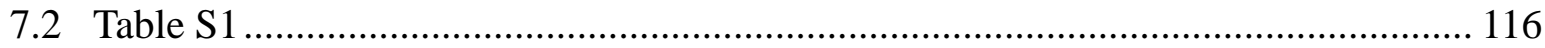

\section{List of figures}

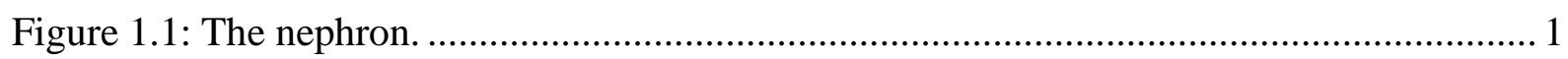

Figure 1.2: Localization of organic anion transporters in a human renal proximal tubules cell.6

Figure 1.3: Schematic overview of human androgen receptor (AR). .................................. 12

Figure 1.4: Overview of the androgen-dependent activation cascade................................... 14

Figure 2.1: Bioluminescent reaction catalyzed by firefly and Renilla luciferase. .................. 41

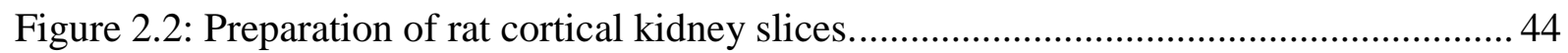

Figure 2.3: Agilent 2100 Bioanalzer: quality and quantity of isolated total RNA................. 45

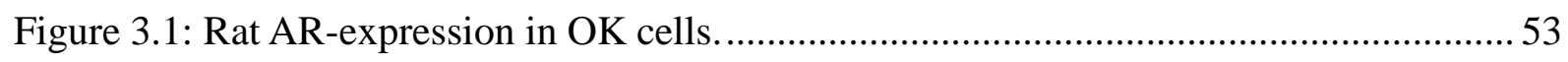

Figure 3.2: Effect of testosterone on probasin, Oat1, Oat3, OAT1, and OAT3 promoter

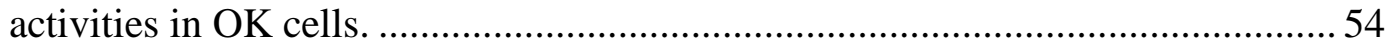

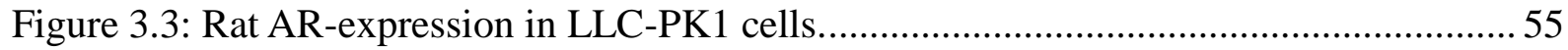

Figure 3.4: Testosterone-dependent promoter activities of probasin, Oat1, Oat3, and Oct2 in

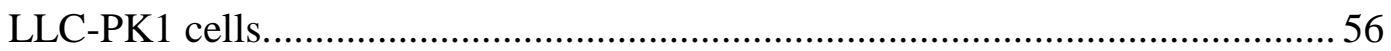

Figure 3.5: Sex-dependent expression of Oat1 and Oat3 in rat cortical kidney slices.............58

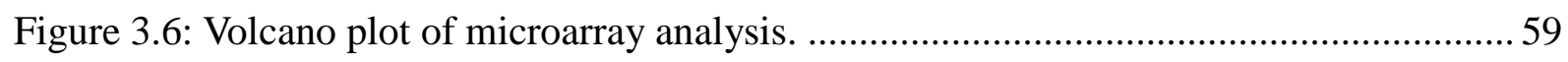

Figure 3.7: Verification of microarray results using TaqMan ${ }^{\circledR}$ real-time PCR ...................... 61

Figure 3.8: Alignment of mouse, rat, and human BCL6 protein sequences........................... 63

Figure 3.9: Transfection efficiency of BCL6 in different epithelial cell lines. ........................ 64

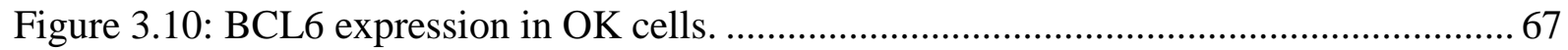

Figure 3.11: Detection of apoptosis by measuring caspase-3 activity in OK cells................ 67 


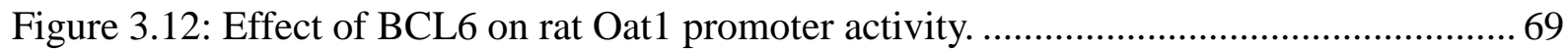

Figure 3.13: BCL6-dependent rat Oat1 promoter activity after binding sites mutation.......... 70

Figure 3.14: Impact of BCL6 on rat Oat3 promoter activity................................................ 71

Figure 3.15: Rat Oat3 promoter activity after mutation of BCL6 binding sites. .................... 72

Figure 3.16: BCL6-dependent human OAT1 promoter activity............................................ 74

Figure 3.17: BCL6-induced human OAT1 promoter activity after mutation of BCL6 binding

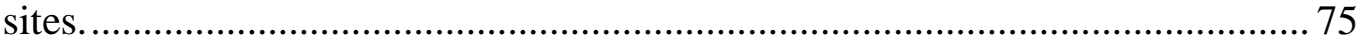

Figure 3.18: Effect of BCL6 on truncated human OAT1 promoter constructs. ....................... 77

Figure 3.19: Involvement of BCL6 on human OAT3 promoter activity................................ 78

Figure 3.20: Impact of BCL6 on truncated human OAT3 promoter constructs....................... 79

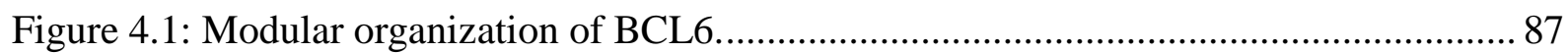

Figure 4.2: Mechanism by which BCL6 possibly activates the transcription of rat and human

Oat1/OAT1 and Oat3/OAT3. 92

\section{List of tables}

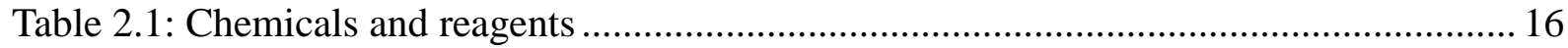

Table 2.2: Consumables for general laboratory work ......................................................... 17

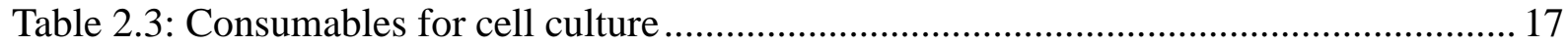

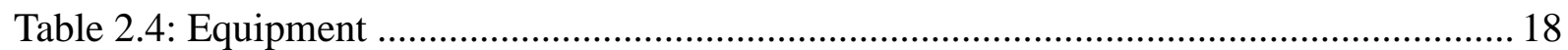

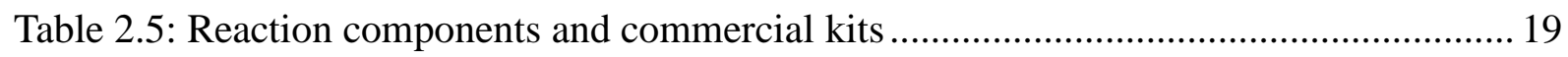

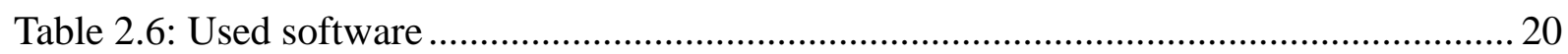

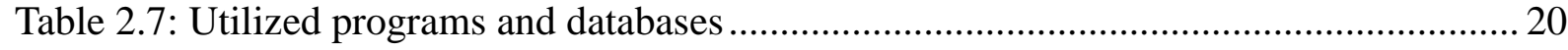

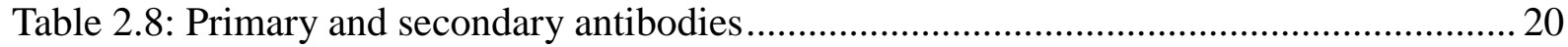

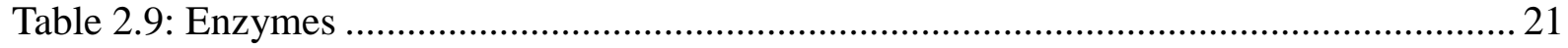

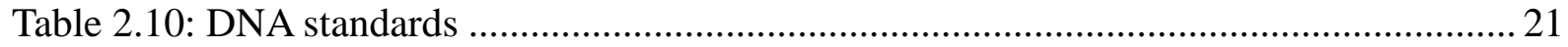

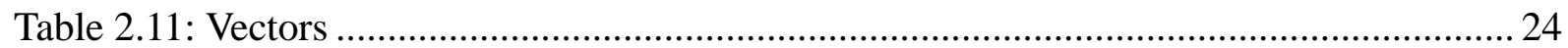

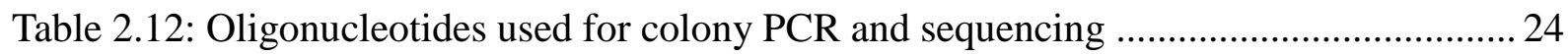

Table 2.13: Oligonucleotides for site directed mutagenesis .............................................. 25

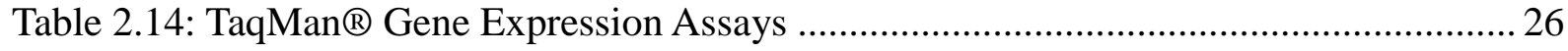

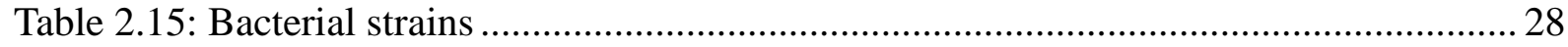

Table 2.16: Used oligonucleotides, restriction endonucleases, and backbone vectors to generate rat Oat1, Oat 3 , and Oct 2 promoter constructs. 
Content

Table 2.17: Used oligonucleotides, restriction endonucleases, and backbone vectors to generate human OAT1, and OAT3 promoter constructs.

Table 2.18: Cell lines with respectively growth medium.

Table 3.1: In silico promoter analyses of rat and human Oat1/OAT1 and Oat3/OAT3, with respect to androgen response elements (ARE).

Table 3.2: Sex-dependently expressed genes in rat proximal tubule cells. 60

Table 3.3: Promoter activity of rat and human Oat1/OAT1 and Oat3/OAT3 in different cell lines .65

Table 3.4: In silico analyses of rat and human Oat1/OAT1 and Oat3/OAT3 promoters due to BCL6 binding sites. 66

Table 3.5: In silico analyses of OAT1 (-63/+88) and OAT3 (-112/-59). 80

Table S1: Sex-dependently expressed genes in rat cortical kidney slices. 116

\section{List of abbreviations}

\section{III.I Abbreviations, which were often used or not introduced in detail}

aa amino acid

ADR adverse drug reaction

ATP adenosine triphosphate

AR androgen receptor

ARE androgen response element

$\mathrm{A}_{260}$ absorbance at the wavelengths of $260 \mathrm{~nm}$

$\mathrm{A}_{280}$ absorbance at the wavelengths of $280 \mathrm{~nm}$

$\beta$-actin beta actin

BCDF biocoid-like homeodomain transcription factors

BCL6 B-cell CLL/lymphoma 6

BSA bovine serum albumin

bp base pairs

cAMP cyclic adenosine monophosphate

cGMP cyclic guanosine monophosphate

cDNA complementary DNA

$\mathrm{CO}_{2} \quad$ carbon dioxide

CREB cAMP response element binding proteins 


\begin{tabular}{|c|c|}
\hline $\mathrm{Da}$ & dalton \\
\hline DAPI & 4',6-diamidino-2-phenylindole \\
\hline ddNTP & dideoxyribonucleotide triphosphate \\
\hline $\mathrm{dH}_{2} \mathrm{O}$ & aqua destillata \\
\hline$\Delta$ & delta \\
\hline DMSO & dimethyl sulfoxide \\
\hline DNA & deoxyribonucleic acid \\
\hline dNTP & deoxyribonucleotide triphosphate \\
\hline DMEM & Dulbeco's modified eagle medium \\
\hline ds & double stranded \\
\hline DTT & dithiotreitol \\
\hline E.coli & Escherichia coli \\
\hline EDTA & ethylenediaminetetraacetric acid \\
\hline ES & estrone-3-sulfate \\
\hline $\mathrm{F}$ & forward \\
\hline $\mathrm{F} / \mathrm{f}$ & female \\
\hline FAM & 6-carboxy-fluorescein \\
\hline FBS & fetal bovine serum \\
\hline FDA & Food and Drug Administration \\
\hline $\mathrm{HCl}$ & hydrochloride \\
\hline $\mathrm{HG}$ & high glucose \\
\hline $\mathrm{HNF}$ & hepatocyte nuclear factor \\
\hline Hprt1 & hypoxanthine phosphoribosyltransferase 1 \\
\hline HSD17B1 & hydroxysteroid (17-beta) dehydrogenase 1 \\
\hline $\mathrm{H}_{2} \mathrm{O}$ & water \\
\hline $\mathrm{KCl}$ & potassium chloride \\
\hline$K_{\mathrm{M}}$ & Michaelis-Menten constant \\
\hline LB & Luria broth \\
\hline $\mathrm{LG}$ & low glucose \\
\hline $\log 2$ & binary logarithm \\
\hline $\log 10$ & base-10 logarithm \\
\hline $\mathrm{M} / \mathrm{m}$ & male \\
\hline $\mathrm{MgCl}_{2}$ & magnesium chloride \\
\hline MYBL & cellular and viral myb-like transcriptional regulators \\
\hline
\end{tabular}


Content

mRNA messenger ribonucleic acid

$\mathrm{NaCl} \quad$ sodium chloride

NCBI National Center for Biotechnology Information

NEB New England Biolabs

NFкB nuclear factor kappa-light-chain-enhancer of activated B-cells

OAT organic anion transporter

OCT organic cation transporter

OK Opossum kidney

PAH $\quad \operatorname{para}(p)$-aminohippurate

PBS phosphate buffered saline

PCR polymerase chain reaction

POLR3G polymerase (RNA) III (DNA directed) polypeptide G

POZ/BTB Poxviruses Zinc-finger (POZ) or Broad complex, Tramtrack, and Bric à brac (BTB) domain

$\mathrm{R} \quad$ reverse

RNA ribonucleic acid

ROX 6-carboxy-X-rhodamin

rpm rounds per minute

RT room temperature $\left(21-25^{\circ} \mathrm{C}\right)$

SLC22 solute carrier family 22

SOC derivate of super optimal broth (SOB) medium

ss single stranded

TAMARA 6-carboxy-tetramethyl-rhodamin

TBE Tris borat EDTA buffer

TF transcription factor

tRNA transfer RNA

Tris tris(hydroxymethyl)aminomethane 


\section{III.II Prefixes and units}

$\begin{array}{llllll}\mathrm{b} & \text { base } & \mathrm{l} & \text { liter } & \mathrm{n} & \text { nano } \\ { }^{\circ} \mathrm{C} & \text { degree Celsius } & \mathrm{m} & \text { meter } & \mathrm{p} & \text { pico } \\ \mathrm{F} & \text { farad } & \mathrm{m} & \text { milli } & \mathrm{s} & \text { second } \\ \mathrm{g} & \text { gram } & \mathrm{min} & \text { minute } & \mathrm{U} & \text { unit } \\ \mathrm{h} & \text { hour } & \mathrm{M} & \text { molar } & \mathrm{V} & \text { Volt } \\ \mathrm{k} & \text { kilo } & \mu & \text { micro } & \mathrm{x} \mathrm{g} & \text { acceleration of gravity }\end{array}$

\section{III.III Amino acids}

\begin{tabular}{|c|c|c|}
\hline \multirow{2}{*}{ Name } & \multicolumn{2}{|c|}{ Abbreviation } \\
\hline & 3 letter code & 1 letter code \\
\hline Alanine & Ala & $\mathrm{A}$ \\
\hline Arginine & Arg & $\mathrm{R}$ \\
\hline Asparagine & Asn & $\mathrm{N}$ \\
\hline Aspartic acid & Asp & $\mathrm{D}$ \\
\hline Cysteine & Cys & $\mathrm{C}$ \\
\hline Glutamic acid & Glu & $\mathrm{E}$ \\
\hline Glutamine & Gln & $\mathrm{Q}$ \\
\hline Glycine & Gly & $\mathrm{G}$ \\
\hline Histidine & His & $\mathrm{H}$ \\
\hline Isoleucine & Ile & $\mathrm{I}$ \\
\hline Leucine & Leu & $\mathrm{L}$ \\
\hline Lysine & Lys & $\mathrm{K}$ \\
\hline Methionine & Met & $\mathrm{M}$ \\
\hline Phenylalanine & Phe & $\mathrm{F}$ \\
\hline Proline & Pro & $\mathrm{P}$ \\
\hline Serine & Ser & $S$ \\
\hline Threonine & Thr & $\mathrm{T}$ \\
\hline Tryptophan & $\operatorname{Trp}$ & $\mathrm{W}$ \\
\hline Tyrosin & Tyr & $\mathrm{Y}$ \\
\hline Valine & Val & $\mathrm{V}$ \\
\hline
\end{tabular}


Content

III.IV Deoxyribonucleotides

\begin{tabular}{|c|c|}
\hline Deoxyribonucleotide & Abbreviation \\
\hline Deoxyadenosine & $\mathrm{A}$ \\
\hline Deoxycytidine & $\mathrm{C}$ \\
\hline Deoxyguanosine & $\mathrm{G}$ \\
\hline Deoxythymidine & $\mathrm{T}$ \\
\hline Any deoxyribonucleotide & $\mathrm{N}$ \\
\hline
\end{tabular}




\section{Abstract}

The renal organic anion transporters (OATs) play a pivotal role in the elimination of endogenous and exogenous substrates. In rats, an often used preclinical animal model, the basolateral located organic anion transporter 1 (Oat1) and 3 (Oat3) are known to be male-dominant and testosterone-dependently expressed. They are involved in the secretion of organic anions, including negatively charged drugs such as adefovir, furosemide, or penicillin. Human OAT1 and OAT3 were mentioned as clinically relevant transporters in the kidneys, which have to be investigated during drug development. The antibiotic penicillin has been shown to cause more adverse drug reactions (ADRs) in women compared to men. This higher risk is supposed to be partially due to sex-differences in the OAT1 and OAT3 expression.

The aim of my thesis was to identify the molecular mechanism involved in the male-dominant expression of rat Oat1 and Oat3.

Activation of rat and human Oat1/OAT1 and Oat3/OAT3 promoters were investigated by using luciferase activity assays. A series of promoter-length-varying rat and human Oat1/OAT1 and Oat3/OAT3 reporter constructs were generated and transiently transfected into OK or LLC-PK1 cells. By co-transfection of the supposed transcriptional regulators, their effects on Oat1/OAT1 and Oat3/OAT3 promoter activities were examined. For the identification of sex-dependently expressed genes in rat proximal tubule cells, RNA from four male and four female rats were investigated by using microarray analyses and real-time PCR. In this thesis, it was shown that the known male-dominant expression of rat Oat1 and Oat3 was not regulated via the testosterone/androgen receptor mediated transcriptional pathway. Similar to rat Oat1 and Oat3, testosterone/androgen receptor complex did not activate human OAT1 and OAT3 promoters. While searching for sex-dependently expressed transcriptional regulators, the transcription factor B-cell CLL / lymphoma 6 (BCL6) was newly identified as a highly male-dominantly expressed gene within the rat kidneys. The known Oats/OATs transcriptional regulators hepatocyte nuclear factor $1 \alpha(\mathrm{HNF} 1 \alpha), \mathrm{HNF} 1 \beta$, and HNF4 $\alpha$, revealed not sex-dependent expression. Moreover, BCL6 was shown to activate the promoters of rat and human Oat1/OAT1 and Oat3/OAT3, independent of predicted BCL6 binding sites, but probably via protein-protein interactions with the transcription factors HNF1 or cAMP response element binding protein (CREB).

In conclusion, the male-dominantly expressed transcription factor BCL6 is a promising regulator for the sex-dependent rat Oat1 and Oat3 expression, furthermore, it is also assumed to be involved in the regulation of human OAT1 and OAT3 transcription. 


\section{Introduction}

\subsection{The kidneys}

The kidneys are bean-shaped paired organs which play an important role in the regulation of electrolyte-, water-, mineral-, and acid-base balance (Schmidt et al., 2010). Furthermore, they are involved in the mineralization of bones, maintenance of blood pressure, and in the production of the hormones calcitriol, erythropoietin, and renin (Klinke et al., 2010; Schmidt et al., 2010). The elimination of endogenous and exogenous substrates occurs in the functional units, the nephrons. Each healthy human kidney consists of approximately one million nephrons (Chabardes-Garonne et al., 2003). The five major segments of each nephron are the glomerulus, the proximal tubule, the loop of Henle, the distal tubule, and the collecting duct (figure 1.1).

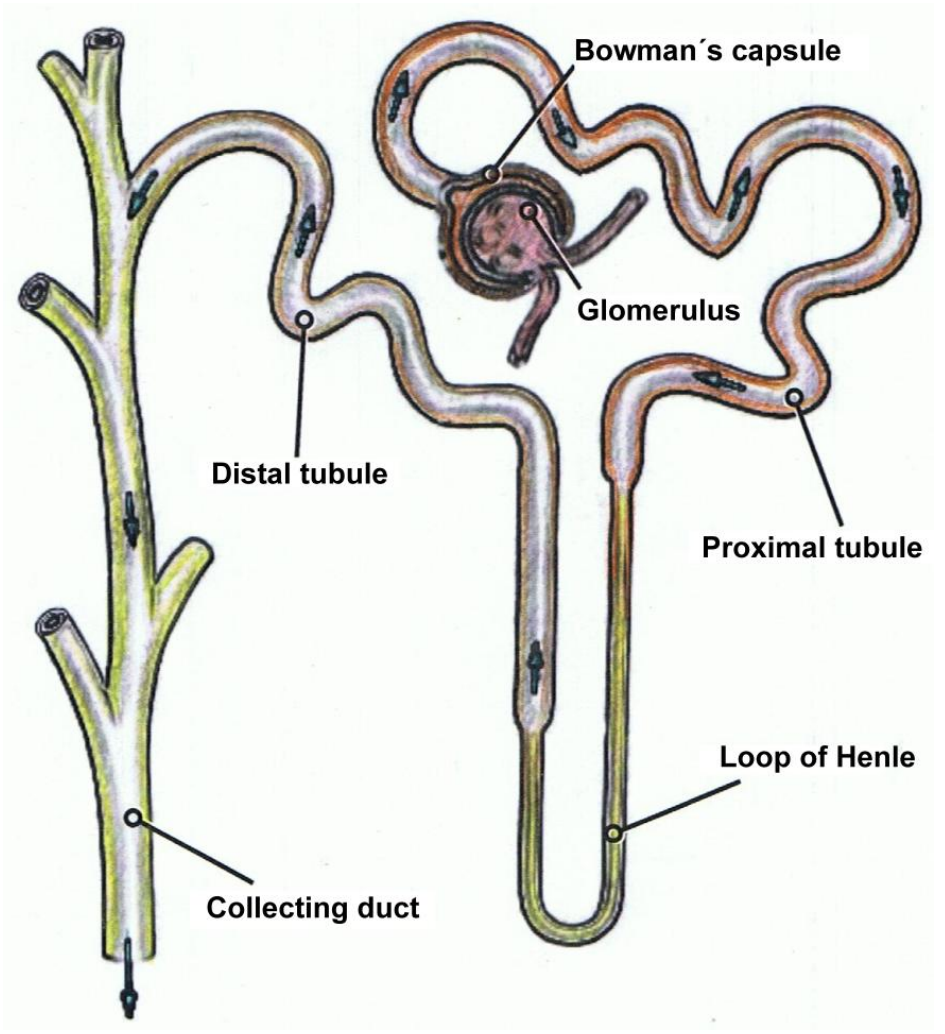

Figure 1.1: The nephron.

The diagram shows the five major parts of a nephron. The glomerulus with Bowman's capsule, the proximal tubule, the loop of Henle, the distal tubule, and the collecting duct. Arrows indicate the flow direction.

During the first step of renal waste elimination, the blood passes the glomerulus, which is surrounded by the Bowman's capsule, and acts as a filtering or sieve unit (Schmidt et al., 
2010). After passing Bowman's capsule, the filtered liquid, now called primary urine, enters the proximal tubule. As a reason of glomerulus and Bowman's capsule permselectivity, the primary urine consists of waste materials but also of small proteins $(<70 \mathrm{kDa})$ and chemicals likes potassium, sodium, and glucose, which are still useful for the body (Klinke et al., 2010; Schmidt et al., 2010). After leaving the proximal tubules, the filtrate passes the loop of Henle, the distal tubules, and ends up in the collecting duct, to leave the body as the concentrated final urine. Due to reabsorption and secretion processes along the whole nephron, the composition of glomerulus filtrate and final urine differs (Klinke et al., 2010; Schmidt et al., 2010).

\subsection{Proximal tubule}

The proximal tubule is directly connected to the glomerulus (figure 1.1) and executes two major tasks: (1) reabsorption of salts, water, and organic compounds from the primary urine back into the blood, to avoid their loss, and (2) secretion of waste products from the blood into the primary urine, including exogenous negatively charged drugs and their metabolites, to ensure their effective elimination (Burckhardt and Burckhardt, 2003).

Renal proximal tubule cells are polar cells, which are determined by the occurrence of an apical and basolateral membrane (Heidrich et al., 1972; Genestie et al., 1995; Phillips et al., 1997). Secretion processes by the proximal tubules has been demonstrated early in 1874 , at which Heidenhain demonstrated that the anion indigo carmine was actively secreted by the proximal tubules from the blood into the urine (Heidenhain, 1874). Beside secretion, also reabsorption processes take place, for example $95 \%$ of lactate and $100 \%$ of glucose are reabsorbed in the proximal tubules (Hohmann et al., 1974; Wright, 2001).

For such translocation processes across the highly selective apical and basolateral membrane, expressions of transport proteins are required. These proteins are arranged in a complex system, establishing proper transmembrane gradients to ensure a directed transport of a variety of compounds [for an overview see (Koepsell et al., 2007; Ahn and Nigam, 2009; Keppler, 2011; Burckhardt, 2012; Riedmaier et al., 2012)]. Among others, transport proteins which are expressed at the basolateral and apical membrane of proximal tubules cells belong to the solute carrier family 22 (SLC22). This family is known as the organic cation/anion/zwitterions transporter family, which includes 22 genes in humans, with additionally six structurally related but so far not assigned genes (Hediger et al., 2004; 
Koepsell and Endou, 2004; Jacobsson et al., 2007). The SLC22 family includes the organic anion transporters (OATs), the organic cation transporters (OCTs), the organic carnitine transporters (OCTNs), unknown substrate transporters (USTs), and urate transporters (URATs) (Koepsell and Endou, 2004; Jacobsson et al., 2007; Ahn and Nigam, 2009; Wu et $a l ., 2009)$. In this thesis the focus will be on the organic anion transporter 1 (OAT1), and 3 (OAT3). Human OAT1 or OAT3 will always be indicated as capital letters, whereas Oat1 or Oat3 from rat or other species will be represented in small letters.

\subsection{Organic anion transporter 1 (Oat1/OAT1) and 3 (Oat3/OAT3)}

Genes for human OAT1 (SLC22A6) and rat Oat1 (Slc22a6) are located on chromosome 11q12.3, and chromosome 1q34, respectively [The National Center for Biotechnology Information (NCBI), Gene ID: 9356, and Gene ID: 29509]. OAT3 (SLC22A8) is found at 11q11 (NCBI: Gene ID: 9376), whereas Oat3 (Slc22a8) is localized to chromosome 1q34, in the direct neighborhood of Oat1 (NCBI: Gene ID: 83500).

Cloning and functional characterization of Oat1/OAT1 and Oat3/OAT3 in several species have been published. The Oat1/OAT1 has been identified and characterized in human (Reid et al., 1998; Cihlar et al., 1999; Hosoyamada et al., 1999; Lu et al., 1999a; Race et al., 1999), rat (Sekine et al., 1997; Sweet et al., 1997), mouse (Lopez-Nieto et al., 1997), pig (Hagos et al., 2002), rabbit (Bahn et al., 2002), monkey (Tahara et al., 2005), winter flounder (Wolff et al., 1997), and Caenorhabditis elegans (George et al., 1999), whereas the Oat3/OAT3 has been cloned and functionally investigated in human (Race et al., 1999; Cha et al., 2001), rat (Kusuhara et al., 1999), mouse (Brady et al., 1999), pig (Hagos et al., 2005), rabbit (Zhang et al., 2004), and monkey (Tahara et al., 2005). Rat and human Oat1/OAT1 and Oat3/OAT3 have been shown to be widely expressed, including the retina, liver, kidneys, brain, placenta, and skeletal muscle with the highest abundance in the kidneys (Sekine et al., 1997; Cihlar et al., 1999; Hosoyamada et al., 1999; Kusuhara et al., 1999; Lu et al., 1999a; Sweet et al., 1999; Cha et al., 2001; Nishimura and Naito, 2005; Bleasby et al., 2006).

With regard to their proteins, rat Oat1 exhibits one splice variant, which is composed of 551 amino acids (NCBI: NP_058920.1), whereas human OAT1 has four splice variants, varying from 550 to 506 amino acids (NCBI: Gene ID: 9356, NP_004781.2, NP_695008.1, NP_695010.1, and NP_695009.1). Only the two longest isoforms OAT1-1 (563 aa) and OAT1-2 (550 aa) have been shown to be functional with identical properties (Bahn et al., 
2000; Bahn et al., 2004). Rat Oat3 has one isoform, which is composed of 536 amino acids (NCBI: NP_112622.1). Human OAT3 has again four different transcripts, leading to three different proteins (NCBI). The longest protein consists of 542 amino acids and was shown to be the only functional isoform [NCBI: NP_001171661.1, (Cha et al., 2001; Bakhiya et al., 2003)]. Prediction of the three-dimensional protein structure of Oat1/OAT1 and Oat3/OAT3 revealed 12 transmembrane helices, with an intracellular localization of the $\mathrm{N}$ - and C-termini [summarized in (Koepsell and Endou, 2004; Jacobsson et al., 2007; Srimaroeng et al., 2008)]. Focusing on the kidneys, rat and human Oat1/OAT1 and Oat3/OAT3 are expressed on the basolateral membrane of proximal tubule cells (Hosoyamada et al., 1999; Tojo et al., 1999; Cha et al., 2001; Kojima et al., 2002; Motohashi et al., 2002). Concerning the highest abundance of both transporters some controversial literature exists. In rats, a higher renal Oat3 mRNA level compared to Oat1 was found by the group of Leazer and Agustine, whereas Buist detected a higher Oat1 mRNA level compared to Oat3 (Buist et al., 2002; Leazer and Klaassen, 2003; Augustine et al., 2005). In human, Motohashi and colleagues published a higher mRNA level of OAT3 than OAT1 whereas, in other studies, the mRNA levels were either equal or OAT1 slightly higher than OAT3 (Motohashi et al., 2002; Sakurai et al., 2004; Hilgendorf et al., 2007).

\subsubsection{Factors influencing rat and human Oat1/OAT1 and Oat3/OAT3 abundance and activity}

In general, little is known about the transcriptional regulation of Oats/OATs. Three members of the hepatocyte nuclear factor (HNF) family, HNF1 $\alpha, \mathrm{HNF} 1 \beta$, and HNF4 have been shown to be involved in their regulation (Kikuchi et al., 2006; Ogasawara et al., 2007; Saji et al., 2008; Jin et al., 2011). The promoters of mouse and human Oat1/OAT1, human OAT3, and human OAT4 are known to be activated by HNF1 $\alpha / \beta$ (Kikuchi et al., 2006; Saji et al., 2008; Jin et al., 2011). Furthermore, the HNF1 $\alpha$ knockout mice exhibited a reduced Oat1 and Oat3 expression (Maher et al., 2006). The transcription factor HNF4 $\alpha$ activates the promoter of human OAT1 (Ogasawara et al., 2007). Activated liver X receptor decreases human OAT1 expression in the proximal tubules (Kittayaruksakul et al., 2011). Furthermore, an increased promoter activity of human OAT3 was reported in the presence of cAMP (Ogasawara et al., 2006). DNA methylation was also indicated to influence the regulation of human OAT3 promoter, and moreover, it is responsible for the tissue-specific expression of several 
transporters like OAT1, OAT3, OAT4, and urate transporter 1 (URAT1) (Kikuchi et al., 2006; Jin et al., 2011).

Posttranscriptional modification leading to impaired function of Oat1/OAT1 and Oat3/OAT3 has also been reported. Protein kinase C (PKC) reduces the transport rate of human OAT1 by altering their trafficking through a dynamin- and clathrin-dependent pathway, and not by phosphorylation of classical PKC sites within OAT1 (Wolff et al., 2003; Zhang et al., 2008). Furthermore, angiotensin II has been demonstrated to activate PKCa, which leads to the acceleration of human OAT3 endocytosis, resulting in a decreased activity (Duan et al., 2009). In contrast to these inhibitory effects, activation of the atypical $\mathrm{PKC} \zeta$ leads to an increase in rat Oat1/Oat3 and human OAT3 function (Barros et al., 2009; Li et al., 2010). Moreover, epidermal growth factor enhances the transport rate of rabbit and human Oat1/OAT1 through a complex cascade, resulting in the prostaglandin $\mathrm{E}_{2}$-receptor mediated activation of protein kinase A (PKA) (Sauvant et al., 2003; Sauvant et al., 2004).

\subsubsection{Function of rat and human Oat1/OAT1 and Oat3/OAT3}

During secretion, Oat1/OAT1 and Oat3/OAT3 act as exchangers coupling the entry of an organic anion to the exit of a dicarboxylate such as $\alpha$-ketoglutarate (Shimada et al., 1987; Pritchard, 1988; Pritchard, 1995). The transport of an organic anion across the basolateral membrane is energetically uphill (Sweet et al., 1997). Thus Oats/OATs have the capacity to concentrate organic anions against their chemical gradient with a tertiary active based transport (figure 1.2) (Sweet et al., 1997; Sweet et al., 2001; Dantzler, 2002). The first step is mediated by the hydrolysis of ATP, which drives the $\mathrm{Na}^{+} / \mathrm{K}^{+}$-ATPase pump to develop an inwardly driven $\mathrm{Na}^{+}$-gradient across the basolateral membrane (figure 1.2) (Jørgensen, 1980; Kashgarian et al., 1985; VanWert et al., 2010). In the second step, the potential energy of $\mathrm{Na}^{+}$ is used by the $\mathrm{Na}^{+} /$dicarboxylate co-transporter $3(\mathrm{NaDC} 3)$, to force another ion, in most cases the endogenously available dicarboxylate $\alpha$-ketoglutarate, to enter the cell against its electrochemical gradient (figure 1.2) (Shimada et al., 1987; Pritchard, 1988; Sweet et al., 1997; VanWert et al., 2010; Kaufhold et al., 2011). The third and last step is mediated by Oat1/OAT1 and Oat3/OAT3, and includes the exchange of $\alpha$-ketoglutarate against a negatively charged organic ion $\left(\mathrm{OA}^{-}\right)$(figure 1.2) (Shimada et al., 1987; Pritchard, 1988; Sweet et al., 1997; Sweet et al., 2003; VanWert et al., 2010). In humans, basolateral located OAT2 also absorbs $\mathrm{OA}^{-}$from the blood into the proximal tubules cell, the counterion being 
unknown (Enomoto et al., 2002b). On the apical side, the sodium-dependent monocarboxylate transporter (SMCT) and the $\mathrm{Na}^{+} /$dicarboxylate co-transporter $1(\mathrm{NaDC} 1)$ are responsible for the intracellular > extracellular gradient of lactate or organic anions, including dicarboxylates $\left(\mathrm{dic}^{2}\right)$, leading to the driving forces for the reabsorption of organic anions from the urine into the proximal tubule cell (figure 1.2) (Pajor, 1996; Sekine et al., 1998; Pajor and Sun, 2010; Hering-Smith et al., 2011). Apically expressed OAT4 and urate transporter 1 (URAT1), both belonging to the organic anion transporter family, are responsible for the reabsorption of organic anions ( $\left.\mathrm{OA}^{-}\right)$including urate (figure 1.2) (Roch-Ramel et al., 1996; Cha et al., 2000; Enomoto et al., 2002a; Ekaratanawong et al., 2004). Human OAT4 is also involved in the transcellular secretion of OA;, which were absorbed by the OAT1, OAT2, and OAT3 from the blood into the proximal tubule cell (figure 1.2) (Ekaratanawong et al., 2004).

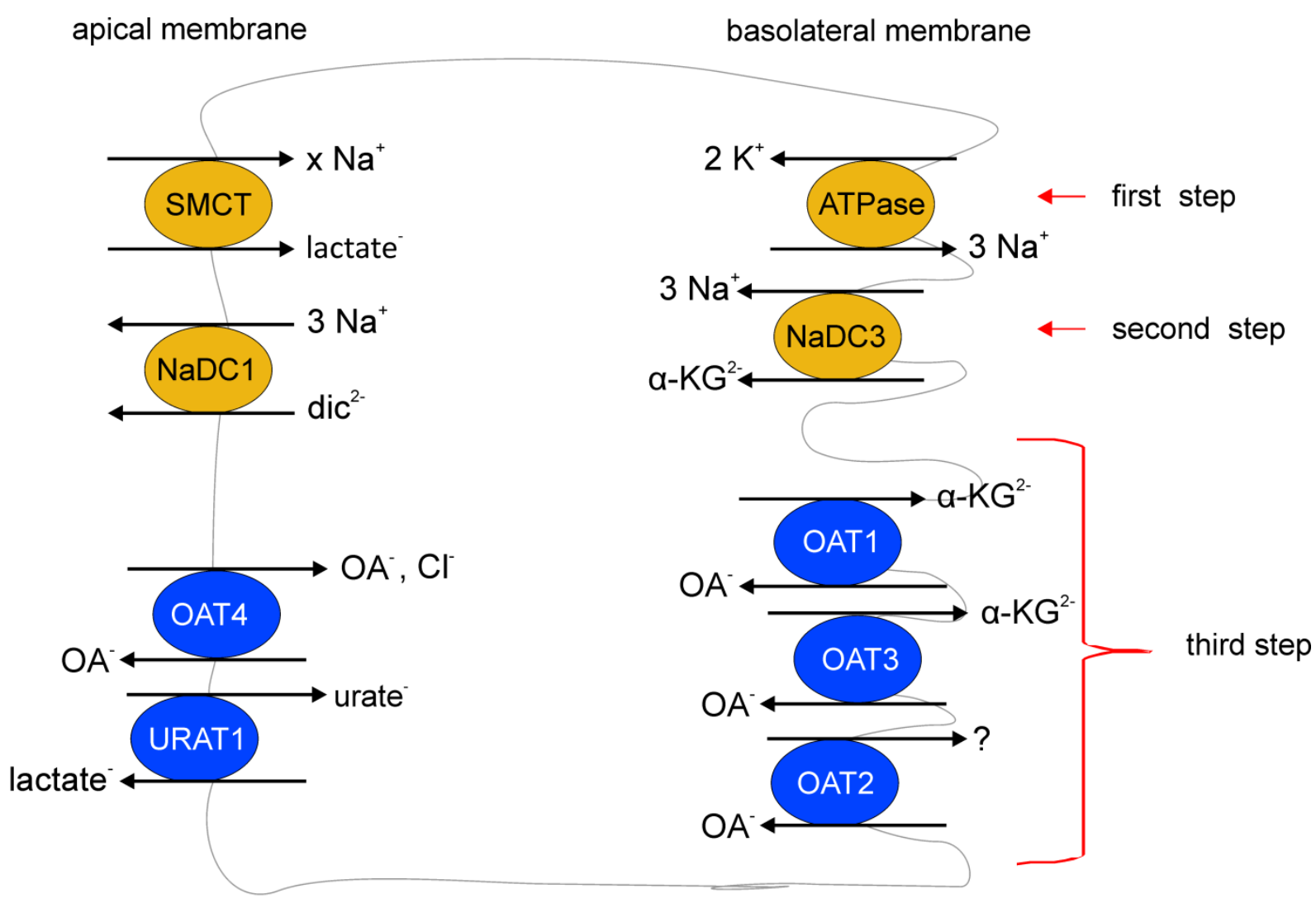

Figure 1.2: Localization of organic anion transporters in a human renal proximal tubules cell.

Transporters responsible for the driving forces of organic anion uptake are shown in orange. Members of the organic anion transporter (OAT) family are shown in blue. SMCT: sodium-coupled monocarboxylate transporter; ATPase: $\mathrm{Na}^{+} / \mathrm{K}^{+}$ATPase; NaDC1 sodium-dependent dicarboxylate transporter 1; NaDC3: sodium-dependent dicarboxylate transporter 3; OAT1-4: organic anion transporter 1-4; URAT1: urate transporter 1; OA ${ }^{-}$(organic anion); $\alpha-\mathrm{KG}^{2-}: \alpha$-ketoglutarate; dic $^{2-}$ : dicarboxylate. 


\subsubsection{Substrates of rat and human Oat1/OAT1 and Oat3/OAT3}

As their name implicates, organic anion transporters are responsible for the transport of negatively charged ions. Characteristic of renal Oats/OATs is their broad substrate specificity [summarized in (Rizwan and Burckhardt, 2007; VanWert et al., 2010; Burckhardt, 2012)]. Identification of substrates is mostly accomplished via two different methods: (1) direct transport by using radiolabeled substrates, or (2) interaction of potentially substrates with the investigated transporter (Burckhardt, 2012). The interaction of the prospective substrates with the transporter is examined by measuring the inhibition of a radiolabeled prototypical substrate $p$-aminohippurate (PAH) for Oat1/OAT1 and estrone-3-sulfate (ES) for Oat3/OAT3 in response to the test substrate. Inhibition of PAH or ES transport designates an interaction of the test substance with the investigated transporter, but does not necessarily implicate its transport. Regarding the prototypical substrate $\mathrm{PAH}$, some species-specific differences exist. Human OAT1 shows a high PAH affinity with a $K_{\mathrm{M}}=4 \mu \mathrm{M}$, whereas the affinity for OAT3 is lower with a $K_{\mathrm{M}}=87 \mu \mathrm{M}$ (Cihlar et al., 1999; Cha et al., 2001). However, rat Oat1 and Oat3 have comparable affinities for PAH: $K_{\mathrm{M}}=70 \mu \mathrm{M}$ (Oat1) and $K_{\mathrm{M}}=65 \mu \mathrm{M}$ (Oat3) (Sweet $e t$ al., 1997; Kusuhara et al., 1999).

Among others, following endogenous substrates are transported by the rat and human Oat1/OAT1: the metabolic intermediate $\alpha$-ketoglutarate (Sekine et al., 1997; Lu et al., 1999a), the second messengers cAMP and cGMP (Sekine et al., 1997), the purine breakdown product urate (Sekine et al., 1997; Ichida et al., 2003), and the hormone prostaglandine $\mathrm{E}_{2}\left(\mathrm{PGE}_{2}\right)$ (Sekine et al., 1997; Kimura et al., 2002). The rat and human Oat3/OAT3 exhibit transport activity for cAMP (Cha et al., 2001), $\alpha$-ketoglutarate (Bakhiya et al., 2003; Sweet et al., 2003), the hormones cortisol and $\mathrm{PGE}_{2}$ (Cha et al., 2001; Kimura et al., 2002; Asif et al., 2005), urate (Cha et al., 2001), the bile salt taurocholate (Cha et al., 2001; Chen et al., 2008), and estrone-3-sulfate (Cha et al., 2001; Asif et al., 2005; Chen et al., 2008). The physiological impact of Oat 1 and Oat 3 in the transport of organic anions was confirmed in their particular knockout mice, which were viable, fertile, healthy, with no obvious morphological alterations, but showed impaired transport of typical substrates (Sweet et al., 2002; Eraly et al., 2006; Torres et al., 2011; Vallon et al., 2012).

Besides endogenous substrates, rat and human Oat1/OAT1 and Oat3/OAT3 transport a multitude of exogenous substrates like environmental toxins, and negatively charged drugs including their metabolites. Transported drugs belong to several different drug families like angiotensin converting enzyme (ACE) inhibitors, diuretics, antibiotics, antiviral-, and 
non-steroidal anti-inflammatory drugs (NSAIDs) [for review see (Rizwan and Burckhardt, 2007; Hagos and Wolff, 2010; VanWert et al., 2010; Burckhardt, 2012; Riedmaier et al., 2012)].

For the rat and human Oat1/OAT1 amongst others, a transport of the following drugs has been shown: the ACE inhibitors captopril, quinaprilat, and temocapril (Hasegawa et al., 2003; Ueo et al., 2005; Ueo et al., 2007; Yuan et al., 2009), the antiviral drug adefovir and cidofovir (Cihlar et al., 1999; Ho et al., 2000), the NSAIDs ibuprofen and ketoprofen (Khamdang et al., 2002), and the diuretics bumetanide and furosemide (Uwai et al., 2000; Hasannejad et al., 2004). Focusing on rat and human Oat3/OAT3 amongst others, the ACE inhibitors captopril, quinaprilat and temocapril (Hasegawa et al., 2003; Ueo et al., 2005; Ueo et al., 2007; Yuan et al., 2009), the NSAIDs ibuprofen and ketoprofen (Khamdang et al., 2002), the antibiotics cefotiam and cephaloridine (Jung et al., 2002; Ueo et al., 2005; Chen et al., 2008) and the ochratoxin A (Cha et al., 2001; Feng et al., 2001; Jung et al., 2001) have been shown to be transported.

Due to the known interaction and transport of OATs with numerous drugs, "The International Transporter Consortium" published a recommendation as to which transport proteins are clinically important in drug development (Giacomini et al., 2010). In this recommendation, amongst others, the human OAT1 and OAT3 were mentioned as clinically relevant transporters in the kidneys (Giacomini et al., 2010).

\subsubsection{Adverse drug reactions (ADRs), a possible involvement of Oat1/OAT1 and Oat3/OAT3}

The Oat/OAT-dependent transport of drugs is in part responsible for their distribution, concentration and retention in the body (Gandhi et al., 2004; Franconi et al., 2007). Thus, Oats/OATs are involved in their therapeutic efficancy and potential toxicity (Cihlar et al., 1999; Ho et al., 2000; Srimaroeng et al., 2008; Hagos and Wolff, 2010; Riedmaier et al., 2012). In general, for a multitude of drugs, e.g. ACE-inhibitors, antihistamines and analgesics, women have a 1.6 times higher risk of getting an adverse drug reaction (ADR) (Martin et al., 1998). For example the antibiotic penicillin has been shown to cause more ADRs in women compared to men (Zopf et al., 2009). As penicillin G is unstable in the acid environment of the stomach, it is typically given by a parenteral route of administration (not orally) (Aktories et al., 2010). It is metabolized only to a slight extend and its plasma protein binding amounts 
to approximately 50\% (Aktories et al., 2010). The elimination of penicillin G occurs at $\sim 80 \%$ by tubular transport, and at $\sim 20 \%$ by glomerular filtration (Aktories et al., 2010). Therefore, the excretion of penicillin $\mathrm{G}$ from the body is mainly mediated by tubular transporters. In cells or oocytes expressing human OAT1 and OAT3, an interaction of penicillin G with both transporters has been shown (Hosoyamada et al., 1999; Jung et al., 2001). Moreover, a transport of the OAT1 and OAT3 substrate penicillin G has detected in human kidney slices (Nozaki et al., 2007). In LLC-PK1 cells, penicillin G interacts with the overexpressed rat Oat1 and Oat3 (Jariyawat et al., 1999). Furthermore, expressed in oocytes, Oat1 has been shown to transport penicillin G (Hasegawa et al., 2002). The physiological impact of Oat3 in the secretion of penicillin $G$ was confirmed in the Oat3 knockout mice, which exhibit a reduced volume of its distribution and diminished clearance (VanWert et al., 2007). These data demonstrate that Oat1/OAT1 and Oat3/OAT3 are involved in the elimination of penicillin G. In human, differences in the OAT1 and OAT3 expression are so far unknown, but suggested.

In 1977, the food and drug administration (FDA) published a guideline concerning the exclusion from women of childbearing potential in early drug development studies (FDA, homepage). Till 1993, this exclusion was practiced, then a new instruction was released, which provided guidance regarding inclusion of men and women in drug development (FDA, homepage). However, until now, women are still underrepresented in clinical trials due to their fluctuating hormone levels which constitute unforeseeable variables. But even without the investigation of representative women cohorts or the sex-dependent differences of OATs, men and women are often prescribed the same dose of drugs, which maybe lead to the higher frequency of ADRs in women.

\subsubsection{Sex-dependent expression of Oat1/OAT1 and Oat3/OAT3 and the impact of testosterone}

Considering the growing knowledge of sex-differences in human and animal health (Nieuwenhoven and Klinge, 2010; Breithaupt, 2012; Miller, 2012), the influence of sex-dependently expressed renal transport proteins like Oat1/OAT1 and Oat3/OAT3 and their possible impact in the female-predominant development of adverse drug reactions, should be investigated. The two major excretory organs in the body are the kidneys, and the liver (Riedmaier et al., 2012). Focusing on the kidneys, sex differences in the transport of 
endogenous and exogenous compounds, like PAH, egualen sodium, taurocholate, and mercury have been shown (Sato et al., 2000; Cerrutti et al., 2002; Kato et al., 2002; Hazelhoff et al., 2012). Early in 1955, Huang and McIntosh showed that the uptake of the typical Oat1 substrate $p$-aminohippurate $(\mathrm{PAH})$ in rat renal cortical kidney slices was higher in males compared to females (Huang and McIntosh, 1955). Additionally, Kleinman and colleagues demonstrated that gonadectomy of male rats abolished the sex differences in PAH uptake (Kleinman et al., 1966). Administration of the typical male hormone, testosterone, restored the PAH transport rate to that of intact males (Kleinman et al., 1966). Later, starting in 1997, the renal transport proteins Oat1 and Oat3, which mediate the secretion of PAH from the blood into the proximal tubules of rats, were identified and characterized (Sekine et al., 1997; Sweet et al., 1997; Kusuhara et al., 1999; Sugiyama et al., 2001; Hasegawa et al., 2002). In rats, an often used preclinical animal model, Oat1 and Oat3 are higher expressed in male than in female kidneys (Cerrutti et al., 2002; Buist and Klaassen, 2004; Ljubojevic et al., 2004; Hazelhoff et al., 2012). Moreover, testosterone has been shown to influence the expression (Ljubojevic et al., 2004) and function of Oat1 and Oat3 in rats (Huang and McIntosh, 1955; Kleinman et al., 1966; Reyes et al., 1998). Castrated male rats exhibited a markedly slowed elimination rate of PAH, which was equal to those of intact females (Reyes et al., 1998). Treatment of castrated male and intact female rats with testosterone increased the elimination rate and Oat1/Oat3 protein abundance to those observed in intact males (Reyes et al., 1998; Ljubojevic et al., 2004). On the contrary, the female hormone estradiol caused an inhibitory effect. Oat1 and Oat3 expression in ovariectomized female rats was increased, and decreased after treatment with estradiol (Ljubojevic et al., 2004). The inhibitory effect of estradiol was also seen in male rats, which showed reduced Oat 1 and Oat 3 expression after administration of estradiol (Ljubojevic et al., 2004). In prepubertal rats, the expression of Oat1 and Oat3 in the proximal tubules showed no sex-dependent expression, and was less compared to adult rats (Buist et al., 2002; Ljubojevic et al., 2004). A comparable age-depended expression pattern for Oat1 and Oat3 was also found in mice (Buist and Klaassen, 2004). Prepubertal mice showed a low and rather equal Oat1 and Oat 3 expression whereas in adult mice the expression was higher and became sex-dependent with a higher expression of Oat1 in males compared to females (Buist and Klaassen, 2004).

Although testosterone enhances the renal expression of Oat1 and Oat3 in rats (Ljubojevic et al., 2004) and to increase the elimination rates of PAH (Huang and McIntosh, 1955; Kleinman et al., 1966; Reyes et al., 1998), a direct involvement of testosterone in the transcriptional regulation of rat and human Oat1/OAT1 and Oat3/OAT3 expression has not been investigated. 
Low androgen and high estrogen levels might be responsible for the diminished Oat1/OAT1 and Oat3/OAT3 expression in females/women which may decrease drug excretions, leading possibly to a higher risk of ADRs in women.

\subsection{Testosterone-dependent and androgen receptor mediated transcriptional activation of gene expression}

Androgens, including testosterone, regulate a variety of physiological functions. Their action is mediated through binding to the androgen receptor (AR) which itself binds sequencespecifically to particular DNA parts, thereby influencing the transcription of androgen responsive genes [reviewed in (Beato, 1989; Gelmann, 2002; Lee and Chang, 2003; Bain et al., 2007)]. AR plays a pivotal role in the reproduction, pubertal development, leading to male sex differentiation, and the development of muscle mass (Gelmann, 2002; Schmidt et al., 2010). In addition to its normal physiological roles, AR is also involved in the development of prostatic hyperplasia and prostate cancer (Henshall et al., 2001; Gelmann, 2002; Carson and Rittmaster, 2003; Chen et al., 2004; Ricciardelli et al., 2005).

The androgen receptor belongs to the nuclear receptor superfamily (Bain et al., 2007). This superfamily is subdivided into three classes: (1) the steroid receptor family, (2) the thyroid/retinoid family, and (3) the orphan receptor family (Bain et al., 2007). The steroid receptor family further consists of the mineralocorticoide receptor (MR), the glucocorticoide receptor (GR), the progesterone receptor (PR), the estrogen receptor (ER), and the androgen receptor (AR) (Bain et al., 2007). Genes for rat and human AR are localized to the X-chromosome [human AR: Xq12 (NCBI: Gene ID: 367), rat AR: Xq22-q32, (NCBI: Gene ID: 24208)]. Human AR encodes for two different isoforms with either 920 or 388 amino acids (NCBI: NP_000035.2 and NP_001011645.1). Rat AR encodes for only one isoform consisting of 902 amino acids (NCBI: NP_036634.1). Homology screens between human full length and rat androgen receptor sequence revealed a 90\% homology at the protein level (NCBI, HomoloGene).

The androgen receptor has a modular structure consisting of four distinct domains: starting from the $\mathrm{N}$-terminus, where the poorly conserved $\mathrm{N}$-terminal domain is located, followed by the highly conserved DNA-binding domain, which is linked to a small amino acid sequence called "hinge region", followed by the C-terminal ligand binding domain (figure 1.3) [summarized in (Gelmann, 2002; Bain et al., 2007; Claessens et al., 2008; Lonergan and 
Tindall, 2011)]. The N-terminal domain is considered to be the major activation domain of AR by harboring the transcriptional activation function 1 (AF-1) (Jenster et al., 1995; Chamberlain et al., 1996).

One special characteristic of the androgen receptor is its mode of action. AR functions as head-to-head or head-to-tail homodimers, via binding to certain DNA sequences, called androgen response elements (AREs) (Shaffer et al., 2004; Denayer et al., 2010). These AREs are organized as inverted repeats of hexameric binding sites which are separated by three nucleotides (Shaffer et al., 2004; Denayer et al., 2010). Within the literature, two different consensus sequences are described, GGTACAnnnTGTTCT or AGAACAnnnTGTTCT, both known to bind AR in an active manner (Cleutjens et al., 1996; Shaffer et al., 2004; Asaka et al., 2006; Denayer et al., 2010). The DNA-binding domain, which is responsible for the correct binding of AR to its AREs, consists of two zinc fingers and shares a 100\% homology between rat and human protein (figure 1.3) (Gelmann, 2002; Wickert and Selbig, 2002; Claessens et al., 2008). The first zinc finger defines the so called P-box and mediates the sequence-specific contact with the major groove of DNA, whereas the second zinc finger called D-box is responsible for the dimerization of AR (Wickert and Selbig, 2002).

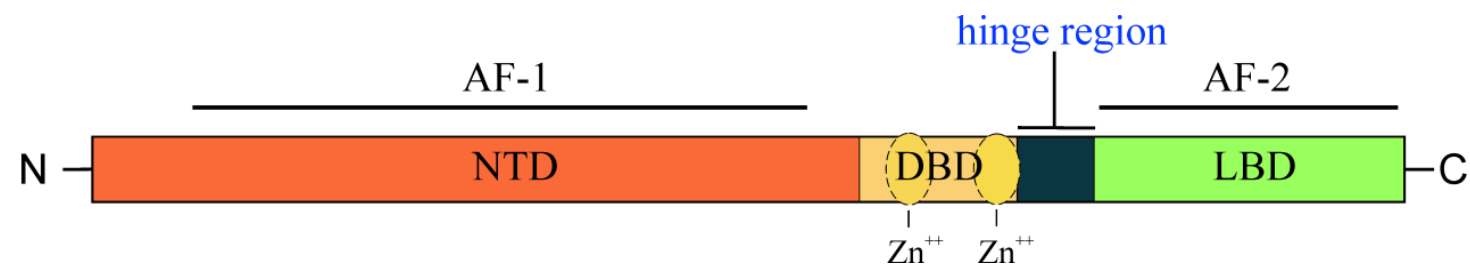

Figure 1.3: Schematic overview of human androgen receptor (AR).

The N-terminal domain (NTD), which includes the transcriptional activation function 1 (AF-1), is localized to the N-terminus. The next attached domain is called DNA-binding domain (DBD) and includes two zinc fingers $\left(\mathrm{Zn}^{++}\right)$, followed by the hinge region. The last domain is the ligand binding domain (LBD), which is localized to the C-terminus of AR and contains the transcriptional activation function 2 (AF-2).

The poorly conserved hinge domain is a flexible linker, containing the nuclear localization signal for AR, and separates the DNA binding domain from the ligand binding domain (Claessens et al., 2008; Lonergan and Tindall, 2011). The nuclear localization signal itself consists of amino acids belonging to the second zinc finger motive of the DNA binding domain, amino acids of the hinge region, and some amino acids of the flanking carboxylterminus (Zhou et al., 1994). The actin-binding protein filamin (ABP 280) has been shown to interact with the nuclear localization signal of $\mathrm{AR}$ and directs the receptor within the cytoplasmic trafficking to the nucleus (Ozanne et al., 2000). 
In 2001, the three dimensional structure of the human AR ligand binding domain (LBD) was discovered (Sack et al., 2001). The LBD consist of 12 helices, at which helices 3, 5, and 11 are involved in the ligand binding of dihydrotestosterone (DHT), forming a so called binding pocket (Sack et al., 2001; Gelmann, 2002; Bain et al., 2007). DHT is a metabolite of testosterone, which is produced by the steroid 5 $\alpha$-reductase (Andersson et al., 1989; Jenkins et al., 1992). Both, testosterone and DHT, are known to bind the AR with similar affinities, thereby DHT being the more potent androgen regarding receptor activation (Wilson and French, 1976; Askew et al., 2007). After ligand-binding, AR is restructured leading to the formation of the second activation function, called activation function 2 (AF-2), which serves as co-activator binding site (Danielian et al., 1992; Askew et al., 2007; Claessens et al., 2008). Mutation in this conserved AF-2 region abolishes the transcriptional activation, but does not affect ligand or DNA binding of the AR (Danielian et al., 1992). The AR is known to interact with a multiplicity of co-activators and co-repressors, for example the steroid receptor co-activator 1 (SRC-1), the CREB-binding protein (CBP), or the tumor suppressor protein 53 (p53) [summarized in (McKenna et al., 1999a; McKenna et al., 1999b; Lee and Chang, 2003; Heemers and Tindall, 2007)]. Moreover, co-activators and co-repressors also interact with the N-terminal domain (NTD) (Lee and Chang, 2003).

Without androgen stimulation, AR is predominantly located in the cytoplasm, associated with heat shock proteins (HSPs), which are required to establish and maintain ligand binding ability (figure 1.4) (Tyagi et al., 2000; Farla et al., 2005; Smith and Toft, 2008). Binding of testosterone or DHT to the ligand binding domain induces conformational changes, leading to the dissociation of HSPs, and the formation of the AF-2 binding surface (figure 1.4) (Danielian et al., 1992; Sack et al., 2001; Askew et al., 2007; Claessens et al., 2008; Lonergan and Tindall, 2011). Moreover, ligand binding to the AR is followed by a subsequent dimerization of AR in the cytoplasm (figure 1.4) [reviewed in (Claessens et al., 2008)]. After this dimerization, AR is translocated from the cytoplasm into the nucleus within 15 - 60 min (figure 1.4) (Tyagi et al., 2000; Farla et al., 2005). Upon arrival in the nucleus, AR binds via its DNA binding domain to specific androgen response elements (AREs), which are located in the promoter and enhancer region of target genes (figure 1.4) (Claessens et al., 2008). Subsequent to the binding of AR to its AREs, co-regulators of the androgen transcriptional complex are recruited, leading to the transcription of target genes like the $\alpha$-subunit of the epithelial sodium channel $(\alpha$ EnaC), the cyclin-dependent kinase inhibitor $\mathrm{p} 21$, or the prostate specific antigen (PSA) (figure 1.4) (Lu et al., 1999b; Kim and Coetzee, 2004; Quinkler et al., 2005). 


\section{Introduction}

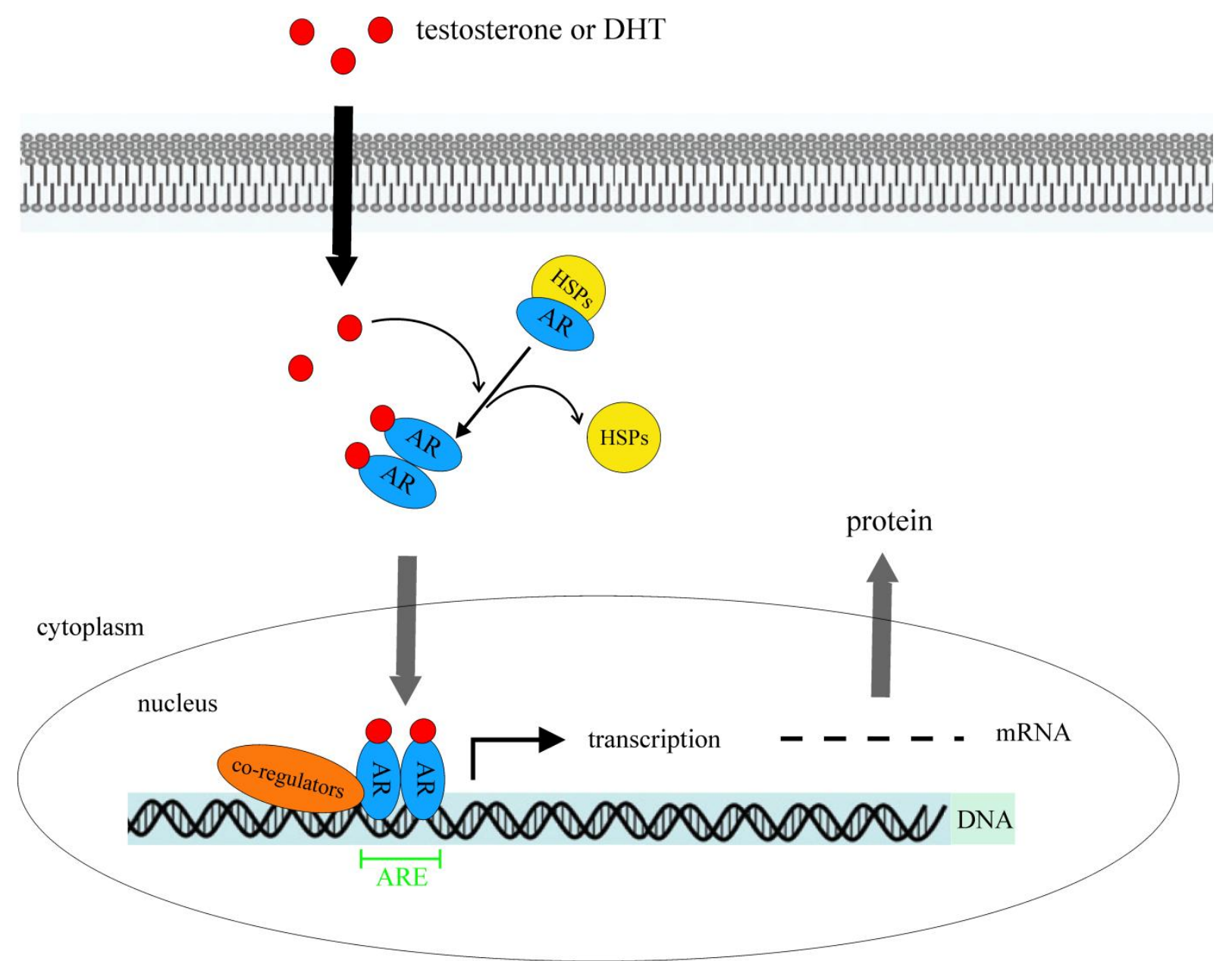

Figure 1.4: Overview of the androgen-dependent activation cascade.

Testosterone and its metabolite dihydrotestosterone (DHT) can freely diffuse into the cell (Carson and Rittmaster, 2003; Oren et al., 2004). Without ligand exposure, androgen receptor (AR) is bound to heat shock proteins (HSPs) in the cytoplasm. After androgen stimuli, testosterone or DHT binds to the AR, followed by a conformational switch, which leads to its dissociation from HSPs, and dimerization of AR. As a homodimer AR is then transported into the nucleus where it binds to specific DNA sequences called androgen response elements (AREs) present in the promoter. In the last step AR recruits co-regulators, which are necessary for transcription of a certain androgen responsive gene. 


\subsection{Aim of the thesis}

The aim of my thesis was to elucidate the molecular mechanism by which testosterone influences the transcriptional regulation of rat renal Oat 1 and Oat 3 and, furthermore, to localize the functional androgen response elements (AREs) within their promoters. In addition, localization of functional AREs in the human OAT1 and OAT3 promoters should also be examined due to their suggested similar transcriptional regulation.

Therefore, following steps were prearranged:

- in silico analyses of rat and human Oat1/OAT1 and Oat3/OAT3 promoters to localize predicted AREs

- generation of several rat and human Oat1/OAT1 and Oat3/OAT3 promoter constructs, each differing in their length of promoter region and number of predicted AREs

- cloning and testing of positive controls for testosterone/androgen receptor regulation

- establishment of a cell system for testosterone/androgen receptor-dependent promoter activation studies by using luciferase activity measurement, including the optimization of promoter constructs and expression vectors amounts, concentration of testosterone treatment, and incubation duration

- investigation of testosterone-dependent promoter activation of rat and human Oat1/OAT1 and Oat3/OAT3 promoter constructs

After the identification of supposed functional AREs within the testosterone-dependent activated promoter constructs, these elements should be further investigated. Therefore subsequent steps were intended:

- mutagenesis of the functional suggested AREs, followed by repeated luciferase activity measurements

- investigation of the interaction between androgen receptor and the identified AREs by using electrophoretic mobility shift assay 


\section{Material and Methods}

\subsection{Material}

\subsubsection{Chemicals and reagents}

Table 2.1: Chemicals and reagents

\begin{tabular}{|c|c|}
\hline Name & Supplier \\
\hline Agar & AppliChem \\
\hline Albumin fraction $\mathrm{V}$ protease free (BSA) & Carl Rothß \\
\hline Ampicillin sodium salt & AppliChem \\
\hline Boric acid & Merck \\
\hline Bromphenol blue sodium salt & Sigma-Aldrich® \\
\hline$\beta$-mercaptoethanol & AppliChem \\
\hline Coomassie brilliant blue/Serva Blue G & Serva \\
\hline DEPC treated, sterile, autoclaved $\mathrm{H}_{2} \mathrm{O}$ & Carl Rothß \\
\hline Dimethyl sulfoxide (DMSO) & AppliChem \\
\hline Disodium hydrogen phosphate $\left(\mathrm{Na}_{2} \mathrm{HPO}_{4}\right)$ & AppliChem \\
\hline Dulbecco's modified Eagle Medium with high glucose (DMEM-HG) & Biochrom AG \\
\hline Dulbecco's modified Eagle Medium with low glucose (DMEM-LG) & AppliChem \\
\hline Ethanol & Carl Roth® \\
\hline Ethidiumbromide & Sigma-Aldrich® \\
\hline Ethylenediaminetetraacetric acid (EDTA) & AppliChem \\
\hline Fetal bovine serum (FBS) & $\begin{array}{l}\text { Gibco }^{\mathrm{TM}} \text {, life } \\
\text { technologies }\end{array}$ \\
\hline Formaldehyde & Carl Rothß \\
\hline Glucose & AppliChem \\
\hline Glycerol & AppliChem \\
\hline Hydrochloride acid $(\mathrm{HCl})$ & AppliChem \\
\hline L-glutamine & AppliChem \\
\hline Magnesium chloride $\left(\mathrm{MgCl}_{2}\right)$ & AppliChem \\
\hline Non essential amino acids (NEA) $100 x$ & Biochrom AG \\
\hline Ortho-phosphoric acid $85 \%$ & Carl Rothß \\
\hline Penicillin $(10,000$ Units/ml $) /$ Streptomycin $(10 \mathrm{mg} / \mathrm{ml})$ & PAA Laboratories GmbH \\
\hline Phosphate buffered saline (PBS) & AppliChem \\
\hline Poly-D-lysine hydrobromide & Sigma-Aldrich® \\
\hline Potassium chloride $(\mathrm{KCl})$ & AppliChem \\
\hline 2-propanol & AppliChem \\
\hline Sodium acetate $\left(\mathrm{C}_{2} \mathrm{H}_{3} \mathrm{NaO}_{2}\right)$ & AppliChem \\
\hline Sodium chloride $(\mathrm{NaCl})$ & Merck \\
\hline Sodium dihydrogen phosphate $\left(\mathrm{NaH}_{2} \mathrm{PO}_{4}\right)$ & Merck \\
\hline Sodium hydrogen carbonate $\left(\mathrm{NaCHO}_{3}\right)$ & AppliChem \\
\hline Sodium pyruvate $\left(\mathrm{C}_{3} \mathrm{H}_{3} \mathrm{NaO}_{3}\right)$ & AppliChem \\
\hline Sodium hydroxide $(\mathrm{NaOH})$ & Carl Roth® \\
\hline
\end{tabular}




\begin{tabular}{ll}
\hline Testosterone & Fluka \\
Tris & AppliChem \\
Triton X-100 & Carl Roth® \\
Trypsin & Biochrom AG \\
Tryptone/Peptone & Carl Roth® \\
Yeast extract & AppliChem \\
Xylene cyanole FF & Sigma-Aldrich® \\
\hline
\end{tabular}

\subsubsection{Consumables and equipment}

All used pipette tips, reaction tubes, and laboratory glassware were autoclaved for $20 \mathrm{~min}$ at $120{ }^{\circ} \mathrm{C}$ before general laboratory work. For cell culture, only sterile glass pipettes and disposable consumables were utilized.

Table 2.2: Consumables for general laboratory work

\begin{tabular}{ll}
\hline Name & Supplier \\
\hline Agar dishes $(100 \times 20 \mathrm{~mm})$ & Sarstedt \\
Filtropur S 0.2, 0,2 $\mu \mathrm{m}$ & Sarstedt \\
Microplates 96-well, white & Berthold Technologies GmbH \& Co KG \\
Micro tubes, $1.5 \mathrm{ml}$ & Sarstedt \\
Micro tubes, $2 \mathrm{ml}$ & Sarstedt \\
Multiply-pro cups, $0.2 \mathrm{ml}$ & Sarstedt \\
Optical caps, 8 x strip & Agilent Technologies \\
Piepette tips & Sarstedt \\
Qpcr 96-well plates, non skirted & Agilent Technologies \\
Tissue culture plates 96-Well & Sarstedt \\
Tubes, $13 \mathrm{ml}$ & Sarstedt \\
Tubes, $15 \mathrm{ml}$ & Sarstedt \\
Tubes, $50 \mathrm{ml}$ & Sarstedt \\
\hline
\end{tabular}

Table 2.3: Consumables for cell culture

\begin{tabular}{ll}
\hline Name & Supplier \\
\hline CryoPure tubes, $1.8 \mathrm{ml}$ & Sarstedt \\
Filter, $0,22 \mu \mathrm{m}$, PES membrane & Biochrom AG \\
Tissue culture dishes $(100 \mathrm{x} 20 \mathrm{~mm})$ & Sarstedt \\
Tissue culture dishes $(150 \times 20 \mathrm{~mm})$ & Sarstedt \\
Tissue culture plates $24-$ well flat bottom & Sarstedt \\
\hline
\end{tabular}


Material and Methods

Table 2.4: Equipment

\begin{tabular}{|c|c|}
\hline Name & Supplier \\
\hline Accu-jet ${ }^{\circledR}$ pro (pipette boy) & Brand \\
\hline \multicolumn{2}{|l|}{ Centrifuges: } \\
\hline Biofuge fresco & Heraeus instruments $\mathrm{GmbH}$ \\
\hline Centrifuge 5415D & Eppendorf \\
\hline Heraeus Megafuge 40R & Thermo Scientific \\
\hline Minicentrifuge & National Labnet Co. \\
\hline Minispin & Eppendorf \\
\hline Sorvall@ RT7 & Sorvall \\
\hline Circulating water bath $\mathrm{D} 8 / \mathrm{G}$ & Haake \\
\hline Digitale scales & Sartorius \\
\hline Easyject prima (electroporation) & PeqLab Biotechnologie GmbH \\
\hline \multicolumn{2}{|l|}{ Electrophoretic system: } \\
\hline Electrophoretic chamber & MWG-Biotech \\
\hline Power supply PPS 200-1D & MWG-Biotech \\
\hline \multicolumn{2}{|l|}{ Freezer/fridge: } \\
\hline$-80{ }^{\circ} \mathrm{C}$ freezer & Heraeus instruments $\mathrm{GmbH}$ \\
\hline$-20^{\circ} \mathrm{C}$ freezer & Liebherr \\
\hline$+4^{\circ} \mathrm{C}$ fridge & Privileg/Bauknecht \\
\hline \multicolumn{2}{|l|}{ Gel documentation: } \\
\hline Dual intensity ultra violett transiluminator & Uni Equip \\
\hline Intas digital interface & Intas science imaging instrument \\
\hline Gene Quant (RNA/DNA calculator) & Pharmacia Biotech \\
\hline IKAMAG® RCT (magnetic stirrer) & IKA®-Werke GmbH \& Co. KG \\
\hline \multicolumn{2}{|l|}{ Incubators: } \\
\hline Function line type BB16 & Heraeus instruments $\mathrm{GmbH}$ \\
\hline GFL 3031 & Gesellschaft für Labortechnik GmbH \\
\hline Heraeus type B15 & Heraeus instruments $\mathrm{GmbH}$ \\
\hline Laminar flow: Safe 2020 & Thermo Scientific \\
\hline \multicolumn{2}{|l|}{ Microscopes: } \\
\hline Fluorescence microscope AXID observer D1 & Carl Zeiss AG \\
\hline Telaval 31 & Carl Zeiss AG \\
\hline Mikrowave Privileg 8521 & Privileg \\
\hline Minishaker MS1 (vortex) & IKA®-Werke GmbH \& Co. KG \\
\hline Mithras LB940 luminometer & Berthold Technologies GmbH \& Co. KG \\
\hline NanoDrop ND-1000 Spectrophotometer & Thermo Scientific \\
\hline Neubauer counting chamber & Saaringia \\
\hline $\mathrm{pH} /$ Ion level 2 & InoLab \\
\hline Shaker KS 250 basic & IKA®-Werke GmbH \& Co. KG \\
\hline Speed vac concentrator & Savant instruments, Inc. \\
\hline
\end{tabular}




\begin{tabular}{cl}
\hline Thermal cyclers: & \\
C1000® Thermal Cycler & BioRad \\
PTC-200 peltier thermal cycler & MJ Reasearch \\
Stratagene Mx3000P & Agilent Technologies \\
Unijet II refrigerated aspirator & Uni Equip \\
Water purification system arium® 611VF & Sartorius \\
\hline
\end{tabular}

\subsubsection{Reaction components and commercial kits}

Except stated otherwise, technical procedures were performed according to manufacturer's recommendations.

Table 2.5: Reaction components and commercial kits

\begin{tabular}{|c|c|}
\hline Name & Supplier \\
\hline Agilent RNA 6000 nano kit & Agilent Technologies \\
\hline BigDye $\AA$ terminator v1.1 cycle sequencing kit & Applied Biosystems \\
\hline Dual-luciferase ${ }^{\circledR}$ reporter assay system & Promega \\
\hline EnzChek $\AA$ caspase-3 assay kit \# 2 & Molecular probes \\
\hline Gene expression hybridization kit & Agilent Technologies \\
\hline Gene expression wash buffer kit & Agilent Technologies \\
\hline High pure PCR product purification kit & Roche \\
\hline Lipofectamine $\AA 2000$ & Invitrogen ${ }^{\mathrm{TM}}$, life technologies \\
\hline Low input quick amp labeling kit $\mathrm{Cy} 3$, one-color & Agilent Technologies \\
\hline One-color RNA spike-in kit & Agilent Technologies \\
\hline PeqGOLD dNTP-Set & PeqLab Biotechnologie GmbH \\
\hline Qiagen® Plasmid Plus Midi Kit & Qiagen \\
\hline QIAprep® Spin Miniprep Kit & Qiagen \\
\hline QuickChange®II site-directed mutagenesis kit & Agilent Technologies \\
\hline RNAlater ${ }^{\circledR}$ & Ambion, Applied Biosystem \\
\hline RNeasy® mini kit & Qiagen \\
\hline Superscript $\AA I I$ reverse transcriptase & Invitrogen ${ }^{\mathrm{TM}}$, life technologies \\
\hline TaqMan® Universal Master Mix II & Applied Biosystems, life technologies \\
\hline
\end{tabular}


Material and Methods

\subsubsection{Software}

Table 2.6: Used software

\begin{tabular}{ll}
\hline Name & Application \\
\hline AxioVision Rel. 4.6 & Fluorescence microscope \\
Chromas Lite 2.01 & Sequence analysis \\
CorelDRAW X3 & Image editing \\
EndNote X1 & Bibliography \\
Gene Runner 3.05 & Sequence analysis \\
GraphPad Prism 4 version 4.03 & Scientific graphing and biostatistics \\
ImageJ 1.44p & Image editing \\
IntasGelCapture & Gel imaging \\
MikroWin 2000 version 4.41 & Software for plate reader Mithras LB940 \\
MS Office 2007 & Writing thesis, spreadsheet analysis \\
\hline
\end{tabular}

\subsubsection{Programs and databases}

Table 2.7: Utilized programs and databases

\begin{tabular}{ll}
\hline Name & Address \\
\hline ClustalW & http://www.genome.jp/tools/clustalw/ \\
Genomatix MatInspector & http://www.genomatix.de/ \\
HomoloGene & http://www.ncbi.nlm.nih.gov/ \\
NCBI (National Center for Biotechnology Information) & http://www.ncbi.nlm.nih.gov/ \\
NEBcutter V2.0 & http://tools.neb.com/NEBcutter2/index.php \\
PrimerBlast & http://www.ncbi.nlm.nih.gov/ \\
Primer3 version 0.4.0 & http://frodo.wi.mit.edu/ \\
QuickChange Primer Design Program & http://www.agilent.com/genomics/qcpd \\
Rat Proximal Tubule Transcription database & http://dir.nhlbi.nih.gov/papers/lkem/pttr/ \\
\hline
\end{tabular}

\subsubsection{Antibodies}

Table 2.8: Primary and secondary antibodies

\begin{tabular}{lll}
\hline Name & Application & Supplier \\
\hline Alexa Fluor® 488 goat anti-mouse IgG $(\mathrm{H}+\mathrm{L})$ & $8 \mu \mathrm{g} / \mathrm{ml}$ & Invitrogen $^{\mathrm{TM}}$, life technologies \\
Alexa Fluor ${ }^{\circledR}$ 488 goat anti-rabbit IgG $(\mathrm{H}+\mathrm{L})$ & $8 \mu \mathrm{g} / \mathrm{ml}$ & Invitrogen $^{\mathrm{TM}}$, life technologies \\
AR (N-20): sc-816 & $0.5 \mu \mathrm{g} / \mathrm{ml}$ & Santa Cruz ${ }^{\circledR}$ biotechnology \\
BCL6 (H-12): sc-365618 & $0.5 \mu \mathrm{g} / \mathrm{ml}$ & Santa Cruz ${ }^{\circledR}$ biotechnology \\
DAPI (dihydrochloride) & $1 \mu \mathrm{g} / \mathrm{ml}$ & Invitrogen \\
\hline
\end{tabular}




\subsubsection{Enzymes}

Enzymes were used according to manufacturer's recommendations.

Table 2.9: Enzymes

\begin{tabular}{ll}
\hline Name & Supplier \\
\hline Alkaline phosphatase, calf intestinal & New England Biolabas \\
Phusion® high-fidelity PCR master mix with HF buffer & New England Biolabas \\
restriction endonucleases: & \\
ApaI & New England Biolabas \\
AvrII & New England Biolabas \\
BamHI & New England Biolabas \\
BbvCI & New England Biolabas \\
HindIII & New England Biolabas \\
MluI & New England Biolabas \\
NdeI & New England Biolabas \\
NheI & New England Biolabas \\
PstI & New England Biolabas \\
SacI & New England Biolabas \\
XbaI & New England Biolabas \\
XhoI & New England Biolabas \\
Taq-polymerase (for standard PCRs) & Self-made in our laboratory \\
T4-DNA ligase & Promega \\
T4-DNA ligase high concentrated & New England Biolabas \\
T4-DNA polymerase & New England Biolabas \\
\hline
\end{tabular}

\subsubsection{DNA standards}

For DNA size determination and approximate quantification by gel electrophoresis, following standards were used:

Table 2.10: DNA standards

\begin{tabular}{|c|c|}
\hline Name & Supplier \\
\hline Gene RulerTM 100 bp DNA Ladder & Fermentas, Thermo Scientific \\
\hline Gene Ruler ${ }^{\mathrm{TM}} 100$ bp Plus DNA Ladder & Fermentas, Thermo Scientific \\
\hline $1 \mathrm{~Kb}$ DNA Ladder & Invitrogen $^{\mathrm{TM}}$, life technologies \\
\hline
\end{tabular}


Material and Methods

\subsubsection{Solutions and buffers}

Solutions and buffers were prepared with distilled $\mathrm{H}_{2} \mathrm{O}$ and stored at room temperature unless stated otherwise.

$5 \times \mathrm{TBE}$

DNA stop (10 ml)

10x PCR-buffer

Bradford solution

HiDye Solution

Permeabilisation puffer

\section{For cell culture:}

DMEM-HG (25 mM glucose)

DMEM-LG (5.5 mM glucose)

Trypsin/EDTA

PBS
$54 \mathrm{~g} / \mathrm{l}$ Tris base

$27.5 \mathrm{~g} / \mathrm{l}$ boric acids

$20 \mathrm{ml} 0.5$ M EDTA, pH 8.0

$5 \mathrm{ml}$ glycerol

$2 \mathrm{ml} 0.5 \mathrm{M}$ EDTA, pH 8.0

$50 \mu 12$ M Tris-HCl, pH 7.6

$\rightarrow$ add to $10 \mathrm{ml}$, steril filtrated

$\rightarrow$ add few crystals of bromphenol blue

$\rightarrow$ add few crystals of xylene cyanole FF

$500 \mathrm{mM} \mathrm{KCl}$

$100 \mathrm{mM}$ Tris, $\mathrm{pH} 9.0$

$15 \mathrm{mM} \mathrm{MgCl}_{2}$

$1 \%$ Triton $\mathrm{X}-100$

70 mg Serva Blue G (Comassie Blue)

$50 \mathrm{ml}$ ethanol

$100 \mathrm{ml}$ phosphoric acid $85 \%$

$\rightarrow$ add to $250 \mathrm{ml}$

$\rightarrow$ store at $4{ }^{\circ} \mathrm{C}$, prior to use dilute $1: 4$

Applied Biosystems

$77.4 \mathrm{ml} 0.1 \mathrm{M} \mathrm{Na}_{2} \mathrm{HPO}_{4}$

$22.6 \mathrm{ml} 0.1 \mathrm{M} \mathrm{NaH}_{2} \mathrm{PO}_{4}$

$20 \mathrm{ml} 5 \mathrm{M} \mathrm{NaCl}$

0.64 g Triton X-100

$\rightarrow$ add to $200 \mathrm{ml}$
Biochrom AG

AppliChem

$0.1 \%$ trypsin in PBS

$0.02 \%$ EDTA

$\rightarrow$ adjust pH 7.4

AppliChem 


\subsubsection{Media for bacteria}

Media were prepared with distilled $\mathrm{H}_{2} \mathrm{O}$, autoclaved for $20 \mathrm{~min}$ at $120{ }^{\circ} \mathrm{C}$, and stored at room temperature unless stated otherwise.

LB medium (per liter)

$10 \mathrm{~g}$ tryptone/peptone

$10 \mathrm{~g} \mathrm{NaCl}$

$5 \mathrm{~g}$ yeast extract

$\rightarrow$ adjustment of $\mathrm{pH}$ to 7.0 with $\mathrm{NaOH}$

SOC medium (per liter)

$20 \mathrm{~g}$ tryptone/peptone

$5 \mathrm{~g}$ yeast extract

$0.5 \mathrm{~g} \mathrm{NaCl}$

$2.5 \mathrm{ml} 1 \mathrm{M} \mathrm{KCl}$

$\rightarrow$ adjust $\mathrm{pH}$ to 7.0 with $\mathrm{NaOH}$ and add $\mathrm{dH}_{2} \mathrm{O}$ to $990 \mathrm{ml}$

$\rightarrow$ autoclave

$\rightarrow$ add $10 \mathrm{ml} 1 \mathrm{M} \mathrm{MgCl}_{2}$

$\rightarrow$ add $1 \mathrm{M}$ glucose

\subsubsection{Agar plates}

Preparation of agar plates was done by adding $15 \mathrm{~g}$ agar to 11 of LB medium just before autoclaving. Afterwards, LB agar was cooled down to $\sim 50{ }^{\circ} \mathrm{C}$, supplemented with $100 \mu \mathrm{g} / \mathrm{ml}$ ampicillin, mixed by swirling, and poured into sterile plates. Cured agar plates were stored at $4{ }^{\circ} \mathrm{C}$ in the inverted position. 
Material and Methods

\subsubsection{Vectors}

Table 2.11: Vectors

\begin{tabular}{|c|c|}
\hline Name & Application, Supplier/Source \\
\hline pcDNA3-BCL6 & $\begin{array}{l}\text { Human BCL6 expression vector; kind gift from Giovanna Roncador, } \\
\text { Monoclonal Antibodies Unit Centro Nacional de Investigaciones Oncológicas, } \\
\text { Spain (Garcia et al., 2006) }\end{array}$ \\
\hline pcDNA3 & $\begin{array}{l}\text { Eukaryotic expression vector; this thesis, by cutting BCL6-cDNA out of } \\
\text { pcDNA3-BCL6 }\end{array}$ \\
\hline pGL3-Basic & Firefly luciferase reporter vector; Promega \\
\hline pGL3-Enhancer & Firefly luciferase reporter vector; Promega \\
\hline pRL-TK & Renilla luciferase control reporter vector; Promega \\
\hline pSG5-AR & $\begin{array}{l}\text { Human AR expression vector; kind gift from Ivan V. Litvinov, John Hopkins } \\
\text { University School of Medicine, Baltimore, USA (Litvinov et al., 2004). } \\
\text { Baltimore, USA }\end{array}$ \\
\hline pSG5-ratAR & $\begin{array}{l}\text { Rat AR expression vector; kind gift from Olli A. Jänne, Institute of Biomedicine, } \\
\text { University of Helsinki, Finland (Palvimo et al., 1993) }\end{array}$ \\
\hline pSG5 & $\begin{array}{l}\text { Eukaryotic expression vector; this thesis, by cutting rat AR-cDNA out of } \\
\text { pSG5-ratAR }\end{array}$ \\
\hline $\mathrm{rPb}-\mathrm{Luc}$ & $\begin{array}{l}\text { Minimal promoter of the rat probasin gene, which was cloned into the } \\
\text { pGL3-Basic; kind gift from Silke Kaulfuss, Institute of Human Genetics, } \\
\text { University of Göttingen (Kaulfuss et al., 2008) }\end{array}$ \\
\hline
\end{tabular}

\subsubsection{Oligonucleotides}

Oligonucleotides for PCR were designed by Primer3 software, tested for sequence-specificity by PrimerBlast (NCBI), and purchased from Eurofins MWG Operon. Oligonucleotides for the site-directed mutagenesis were designed by the QuickChange Primer Design Program and acquired from Eurofins MWG Operon.

Table 2.12: Oligonucleotides used for colony PCR and sequencing

\begin{tabular}{lll}
\hline Name & Sequence & Position \\
\hline pcDNA3 & F: 5'-TTGGCACCAAAATCAACGGGAC-3' & 713 to 734 bp \\
pcDNA3 & R: 5'-ATTAGGAAAGGACAGTGGGAG-3' & 1114 to 1134 bp \\
pSG5 & F: 5'-GTCATCATCCTGCCTTTCTC-3' & 842 to $861 \mathrm{bp}$ \\
pSG5 & R: 5'-GTTCTTTCCTGCGTTATCCC-3' & 1319 to $1338 \mathrm{bp}$ \\
pGL3-Enhancer & F: 5'-CTGTGTGTTGGTTTTTTGTGTG-3' & 4931 to $4952 \mathrm{bp}$ \\
pGL3-Enhancer & R: 5'-TCTCCAGCGGTTCCATCTTC-3' & 139 to $158 \mathrm{bp}$
\end{tabular}

F: forward, R: reverse; position relative to the numbering of respectively supplier. (Vector references: pcDNA3: Invitrogen ${ }^{\mathrm{TM}}$, life technologies; pSG5: Stratagene; pGL3-Enhancer: Promega) 
Table 2.13: Oligonucleotides for site directed mutagenesis

\begin{tabular}{l} 
Name Sequence \\
\hline Promoter construct: Oat1 (-1226/+113)
\end{tabular}

Mut 1 F: 5'-CAGAAGGCCACCATATTGAACCGCTCCCAGACTACTCGATGG-3' R: 5'-CCATCGAGTAGTCTGGG $\underline{\mathbf{A G C}}$ GGTCAATATGGTGGCCTTCTG-3'

Mut 2 F: 5'-GGTAAAAAGAGAGAAACTGTCAGCGCAGGTTATCCTCAGACCTCCATGC-3' R: 5'-GCATGGAGGTCTGAGGATAACETGCGCTGACAGTTTCTCTCTTTTTACC-3'

Promoter construct: Oat3 (-444/+12)

Mut 1 F: 5'-CCCTCAGACTCGAATCCCTGAACTGCTTCTCTCTTAGGAAAC-3'

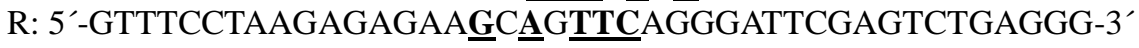

Mut 2 F: 5'-CCCCTAACATTCTTCGCTGACCTACTCGGGAGCTG-3'

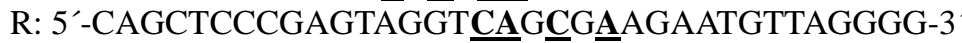

\section{Promoter construct: OAT1 (-1982/+88)}

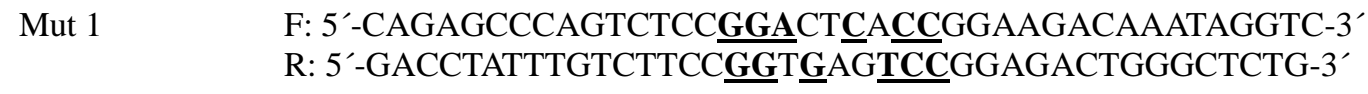

Mut 2 F: 5'-CAAGAGGCCACCACACTGAACCTCGCCCAGTCTCCTTC-3'

R: 5'-GAAGGAGACTGGGC

Mut 3 F: 5'-GGAGCCAAAACTCTGTCGGCGTCCTTCACGTGATTGTCTTAG-3'

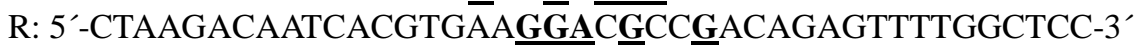

Oat/OAT: Organic anion transporter; Mut: mutation; F: forward; R: reverse; bold and underlined nucleotides: inserted mutations. 
Material and Methods

\subsubsection{TaqMan® Gene Expression Assays}

Following TaqMan ${ }^{\circledR}$ Gene Expression Assays were purchased from Applied Biosystems and used for real-time PCR.

Table 2.14: TaqMan® Gene Expression Assays

\begin{tabular}{lll}
\hline Gene & Protein & Assays \\
\hline Androgen receptor & AR & Rn00560747_m1 \\
Beta-actin & $\beta$-actin & Rn00667869_m1 \\
B-cell CLL/lymphoma 6 & BCL6 & Rn01404339_m1 \\
Hepatocyte nuclear factor 1 $\alpha$ & HNF1 $\alpha$ & Rn00562020_m1 \\
Hepatocyte nuclear factor 1 $\beta$ & HNF1 $\beta$ & Rn00447453_m1 \\
Hepatocyte nuclear factor 4 $\alpha$ & HNF4 $\alpha$ & Rn00573309_m1 \\
Hydroxysteroid (17-beta) dehydrogenase 1 & HSD17B1 & Rn00563388_g1 \\
Hypoxanthine phosphoribosyltransferase 1 & Hprt1 & Rn01527840_m1 \\
Polymerase (RNA) III (DNA directed) polypeptide G & POLR3G & Rn01494192_m1 \\
Slc22a6 & Oat1 & Rn00568143_m1 \\
Slc22a8 & Oat3 & Rn00580082_m1 \\
\hline
\end{tabular}

\subsubsection{Cell lines}

Cell lines, unless stated otherwise, were obtained from Deutsche Sammlung von Mikroorganismen und Zellkulturen (DSMZ) or LGC (European distributor for American Type Culture Collection (ATCC)).

\section{OK cells}

\section{Opossum kidney}

Established from a female opossum proximal tubule epithelium

\section{$\underline{\text { LLC-PK1 cells }}$}

Sus scrofa (porcine) kidney

Established from the normal kidney of a juvenile male Hampshire pig in 1958

\section{NRK-52E cells}

Rattus norvegicus kidney

Rat kidney epithelial cell line 


\section{HEK-293 cells}

Human embryonic

Established from a human primary embryonal kidney transformed by adenovirus type 5

\section{HK-2 cells}

Human kidney

Proximal tubular cell line derived from an adult normal kidney

\section{Caco-2 cells}

Human colon adenocarcinoma

Established in 1974 from the primary colon tumor (adenocarcinoma) of a 72-year-old

Caucasian man

\section{$\underline{\text { HT-29 cells }}$}

Human colon adenocarcinoma

Established in 1964 from the primary tumor of a 44-year-old Caucasian woman with colon adenocarcinoma

\section{$\underline{\text { Hep-G2 cells }}$}

Human hepatocellular carcinoma

Established in 1975 from the tumor tissue of a 15-year-old Argentine boy with hepatocellular carcinoma

\section{TK-173 cells}

\section{Human renal fibroblast}

Established from the normal part of kidney and kindly provided by Prof. Dr. Müller, department of nephrology and rheumatology, University Medical Center Göttingen. 
Material and Methods

\subsubsection{Bacterial strains}

Following bacterial strains were used for the generation of promoter constructs and for propagation of expression vectors for high amounts of plasmid DNA.

Table 2.15: Bacterial strains

\begin{tabular}{|c|c|}
\hline E. coli strain & Genotype \\
\hline $\begin{array}{l}\text { One Shot® TOP10F' Competent Cells } \\
\text { (Invitrogen }{ }^{\mathrm{TM}} \text {, life technologies) }\end{array}$ & 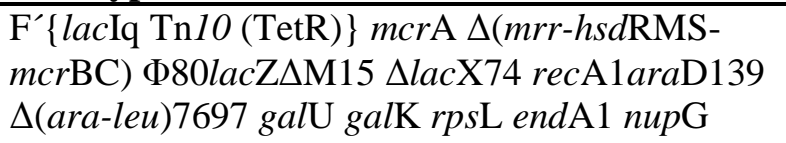 \\
\hline XL1-Blue supercompetent cells (Stratagene) & $\begin{array}{l}\text { recAl endA1 gyrA96 thi-1 hsdR17 supE44 relAl } \\
\text { lac }\left[\mathrm{F}^{\prime} \text { proAB lacIqZAM15 Tn } 10 \text { (Tetr)] }\right.\end{array}$ \\
\hline $\begin{array}{l}\text { XL10-Gold® ultracompetent cells } \\
\text { (Stratagene) }\end{array}$ & $\begin{array}{l}\text { Tetr } \Delta(\text { mcrA }) 183 \Delta(\text { mcrCB-hsdSMR-mrr }) 173 \\
\text { endA1 supE44 thi-1 recAl gyrA96 relAl lac Hte } \\
{\left[\mathrm{F}^{\prime} \text { proAB lacIqZDM15 Tn10 (Tetr) Amy Camr] }\right.}\end{array}$ \\
\hline $\begin{array}{l}\text { XL1-Blue electrocompetent cells } \\
\text { (Self-made by the technical assistant } \\
\text { Gesche Dallmayer) }\end{array}$ & $\begin{array}{l}\text { recAl endA1 gyrA96 thi-1 hsdR17 supE44 relAl } \\
\text { lac }\left[\mathrm{F}^{\prime} \text { proAB lacIqZAM15 Tn } 10 \text { (Tetr) }\right]\end{array}$ \\
\hline
\end{tabular}

\subsubsection{Animals}

Male and female RCCHan ${ }^{\mathrm{TM}}:$ WIST rats were purchased from Harlan Laboratories (Venray, Netherlands). 


\subsection{Methods}

\subsubsection{Methods required for promoter construct generation}

\subsubsection{Polymerase chain reaction $(\mathrm{PCR})$}

The polymerase chain reaction is a method for amplification and detection of DNA fragments. For a standard PCR heat-stable polymerase, DNA template, specific oligonucleotides (primers), and deoxynucleotides (dNTPs) are required. One typical PCR cycle consists of three consecutive steps: denaturation, annealing, and elongation step. During the initial denaturation step, double-stranded DNA (dsDNA) is separated into two single strands. In the second step, called annealing, PCR reaction is cooled down and hybridization of sequencespecific primers to the single stranded DNA occurs. Once the primers have annealed to their complementary DNA sequences, the temperature is raised to the optimum of used polymerase, at which polymerase adds complementary dNTP's in $5^{\prime} \rightarrow 3^{\prime}$-direction to the new expanded DNA strand. Duration of this elongation step depends on the length of newly amplified fragments and the source of utilized polymerase. A typical PCR consists of 20 to 35 PCR cycles, with a final elongation step at the end of PCR ensuring the complete elongation of all newly synthesized double-stranded DNA fragments.

\subsection{Standard PCR}

Reaction set up for a $50 \mu 1$ standard PCR:

50 ng plasmid DNA/100 ng genomic DNA/a single bacterial colony $5 \mu$ PCR-buffer (10x)

20 pmol forward primer

20 pmol reverse primer

$8 \mu \mathrm{ldNTPs}$ (1.25 mM each)

$2 \mu \mathrm{Taq}$-polymerase

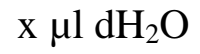

Thermal cycling conditions for standard PCR:

$\begin{array}{ll}94{ }^{\circ} \mathrm{C} & 2 \mathrm{~min} \\ 94{ }^{\circ} \mathrm{C} & 30 \mathrm{~s} \\ 50-75{ }^{\circ} \mathrm{C} & 30 \mathrm{~s} \\ 72{ }^{\circ} \mathrm{C} & 0.5-4 \mathrm{~min} \\ 72{ }^{\circ} \mathrm{C} & 10 \mathrm{~min}\end{array}$

initial denaturation denaturation annealing elongation

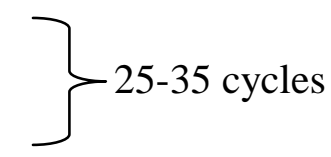
final elongation 


\subsection{High fidelity PCR}

A high fidelity polymerase is able to detect and correct false incorporated dNTPs by using his $3^{\prime} \rightarrow 5^{\prime}$ exonuclease activity. Depending on the supplier, such enzymes are named high fidelity or proof reading polymerases. In this thesis the Phusion ${ }^{\circledR}$ High-Fidelity DNA Polymerase from New England Biolabs was used.

Reaction set up for a $50 \mu 1$ high fidelity PCR:

100 ng genomic DNA

25 pmol forward primer

25 pmol reverse primer

$25 \mu$ l Phusion High-Fidelity PCR Master Mix with HF Buffer

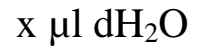

Thermal cycling conditions for high fidelity PCR:

\begin{tabular}{|c|c|c|}
\hline $98^{\circ} \mathrm{C}$ & $30 \mathrm{~s}$ & initial denaturation \\
\hline $98^{\circ} \mathrm{C}$ & $10 \mathrm{~s}$ & denaturation 7 \\
\hline $65-75^{\circ} \mathrm{C}$ & $30 \mathrm{~s}$ & annealing \\
\hline $72{ }^{\circ} \mathrm{C}$ & $0.5-2 \mathrm{~min}$ & elongation \\
\hline $72{ }^{\circ} \mathrm{C}$ & $10 \mathrm{~min}$ & final elongation \\
\hline
\end{tabular}

\subsubsection{Sequencing}

The non radioactive chain determination sequencing was performed according to Sanger et al. (Sanger et al., 1977). By using the BigDye ${ }^{\circledR}$ terminator v1.1 cycle sequencing kit (Applied Biosystems) some minor modifications in comparison to Sanger were done. For standard sequencing DNA template, DNA polymerase, one specific primer, deoxynucleotides (dNTPs), and fluorescence-dye labeled dideoxynucleotides (ddNTPs) are required. Briefly, doublestranded template DNA was denaturized, followed by primer annealing to a specific complementary sequence. Subsequent primer elongation was carried out by random incorporation of dNTPs or dye-labeled ddNTPs. Incorporation of ddNTPs during each cycle leads to the termination of template elongation due to their lacking 3'-hydroxyl group.

Reaction set up for a $10 \mu \mathrm{l}$ sequencing mixture:

350-400 ng plasmid

$1.5 \mu 1$ Seq-Mix (dNTPs and dye-labeled ddNTPs)

$2 \mu 15 \mathrm{x}$ sequencing buffer

10 pmol primer

$\mathrm{x} \mu \mathrm{l} \mathrm{dH}_{2} \mathrm{O}$ 
Thermal cycling conditions for sequencing PCR:

$\left.\begin{array}{ll}96^{\circ} \mathrm{C} & 10 \mathrm{~s} \\ 55^{\circ} \mathrm{C} & 15 \mathrm{~s} \\ 60^{\circ} \mathrm{C} & 4 \mathrm{~min}\end{array}\right\} 25$ cycles

Accumulated, dye-labeled DNA-fragments were purified, separated by capillary electrophoresis, and then detected. Purification of dye-labeled DNA fragments were done at RT, by adding $1 \mu \mathrm{l}$ of $125 \mathrm{mM}$ EDTA, $1 \mu \mathrm{l}$ of $3 \mathrm{M} \mathrm{C}_{2} \mathrm{H}_{3} \mathrm{NaO}_{2}$, and $50 \mu 1100 \%$ ethanol to the PCR reaction-mixture. After mixing by pipetting, the reaction was incubated for 5 min at RT and subsequently centrifuged for $20 \mathrm{~min}$ at $13.000 \mathrm{x} \mathrm{g}$. Supernatant was removed, $70 \mu \mathrm{l}$ of $70 \%$ ethanol added, mixed, and again centrifuged for $5 \mathrm{~min}$ at $13.000 \mathrm{x} \mathrm{g}$. The obtained supernatant was removed and the pellet was dried for $2 \mathrm{~min}$ in a vacuum centrifuge at full speed. Finally, the dried pellet was adsorbed in $15 \mu \mathrm{l}$ HiDye solution and stored at $-20{ }^{\circ} \mathrm{C}$ till sequencing.

\subsubsection{Concentration determination of DNA and RNA}

DNA/RNA concentration and purity were determined by the Gene Quant (Pharmacia Biotech) or NanoDrop ND-1000 Spectrophotometer (Thermo Scientific) according to manufacturer's recommendation. After adjustment of the reference, absorption at $260 \mathrm{~nm}$ was measured. Additionally contamination by proteins was measured at $280 \mathrm{~nm}$. The ratio of A260/280 determined the purity of RNA or DNA, and should obtain values between 1.8 and 2.1. DNA was stored at $-20{ }^{\circ} \mathrm{C}$, whereas RNA was stored immediately at $-80{ }^{\circ} \mathrm{C}$.

\subsubsection{Agarose gel electrophoresis}

Agarose gel electrophoresis was used to separate DNA-fragments according to their size. DNA is negatively charged and could be therefore separated through an agarose matrix by applying an electric field. DNA-fragments moved from the negatively charged cathode to the positively charged anode. Small fragments move quickly appearing in the lower part of an agarose gel, big fragments moved slower appearing at the top of an agarose gel. For an optimal separation, different agarose matrixes were prepared. For molecules $>500$ bp a $0.8 \%$ and for molecules < $500 \mathrm{bp}$ a $1.5 \%$ agarose gels were prepared. The agarose was dissolved in $0.5 \times$ TBE buffer and boiled in the microwave. After addition of $0.5 \mu \mathrm{g} / \mathrm{ml}$ ethidiumbromide 
to the gel, it was poured into a gel chamber. Subsequent to polymerization, the gel was placed into an electrophoresis chamber filled with $0.5 \times$ TBE. DNA-fragments were mixed with DNA Stop and loaded onto the gel. The separation of DNA was performed at $110 \mathrm{~V}$ for approximately 40-60 min, followed by DNA visualization under UV light.

\subsubsection{Isolation and purification of nucleic acids}

Plasmid purification was done using QIAprep Kits (Qiagen). These kits are based on a bindwash-elute procedure. First, bacterial cultures were harvested, then the remained pellets were lysed, and again centrifuged. The cleared lysate was applied to a QIAprep® column, which consist of a silicagel membrane at which the DNA adsorbs. Remaining contaminants were washed away and the isolated pure DNA was finally eluted in a small volume of elution buffer. All steps were carried out at room temperature.

\subsection{Plasmid preparation (mini scale)}

For plasmid preparation in mini scale the QIAprep® Spin Mini Kit was used. Starter culture was prepared by incubating $3 \mathrm{ml}$ of LB medium, supplemented with $100 \mu \mathrm{g} / \mathrm{ml}$ ampicillin, with a single bacterial colony for approximately $8 \mathrm{~h}$ at $37{ }^{\circ} \mathrm{C}$, while shaking at $220 \mathrm{rpm}$. Afterwards, $250 \mu \mathrm{l}$ of starter culture were inoculated to $7 \mathrm{ml}$ of LB medium, supplemented with $100 \mu \mathrm{g} / \mathrm{ml}$ ampicillin, and incubated over night (o/n). The following day, 2-4 $\mathrm{ml}$ of the $\mathrm{o} / \mathrm{n}$ culture were harvested by centrifugation for $2 \mathrm{~min}$ at $13.000 \mathrm{x}$ g. Subsequent DNA isolation and preparation were done according to manufacturer's recommendations.

\subsection{Plasmid preparation (midi scale)}

For plasmid preparation in midi scale the Qiagen® Plasmid Plus Midi Kit was used. A single bacterial colony was picked from a selective agar plate and incubated in $3 \mathrm{ml}$ of LB medium with $100 \mu \mathrm{g} / \mathrm{ml}$ ampicillin for $8 \mathrm{~h}$ at $37^{\circ} \mathrm{C}$, and $220 \mathrm{rpm}$. After $8 \mathrm{~h}, 1-3 \mathrm{ml}$ of these starter culture were inoculated to $50 \mathrm{ml} \mathrm{LB}$-ampicillin-medium and incubated over night $(\mathrm{o} / \mathrm{n})$. The next day, $30-35 \mathrm{ml}$ of the o/n culture were harvested by centrifugation for $15 \mathrm{~min}$ at $5.000 \mathrm{x} \mathrm{g}$. Following DNA isolation and preparation were done according to manufacturer's recommendations. 


\subsubsection{Purification of PCR products, restricted-, and dephosphorylated DNA- fragments}

Purification of PCR products, restriction, and dephosphorylation mixtures was conducted using the HighPure PCR Product Purification Kit (Roche). PCR products, restriction, and dephosphorylation samples were mixed with chaotropic salt, which allows the DNA to bind to glass fiber fleece within special High Pure tubes. During wash and spin steps, contaminants like proteins, salts, and nucleotides were removed. Bounded pure DNA was eluted, using a low salt buffer. All steps were performed according to manufacturer's recommendations and carried out at room temperature.

\subsubsection{Digestion of DNA with restriction endonucleases}

Digestion of PCR-fragments and vector-DNA was performed using different restriction endonucleases, which are able to cleave dsDNA in a sequence-specific manner. Each enzyme recognize a specific, in most case palindromic sequence of four to ten nucleotides, and cleave dsDNA by hydrolyzing the phosphodiester bonds of the DNA backbone. Digestion was done according to NEB's recommendations.

\subsubsection{Dephosphorylation of linearized vector}

Dephosphorylation of linearized vector was done by using the calf intestinal (CIP) alkaline phosphatase. After cleaving dsDNA with restriction endonucleases a free 5'-phosphate group remained. This group is removed by hydrolysis catalyzed by the enzyme CIP. Dephosphorylation was carried out to minimize the ability of vector self-ligation according to manufacturer's recommendations.

\subsubsection{Generation of blunt ends}

Conversion of 5'- and 3'- overhangs to form blunt ends was used to ligate DNA fragments which were digested with restriction endonucleases, producing non complementary overhangs. The enzyme T4 DNA polymerase (New England Biolabs) catalyzes the synthesis 
Material and Methods

of dsDNA with blunt ends by filling in 5'-overhangs, or removing 3'-overhangs. Generation of blunt ends was performed according to manufacturer's recommendations.

\subsubsection{Ligation of DNA}

Ligation of DNA was done using the T4-ligase from Promega, or in case of PCR fragments obtained from NEBs High Fidelity polymerase using the T4-ligase from New England bioloabs. Both enzymes catalyses the ATP-dependent formation of a new phospodiester bond between juxtaposed 5'- and 3'-phosphates of two different dsDNAs. Ligation was carried out according to manufacturer's recommendations.

\subsubsection{Transformation of competent bacteria with DNA}

Competent bacteria are able to uptake and propagate foreign dsDNA. In this thesis two types of competent bacteria were used: chemically competent bacteria and electrocompetent bacteria. In the case of the self-made electrocompetent XL1-blue cells, cells were thawed 5-10 min on ice and afterward transferred to a pre-chilled $1.5 \mathrm{ml}$ tube. Two $\mu$ l of ligation reaction or $50 \mathrm{ng}$ dsDNA were added to the cells and incubated for $1 \mathrm{~min}$ on ice. Next, mixture was transferred into an electroporation cuvette and transformed by a current pulse of $2500 \mathrm{~V}, 25 \mu \mathrm{F}$, for $5 \mathrm{~ms}$. After electroporation, cells were immediately resuspended in $1 \mathrm{ml}$ SOC medium and incubated at $37^{\circ} \mathrm{C}$, while shaking at $220 \mathrm{rpm}$. After $1.5 \mathrm{~h}, 50-1000 \mu \mathrm{l} \mathrm{cell}$ suspension was dispensed on ampicillin agar plates. Plates were incubated in the inverted position at $37^{\circ} \mathrm{C}$ for at least $16 \mathrm{~h}$. Transformation of chemically competent bacteria was done according to manufacturer's recommendations.

\subsubsection{Promoter constructs}

Generation of different promoter constructs was done according to the following procedure. First, sequence-specific oligonucleotides were designed to amplify the particular promoter region by polymerase chain reaction (PCR). Amplified PCR product was then purified and cleaved by their two corresponding restriction endonucleases. At the same time, particular pGL3-Enhancer backbone vector was digested with same restriction endonucleases as they were used for PCR product. After purification and dephosphorylation of cleaved backbone 34 
vector, purified PCR product and backbone vector were jointly ligated, and transfected into electrocompetent cells. Remaining colonies were checked for promoter insertion with colony PCR, followed by DNA isolation, and sequencing. An overview of each cloned promoter construct and therefore utilized oligonucleotides, restriction endonucleases, and back bone vectors is given in table 2.16 and 2.17. All constructs consist of the coding region for the bioluminescent protein firefly, whose expression is under the control of inserted promoter region in the pGL3-Enhancer. First part of the construct name denotes the particular transporter (Oat1, Oat3, Oct2, OAT1, and OAT3) and the second part, which is shown in braces, described their corresponding promoter region in base pairs. Negative numbers represent nucleotides from the $5^{\prime}$-region upstream of the transcription start site $(+1)$. Positive numbers correspond to nucleotides from the $3^{\prime}$-region downstream of the transcription start site. 
Material and Methods

Table 2.16: Used oligonucleotides, restriction endonucleases, and backbone vectors to generate rat Oat1, Oat3, and Oct 2 promoter constructs.

\begin{tabular}{|c|c|c|c|}
\hline Name \& position & Oligonucleotide & Enzymes & Backbone vector \\
\hline \multicolumn{4}{|l|}{ Oat1 $(-1226 /+113)$} \\
\hline-1226 to -1207 & 5'-GGGCTAGCAGTGAGATGACAGGCAAAGG-3' & NheI/ & pGL3-Enhancer \\
\hline+94 to +113 & 5'-ggCTCGAGATGGTGACCTGGATCAACTG-3' & XhoI & \\
\hline \multicolumn{4}{|l|}{ Oat1 $(-1666 /+113)$} \\
\hline-1666 to -1647 & 5'-ggGCTAGCCAGAGTGAGTTCCAGGACAG-3' & NheI/ & Oat1 $(-1226 /+113)$ \\
\hline-1131 to -1111 & 5'-ggggggGCATGGAGGTCTGAGGATAAC-3' & NdeI & \\
\hline \multicolumn{4}{|l|}{ Oat1 $(-2252 /+113)$} \\
\hline-2252 to -2232 & 5'-ggGCTAGCCTGCCCAAGATGATTTTGAAC-3' & NheI/ & Oat1 $(-1666 /+113)$ \\
\hline-1545 to -1526 & 5'-gcgcgATTGGAGCTGAGGACTGAAC-3' & BbvCI & \\
\hline \multicolumn{4}{|l|}{ Oat3 $(-444 /+12)$} \\
\hline-444 to -425 & 5'-ggGAGCTCCCCTAACATTCTCCACGAAC-3' & $\mathrm{SacI} /$ & pGL3-Enhancer \\
\hline-7 to +12 & $5^{\prime}-g g$ CTCGAGAGGACAGCTCAGCTCTAAC-3' & XhoI & \\
\hline \multicolumn{4}{|l|}{ Oat3 $(-752 /+12)$} \\
\hline-752 to -732 & 5'-ggGAGCTCGGAGAACAGACAACCACATAC-3' & $\mathrm{SacI} /$ & pGL3-Enhancer \\
\hline-7 to +12 & 5'-gg CTCGAGAGGACAGCTCAGCTCTAAC-3' & XhoI & \\
\hline \multicolumn{4}{|l|}{ Oat3 $(-1823 /+12)$} \\
\hline-1823 to -1802 & 5'-gggGAGCTCGGCCAACTAGGAACTAGAAAAG-3' & $\mathrm{SacI} /$ & Oat3 $(-752 /+12)$ \\
\hline-685 to -665 & 5'-gcggcgggCAAGCCAACACAAACTGAATC-3' & AvrII & \\
\hline \multicolumn{4}{|l|}{ Oat3 $(-2567 /+12)$} \\
\hline-2631 to -2613 & 5'-TGAGATGAGGACAACGGAC-3' & $\mathrm{SacI} /$ & Oat3 $(-1823 /+12)$ \\
\hline-1702 to -1681 & 5'-TTAAATTATACTCCAAGGCCGC-3' & PstI & \\
\hline \multicolumn{4}{|l|}{ Oat3 $(-3261 /+12)$} \\
\hline-3261 to -3240 & 5'-gc GGTACCAACAGAGGTTCTACCCAGATGAA-3' & $\mathrm{SacI} /$ & Oat3 $(-2567 /+12)$ \\
\hline-2563 to -2538 & $5^{\prime}$-gccggTCTAGTCTCCTCTAATCTGAAGCTGA-3' & KpnI & \\
\hline \multicolumn{4}{|l|}{ Oct2 $(-1173 /+12)$} \\
\hline-1173 to -1149 & $5^{\prime}-c g$ GAGCTCAAGGCTCTGAACCCACTCAATAAAC-3' & $\mathrm{SacI} /$ & pGL3-Enhancer \\
\hline-12 to +12 & 5'-atCTCGAGGCTCAGCTCAGGATGACTCTTGAC-3' & XhoI & \\
\hline \multicolumn{4}{|l|}{ Oct2 $(-1958 /+12)$} \\
\hline-1958 to -1939 & 5'-ggGAGCTCCAGACCATCACCTGAAGCAC-3' & $\mathrm{SacI} /$ & Oct2 $(-1173 /+12)$ \\
\hline-1091 to -1071 & 5'-cggcggCCTTGACTGCCTGTAATAGCC-3' & PstI & \\
\hline
\end{tabular}

Oat: organic anion transporter; Oct: organic cation transporter; bold nucleotides: artificial restriction sides (not included in numbering); small italic nucleotides: adjustment of primer melting temperature (not included in numbering). Positions: relative to transcription start site +1 of respectively NCBI Reference Sequences: Oat 1 (NW_047563.2.), Oat3 (NW_047563.2.), and Oct2 (NW_047553.1.). 
Table 2.17: Used oligonucleotides, restriction endonucleases, and backbone vectors to generate human OAT1, and OAT3 promoter constructs.

\begin{tabular}{|c|c|c|c|}
\hline Name \& position & Oligonucleotide & Enzymes & Backbone vector \\
\hline \multicolumn{4}{|l|}{ OAT1 $(-63 /+88)$} \\
\hline-63 to -42 & 5'- $g c c g g$ GCTAGCTTGGAGGGTTAATCCTTCTGAT-3' & NheI/ & pGL3-Enhancer \\
\hline+88 to +64 & 5'-ggCTCGAGTCCCTTGCAGCTTCTCCTCACTTTG-3' & XhoI & \\
\hline \multicolumn{4}{|l|}{ OAT1 $(-198 /+88)$} \\
\hline-198 to -177 & 5'-gcGCTAGCGGTCCAATAGATCCCACTCTGG-3' & NheI/ & pGL3-Enhancer \\
\hline+88 to +64 & 5'-gg CTCGAGTCCCTTGCAGCTTCTCCTCACTTTG-3' & XhoI & \\
\hline \multicolumn{4}{|l|}{ OAT1 $(-342 /+88)$} \\
\hline-342 to -319 & 5'-ggGCTAGCTTTGACTGGGCACCCTGTAATTTC-3' & NheI/ & pGL3-Enhancer \\
\hline+88 to +64 & 5'-gg CTCGAGTCCCTTGCAGCTTCTCCTCACTTTG-3' & XhoI & \\
\hline \multicolumn{4}{|l|}{ OAT1 $(-746 /+88)$} \\
\hline-746 to -723 & 5'-ggGCTAGCGGGGAGGGGAGAAGAGAAGAAAAC-3' & NheI/ & pGL3-Enhancer \\
\hline+88 to +64 & 5'-gg CTCGAGTCCCTTGCAGCTTCTCCTCACTTTG-3' & XhoI & \\
\hline \multicolumn{4}{|l|}{ OAT1 $(-1419 /+88)$} \\
\hline-1419 to -1445 & 5'-ggGCTAGCAAAATAACACTATGGCTGGGTGCG-3' & NheI/ & pGL3-Enhancer \\
\hline+88 to +64 & 5'-gg CTCGAGTCCCTTGCAGCTTCTCCTCACTTTG-3' & XhoI & \\
\hline \multicolumn{4}{|l|}{ OAT1 $(-1982 /+88)$} \\
\hline-1982 to -1959 & 5'-ggGCTAGCACCGCCAGTCAAAAATCACCGTTC-3' & NheI/ & OAT1 $(-1419 /+88)$ \\
\hline-1177 to -1152 & 5'-ggCCAGCCTGGAGTGTAGTGGCACAATC-3' & PstI & \\
\hline \multicolumn{4}{|l|}{ OAT1 $(-3049 /+88)$} \\
\hline-3049 to -3026 & 5'-ggGCTAGCCATCCCTTCAACAGCAAGACGGAG-3' & NheI/ & OAT1 $(-1982 /+88)$ \\
\hline-1867 to -1842 & 5'-ggggggAGCTCATATGCCCTGTAATTCAGTGG-3' & NdeI & \\
\hline \multicolumn{4}{|l|}{ OAT3 $(-59 /+21)$} \\
\hline-59 to -42 & 5'-gcgGCTAGCCATTAGCCCGGGAAACAG-3' & NheI/ & pGL3-Enhancer \\
\hline+2 bis +21 & 5'-gg CTCGAGGCAGCTCAGCTCTAACAAGC-3' & XhoI & \\
\hline \multicolumn{4}{|l|}{ OAT3 (-112/+21) } \\
\hline-112 to -95 & 5'-ctGCTAGCGGGTCCACAGCACTCTCC-3' & NheI/ & pGL3-Enhancer \\
\hline+2 bis +21 & 5'-gg CTCGAGGCAGCTCAGCTCTAACAAGC-3' & XhoI & \\
\hline \multicolumn{4}{|c|}{ OAT3 $(-214 /+21)($ cloned according to Ogasawara et al. 2006) } \\
\hline-323 to -301 & 5'-ggGCTAGCTCAGAGGTCAGGCCAGATTC-3' & NheI/Xho & pGL3-Enhancer \\
\hline+2 bis +21 & 5'-gg CTCGAGGCAGCTCAGCTCTAACAAGC-3' & ApaI/Mlu & \\
\hline \multicolumn{4}{|l|}{ OAT3 $(-1499 /+21)$} \\
\hline-1499 to -1480 & $5^{\prime}-t t \mathbf{G C T A G C G G G C A G C T C C C A G G G G T T T C - 3 ^ { \prime }}$ & NheI/ & pGL3-Enhancer \\
\hline+2 to +21 & 5'-ggCTCGAGGCAGCTCAGCTCTAACAAGC-3' & XhoI & \\
\hline \multicolumn{4}{|l|}{ OAT3 $(-3047 /+21)$} \\
\hline-3047 to -3028 & $5^{\prime}-t t$ GCTAGCGTGAGCAGCTAGGAGGGTTG-3' & NheI/ & OAT3 $(-1499 /+21)$ \\
\hline-1368 to -1350 & 5'-cgccgAGATCGTGCCACTGCACTC-3' & AvrII & \\
\hline
\end{tabular}

OAT: organic anion transporter; bold nucleotides: artificial restriction sides (not included in numbering); small italic nucleotides: adjustment of primer melting temperature (not included in numbering). Positions: relative to transcription start site +1 of respectively NCBI Reference Sequences: OAT1 (NT_167190.1.) and OAT3 (NT_167190.1.). 


\subsubsection{Site-directed mutagenesis}

Beside DNA amplification, PCR can also be used for the introduction of mutations within the DNA. In general, the QuickChange®II site-directed mutagenesis kit (Agilent Technologies) was used to introduce point mutations into B-cell CLL/lymphoma 6 (BCL6) binding sites of different promoter constructs. Constructs harboring more than one mutation were generated by consecutive rounds of mutagenesis. Site-directed mutagenesis was performed in a $50 \mu 1$ reaction set up with $50 \mathrm{ng}$ of respectively plasmid DNA and according to manufacturer's recommendation.

Subsequent to site-directed mutagenesis PCR, DpnI is added to the reaction to digest selectively the methylated and hemimethylated parental DNA template. Thereby, mutationcontaining plasmids are unaffected and can be therefore transformed into chemical competent E.coli cells. All steps were carried out according to manufacturer's recommendation.

\subsubsection{Cell biological methods}

\subsubsection{Culturing of adherent cells}

Adherent cells were grown as monolayers in their respective growth medium (see table 2.18) in an incubator at $37{ }^{\circ} \mathrm{C}$ and $5 \% \mathrm{CO}_{2}$ humidified atmosphere. Liquids used for cell culture were sterile and pre-warmed to $37^{\circ} \mathrm{C}$ just before use. Cells were passaged at a confluence of 80-90\% and subcultured. Therefore cells were washed in PBS and detached with trypsin/EDTA for $5-15 \mathrm{~min}$ at $37{ }^{\circ} \mathrm{C}$. Inactivation of trypsin was achieved by adding $2 \mathrm{x}$ volume of FBS-containing growth medium. 
Table 2.18: Cell lines with respectively growth medium

\begin{tabular}{|c|c|c|}
\hline Cell line & Medium & Supplementals \\
\hline Caco-2 & DMEM-HG & $\begin{array}{l}20 \% \text { FBS } \\
1 \% \text { NEA (non-essential amino acids) } \\
100 \mathrm{units} / \mathrm{ml} \text { penicillin } \\
100 \mu \mathrm{g} / \mathrm{ml} \text { streptomycin }\end{array}$ \\
\hline Hep-G2 & DMEM-HG & $\begin{array}{l}10 \% \mathrm{FBS} \\
100 \mathrm{units} / \mathrm{ml} \text { penicillin } \\
100 \mu \mathrm{g} / \mathrm{ml} \text { streptomycin } \\
1.25 \mathrm{mM} \text { sodium pyruvate }\end{array}$ \\
\hline HEK-293 & Quantum 286 for epithelial cells & $\begin{array}{l}100 \mathrm{units} / \mathrm{ml} \text { penicillin } \\
100 \mu \mathrm{g} / \mathrm{ml} \text { streptomycin }\end{array}$ \\
\hline HK-2 & Quantum 286 for epithelial cells & $\begin{array}{l}100 \mathrm{units} / \mathrm{ml} \text { penicillin } \\
100 \mu \mathrm{g} / \mathrm{ml} \text { streptomycin }\end{array}$ \\
\hline HT-29 & DMEM-HG & $\begin{array}{l}10 \% \mathrm{FBS} \\
100 \mathrm{units} / \mathrm{ml} \text { penicillin } \\
100 \mu \mathrm{g} / \mathrm{ml} \text { streptomycin }\end{array}$ \\
\hline LLC-PK1 & DMEM-LG & $\begin{array}{l}10 \% \mathrm{FBS} \\
100 \mathrm{units} / \mathrm{ml} \text { penicillin } \\
100 \mu \mathrm{g} / \mathrm{ml} \text { streptomycin }\end{array}$ \\
\hline NRK-52E & Quantum 286 for epithelial cells & $\begin{array}{l}100 \mathrm{units} / \mathrm{ml} \text { penicillin } \\
100 \mu \mathrm{g} / \mathrm{ml} \text { streptomycin }\end{array}$ \\
\hline OK & Quantum 286 for epithelial cells & $\begin{array}{l}100 \mathrm{units} / \mathrm{ml} \text { penicillin } \\
100 \mu \mathrm{g} / \mathrm{ml} \text { streptomycin }\end{array}$ \\
\hline TK-173 & DMEM-LG & $\begin{array}{l}10 \% \text { FBS } \\
2 \mathrm{mM} \text { L-glutamine } \\
100 \mathrm{units} / \mathrm{ml} \text { penicillin } \\
100 \mu \mathrm{g} / \mathrm{ml} \text { streptomycin }\end{array}$ \\
\hline
\end{tabular}

\subsubsection{Determination of cell density}

Determination of cell density was done by using a Neubauer counting chamber, according to manufacturer's recommendation. In brief, this chamber consists of a predefined volume, which permits the determination of cell density. Therefore, cells were washed in PBS, trypsinized, and pelleted. The remaining pellet was further resuspended in $1 \mathrm{ml}$ medium, diluted 1:10-1:20, and $10 \mu 1$ of this solution was applied to Neubauer counting chamber. Cell density was calculated using following formula:

$$
\frac{\# \text { cell number }}{\# \text { squares }} \cdot \text { dilution factor } \cdot 10^{4}=\text { cell } \frac{\text { density }}{\mathrm{ml}}
$$




\subsubsection{Transiently transfection of adherent cells}

For transiently transfection of adherent cells, cells ( $0.75-2 \times 10^{5}$ cells/well) were seeded into a 24-well culture plates within their respectively growth medium but without antibiotics. The following day, cells were transiently transfected at a confluence of 70-80\%.

\subsection{Transiently transfection with pSG5-ratAr/AR}

For the investigation of rat Oat1/Oat3, Oct2, and rat probasin promoter activity, OK or LLC-PK1 cells were transiently transfected with the following vectors: $0.6 \mu \mathrm{g}$ of particular promoter-constructs, rPb-Luc, pGL3-Enhancer, or pGL3-Basic, $0.1 \mu \mathrm{g}$ of the rat AR expression vector psG5-ratAR, or empty control vector pSG5, and 30 ng Renilla luciferase expression vector pRL-TK. Transfection was done using DMEM-HG for OK, DMEM-LG for LLC-PK1 cells, and Lipofectamine ${ }^{\mathrm{TM}} 2000$ (Invitrogen $^{\mathrm{TM}}$ life technologies) according to manufacturer's recommendations. Five hours after transfection, medium was replaced by their corresponding growth medium, without antibiotics, but supplemented with $100 \mathrm{nM}$ testosterone or $0.0003 \%$ DMSO. In case of human OAT1/OAT3 promoter activity, the same amount and constructs/vectors were transfected with the exception that human AR vector pSG5-AR instead of rat AR was utilized. $48 \mathrm{~h}$ post transfection, firefly and Renilla activity were measured using the Dual-Luciferase $\AA^{\circledR}$ Reporter Assay System (Promega), and Mithras LB940 luminometer (Berthold technologies).

\subsection{Transiently transfection with pcDNA3-BCL6}

Involvement of BCL6 on the promoter activity of rat and human Oat1/OAT1 and Oat3/OAT3 was examined by transiently transfecting OK cells in DMEM-HG with $0.5 \mu \mathrm{g}$ of each promoter construct or pGL3-Enhancer, $0.5 \mu \mathrm{g}$ pcDNA3-BCL6 or empty vector pcDNA3, and $25 \mathrm{ng}$ of the Renilla reniformis vector pRL-TK using Lipofectamine ${ }^{\mathrm{TM}} 2000$ (Invitrogen $^{\mathrm{TM}}$, life technologies) according to manufacturer's recommendations. Five hours after transfection, medium was replaced by complete growth medium. $48 \mathrm{~h}$ post transfection, firefly and Renilla activity were measured using the Dual-Luciferase ${ }^{\circledR}$ Reporter Assay System (Promega) and Mithras LB940 luminometer (Berthold technologies). 


\subsubsection{Luciferase assay}

Promoter activities were investigated using the Dual-Luciferase ${ }^{\circledR}$ Reporter Gene Assay (Promega). The firefly (Photinus pyralis) and Renilla (Renilla reniformis) luciferase are reporter genes, encoding proteins which are characterized by easily quantification, no need for post-translational modifications, and no ubiquitous expression. As a reason of their distinct evolutionary origin, both enzymes have divergent enzyme structures and substrate requirements, enabling to distinguish between their respective bioluminescent reactions (figure 2.1).

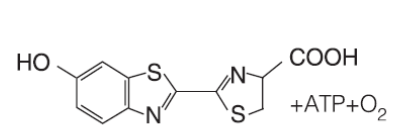

Beetle Luciferin

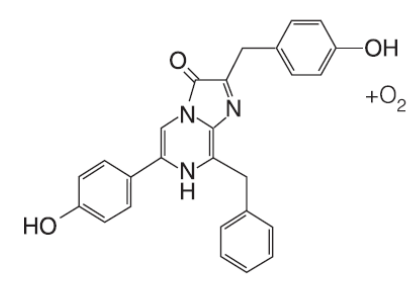

Coelenterazine

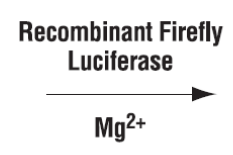$$
\text { (1) }
$$

Oxyluciferin

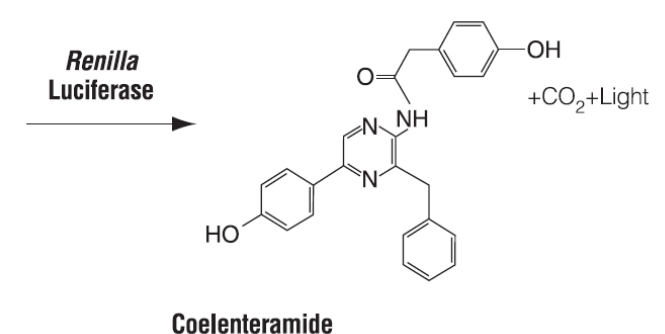

Coelenteramide

Figure 2.1: Bioluminescent reaction catalyzed by firefly and Renilla luciferase.

(Figure out of Dual-Luciferase $®$ Reporter Assay System, Technical Manual, www. Promega.com)

As the name Dual-Luciferase ${ }^{\circledR}$ Reporter Assay System indicates, activities of firefly and Renilla luciferase are measured sequentially within one single sample. Therefore cells are co-transfected with a firefly luciferase containing promoter construct and with the Renilla luciferase containing pRL-TK vector. Activity of Renilla luciferase, whose expression is controlled by the constitutively active herpes simplex virus thymidine kinase (HSV-TK) promoter, serves as internal control.

Luciferase measurement was done according to manufacturer's recommendations. In brief, cells were washed with $500 \mu \mathrm{l} /$ well PBS, and lysed with $100 \mu \mathrm{l} /$ well passive lysis buffer (Promega) for $15 \mathrm{~min}$ at RT, while gentle shaking. Complete passive lysis was checked via microscope and the supernatant was transferred to a $1.5 \mathrm{ml}$ tube. Each well was additionally rinsed with $400 \mu \mathrm{l}$ of PBS and transferred to the identical $1.5 \mathrm{ml}$ tube. Samples were mixed, centrifuged for $30 \mathrm{~s}$ at $13.000 \mathrm{x} \mathrm{g}$, diluted 1:20 in PBS, and 10 $\mu 1$ of diluted sample were 
pipette into a microreader plate. After the addition of $50 \mu 1$ Luciferase Assay Reagent II (LARII, Promega), firefly luciferase activity was measured. Immediately after the first measurement, $50 \mu \mathrm{l}$ of Stop \& Glow ${ }^{\circledR}$ Reagent (Promega) was added to the same sample, followed by the measurement of Renilla luciferase activity. Stop \& Glow® Reagent quenches the firefly activity and simultaneously activates Renilla activity. For quantification of investigated promoter construct, firefly was normalized to Renilla luciferase activity. Levels of normalized firefly activity are proportional to the degree of promoter activity.

\subsection{Immunostaining and evaluation of transfection efficiency}

Cells were seeded $\left(0.75-2 \times 10^{5}\right)$ on poly-D-lysine coated cover slips in 24-well culture plates in their appropriate growth medium without antibiotics. After overnight cultivation, cells were transiently transfected with either $0.5 \mu \mathrm{g}$ pSG5-ratAR/empty control vector pSG5, or $0.5 \mu \mathrm{g}$ pcDNA3-BCL6/empty vector pcDNA3. Transfection was done using either DMEM-HG or DMEM-LG, and Lipofectamine ${ }^{\mathrm{TM}} 2000$ (Invitrogen $^{\mathrm{TM}}$, life technologies) according to manufacturer's recommendations. Five hours after transfection, medium was replaced by growth medium. $48 \mathrm{~h}$ post transfection cells were washed with PBS, and fixed in $1 \mathrm{ml} \mathrm{3.8 \%} \mathrm{paraformaldehyde/well} \mathrm{for} 8 \mathrm{~min}$ at RT. All further steps were done at room temperature and moreover, after each step, cells were washed three times with $500 \mu \mathrm{l} / \mathrm{well}$ PBS for $15 \mathrm{~min}$. Next, cells were permeabilized for $5 \mathrm{~min}$ in $1 \mathrm{ml}$ buffer consisting of $50 \mathrm{mM} \mathrm{Na} 2 \mathrm{HPO}_{4} / \mathrm{NaH}_{2} \mathrm{PO}_{4}(\mathrm{pH} 7.4), 0.5 \mathrm{mM} \mathrm{NaCl}$, and 0.3\% Triton X-100. Afterwards, cells were stained with $150 \mu \mathrm{l}$ of $0.5 \mu \mathrm{g} / \mathrm{ml}$ primary polyclonal rabbit anti-rat AR antibody (Santa Cruz), or monoclonal mouse anti-human BCL6 antibody (Santa Cruz), and incubated for $2 \mathrm{~h}$. Antibodies, first and second, were diluted in PBS containing 0.1\% BSA. After incubation, cells were blocked by $150 \mu \mathrm{l} /$ well of $1 \%$ PBS-BSA solution for $15 \mathrm{~min}$, followed by the second staining with $150 \mu \mathrm{l} /$ well of $8 \mu \mathrm{g} / \mathrm{ml}$ secondary antibody Alexa Fluor ${ }^{\circledR} 488$ goat anti-rabbit $\operatorname{IgG}(\mathrm{H}+\mathrm{L})$ (Invitrogen ${ }^{\mathrm{TM}}$, life technologies), or Alexa Fluor ${ }^{\circledR} 488$ goat anti-mouse $\mathrm{IgG}(\mathrm{H}+\mathrm{L})$ (Invitrogen ${ }^{\mathrm{TM}}$, life technologies) for $1 \mathrm{~h}$ in the dark. Last staining was done by adding $150 \mu \mathrm{l} /$ well of $300 \mathrm{nM}$ 4',6-diamidino-2-phenylindole dihydrochloride (DAPI) (Invitrogen $^{\mathrm{TM}}$, life technologies) (diluted in PBS containing 0.1\% BSA) for 3 min in the dark, followed by three additional wash steps in the dark.

Immunfluorescence was detected under the fluorescence microscope AXID observer D1 (Carl Zeiss AG), with the excitation wavelengths of $488 \mathrm{~nm}$ for AR/BCL6 and $365 \mathrm{~nm}$ for DAPI. 
Evaluation of transfection efficiency was estimated under a 20x magnification. Five pictures across one cover slip were made. Using Image J version 1.44, DAPI (blue) stained cells were counted and set to $100 \%$. AR and BCL6-positive cells, stained in green, were further counted and their ratio to DAPI stained cells was calculated. The mean of all five pictures was determined and is referred as transfection efficiency in percent.

\subsubsection{Caspase-3 activity assay}

Apoptosis, or programmed cell death, is a biochemical process characterized by cell shrinkage, nuclear fragmentation, chromatin condensation, chromosomal DNA fragmentation, and cleavage or degradation of several cellular proteins. Members of the caspase family play an important role in apoptosis. The enzyme activity of caspae-3, as an indicator for apoptosis, was investigated by using the EnzChek® Caspase-3 Assay Kit \#2 (Molecular probes). Caspase-3 cleaves a number of different enzymes with the amino acid sequence Asp-Glu-ValAsp. In this kit, caspase-3 substrate is a nonfluorescent bisamide derivate of rhodamine 110, which is covalently bound to the amino acid sequence Asp-Glu-Val-Asp. Cleavage of Asp-Glu-Val-Asp sequence by caspase-3 is caused by the conversion of the nonfluorescent substrate into its fluorescent forms, which could be detected at the excitation wavelength of $490 \mathrm{~nm}$, and the emission wavelength of $535 \mathrm{~nm}$, respectively. Briefly, $48 \mathrm{~h}$ after transfection cells were washed with PBS, trypsinized, and centrifuged for $3 \mathrm{~min}$ at $300 \mathrm{x} \mathrm{g}$, RT. The remaining pellet was again washed with PBS and then stored at $-80{ }^{\circ} \mathrm{C}$. At the time of analyses, cells were thawed and subsequently resuspended in $50 \mu \mathrm{l}$ lysis buffer. For optimal lysis, cells were exposured to two to three freeze-thaw cycles consisting of $1 \mathrm{~min}$ in liquid nitrogen followed by thawing. The ongoing procedure was done according to manufacturer's recommendation. Caspase- 3 activity was calculated as the ratio of fluorescence to the total amount of protein.

\subsubsection{Methods required for microarray analyses}

\subsubsection{Preparation of rat cortical kidney slices}

RCCHan $^{\mathrm{TM}}$ :WIST rats were obtained from Harlan Laboratories (Venray, Netherlands) and were kept in the animal facility of the University Medical Center Göttingen. Housing 
conditions were $22{ }^{\circ} \mathrm{C}, 55 \%$ humidity, and $12 \mathrm{~h}$ day/night circle. Rats were given free access to water and rat chow at any time. Acclimatization period was at least 14 days. Age of rats at the time of preparation was $\sim 80$ days. Four rats per sex were anesthetized with $\mathrm{CO}_{2}$ and euthanized by cervical dislocation. Kidneys were immediately removed, washed three times in ice-cold PBS, and stored on ice. All subsequent steps were carried out on ice and done as fast as possible to prevent RNA degradation. After removal of kidney capsule, cortical slices were prepared (figure 2.2). The obtained slices were immediately transferred to the RNA stabilization reagent RNAlater ${ }^{\circledR}$ (Ambion, Applied Biosystem), and stored at $4{ }^{\circ} \mathrm{C}$ over night. For long-time storage, cortical kidney slices were removed from RNAlater ${ }^{\circledR}$, dried, and stored at $-80{ }^{\circ} \mathrm{C}$.

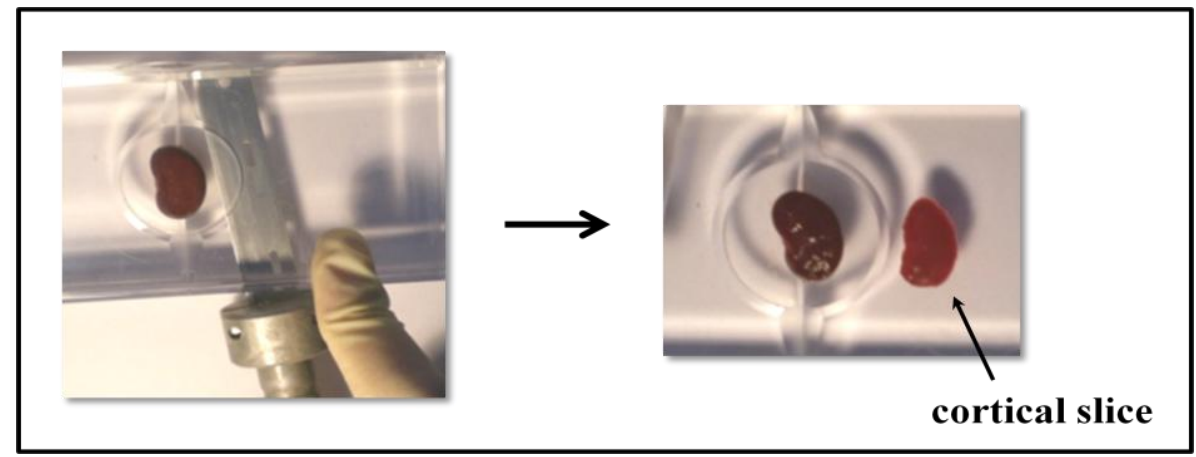

Figure 2.2: Preparation of rat cortical kidney slices.

\subsubsection{Isolation and purification of total RNA}

Isolation and purification of total RNA was done using the RNeasy® Mini Kit (Qiagen). This kit is also based on a bind-wash-elute procedure. First, tissue/cells are lysed with guanidineisothiocyanate and then added to an RNeasy column. This specialized column consists of a RNA adsorbing silicagel membrane. Impurities are washed away and isolated pure total RNA is finally eluted in $30 \mu 1$ of RNase free water. All steps were carried out at room temperature.

\subsection{Preparation of total RNA from rat cortical kidney slices}

Rat cortical kidney slices were removed from RNAlater and disrupted in liquid nitrogen by using mortar and pestle. $20 \mathrm{mg}$ of the disrupted tissue were then transferred to a $1.5 \mathrm{ml}$ tube and lysed by adding $600 \mu 1$ RLT-buffer, supplemented with $6 \mu 1 \beta$-mercaptoethanol. After 
pipetting several times up and down, samples were centrifuged for $3 \mathrm{~min}$ at $13.000 \mathrm{x} \mathrm{g}$. Following procedure was done according to the manufacturer's protocol with the exception of an additional 10 min incubation step subsequent to the addition of $30 \mu \mathrm{l}$ Rase free water to the membrane.

\subsubsection{Sample preparation for microarray analyses}

Gene expression profiling was carried out by using the SurePrint G3 Rat GE 8x60K Kit array (Agilent technologies). Sample preparation was done under the supervision of the Transcriptome Analysis Laboratory members of the University of Göttingen. Quality and quantity of extracted RNA were determined using the Agilent 2100 Bioanalyzer (Agilent Technologies), and NanoDrop® ND-1000 Spectrophotometer (Thermo Scientific), following the manufacturer's standard protocols. Only RNAs with a RNA integrity number (RIN) > 9, at which 10.0 is the maximum, were used for further experiments (figure 2.3).

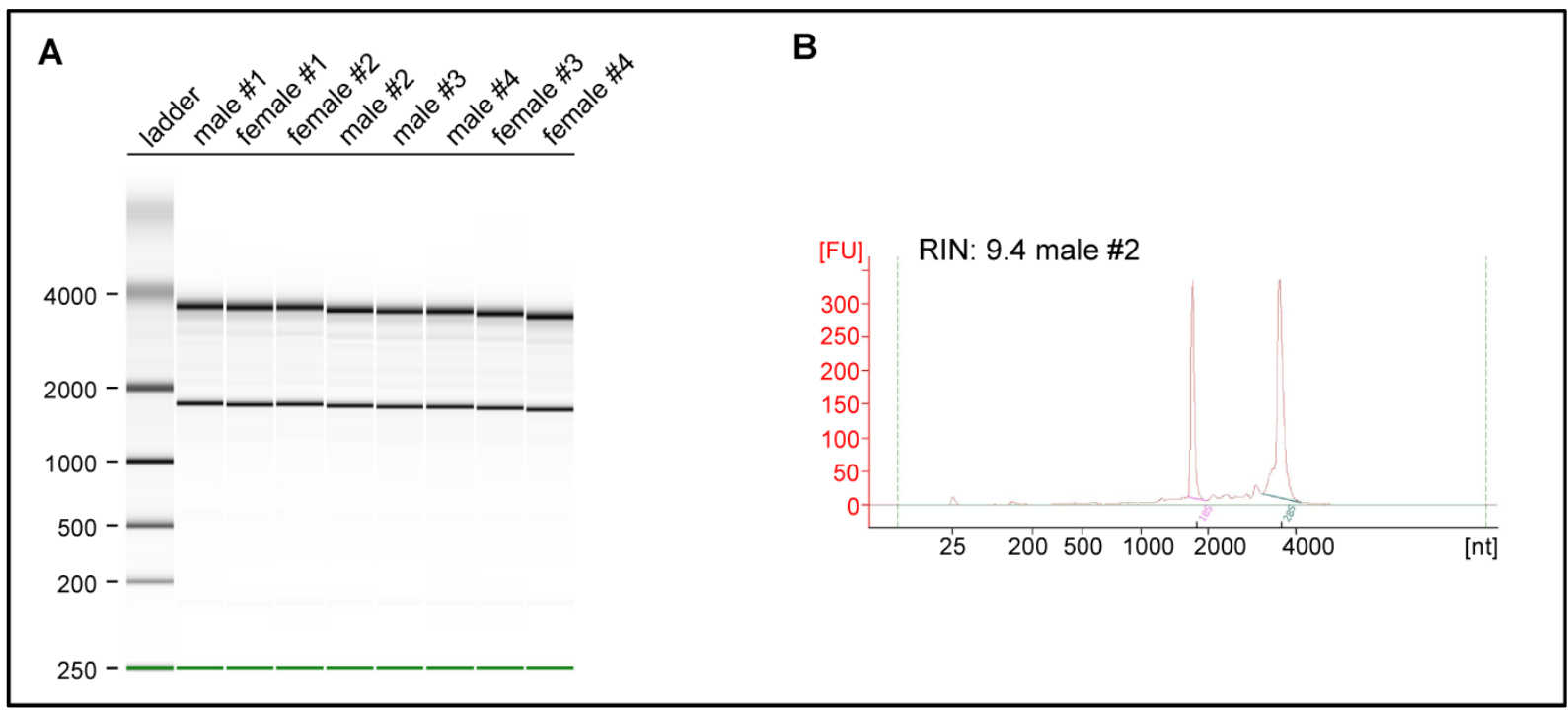

Figure 2.3: Agilent 2100 Bioanalzer: quality and quantity of isolated total RNA.

A: Electrophoresis image shows clear bands of eukaryotic 18S and 28S ribosomal RNA (rRNA) from all isolated total RNAs. B: Electropherogram, quantitative presentation of 18S and 28S rRNA for one representative animal (male \#2). RIN: RNA Integrity Number.

In the following procedure all steps were done according to manufactures recommendations. Briefly, 200 ng of total RNA from each cortical kidney slice was applied as starting material for cDNA preparation. Synthesis of cDNA from samples and controls was done using the Low Input Quick Amp labeling Kit Cy3 One Color for samples, and the One Color RNA spike in Kit for the controls (both kits: Agilent Technologies). The spike in kit contains in vitro 
synthesized polyadenylated transcripts at premixed concentrations, which serve later as controls for the high and low detection limits of the experiment, linear portion of the dynamics range of the microarray, and reproducibility of the microarray. Next, revealed cDNAs were further transcribed into cRNAs, with the incorporation of Cyanine 3-CTP (Cy3). This step and all ongoing were carried out in the dark. Cy3-labeled cRNAs were then purified with the RNeasy® Mini Kit from Qiagen and quantity and efficiency of labeled amplified cRNA were determined using NanoDrop ND-1000 UV-VIS Spectrophotometer. $600 \mathrm{ng}$ of Cy3-labeled cRNA was then cleaved into small fragments and hybridized to the SurePrint G3 Rat GE 8x60K array (Array, Gene Expression Hybridization Kit, and Gene Expression Wash Buffer Kits, all Agilent Technologies). Steps concerning hybridization and ongoing procedure were carried out by a member of the Transcriptome Analysis Laboratory of the University of Göttingen, still in the dark, but additionally in an ozone-free room. Hybridization was performed $17 \mathrm{~h}$ at $10 \mathrm{rpm}$ and $65{ }^{\circ} \mathrm{C} \mathrm{o} / \mathrm{n}$ in a hybridization oven (Agilent Technologies). Following day, several washes steps were carried out before scanning the microarray at a 3 microcon resolution using the Agilent DNA microarray scanner G2505C. Scanned image files were first visually checked for artifacts, followed by analysis.

\subsubsection{Data analysis and adjustments of microarray data}

Data analyses were performed by the Transcriptome Analysis Laboratory (TAL) of the University of Göttingen. In brief, intensity data were extracted using Agilent's Feature (FE) software version 10.7.31, and checked for their quality. Chips which passed the control were further analyzed as described by Opitz et al. (Opitz et al., 2010). The microarray data discussed in this thesis were generated conforming to the Minimum Information About a Microarray Experiment (MIAME) guidelines and were deposited in the Gene Expression Omnibus (GEO) database (accession number: GSE34565).

After TALs first analyses, genes with reliable sex-dependent expressions were filtered due to the following adjustments: (1) exclusion of non significantly ( $p$-value $>0.05$ ) expressed probes between males and females, (2) rejection of probes without Gene ID, (3) retention of genes with a $\log 2$ fold-change $(\mathrm{FC}) \geq 1$ (higher expressed in males) and $\log 2$ fold-change (FC) $\leq-1$ (higher expressed in females), and (4) exclusion of duplicated genes, at which those with the lower $\log 2$ fold-change remained. 
The FDR controls the expected proportion of incorrectly rejected null hypotheses (Benjamini and Hochberg, 1995). In our microarray, equal expression between males and females was the null hypothesis for each gene. This hypothesis was rejected when FDR was $<5 \%$, therefore genes with and FDR > 5\% were not sex-dependently expressed. After these adjustments 335 genes showed a significantly sex-dependent expression between male and female rats. Due to the fact that only genes which are co-expressed with the rat Oat 1 and Oat 3 in the proximal tubules cell were of great interest, all remaining 335 genes were aligned with the "Rat Proximal Tubule Transcriptome Database“. This database was generated by Yu and colleagues and includes the expression profile of freshly isolated rat proximal tubules cells, created by using Rat 230 2.0 Expression Array from Affymetrix (Yu et al., 2009). Volcano plot for sexdependent gene expression was performed by using plot function in "R" (http://cran.rproject.org/).

\subsubsection{Additional methods}

\subsubsection{Determination of protein concentration}

Protein concentrations were determined by the method of Bradford (Bradford, 1976). This method is a colorimetric protein assay based on the characteristics of the dye coomassie brilliant blue. Under acidic conditions, coomassie brilliant blue has the ability to bind proteins, thereby shifting its absorption from $495 \mathrm{~nm}$ (unbound form), to $595 \mathrm{~nm}$ (protein bound form). The increase of absorbance at $595 \mathrm{~nm}$ is proportional to the protein-bound dye and therefore a function of protein concentration. To quantify protein concentration, a convenient standard curve was generated by preparing the following bovine serum albumin (BSA) concentrations in PBS: $50 \mu \mathrm{g} / \mathrm{ml}, 100 \mu \mathrm{g} / \mathrm{ml}, 200 \mu \mathrm{g} / \mathrm{ml}, 300 \mu \mathrm{g} / \mathrm{ml}, 400 \mu \mathrm{g} / \mathrm{ml}$, $500 \mu \mathrm{g} / \mathrm{ml}, 750 \mu \mathrm{g} / \mathrm{ml}$. After this preparation, $200 \mu \mathrm{l}$ Bradford-solution was transferred into each well of a microreader plate, followed by the addition of $20 \mu \mathrm{l}$ of standards, or $20 \mu \mathrm{l}$ of diluted samples respectively. In the next step, samples were mixed by rocking the microreader plate several times and incubated for $15 \mathrm{~min}$ at RT. Absorbance at $595 \mathrm{~nm}$ was measured against the blank PBS. Standard concentrations were measured as duplicates, whereas samples were measured as triplicates. By generating a standard curve of absorbance versus microgram of known protein concentrations, the concentration of unknown samples was 
extrapolated. The average of every sample was calculated and referred as their protein concentration.

\subsubsection{Preparation of RNA from adherent cells}

Cells were grown as monolayers in 24-well plates with a density of $1-2 \times 10^{6}$ cells/well. First step in total RNA preparation was the complete aspiration of cell medium, followed by lyses with $150 \mu$ l RLT-buffer including $1.5 \mu 1 \beta$-mercaptoethanol per well. After the addition of 150 $\mu 170 \%$ ethanol per well, remaining lysates were mixed by pipetting several times up and down, and transferred to an RNeasy spin column. Subsequent procedure was done according to the manufacturer's recommendations.

\subsubsection{Reverse transcription}

Preparation of first strand complementary DNA (cDNA) was done by using the enzyme Superscript ${ }^{\circledR I I}$ reverse transcriptase (Invitrogen ${ }^{\mathrm{TM}}$, life technologies). This enzyme is a RNAdependent DNA polymerase which transcribes single-stranded RNA into single-stranded cDNA. For a standard reverse transcription the enzyme reverse transcriptase, RNA template, oligonucletotide (in this thesis Oligo $\mathrm{dT}_{12} 5^{\prime}$-TTTTTTTTTTTT-3'), and deoxynucleotides (dNTPs) are required. In the first step RNA template, Oligo $\mathrm{dT}_{12}$, and $\mathrm{dNTPs}$ were mixed and heated to destroy the secondary structures of RNA. After this initial denaturation step, first strand buffer and DTT were added, and the reaction was cooled down for Oligo $\mathrm{dT}_{12}$ hybridization. Once the primer has annealed to the RNA, the enzyme reverse transcriptase is added and transcribes the single stranded RNA into cDNA. In a final step, reaction temperature is raised to inactivate the enzyme. Synthesis of cDNA was done according to manufacturer's recommendations with 1-2 $\mu \mathrm{g}$ RNA as starting material.

\subsubsection{Real-time PCR with TaqMan ${ }^{\circledR}$ Gene Expression Assay}

Real-time was performed by using the TaqMan ${ }^{\circledR}$ Gene Expression Assay. TaqMan ${ }^{\circledR}$ probes bind sequence-specific to their homologue cDNA sequence and consist of two particular fluorophores. One fluorophore is the reporter dye 6-FAM ${ }^{\mathrm{TM}}$, which is located at the $5^{\prime}$ - end of probe, and the other one is the quencher dye TAMARA ${ }^{\mathrm{TM}}$, located at $3^{\prime}$ - end of probe. At the 48 
beginning of PCR, specific primer and TaqMan® probe hybridized to their complementary cDNA sequence. In this stage, the 3'-located quencher reduces the fluorescence from 5'-located reporter by using Fluorescence/Förster Resonancy Energie Transfer (FRET). During elongation, AmpliTaq Gold® DNA polymerase adds dNTPs to the newly synthesized strand. At the time when polymerase reaches the bound TaqMan ${ }^{\circledR}$ probe, probe is removed by the $5^{\prime} \rightarrow 3^{\prime}$ exonuclease activity of polymerase, leading to the separation of quencher from reporter. This separation results in the increased fluorescence of the reporter, which therefore is detected by a light cycler. Intensity of reporter fluorescence is proportional to newly amplified DNA. Real-time was performed in a $20 \mu$ l reaction setup with $1 \mu \mathrm{cDNA}$ respectively, and according to manufacturer's recommendation.

The required number of PCR cycles to reach the detection threshold $\left(\mathrm{C}_{t}\right)$ was used to determine the mRNA level of investigated genes. Low expressed genes, showed relatively high numbers of cycles to reach this threshold, whereas highly expressed genes have a relatively low $\mathrm{C}_{\mathrm{t}}$. As endogenous control of mRNA the integrity and quantification, housekeeping genes $\beta$-actin and Hprt1 were examined. The non reactive dye ROX was utilized to correct well-to-well differences such as volume variations or transparency of plastic. Amplification efficiencies of used TaqMan ${ }^{\circledR}$ Gene Expression Assays are 100\% (+/- 10\%) (Application Note: TaqMan ${ }^{\circledR}$ Gene Expression Assays, Applied Biosystems and own experiences of working group) leading to the doubling of specific DNA sequence during each PCR cycle.

Expression levels were calculated by the $2^{-\Delta \Delta \mathrm{Ct}}$ method (Livak and Schmittgen, 2001), representing the fold change of certain protein expression relative to control.

$$
\begin{aligned}
& \Delta \mathrm{C}_{\mathrm{t}}=\mathrm{C}_{\mathrm{t}} \text { gene of interest }-\mathrm{C}_{\mathrm{t}} \text { housekeeping gene } \\
& \Delta \Delta \mathrm{C}_{\mathrm{t}}=\Delta \mathrm{C}_{\mathrm{t}} \text { male }-\Delta \mathrm{C}_{\mathrm{t}} \text { female } \\
& \text { Ratio }=2^{-\Delta \Delta \mathrm{Ct}}
\end{aligned}
$$

\subsubsection{Statistic, non related to microarray}

Statistical analyses were performed using GraphPad Prism 4 version 4.03. Data are presented as mean \pm standard error of the mean (S.E.M.) of three to six different experiments. For comparison of two independent samples, the parametric two-side unpaired $t$-test, whereas for multiple comparisons with one control group the One-way ANOVA with Dunnett's multiple comparison test was used. 
Material and Methods

\subsubsection{Determination of transcription start site}

Transcription start sites of rat Oat 1 and Oat 3 were determined by the alignment of their genomic and mRNA sequences. The first nucleotide of mRNA was determined as the transcription start site indicated as +1 . For comparison of Oat1, the genomic sequence NW_047563.2 and the mRNA sequence NM_017224.2 were compared. In case of Oat3, the genomic sequence NW_047563.2 and the mRNA sequence NM_031332.1 were aligned. The transcription start site for rat Oct2, human OAT1 and OAT3 has been already determined: Oct2 (Asaka et al., 2006), OAT1 (Ogasawara et al., 2007), and OAT3 (Ogasawara et al., 2006). Transcription start site of rat probasin was characterized by Rennie et al. (Rennie et al., 1993).

\subsubsection{In silico analysis}

In silico analyzes of rat and human Oat1/OAT1 and Oat3/OAT3 were done using MatInspector software. Three $\mathrm{kb}$ upstream of the transcription start site, designated as +1 , were investigated. 


\section{Results}

\subsection{Impact of testosterone/androgen receptor complex on the regulation of organic anion transporter expression}

In this study, the molecular mechanisms of sex-dependent expression of the rat renal organic anion transporter 1 (Oat1) and 3 (Oat3) were investigated. The promoter of an adjacent gene is usually assumed to be the regulatory region that initiates and controls the levels of gene expression. Specific DNA sequences within these promoters can interact with transcription factors, leading to an activation or repression of gene transcription. First, the involvement of testosterone/androgen receptor complex in the transcriptional regulation of rat and human Oat1/OAT1 and Oat3/OAT3, via binding to androgen response elements (AREs) located in their promoters, was investigated.

\subsubsection{Localization of predicted androgen response elements (AREs)}

The potential AREs within rat and human Oat1/OAT1 and Oat3/OAT3 promoters were in silico predicted by using the MatInspector software. Approximately three kb upstream of the transcription start site (+1) of Oat1, Oat3, OAT1, and OAT3 were investigated [table 3.1; (Wegner et al., 2012)]. In the promoters of rat and human Oat1/OAT1 and Oat3/OAT3, respectively, two to three potential AREs were postulated. Predicted AREs in the promoter of rat Oat1 were located at -2006 to $-1988 \mathrm{bp}$ and -1655 to $-1637 \mathrm{bp}$, whereas OAT1 contained two predicted AREs at -1601 to -1583 bp and -1261 to -1243 bp (table 3.1). For rat Oat3 promoter, AREs were postulated at -3046 to $-3028 \mathrm{bp},-2863$ to $-2845 \mathrm{bp}$, and -1923 to -1905 $\mathrm{bp}$, whereas predicted AREs in the human OAT3 promoter were located at -1874 to $-1856 \mathrm{bp}$ and -831 to -813 bp (table 3.1 ). 
Results

Table 3.1: In silico promoter analyses of rat and human Oat1/OAT1 and Oat3/OAT3, with respect to androgen response elements (ARE). Date of analyses: November 13, 2012.

\begin{tabular}{llll}
\hline Promoter $(\sim \mathbf{3 ~ k b})$ & Binding & Sequence & Position (bp) \\
\hline \hline Oat1 & ARE & $5^{\prime}$-gcaggactcagtgtttgt-3' & -2006 to -1988 \\
& ARE & $3^{\prime}$-gtagccctggctgtcctgg-5' & -1655 to -1637 \\
OAT1 & ARE & $5^{\prime}$-ctctctctcactgtcctca-3' & -1601 to -1583 \\
& ARE & $5^{\prime}$-tgcacacatgtagtcttag-3' & -1261 to -1243 \\
Oat3 & ARE & $5^{\prime}$-ttctgacatgctgtccact-3' & -3046 to -3028 \\
& ARE & $5^{\prime}$-ggctgcctacctgttctgt-3' & -2863 to -2845 \\
& ARE & $5^{\prime}$-gttgggctctgtgtactct-3' & -1923 to -1905 \\
OAT3 & ARE & $3^{\prime}$-tgagctcccctgttctgg-5' & -1874 to -1856 \\
& ARE & $3^{\prime}$-gagagcctatctgttcttc-5' & -831 to -813 \\
consensus sequence: & ARE & (g/a)g(t/a)acannntgttct & a) \\
\hline
\end{tabular}

Oat/OAT: organic anion transporter; n: any nucleotide, a) Cleutjens et al. 1996, Asaka et al. 2006, Shaffer et al. 2004, and Denayer et al. 2010 [(Wegner et al., 2012), modified]

\subsubsection{Testosterone-dependent promoter activity in opossum kidney (OK) cells}

The effect of testosterone on the transcriptional regulation of Oats/OATs was investigated using luciferase activity measurement. As an often used cell system for Oats/OATs promoter activity studies, epithelial opossum kidney (OK) cells were chosen. These cells did not express endogenous androgen receptor (AR) (data not shown). Therefore, OK cells were transfected with either empty control vector pSG5 (figure 3.1a-c), or with the rat androgen receptor expression vector pSG5-ratAR (figure 3.1d-f). Transfection efficiency and cell localization of transfected androgen receptor were examined by immunofluorescence [figure 3.1; (Wegner et al., 2012)]. OK cells transfected with the empty vector pSG5 were completely negative for $A R$ expression (figure 3.1b and c), whereas AR expression was only detected in pSG5-ratAR transfected OK cells (figure 3.1e and f). Transfection efficiency of pSG5-ratAR was about 39\% and co-localization with DAPI showed that AR was exclusively expressed in the nucleus (figure 3.1f). Moreover, over-expressed AR was homogeneously distributed in the nucleus but excluded from nucleoli (dark areas in the nucleus) (figure 3.1e and f). 


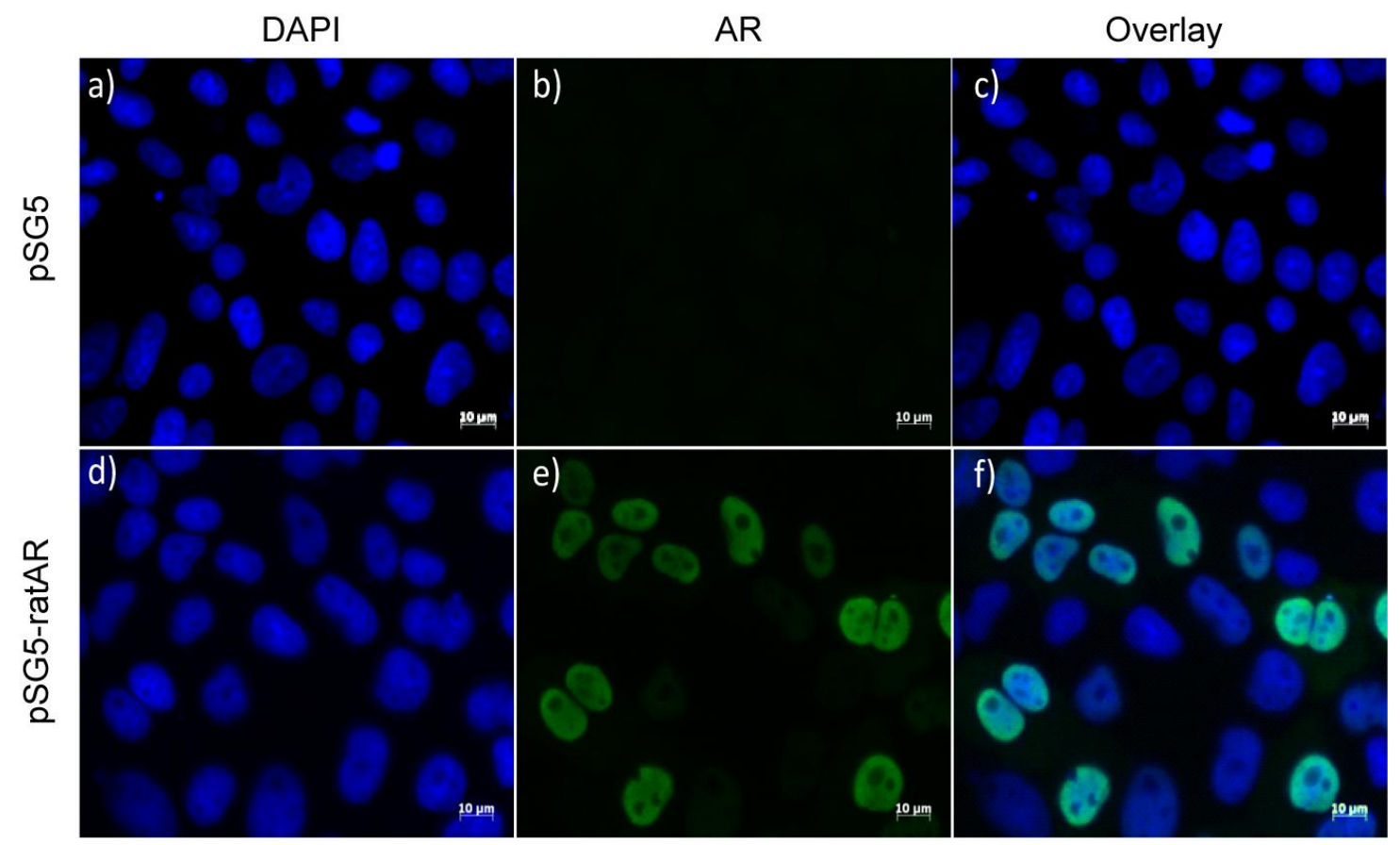

Figure 3.1: Rat AR-expression in OK cells.

OK cells were either transfected with pSG5 (a-c) or pSG5-ratAR (d-f), and AR expression and cellular localization were analyzed using immunofluorescence staining (green color, AR, excitation wavelength $488 \mathrm{~nm}$; blue color, DAPI staining, excitation wavelength $365 \mathrm{~nm}$ ) (Wegner et al., 2012). The figure shows one representative experiment out of three independent replicates.

Before testing the promoter activities in OK cells by luciferase assay, several parameters including the amount of transiently transfected controls, promoter constructs, protein expression vectors, and incubation time, were optimized (data not shown).

In the next step, the involvement of testosterone/androgen receptor complex on sex-dependent regulation of Oat1/OAT1 and Oat3/OAT3 expression was addressed. As a positive control for testosterone/androgen receptor activity, the minimal promoter of rat probasin $(\mathrm{rPb})$ (cloned in pGL3-Basic and named $\mathrm{rPb}-\mathrm{luc}$ ) was used. The promoter of the prostatic protein $\mathrm{rPb}$ is known to be testosterone/androgen receptor-dependently regulated via two functional AREs, located at -236 to $-223 \mathrm{bp}$ and -140 to -117 bp (Rennie et al., 1993).

OK cells were transiently transfected with Oat1, Oat3, OAT1, and OAT3 promoter constructs or positive control $\mathrm{rPb}-\mathrm{Luc}$, and, depending on approach, with rat $\mathrm{AR}$ expression vector pSG5-ratAR, human AR expression vector pSG5-AR or empty control vector pSG5. Additionally all cells were co-transfected with pRL-TK vector, a constitutively expressing Renilla luciferase vector, which served as transfection efficiency control. Transfected cells were incubated with testosterone, followed by quantification of firefly and Renilla luciferase activity. 
Localization of predicted androgen response elements (AREs) in the investigated rat and human promoter constructs are shown in figure 3.2A. The positive control rPb-Luc was highly activated by testosterone in the presence of androgen receptor (figure 3.2B). Without co-transfection of rat $\mathrm{AR}, \mathrm{rPb}-\mathrm{Luc}$ showed no significant activation by testosterone, confirming the absence of endogenous opossum AR. In addition, $\mathrm{rPb}$-Luc was also activated by testosterone in the presence of human androgen receptor (AR) (data not shown).

Under the same condition, the promoter activities of rat Oat1 and Oat3 were not enhanced by testosterone in the presence of rat AR (figure 3.2C). To determine a potential influence of testosterone/androgen receptor on the expression of human OATs, cells were co-transfected with human AR expression vector pSG5-AR. Human OAT1 and OAT3 promoter were also not activated by AR and testosterone (figure 3.2C). In general, the basal promoter activities of rat and human Oat3/OAT3 are stronger than those of Oat1/OAT1 (figure 3.2C).

A

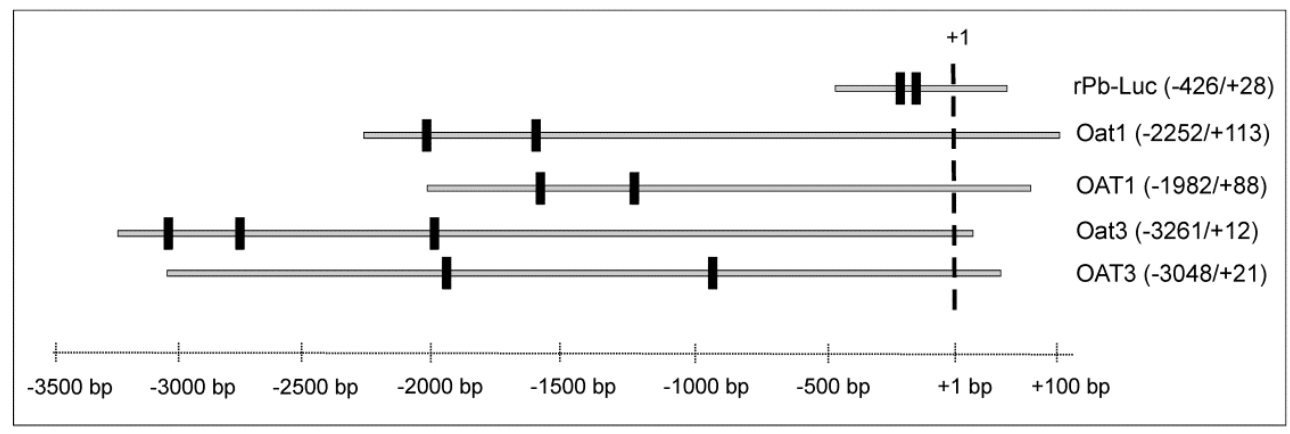

B

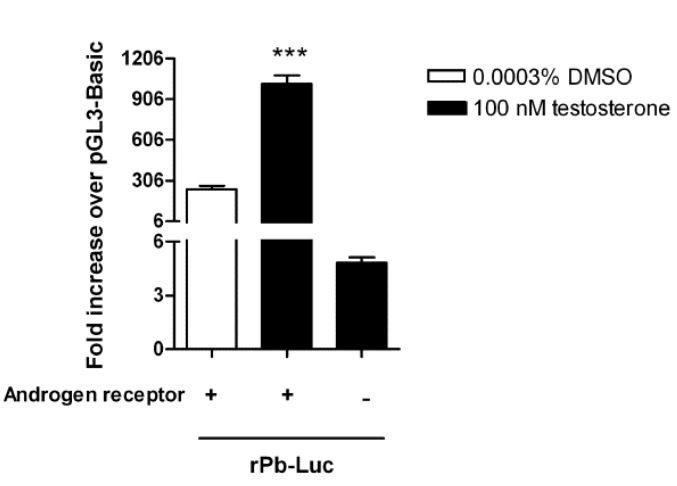

C

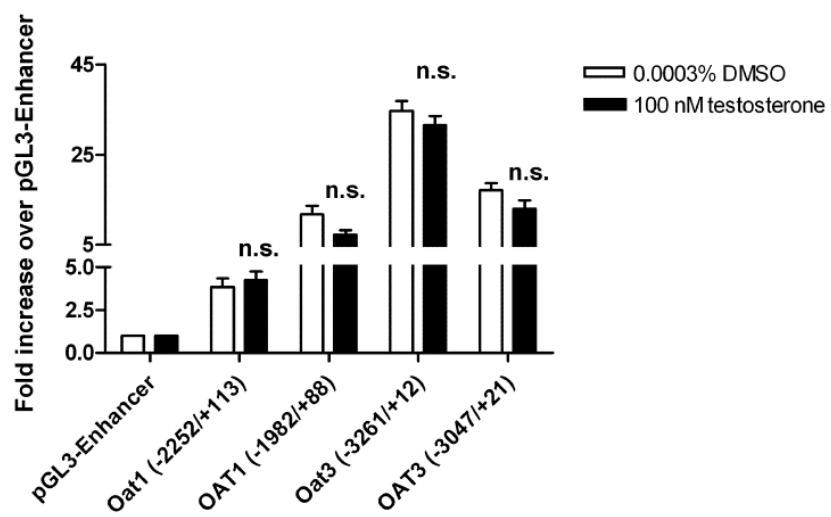

Figure 3.2: Effect of testosterone on probasin, Oat1, Oat3, OAT1, and OAT3 promoter activities in OK cells. A: Localization of predicted androgen response elements (indicated as black bars) in used promoter constructs; +1 : transcriptional start site. B: Response of rat probasin promoter on testosterone. OK cells were transiently transfected with or without expression vector for rat AR and promoter construct of rat probasin $(\mathrm{rPb}-$ Luc). C: Missing response of rat and human Oat1/OAT1 and Oat3/OAT3 promoters on testosterone. OK cells were transfected with the expression vector for rat AR (Oat1, Oat3) or human AR (OAT1, OAT3). Cells were cultured $43 \mathrm{~h}$ with either $100 \mathrm{nM}$ testosterone (black bars) or with $0.0003 \%$ DMSO as control (white bars). Luciferase activity was measured and firefly luciferase was normalized to Renilla luciferase. Data are reported as the fold increase presented as mean \pm S.E.M.; $n=4$; n.s.: not significant; ***: $p<0.001$, significantly different from control (0.0003\% DMSO) using the unpaired two-tailed $t$-test [(Wegner et al., 2012), modified]. 


\subsubsection{Effect of testosterone on promoter activity in the porcine kidney cell line LLC- PK1}

Furthermore, the potential androgen receptor-dependent activation of rat Oat1 and Oat3 was examined in the porcine kidney cell line LLC-PK1. In LLC-PK1 cells, the testosterone/androgen receptor mediated promoter activation of the organic cation transporter 2 (Oct2) has been demonstrated previously (Asaka et al., 2006). The Oct2 promoter construct $(-1958 /+12)$, that contains two known functional AREs, was cloned and used as a second positive control in the following experiments. LLC-PK1 cells did not express endogenous AR (Asaka et al., 2006) and were therefore co-transfected either with empty control vector pSG5 (figure 3.3a-c) or with rat androgen receptor expression vector pSG5-ratAR (figure 3.3d-f). Transfection efficiency and cell localization of androgen receptor were examined by immunofluorescence. The specific antibody staining showed AR expression in pSG5-ratAR transfected cells, with a transfection efficiency of about $26 \%$ (figure $3.3 \mathrm{e}$ and $\mathrm{f}$ ). Co-localization with DAPI confirmed that AR was exclusive expressed in the nucleus of LLC-PK1 cells, but not in the nucleoli (dark areas in the nucleus) (figure 3.f).

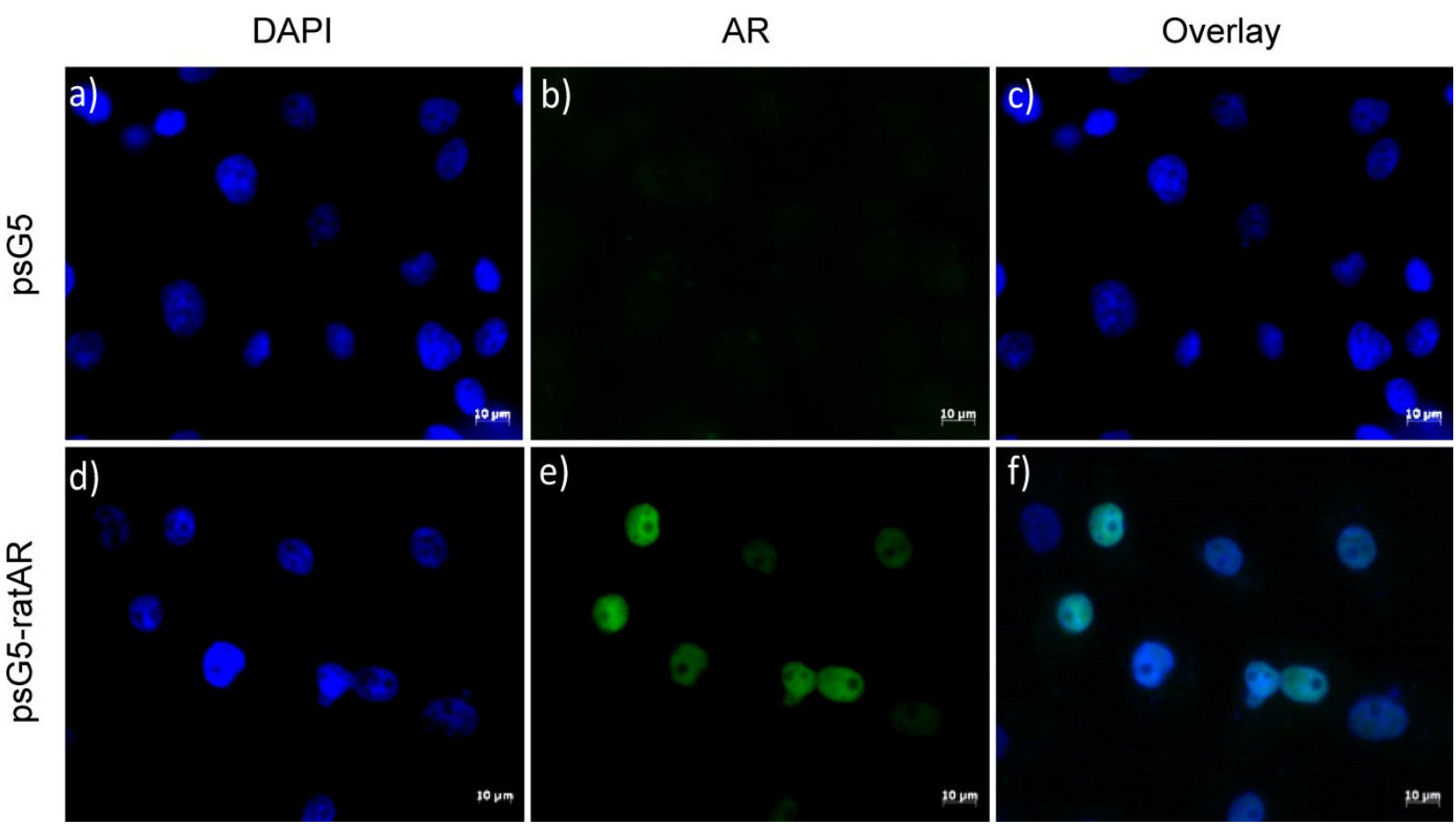

Figure 3.3: Rat AR-expression in LLC-PK1 cells.

LLC-PK1 cells were either transfected with pSG5 (a-c) or pSG5-ratAR (d-f), and AR expression and cellular localization were analyzed using immunofluorescence staining (green color, AR, excitation wavelength $488 \mathrm{~nm}$; blue color, DAPI staining, excitation wavelength $365 \mathrm{~nm}$ ). The figure shows one representative experiment out of three independent replicates. 
In LLC-PK1 cells, the promoters of rat probasin (rPb-Luc), Oct2, Oat1, and Oat3 were investigated with regard to their responsiveness to testosterone/androgen receptor mediated transcriptional activation. Cells were transiently transfected with promoter constructs of Oat1 and Oat3, positive controls rPb-Luc or Oct2 (-1958/+12), rat AR expression vector pSG5ratAR, or empty control vector pSG5. Transfected cells were incubated with testosterone and luciferase activity was measured. Transfection of androgen receptor and incubation with testosterone induced the promoter activation of the positive control $\mathrm{rPb}-\mathrm{Luc}$ (figure 3.4B). The second positive control, the Oct 2 promoter, was also significantly activated under the same conditions as they were used for $\mathrm{rPb}-\mathrm{Luc}$ and Oat1/Oat3 (figure 3.4B and $\mathrm{C}$ ). Focusing on the promoters of rat Oat 1 and Oat 3 , both promoters were not activated by the testosterone/androgen receptor complex in LLC-PK1 cells (figure 3.4C).

A

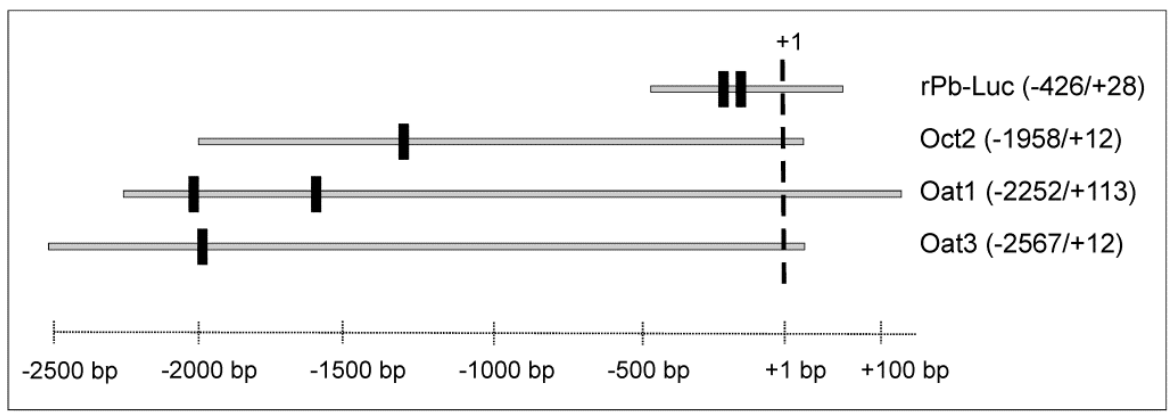

B

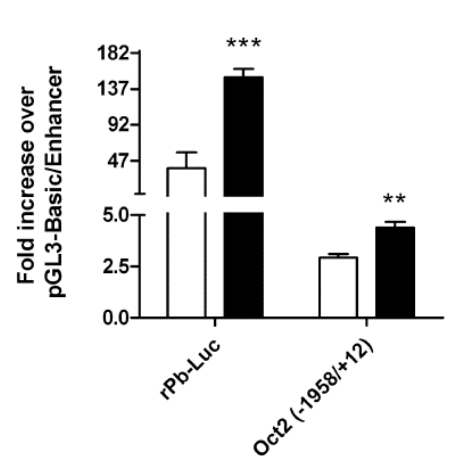

C

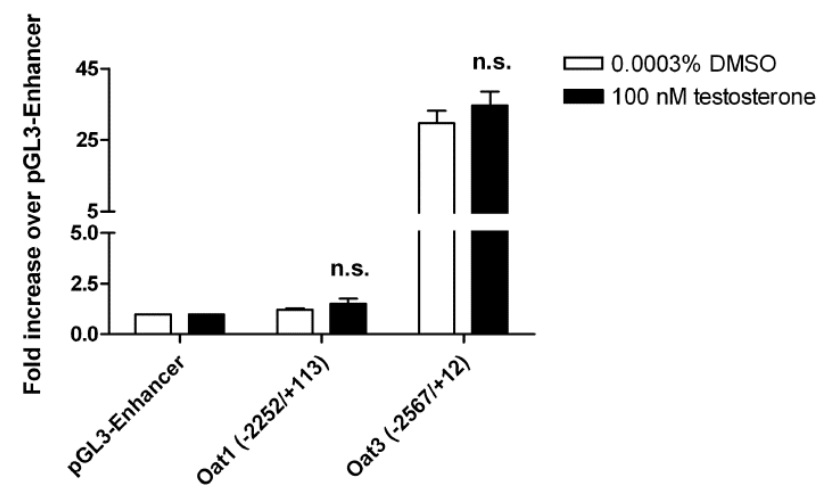

Figure 3.4: Testosterone-dependent promoter activities of probasin, Oat1, Oat3, and Oct 2 in LLC-PK1 cells. A: Localization of androgen response elements (indicated as black bars) in used promoter constructs; +1 : transcriptional start site. B: Response of rat probasin and Oct2 promoter on testosterone. LLC-PK1 cells were transiently transfected with expression vector for rat AR and promoter constructs for rat probasin (rPb-Luc), and Oct2 C: Missing response of rat Oat1 and Oat3 promoters on testosterone. LLC-PK1 cells were transiently transfected with expression vector for rat AR and promoter constructs for rat Oat 1 and Oat3. Cells were cultured $43 \mathrm{~h}$ with either $100 \mathrm{nM}$ testosterone (black bars) or with $0.0003 \%$ DMSO as control (white bars). Luciferase activity was measured and firefly luciferase was normalized to Renilla luciferase. Data are reported as the fold increase over either pGL3-Basic or pGL3-Enhancer and presented as mean \pm S.E.M.; $n=4$; n.s.: not significant; $* *: \mathrm{p}<0.01 ; * * *: \mathrm{p}<0.001$, significantly different from control (0.0003\% DMSO) using the unpaired two-tailed $t$-test. 
In summary, with regard to $\mathrm{OK}$ cells, positive control $\mathrm{rPb}$-Luc was activated by testosterone in an AR-dependent manner, whereas the investigated rat and human Oat1/OAT1 and Oat3/OAT3 promoters were not activated by the testosterone/androgen receptor complex. In LLC-PK1 cells, both positive controls, rPb-Luc and Oct2 (-1958/+12) were activated by the classical androgen receptor mediated transcriptional pathway, but Oat1 and Oat3 promoter constructs were not activated under the same conditions. In conclusion, promoter activities of rat and human Oat1/OAT1 and human Oat3/OAT3 were not regulated by the testosterone/androgen receptor complex, independent of the renal cell system used for testing.

\subsection{Sex-dependent expression of renal proximal tubular genes}

A further purpose of this work was to identify genes in rat proximal tubule cells, which show a sex-dependent expression, and can be therefore involved in the regulation of male-dominant Oat1 and Oat3 expression. Profiling of sex-dependently expressed genes was performed by using a SurePrint G3 Rat GE 8x60K microarray. The mRNA of four male and four female rat cortical kidney slices was investigated.

Prior to microarray analyses, sex-dependency of Oat 1 and Oat3 expression in the renal cortex of all used RCCHan ${ }^{\mathrm{TM}}$ :WIST rats was checked by TaqMan® real-time PCR (Wegner et al., 2012). The mRNA levels of housekeeping genes beta-actin ( $\beta$-actin) and hypoxanthine phosphoribosyltransferase 1 (Hprt1) were not different between males and females, and were therefore used as reference genes (figure 3.5A). Expression levels of Oat1 and Oat3 were determined using $2^{-\Delta \Delta \mathrm{Ct}}$ method. Both transport proteins showed a male-dominant expression with a higher sex-difference in Oat1 compared to Oat3 (figure 3.5B). 
A

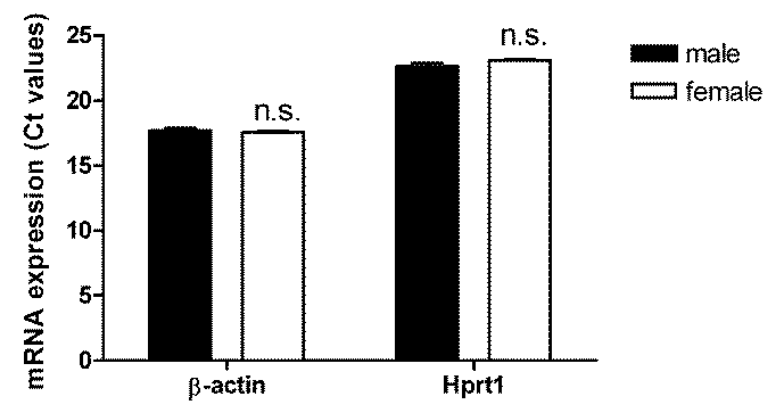

$\mathbf{B}$

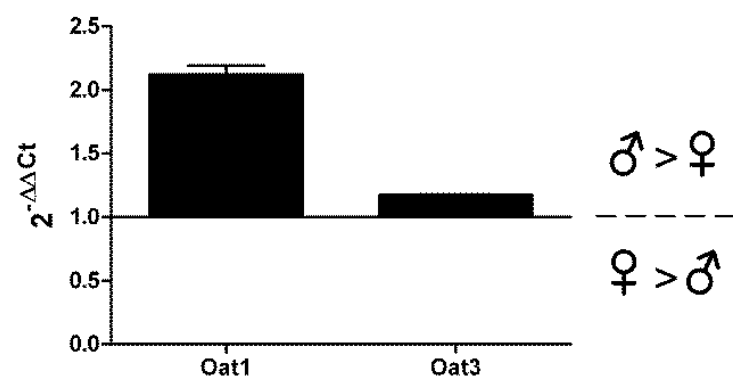

Figure 3.5: Sex-dependent expression of Oat1 and Oat3 in rat cortical kidney slices.

Levels of $\beta$-actin, Hprt1, Oat1 and Oat3 were analyzed by TaqMan® real-time PCR in total RNA from four male and four female rat cortical kidney slices. A: The mRNA expression of reference genes $\beta$-actin and Hprt1 were investigated by comparing their $\mathrm{Ct}$ values between males and females. B: Levels of Oat1 and Oat3 were determined using $2^{-\Delta \Delta \mathrm{Ct}}$ method, at which $\beta$-actin was the reference gene. $\Delta \Delta \mathrm{Ct}$ values were calculated as $\Delta \mathrm{Ct}$ male $-\Delta C t$ female. $\mathrm{n}_{\text {male }}=4 ; \mathrm{n}_{\text {female }}=4$ [(Wegner et al., 2012), modified $]$.

In the subsequent step, microarray analyses of previously used cortical kidney slices from male and female rats were performed. In total, 22,863 probes representing 17,406 different genes were analyzed and the results were published in Gene expression Omnibus (GEO) database under the accession number GSE34565. The Volcano plot gives a first impression of gene expression of males and females, at which each probe is represented as a dot arranged along dimensions of statistical and biological significance [figure 3.6; (Wegner et al., 2012)]. The biological dimension is displayed on the $\mathrm{x}$-axis as the fold-change between the expression of genes from males and females. The fold-change is represented on a log 2 scale, leading to a symmetric expression pattern (higher expressed in males, $\log 2 \geq 1$; or higher expressed in females, $\log 2 \leq-1)$. The statistical dimension is given at the $y$-axis and shows adjusted $p$-values, which are represented at a negative $\log _{10}$ scale, resulting in smaller $p$-values plotted at the top. The red lines denote particular thresholds: the horizontal red line: $p=0.05$, and the vertical red lines: two-fold expression difference between males and females. Probes which are located at the left upper side of the plot are significantly higher expressed in females, whereas probes located at the right upper side of the plot are significantly higher expressed in males (figure 3.6).

After pre-defined adjustments of microarray results (exactly described under Material and Methods), 335 genes showed a sex-dependent expression, 175 being higher expressed in males and 160 higher expressed in females, respectively [table S1 appendix (Wegner et al., 2012)]. 


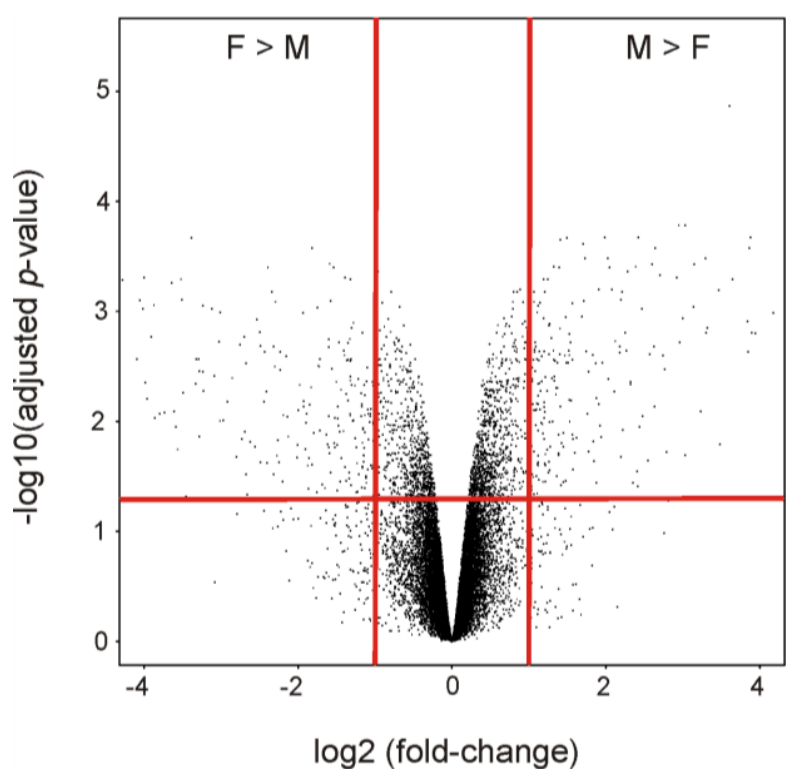

Figure 3.6: Volcano plot of microarray analysis.

In this microarray a total of 22,863 probes were analyzed. On the y-axis the negative $\log 10$ of the adjusted $p$-value and, on the $\mathrm{x}$-axis, the $\log 2$ of the fold-change is plotted. Each probe is represented as a dot. Low $p$-values (highly significant) are localized at the top of the plot. Probes that are expressed higher in females have a negative $\log 2$ fold-change appearing at the left side, and probes that are expressed higher in males have a positive $\log 2$ fold-change appearing at the right side. The horizontal red line denotes the threshold for $p=0.05$. The vertical red lines denote the two-fold thresholds (Wegner et al., 2012).

Because I am interested in genes which are co-expressed with Oat1 and Oat3 in proximal tubule cells, all 335 sex-dependent expressed genes were aligned with the "Rat Proximal Tubule Transcription Database" (http://dir.nhlbi.nih.gov/papers/lkem/pttr/). After this adjustment, 56 genes showed a sex-dependent proximal tubule expression with 13 genes being higher expressed in females, and 43 genes higher expressed in males, respectively [table 3.2 (Wegner et al., 2012)]. In table 3.2, $\log 2$ FC (m-f) represents the fold change (FC) of a particular gene expression between males and females. Here, only genes with a $\log 2$ (> 1 or $<-1)$ are listed, representing genes which have at least a 2-fold expression difference between males and females. The column named "P. Value (m-f)", represents particular $p$-values calculated by the moderate t-statistic and corrected for multiple testing by using BenjaminiHochberg method (Benjamini and Hochberg, 1995). Only genes with a $p$-value $<0.05$ are listed, indicating the statistical evidence, or reliability of the fold-change between males and females. The false discovery rate (FDR) is a measure of false positive genes. Genes with a FDR > 5\% were excluded from our list. All genes were clustered into different groups according to their function (table 3.2). 


\section{Results}

Table 3.2: Sex-dependently expressed genes in rat proximal tubule cells.

\begin{tabular}{|c|c|c|c|c|}
\hline Symbol & Description & $\begin{array}{c}\log 2 \\
\text { FC } \\
(\mathrm{m}-\mathrm{f}) \\
\end{array}$ & $\begin{array}{l}\text { P. Value } \\
(\mathbf{m}-\mathbf{f})\end{array}$ & $\begin{array}{l}\text { FDR } \\
(\mathbf{m}-\mathbf{f})\end{array}$ \\
\hline & ENZYMES & & & \\
\hline Aldh1a1 & aldehyde dehydrogenase 1 family, member A1 & 1.01 & $3.85 \mathrm{E}-06$ & $0.09 \%$ \\
\hline Baat & bile acid Coenzyme A: amino acid $\mathrm{N}$-acyltransferase (glycine $\mathrm{N}$-choloyltransferase) & -1.24 & $1.22 \mathrm{E}-03$ & $2.40 \%$ \\
\hline Cth & cystathionase (cystathionine gamma-lyase) & -1.01 & $1.24 \mathrm{E}-04$ & $0.61 \%$ \\
\hline Cyp2d4v1 & cytochrome P450, family 2 , subfamily d, polypeptide 4 & 1.11 & 4.39E-06 & $0.10 \%$ \\
\hline Сур4а2 & cytochrome P450, family 4 , subfamily a, polypeptide 2 & 3.03 & $9.25 \mathrm{E}-04$ & $2.04 \%$ \\
\hline Ddx19a & DEAD (Asp-Glu-Ala-Asp) box polypeptide 19a & 1.05 & $6.57 \mathrm{E}-05$ & $0.43 \%$ \\
\hline Dnm3 & dynamin 3 & 2.64 & $2.16 \mathrm{E}-07$ & $0.03 \%$ \\
\hline Eepd1 & endonuclease/exonuclease/phosphatase family domain containing 1 & 1.02 & $2.67 \mathrm{E}-04$ & $0.98 \%$ \\
\hline Es22 & esterase 22 & 2.02 & $3.16 \mathrm{E}-07$ & $0.03 \%$ \\
\hline F3 & coagulation factor III (thromboplastin, tissue factor) & 1.10 & $2.80 \mathrm{E}-05$ & $0.27 \%$ \\
\hline Haol & hydroxyacid oxidase (glycolate oxidase) 1 & 1.88 & $1.24 \mathrm{E}-04$ & $0.61 \%$ \\
\hline Hmgcs2 & 3-hydroxy-3-methylglutaryl-Coenzyme A synthase 2 (mitochondrial) & 3.30 & $9.19 \mathrm{E}-06$ & $0.16 \%$ \\
\hline HSD17B1 & hydroxysteroid (17-beta) dehydrogenase 1 & 1.52 & $1.93 \mathrm{E}-05$ & $0.23 \%$ \\
\hline Oat & ornithine aminotransferase (gyrate atrophy) & -1.36 & $3.03 \mathrm{E}-05$ & $0.28 \%$ \\
\hline Pecr & peroxisomal trans-2-enoyl-CoA reductase & 1.15 & $9.75 \mathrm{E}-05$ & $0.53 \%$ \\
\hline Proc & protein $\mathrm{C}$ & 1.01 & $2.22 \mathrm{E}-07$ & $0.03 \%$ \\
\hline Ptgds & prostaglandin D2 synthase (brain) & 2.19 & $2.46 \mathrm{E}-06$ & $0.08 \%$ \\
\hline Rasa2 & RAS p21 protein activator 2 & 1.04 & $5.92 \mathrm{E}-05$ & $0.41 \%$ \\
\hline Rasl12 & RAS-like, family 12 & 2.18 & $2.12 \mathrm{E}-05$ & $0.24 \%$ \\
\hline Rdh2 & retinol dehydrogenase 2 & 1.56 & $4.49 \mathrm{E}-04$ & $1.31 \%$ \\
\hline \multirow[t]{2}{*}{ Usp9x } & ubiquitin specific peptidase $9, \mathrm{X}$-linked & 2.35 & $2.53 \mathrm{E}-03$ & $3.60 \%$ \\
\hline & MEMBRANE PROTEINS/RECEPTORS & & & \\
\hline Asgr1 & asialoglycoprotein receptor 1 & 1.49 & $3.35 \mathrm{E}-05$ & $0.29 \%$ \\
\hline B4galt5 & UDP-Gal:betaGlcNAc beta 1,4-galactosyltransferase, polypeptide 5 & 1.00 & $1.23 \mathrm{E}-05$ & $0.18 \%$ \\
\hline Cd1d1 & CD1d1 molecule & -1.14 & $7.03 \mathrm{E}-04$ & $1.74 \%$ \\
\hline Kifc1 & kinesin family member $\mathrm{C} 1$ & 1.37 & $3.41 \mathrm{E}-05$ & $0.29 \%$ \\
\hline Prlr & prolactin receptor & 1.14 & $1.82 \mathrm{E}-04$ & $0.78 \%$ \\
\hline Sectm1b & secreted and transmembrane 1B & 1.21 & $5.43 \mathrm{E}-05$ & $0.40 \%$ \\
\hline Stra6 & stimulated by retinoic acid gene 6 & -1.16 & $9.07 \mathrm{E}-06$ & $0.16 \%$ \\
\hline Tmem144 & transmembrane protein 144 & 1.02 & $3.89 \mathrm{E}-05$ & $0.32 \%$ \\
\hline \multirow[t]{2}{*}{ Trim59 } & tripartite motif-containing 59 & 1.02 & $5.78 \mathrm{E}-06$ & $0.12 \%$ \\
\hline & TRANSCRIPTION FACTORS & & & \\
\hline Arid3b & AT rich interactive domain 3B (Bright like) & -1.48 & $1.65 \mathrm{E}-04$ & $0.73 \%$ \\
\hline \multirow[t]{2}{*}{ BCL6 } & B-cell CLL/lymphoma 6 & 2.18 & $1.61 \mathrm{E}-05$ & $0.21 \%$ \\
\hline & TRANSPORT PROTEINS & & & \\
\hline Abca7 & ATP-binding cassette, sub-family A (ABC1), member 7 & -1.35 & $1.40 \mathrm{E}-05$ & $0.19 \%$ \\
\hline Abcb1b & ATP-binding cassette, sub-family B (MDR/TAP), member 1B & -2.66 & $3.96 \mathrm{E}-03$ & $4.65 \%$ \\
\hline Ostalpha & organic solute transporter alpha & 1.13 & $3.06 \mathrm{E}-05$ & $0.28 \%$ \\
\hline Slc10a1 & solute carrier family 10 (sodium/bile acid cotransporter family), member 1 & 1.12 & $3.98 \mathrm{E}-04$ & $1.21 \%$ \\
\hline Slc30a2 & solute carrier family 30 (zinc transporter), member 2 & 1.26 & $7.12 \mathrm{E}-06$ & $0.13 \%$ \\
\hline \multirow[t]{2}{*}{ Ust5r } & integral membrane transport protein UST5r & 1.07 & $1.85 \mathrm{E}-04$ & $0.79 \%$ \\
\hline & SIGNAL TRANSDUCTION & & & \\
\hline Cklf & chemokine-like factor & -1.03 & $6.79 \mathrm{E}-05$ & $0.44 \%$ \\
\hline Cks2 & CDC28 protein kinase regulatory subunit 2 & 1.06 & $3.81 \mathrm{E}-03$ & $4.55 \%$ \\
\hline Dock5 & dedicator of cytokinesis 5 & -1.58 & $1.75 \mathrm{E}-03$ & $2.93 \%$ \\
\hline Fgf13 & fibroblast growth factor 13 & 1.12 & $3.32 \mathrm{E}-06$ & $0.09 \%$ \\
\hline Gas2 & growth arrest-specific 2 & 1.40 & $5.73 \mathrm{E}-07$ & $0.04 \%$ \\
\hline \multirow[t]{2}{*}{ Nrep } & neuronal regeneration related protein & 1.16 & $2.97 \mathrm{E}-04$ & $1.02 \%$ \\
\hline & OTHERS & & & \\
\hline Cldn1 & claudin 1 & -1.54 & $5.66 \mathrm{E}-07$ & $0.04 \%$ \\
\hline Ddit4l & DNA-damage-inducible transcript 4-like & -1.76 & $3.62 \mathrm{E}-03$ & $4.40 \%$ \\
\hline Espn & Espin & 1.21 & $1.31 \mathrm{E}-03$ & $2.51 \%$ \\
\hline Klhl14 & kelch-like 14 (Drosophila) & -1.31 & $2.68 \mathrm{E}-05$ & $0.27 \%$ \\
\hline Mlph & Melanophilin & 1.91 & $1.53 \mathrm{E}-06$ & $0.06 \%$ \\
\hline Obfc2a & oligonucleotide/oligosaccharide-binding fold containing $2 \mathrm{~A}$ & 1.17 & $2.45 \mathrm{E}-05$ & $0.26 \%$ \\
\hline Picalm & phosphatidylinositol binding clathrin assembly protein & 1.14 & $2.96 \mathrm{E}-06$ & $0.08 \%$ \\
\hline POLR3G & polymerase (RNA) III (DNA directed) polypeptide G (32kD) & 1.34 & $3.14 \mathrm{E}-05$ & $0.28 \%$ \\
\hline Rpp25 & ribonuclease P 25 subunit (human) & 1.77 & $4.64 \mathrm{E}-05$ & $0.35 \%$ \\
\hline Rufy3 & RUN and FYVE domain containing 3 & 1.06 & $2.06 \mathrm{E}-03$ & $3.20 \%$ \\
\hline Spc25 & SPC25, NDC80 kinetochore complex component, homolog (S. cerevisiae) & 1.02 & $1.73 \mathrm{E}-03$ & $2.92 \%$ \\
\hline Tox & thymocyte selection-associated high mobility group box & 1.07 & $1.81 \mathrm{E}-05$ & $0.22 \%$ \\
\hline
\end{tabular}

FC: $\log 2$ fold-change $(F C) \leq-1$ or $\geq 1$; FDR: false discovery rate $<5 \%$; P. value: $p<0.05 ;(m-f)$ : male-female. Genes shown with a negative $\log 2$ FC are higher expressed in females while genes with a positive $\log 2$ FC are higher expressed in males. Red marked genes were selected for verification by TaqMan® real-time PCR (Wegner et al., 2012). 
The genes polymerase (RNA) III (DNA directed) polypeptide G (POLRG3), hydroxysteroid (17-beta) dehydrogenase 1 (HSD17B1) and B-cell CLL/ lymphoma 6 (BCL6) (highlighted in red) showed a FDR $<5 \%$ and were significantly male-dominantly expressed. Moreover, due to their function, all three genes might be involved in the sex-dependent expression of rat Oat1 and Oat3, and were therefore selected for verification by real-time PCR. In addition, four further, genes androgen receptor (AR), hepatocyte nuclear factor $1 \alpha(\mathrm{HNF} 1 \alpha)$, hepatocyte nuclear factor $1 \beta(\mathrm{HNF} 1 \beta)$, and hepatocyte nuclear factor $4 \alpha(\mathrm{HNF} 4 \alpha)$, whose role in sex-dependent regulation of Oat 1 and Oat3 promoters was hypothesized, were also determined by real-time PCR. Androgen receptor and investigated hepatocyte nuclear factors showed no remarkable sex-dependent expression, whereas POLR3G, HSD17B1 and BCL6 were highly male-dominantly expressed in the rats (figure 3.7). All verified genes confirmed the obtained microarray data (figure 3.7 and GSE34565).

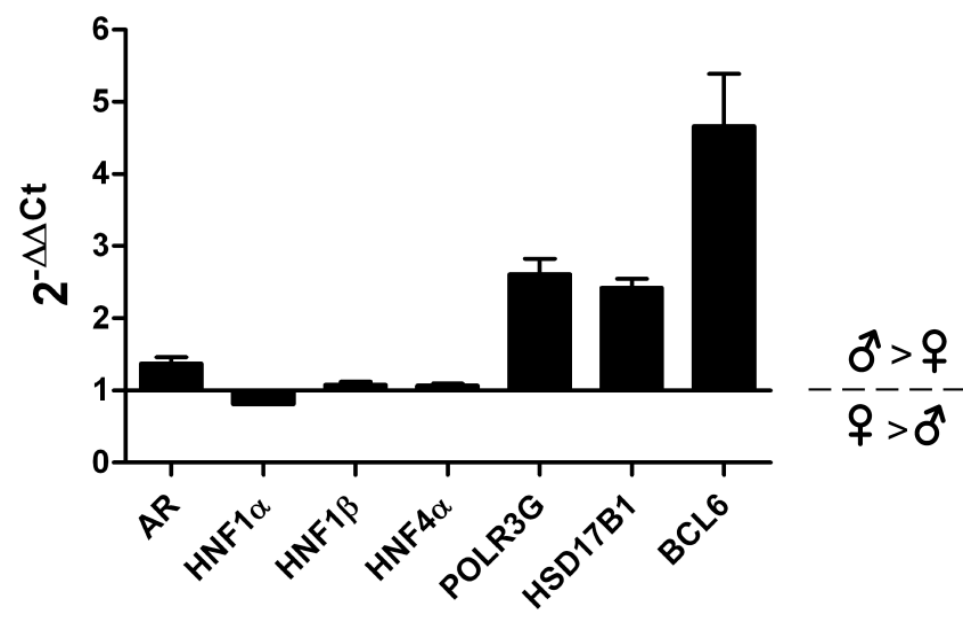

Figure 3.7: Verification of microarray results using TaqMan® real-time PCR.

Gene expression were verified by TaqMan ${ }^{\circledR}$ real-time PCR in total RNA isolated from four male and four female rat cortical kidney slices. Levels of all genes were determined using $2^{-\Delta \Delta C t}$ method, at which $\beta$-actin was the reference gene. $\Delta \Delta \mathrm{Ct}$ values were calculated as $\Delta \mathrm{Ct}$ male $-\Delta \mathrm{Ct}$ female. $\mathrm{n}_{\text {male }}=4 ; \mathrm{n}_{\text {female }}=4$ [(Wegner et al., 2012), modified].

In summary, expression profiling of four male and female rats revealed 13 genes that were higher expressed in females and 43 genes were higher expressed in male renal proximal tubules cells. The known transcriptional regulators for Oat1 and Oat3 expression HNF1 $\alpha$, HNF1 $\beta$, and HNF4 $\alpha$ were not sex-dependently expressed. Furthermore, in microarray analysis identified candidate genes, POLR3G, HSD17B1, and BCL6 were confirmed by real time-PCR to be male-dominantly expressed. 
Results

\subsection{Involvement of transcription factor B-cell CLL/lymphoma 6 (BCL6) in the activation of Oat/OAT promoters}

\subsubsection{Optimization of expression cell system}

The BCL6 protein is highly conserved between man and rodents. Protein alignment of mouse (m), rat (r), and human (h) BCL6 showed a very high protein homology, with alignment scores of $\sim 98 \%$ between rat and mouse, $\sim 95 \%$ between mouse and human, and also $\sim 95 \%$ between human and rat (figure 3.8). Amino acids which are highlighted in grey differ between mouse, rat, and human. N-terminal located Poxviruses Zinc-finger (POZ), or Broad complex, Tramtrack, and Bric à brac (BTB) domain, which is highlighted as blue amino acids, is essential for protein-protein interaction of BCL6 with other proteins and revealed a homology of $\sim 98 \%$ between different species. C-terminal blue marked amino acids belong to the zinc finger domain of BCL6, which showed a 100\% homology between mouse, rat and human. Red and underlined cysteines are involved in the formation of the six zinc fingers. The zinc finger domain is responsible for sequence-specific DNA binding of BCL6 to regulatory regions in target genes, and also for protein-protein interaction. The high protein homology of BCL6, and especially the $100 \%$ zinc finger domain homology between human and rat, permitted us to use the human BCL6 expression vector pcDNA3-BCL6 for both rat and human promoter constructs. 
$\mathrm{MBCL} 6$

rBCL 6

hBCL 6

MBCL 6

rBCL 6

hBCL 6

mBCL 6

rBCL 6

hBCL 6

mBCL 6

rBCL 6

hBCL 6

mBCL 6

rBCL 6

hBCL 6

MBCL 6

rBCL 6

hBCL 6

mBCL 6

rBCL 6

hBCL 6

mBCL 6

rBCL 6

hBCL 6

mBCL 6

rBCL 6

hBCL 6

mBCL 6

rBCL 6

hBCL 6

mBCL 6

rBCL 6

hBCL 6

mBCL 6

rBCL 6

hBCL 6
MASPADSCIOFTRHASDVLLNLNRLRSRDILTDVVIVVSREQ FRAHKTVLMACS GLFYSI MAS PADSCIQFTRHASDVLLNLNRLRSRDILTDVVIVVSREQFRAHKTVLMACS GLFY SI MAS PADSCIQFTRHASDVLLNLNRLRSRD ILTDVVIVVSREQFRAHKTVLMACS GLFY SI

FTDQLKCNLSVINLD PEISPEGFCI LLDFMYT SRLNLREGNIMAVMTTAMYLOMEHVVDT FTDQLKCNLSVINLD PE IS PE GFCI LLDFMYT SRLNLREGNIMAVMATAMYLQMEHVVDT FTDQLKCNLSVINLD PE INPE GFCI LLDFMYT SRLNLREGNIMAVMATAMYLQMEHVVDT

CRKFI KASEAEMAPALKPPREEFLNSRMLMPHDIMAYRGREVVENNMPLRNT PGCE SRAF CRKFIKASEAEMAPALKPPREEFLNSRMLMPHDVMA YRGREVVENNMPLRNT PGCE SRAF CRKFIKASEAEMVSA IKPPREEF LNSRMLMPQDIMA YRGREVVENNLPLRSAPGCE SRAF

APPLYSGLS TP PASY PMYS HL PL ST FL FSDEELRDAPRMPVANP FPKERALPCD SARQVP APPLY SGLS TP PASY PMYS HL PL SS FL FSDEELRDAPRMPVANP FPKERALPCD SARPVP APSLY SGLS TP PASY SMYSHL PVSS LLFSDEE FRDVR-MPVANP FPKERALPCD SARPVP

NEYSRPAMEVS PSLCHSNI YS PKEAVPEEARSDIHY SVPE GPKPAVPSARNA PY FPCDKA NEY SRPTMEVS PS LCHSNI YS PKEAVPEEARSDIHY SVTE GPKPAAPSARHA SY FPCDKA GEY SRPTLEVS PNVCHSNI YS PKET IPEEARSDMHY SVAE GLKPAAPSARNAPY FPCDKA

SKEEERP SSEDEI ALHFEP PNAPLNRKGLVSPQS PQKSDCQPNS PTESCS SKNACILQAS SKEEERP SSEDEI AL HFEP PNAPLNRKGLVSPQS PQKSDCQPNS PTES SS SKNACILQAS SKEEERP SSEDEIALHFEP PNAPLNRKGLVSPQS PQKSDCQPNS PTESCS SKNACILQAS

GSPPAKS PTDPKACNWKKYKF IVLNSLNQNAKPEGSEQAELGRLSPRAYPAPPACQPPME GSPPAKS PTDPKACNWKKYKF IVLNSLNQNAKPE GSEQAE LGRLSPRA YPAPPACQPPME GSPPAKS PTDPKACNWKKYKF IVLNSLNQNAKPEGPEQAELGRL SPRAYTAP PACQPPME

PANLDLQSPTKLSASGEDSTI PQASRLNNLVNRSLAGS PRSS SE SH SPLYMHPPKCTSCG PANLDLQSPTKLSAS GEDS TI PQASRLNNIVNRSLA GS PRSS SE SH SPLYMH PPKCTSCG PENLDLQSPTKLSAS GEDS TI PQASRLNNIVNRSMT GS PRSS SE SH SPLYMH PPKCTSCG

SQSPQHTEMCLHTAGPTFPEEMGETQSEY SDS SCENGTFFCNECDCRF SEEASLKRHTLQ SQSPQHTEMCLHTAGPTFPEEMGETQSEY SDS SCENGAFF CNECCDCRF SEEASLKRHTLQ SQS PQHAEMCL HTAGPT FPEEMGETQSEY SDS SCENGA FF

THSDKPYKCDRCQAS FRYKGNLASHKTVHTGEKPYRCN ICGAQFNRPANLKTHTRI HS GE

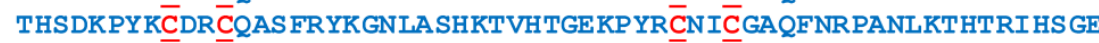

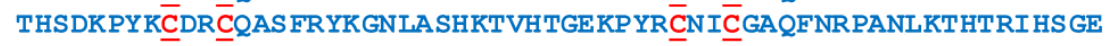

KPYKCETCGARFVQVAHLRAHVL IHTGEKPYPCE ICGTRFRHLQTLKSHLRI HT GEKPYH

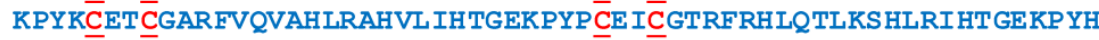

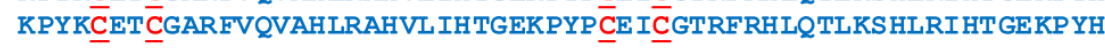

CEKCNLH FRHKSQLRLHLRQKHGAI TNTKVQYRVSAADLP PELPKAC CEKKCNLHFRHKSQLRLHLRQKHGAI TNTKVQYRVSAADLP PELPKAC CEKKCNLH FRHKSOLRLHLROKHGAITNTKVOYRVSATDLP PELPKAC

Figure 3.8: Alignment of mouse, rat, and human BCL6 protein sequences.

Amino acid sequence of mouse (m), rat (r), and human (h) BCL6 were aligned using CLUSTALW software. Grey highlighted amino acids are different between indicated species. N-terminal POZ/BTB and C-terminal zinc finger domain of BCL6 are shown as blue amino acids. Red and underlined cysteines are involved in the formation of six zinc fingers. BCL6 protein homology between mouse and rat is $98.3 \%$, between mouse and human $94.8 \%$, and between rat and human $95.2 \%$, respectively.

Focusing on the potential involvement of BCL6 in the activation of Oat/OAT promoter constructs, nine epithelial cell lines (OK cells, LLC-PK1 cells, rat kidney cell line NRK-52E, human embryonic kidney cell line HEK-293, human kidney cell lines HK-2 and TK-173, human colon carcinoma cell lines Caco-2 and HT-29, and the human hepatocellular carcinoma cell line Hep-G2) were tested. Endogenous BCL6 expression in the six human cell 
lines was investigated by immunofluorescence. Specific antibody staining revealed that all tested cells did not express endogenous BCL6 (data not shown). Therefore, cells were transiently transfected with an expression vector for human BCL6 pcDNA3-BCL6 or empty control vector pcDNA3 and transfection efficiency was determined by immunofluorescence. DAPI stained cells were counted and set to 100\%. BCL6-positive cells were also counted and their ratio to DAPI stained cells was determined and denoted as transfection efficiency in percent (figure 3.9). HEK-293 cells showed the highest transfection efficiency ( 44\%) followed by OK cells ( 23\%), TK-173 ( 23\%), and LLC-PK1 cells $(\sim 16 \%)$.

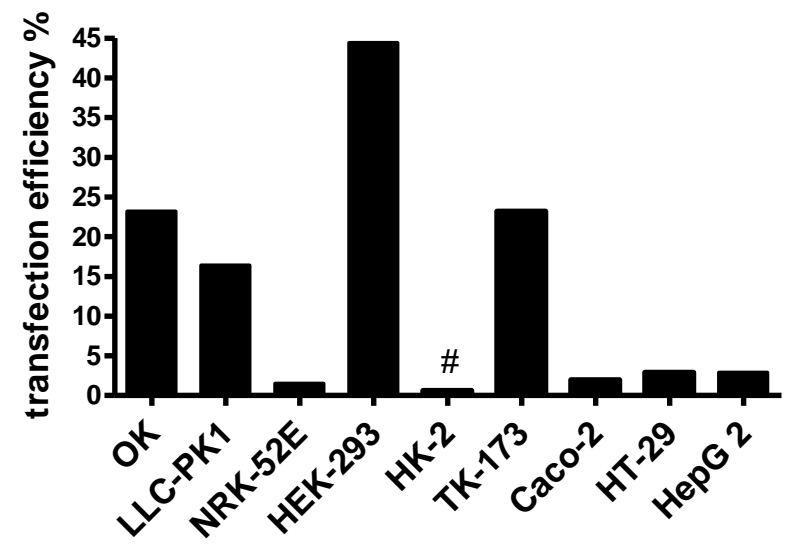

Figure 3.9: Transfection efficiency of BCL6 in different epithelial cell lines.

Indicated cells were transfected with either pcDNA3-BCL6 or pcDNA3 and their transfection efficiency was determined by immunofluorescence staining. Data are represented as the ratio of DAPI stained cells, which were set to $100 \%$, to BCL6 stained cells. \#: transfection efficiency was determined by Aline Noel Millé, PhD student.

For evaluation of the best suitable expression system, Oat1/OAT1 and Oat3/OAT3 promoter constructs were transfected into different cell lines, and their activities were estimated. All four investigated promoters Oat1, Oat3, OAT1, and OAT3 showed high basal promoter activities in OK cells (table 3.3 highlighted in grey). LLC-PK1 cells were characterized by a low basal activity for Oat1 and high basal promoter activities of Oat3, OAT1, and OAT3. HEK-293 and TK-173 cells had only low or no basal promoter activity of OAT1 and high basal promoter activity of OAT3 (table 3.3). 
Table 3.3: Promoter activity of rat and human Oat1/OAT1 and Oat3/OAT3 in different cell lines

\begin{tabular}{c|c|c|c|c}
\hline & OK & LLC-PK1 & HEK-293 & TK-173 \\
\hline Oat1 & +++ & + & n.i. & n.i. \\
\hline OAT1 & +++ & +++ & + & - \\
\hline Oat3 & +++ & +++ & n.i. & n.i. \\
\hline OAT3 & +++ & +++ & $+++{ }^{*}$ & +++ \\
\hline
\end{tabular}

Oat/OAT: organic anion transporter; n.i.: not investigated; -: no basal promoter activity; +: low basal promoter activity; +++: high basal promoter activity. * determined in Kikuchi et al., 2006.

In summary, OK cells are the best suitable expression system to study the effect of BCL6 on Oats/OATs expression by using luciferase assays, due to their sufficient transfection efficiency of about 23\%, and their constant high basal activity of Oat1/OAT1 and Oat3/OAT3.

\subsubsection{Impact of BCL6 on promoter activity}

The involvement of BCL6 in the regulation of rat Oat1 and Oat 3 was investigated. Moreover, the promoters of human OAT1 and OAT3 were examined due to their potentially comparable transcriptional regulation.

Three kb of Oat1, Oat3, OAT1, and OAT3 promoters were analyzed by using the MatInspector software. Localizations of predicted BCL6 binding sites are listed in table 3.4 (Wegner et al., 2012). The rat Oat1 promoter included five postulated BCL6 binding sites, whereas human OAT1 promoter contained six predicted BCL6 binding sites. Regarding Oat3/OAT3, rat Oat3 promoter revealed six and human OAT3 two postulated BCL6 binding sites. Moreover, Oat1 (-1143 to $-1127 \mathrm{bp}$ ) and OAT3 (-1065 to $-1049 \mathrm{bp}$ ) showed a nearly perfectly conserved binding site (table 3.4). 
Results

Table 3.4: In silico analyses of rat and human Oat1/OAT1 and Oat3/OAT3 promoters due to BCL6 binding sites. Date of analyses: November 13, 2012.

\begin{tabular}{|c|c|c|}
\hline Promoter (3 kb) & Sequence & Position (bp) \\
\hline \multirow[t]{5}{*}{ Oat1 } & 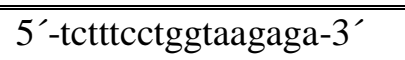 & -2352 to -2336 \\
\hline & $5^{\prime}$-gagttccaggacagcca-3' & -1660 to -1644 \\
\hline & $5^{\prime}$-taatttttagaaataaa-3' & -1295 to -1279 \\
\hline & $5^{\prime}$-ctgttcctacaagttat-3' & -1143 to -1127 \\
\hline & $5^{\prime}$-tatttcccagagcccag-3' & -492 to -476 \\
\hline \multirow[t]{6}{*}{ OAT1 } & $3^{\prime}$-tatttccacgaaccecc-5 & -2577 to -2561 \\
\hline & $5^{\prime}$-gggttcgtggaaatatt-3' & -2575 to -2559 \\
\hline & $3^{\prime}$-gaattgcttgaacctgg- $5^{\prime}$ & -2395 to -2379 \\
\hline & $3^{\prime}$-gaattcctccaacagag- $-5^{\prime}$ & -1494 to -1478 \\
\hline & $5^{\prime}$-cacttcccagagcccag- $3^{\prime}$ & -241 to -225 \\
\hline & $5^{\prime}$-tccttcctaaaaggaag-3' & -222 to -206 \\
\hline \multirow[t]{6}{*}{ Oat3 } & $3^{\prime}$-accttccgtgaaaaaca- $5^{\prime}$ & -2055 to -2039 \\
\hline & $5^{\prime}$-gggtccctggaaatagt- $3^{\prime}$ & -1366 to -1350 \\
\hline & $5^{\prime}$-gacttcatagaaaactc-3' & -1174 to -1158 \\
\hline & $5^{\prime}$-atactcatagaaataaa-3' & -614 to -598 \\
\hline & $3^{\prime}$-aggttcgtggagaatgt-5' & -439 to -423 \\
\hline & $5^{\prime}$-cccttcccagattctct- $3^{\prime}$ & -279 to -263 \\
\hline \multirow[t]{2}{*}{ OAT3 } & $5^{\prime}$-tccttcccagaatctcc- $3^{\prime}$ & -1065 to -1049 \\
\hline & $5^{\prime}$-ggcttcgtagagaatgt- $3^{\prime}$ & -305 to -289 \\
\hline consensus sequence: & $\operatorname{ttcct}(\mathrm{a} / \mathrm{c}) \mathrm{gaa}$ & a) \\
\hline
\end{tabular}

Oat/OAT: organic anion transporter, a) Dent et al. 2002 (Wegner et al., 2012, modified).

The impact of BCL6 on different promoter constructs was determined in OK cells. First, the cellular localization of transfected BCL6 was investigated. OK cells were transiently transfected with either empty vector pcDNA3, or with BCL6 expression vector pcDNABCL6. BCL6 expression was not detected in pcDNA3 transfected OK cells (figure 3.10b and c). Co-staining with DAPI showed that BCL6 was exclusively expressed in the nucleus (figure 3.10f) with additional immunostaining in typical BCL6 punctuated nuclear bodies (figure $3.10 \mathrm{e}$ and $\mathrm{f}$ ). 


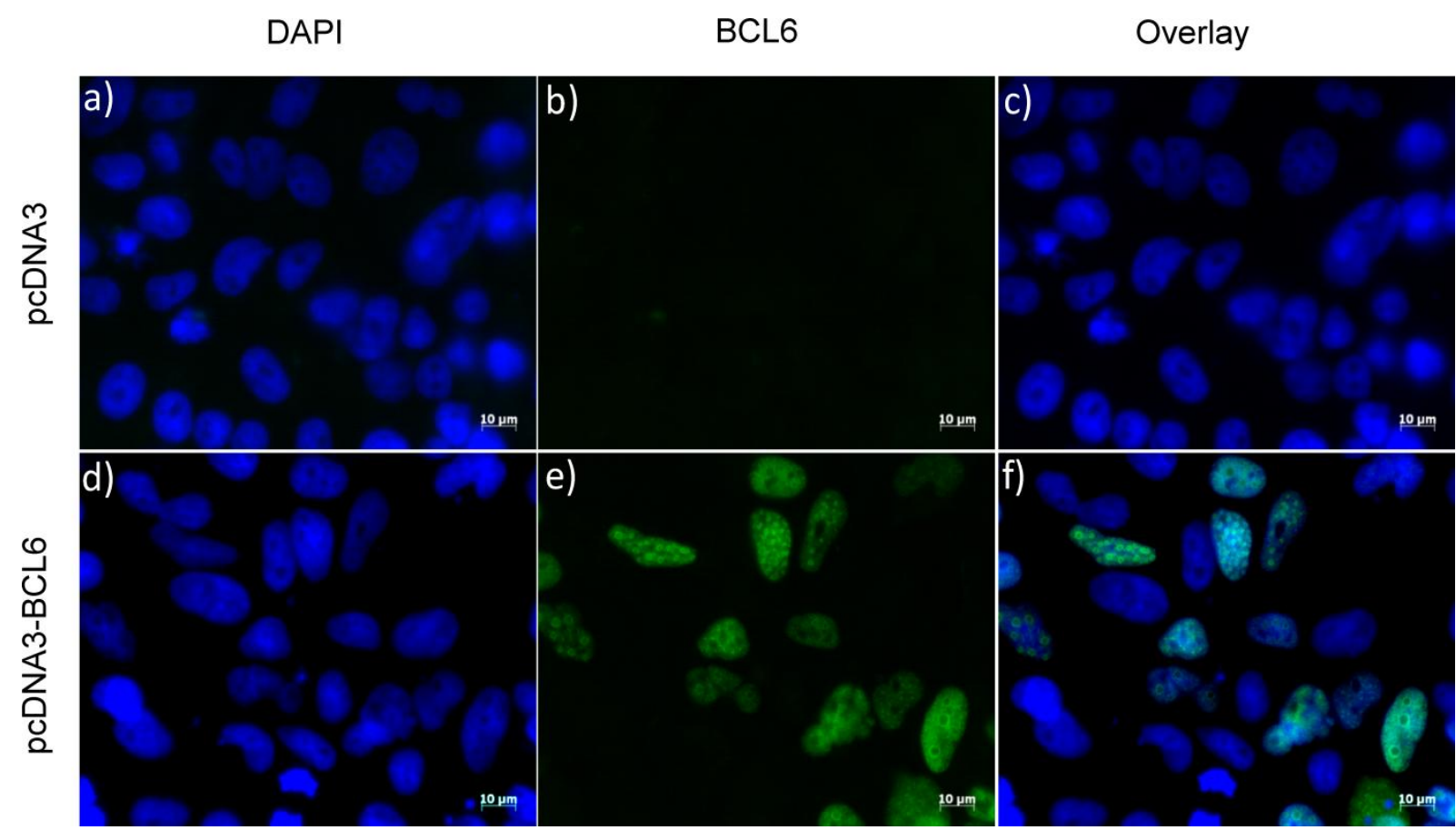

Figure 3.10: BCL6 expression in OK cells.

OK cells were either transfected with pcDNA3 (a-c) or pcDNA3-BCL6 (d-f), and BCL6 expression and cellular localization were analyzed using immunofluorescence staining (green color, BCL6, excitation wavelength 488 $\mathrm{nm}$; blue color, DAPI staining, excitation wavelength $365 \mathrm{~nm}$ ). The figure shows one representative experiment out of three independent replicates.

Because of controversial literature concerning the impact of BCL6 on apoptosis, activity of caspase-3 in pcDNA3-BCL6 and pcDNA3 transfected cells was measured, and is represented as relative fluorescence units per mg protein (figure 3.11). Within these studies, no correlation between BCL6 and the induction or inhibition of apoptosis was observed.

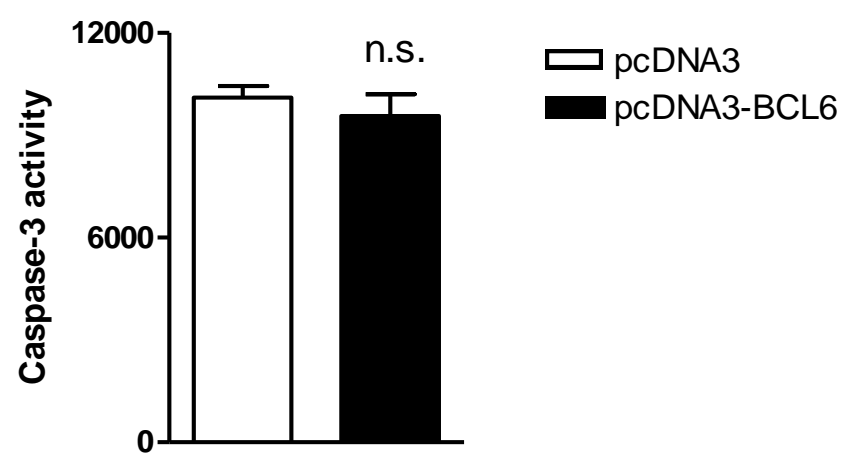

Figure 3.11: Detection of apoptosis by measuring caspase-3 activity in OK cells.

Cells were either transfected with control vector pcDNA3 (white bar) or with expression vector pcDNA3-BCL6 (black bar). OK cells were harvest, lysed, and caspase-3 activity was measured as fluorescence using excitation at $490 \mathrm{~nm}$ and emission at $535 \mathrm{~nm}$. Data are reported as caspase-3 activity (relative fluorescence units per mg protein). Mean \pm S.E.M.; $n=4$; n.s.: not significant. 


\subsubsection{Influence of BCL6 on the regulation of rat Oat1 and Oat3 promoters}

Oat1 and Oat3 promoter constructs, all varying in their lengths of promoters and number of predicted BCL6 binding sites, were investigated with respect to their responsiveness to BCL6. OK cells were transiently transfected with different promoter constructs, BCL6 expression vector pcDNA3-BCL6 or empty control vector pcDNA3, and pRL-TK. Cells were lysed $48 \mathrm{~h}$ after transfection, followed by quantification of firefly and Renilla luciferase activity. Firefly luciferase activity was normalized to Renilla and data are presented as the fold increase over pGL3-Enhancer.

The localization of predicted BCL6 binding sites of examined Oat1 promoter constructs, are shown in figure 3.12A. The promoter construct Oat1 $(-1226 /+113)$ included two, Oat1 $(-1666 /+113)$ four, and Oat1 $(-2252 /+113)$ also four predicted BCL6 binding sites, respectively. All three Oat1 promoter constructs were activated by BCL6 with a comparable induction, independent of their predicted number of response elements [figure 3.12B; (Wegner et al., 2012)]. Comparing the localization of predicted binding sites with the fold increase of investigated Oat1 promoter constructs revealed that the first and second BCL6 binding site (-492 to -476 bp and -1143 to -1127 bp) might be responsible for BCL6dependent activation of Oat1 promoter. 
A

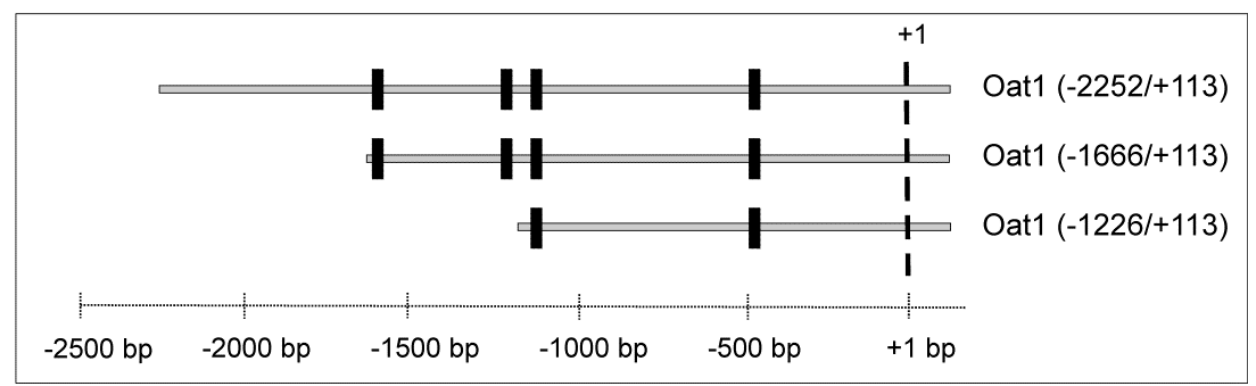

B

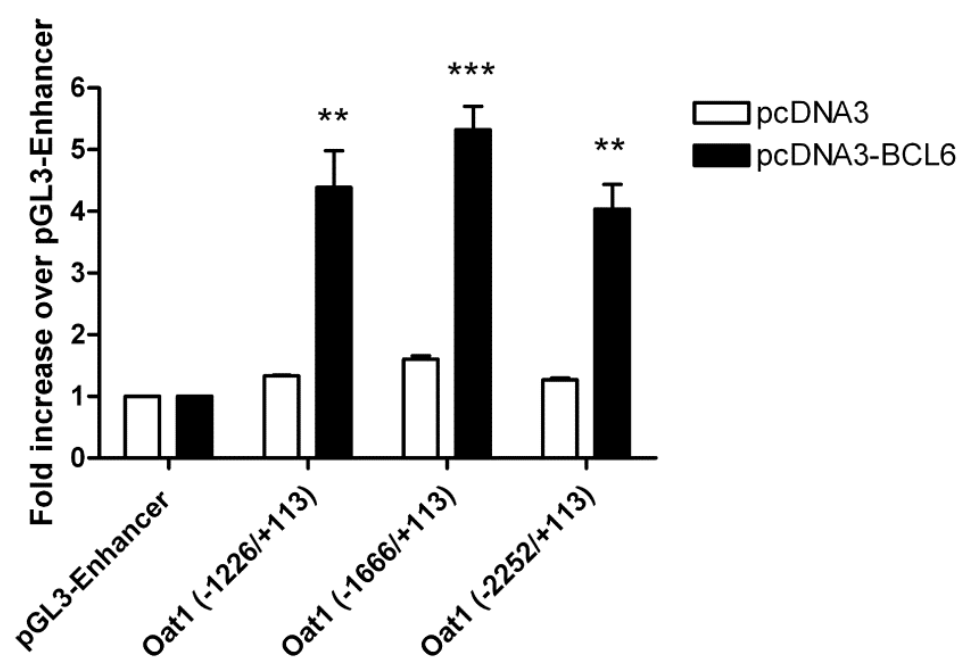

Figure 3.12: Effect of BCL6 on rat Oat1 promoter activity.

A: Localization of BCL6 binding sites (indicated as black bars) in different Oat1 promoter constructs; +1 : transcriptional start site. B: OK cells were transiently transfected with indicated promoter constructs of Oat 1 , and with control vector pcDNA3 (white bars) or expression vector pcDNA3-BCL6 (black bars). Luciferase activity was measured and firefly luciferase was normalized to Renilla luciferase. Data are reported as the fold increase over pGL3-Enhancer and presented as mean \pm S.E.M.; $\mathrm{n}=4$; **: $\mathrm{p}<0.01 ; * * * \mathrm{p}<0.001$, significantly different from control (pcDNA3) using the unpaired two-tailed $t$-test [(Wegner et al., 2012), modified].

Six point mutations in each of the two functional hypothesized BCL6 binding sites, located at -1143 to $-1127 \mathrm{bp}$ and -492 to $-476 \mathrm{bp}$, were introduced into the promoter construct Oat1 $(-1226 /+113)$ (figure 3.13A). Mutation of indicated nucleotides lead to the abolishment of the in silico predicted binding sites.

The promoter construct Oat1 $(-1226 /+113)$ mut 1 contained mutations within the first BCL6 binding site, whereas the Oat1 $(-1226 /+113)$ mut 2 construct harbored mutations in the second BCL6 binding sites. Moreover, the Oat1 (-1226/+113) mut 1+2 construct was generated containing mutations in both BCL6 binding sites. Wild type and mutated Oat1 (-1226/+113) promoter constructs were transfected into OK cells, and their responsiveness to BCL6 was investigated (figure 3.13B). All three mutated Oat1 (-1226/+113) promoter constructs were still activated by BCL6. No significant differences between the mutated promoter constructs 
and the wild type construct were observed, because the ratios between pcDNA3-BCL6 and pcDNA3 of every mutated promoter construct with wild type were comparable (figure $3.13 \mathrm{C})$.

Taken together, all Oat1 $(-1226 /+113)$ promoter constructs showed equal activations, unaffected by mutated BCL6 binding sites.

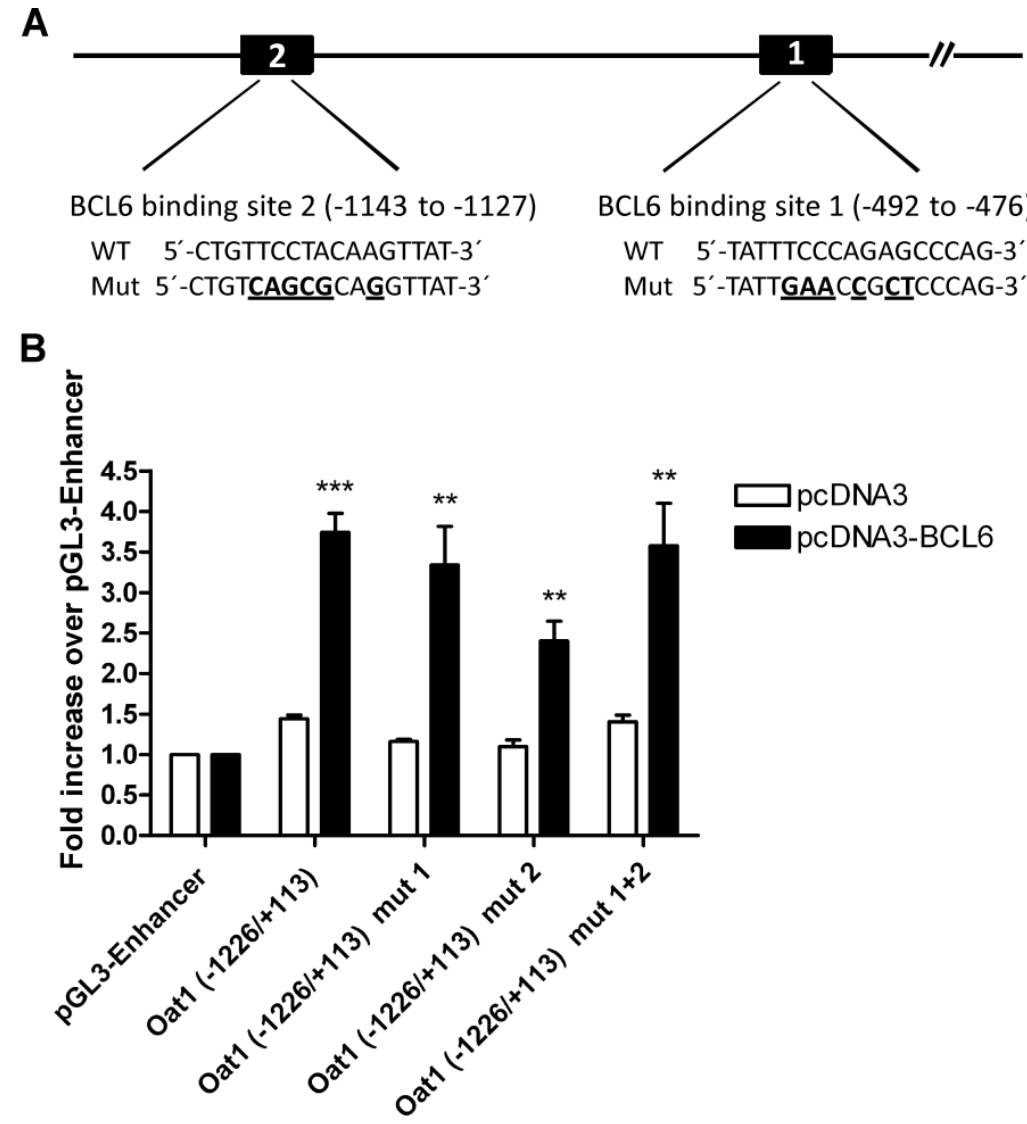

C

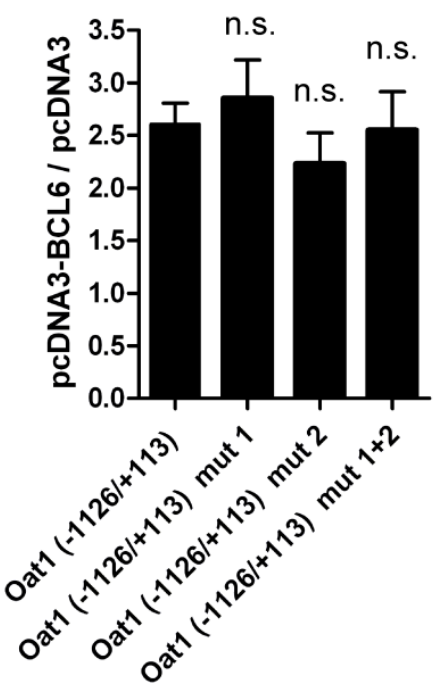

Figure 3.13: BCL6-dependent rat Oat1 promoter activity after binding sites mutation.

A: Predicted BCL6 binding sites in the promoter construct Oat1 $(-1226 /+113)$ were mutated; +1 : transcriptional start site. Bold typed and underlined nucleotides indicate the differences between wild type (WT) and mutated (mut) BCL6 binding site. B: Promoter constructs with or without indicated mutated BCL6 binding sites and pcDNA3 control vector (white bars) or BCL6 expression vector pcDNA3-BCL6 (black bars) were transiently transfected into OK cells. Luciferase activity was measured and firefly luciferase was normalized to Renilla luciferase. Data are reported as the fold increase over pGL3-Enhancer and presented as mean \pm S.E.M.; $\mathrm{n}=4$; $* *: \mathrm{p}<0.01 ; * * * \mathrm{p}<0.001$, significantly different from control (pcDNA3) using the unpaired two-tailed $t$-test. C: The ratio between the fold increase of pcDNA3-BCL6 and pcDNA3 transfected cells was estimated for each promoter construct. Data are presented as mean \pm S.E.M.; $n=4$, n.s. not significant compared to wild type Oat1 $(-1126 /+113)$, by using one-way ANOVA with Dunnett's multiple comparison test.

Subsequently, the influence of BCL6 on the activation of Oat3 promoter was examined. Three promoter constructs, Oat3 $(-444 /+12)$, Oat3 $(-752 /+12)$, and Oat3 $(-256 /+12)$ were investigated (Wegner et al., 2012). The localization of predicted BCL6 binding sites is given in figure 3.14A. The shortest Oat3 promoter construct $(-444 /+12)$ contained two predicted 
BCL6 binding sites, the longer one (-752/+12) three, and the longest one (-2567/+12) six predicted BCL6 binding sites, respectively. OK cells were transiently transfected with Oat3 promoter constructs, BCL6 expression vector pcDNA3-BCL6 or empty vector pcDNA3, and their luciferase activity was measured (figure 3.14B). All three tested promoter constructs showed activation by BCL6. Oat3 $(-444 /+12)$ and Oat3 $(-752 /+12)$ were activated in a significant manner, and the promoter construct of Oat3 $(-2567 /+12)$ showed a trend of activation (figure 3.14B). Adjustment of predicted BCL6 binding sites localization with the fold increase of investigated Oat 3 promoter constructs revealed that the first and second BCL6 binding site (-279 to -263 bp and -439 to -423 bp) might be critical for Oat3 promoter activation by BCL6.

A

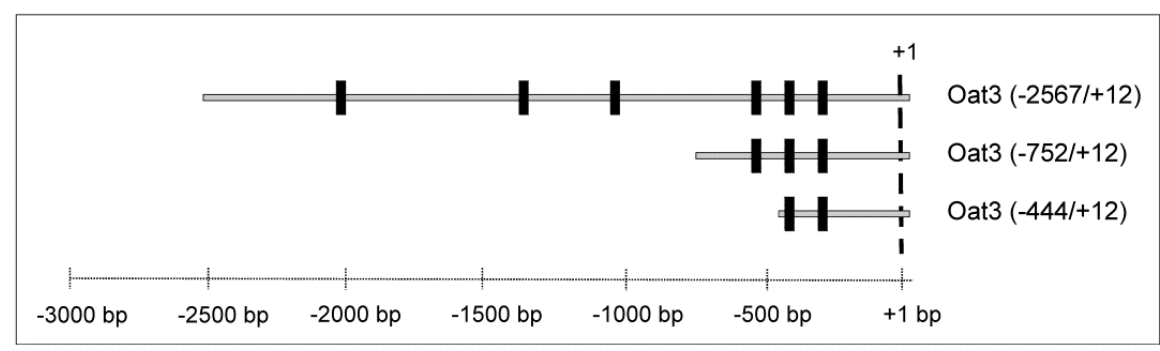

B

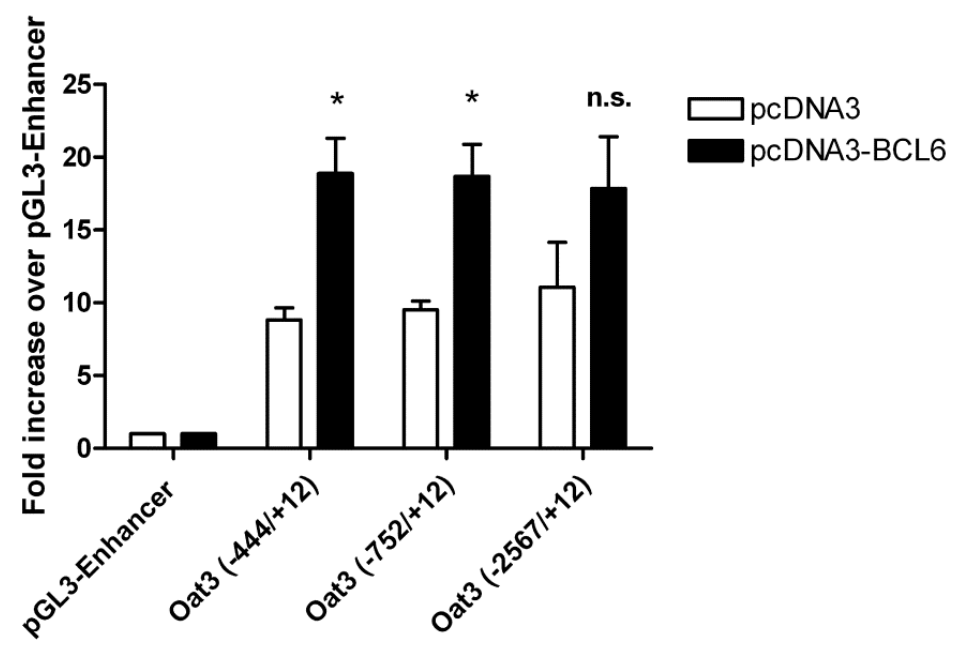

Figure 3.14: Impact of BCL6 on rat Oat3 promoter activity.

A: Localization of predicted BCL6 binding sites (indicated as black bars) in different Oat3 promoter constructs; +1 : transcriptional start site. B: OK cells were transiently transfected with indicated promoter constructs of Oat3, and with control vector pcDNA3 (white bars) or expression vector pcDNA3-BCL6 (black bars). Luciferase activity was measured and firefly luciferase was normalized to Renilla luciferase. Data are reported as the fold increase over pGL3-Enhancer and presented as mean \pm S.E.M.; $\mathrm{n}=3$; n.s.: not significant; *: $\mathrm{p}<0.5$, significantly different from control (pcDNA3) using the unpaired two-tailed $t$-test [(Wegner et al., 2012), modified]. 
Four to six point mutations within the BCL6 binding sites located at -279 to -263 bp and -439 to -423 bp were introduced and led to the loss of in silico predicted BCL6 binding (figure 3.15A). Three different mutated Oat3 $(-444 /+12)$ promoter constructs were generated. Oat3 $(-444 /+12)$ mut 1 contained the first BCL6 binding site being mutated, Oat3 $(-444 /+12)$ mut 2 the second, and Oat3 $(-444 /+12)$ mut 1+2 included both mutated BCL6 binding sites. Although predicted binding sites were mutated, all three Oat3 promoter constructs were still activated by BCL6 (figure 3.15B). The fold induction of mutated promoter constructs were not significantly different from that of wild type, calculated by comparing the ratios between pcDNA3-BCL6 and pcDNA3 of every mutated promoter construct with wild type (figure $3.15 \mathrm{C})$.

These data showed that activation of Oat3 $(-444 /+12)$ promoter construct by BCL6 was independent of predicted BCL6 binding sites located at -279 to $263 \mathrm{bp}$ and -439 to $-423 \mathrm{bp}$.

A

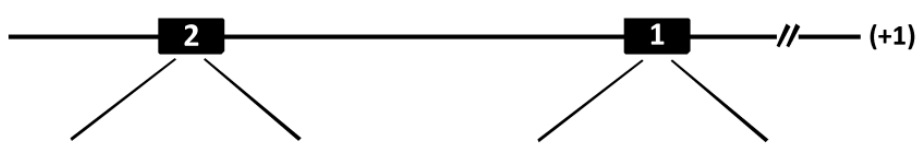

BCL6 binding site 2 (-439 to -423$)$ WT 3'-AGGTTCGTGGAGAATGT-5' Mut $3^{\prime}$-AGGTCAG $\underline{\underline{C}} \underline{\mathrm{A} A G A A T G T-5}$

BCL6 binding site 1 (-279 to -263$)$ WT $5^{\prime}$-CCCTTCCCAGATTCTCT-3 Mut $5^{\prime}$-CCCT $\underline{\text { GAACIG }} \underline{\mathbf{C T T C T C T}}-3$

B C
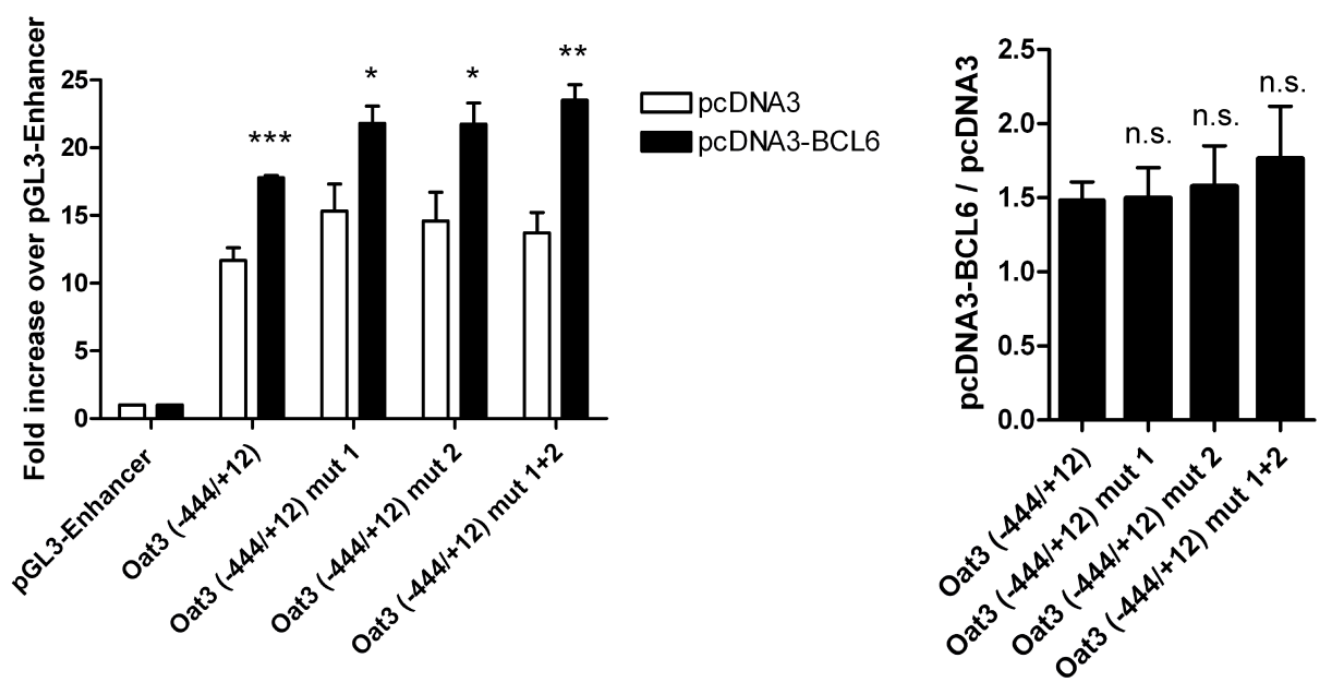

Figure 3.15: Rat Oat3 promoter activity after mutation of BCL6 binding sites.

A: Both predicted BCL6 binding sites in the promoter of Oat 3 were mutated; +1 : transcriptional start site. Bold typed and underlined nucleotides indicate the differences between wild type (WT) and mutated (Mut) BCL6 binding site. B: Promoter constructs with or without indicated mutated BCL6 binding sites and pcDNA3 control vector (white bars) or BCL6 expression vector pcDNA3-BCL6 (black bars) were transiently transfected into OK cells. Luciferase activity was measured and firefly luciferase was normalized to Renilla luciferase. Data are reported as the fold increase over pGL3-Enhancer and presented as mean \pm S.E.M.; $\mathrm{n}=5 ; *$ : $\mathrm{p}<0.05$; $* *: \mathrm{p}<0.01 ; * * *: \mathrm{p}<0.001$, significantly different from control (pcDNA3) using the unpaired two-tailed $t$-test. C: The ratio between the fold increase of pcDNA3-BCL6, and pcDNA3 transfected cells was estimated for each promoter construct. Data are presented as mean \pm S.E.M.; $n=5$, n.s. not significant compared to wild type Oat3 (-444/+12), by using one-way ANOVA with Dunnett's multiple comparison test. 


\subsubsection{Effect of BCL6 on the promoter activity of human OAT1 and OAT3}

Because of potentially comparable regulation mechanisms between rat and human Oats/OATs, the impact of BCL6 on the promoter activity of human OAT1 and OAT3 was also examined. First, the involvement of BCL6 on the promoter activity of human OAT1 was investigated. Five different OAT1 promoter constructs, differing in their length and number of predicted BCL6 binding sites, were analyzed. Promoter constructs were transiently transfected into OK cells and their BCL6-dependent promoter activity was measured by luciferase assay. Localization of predicted BCL6 binding sites in the investigated promoter constructs is given in figure $3.16 \mathrm{~A}$.

OAT1 promoter construct $(-342 /+88)$, OAT1 (-746/+88), and OAT1 (-1419/+88) contained two predicted BCL6 binding sites, OAT1 $(-1982 /+88)$ three, and OAT1 $(-3049 /+88)$ included five predicted BCL6 binding sites. All five tested promoter constructs showed an activation by BCL6, at which OAT1 $(-1982 /+88)$ showed the highest BCL6 induced promoter enhancement (figure 3.16B). By comparing the localization of BCL6 binding sites with the fold induction of tested constructs, the first (-222 to $-206 \mathrm{bp}$ ) and second (-241 to $-225 \mathrm{bp}$ ) binding site might be critical for BCL6-dependent promoter activation of OAT1. Moreover, the third BCL6 binding site, located at -1494 to -1478 bp, seemed to be responsible for an additional activation of OAT1 promoter. 
A

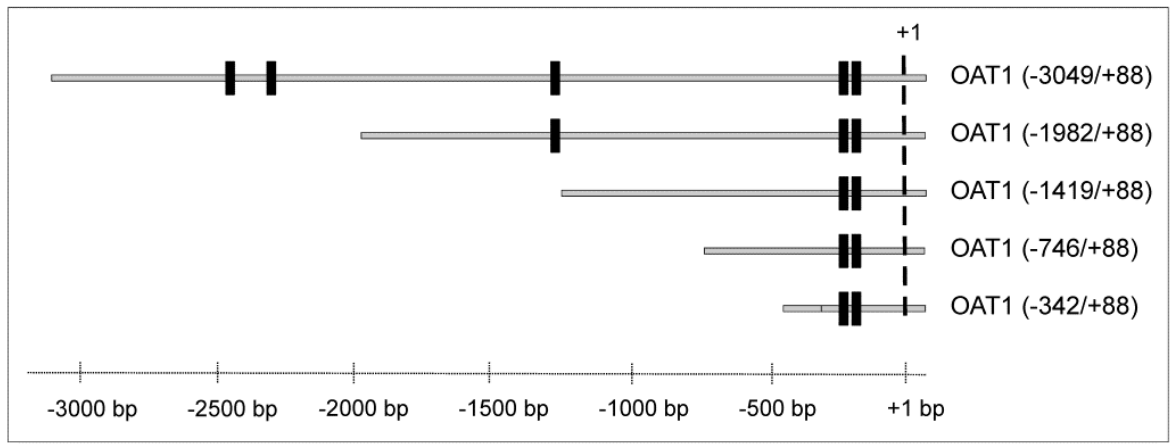

B

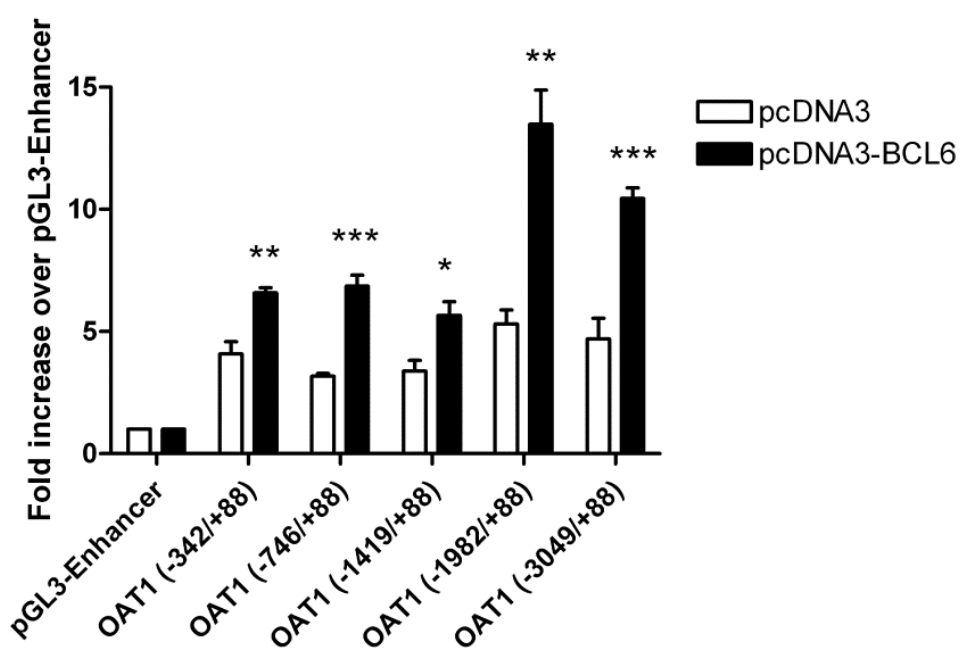

Figure 3.16: BCL6-dependent human OAT1 promoter activity.

A: Localization of BCL6 binding sites (indicated as black bars) in different OAT1 promoter constructs; +1 : transcriptional start site. B: OK cells were transiently transfected with indicated promoter constructs of OAT1, and with control vector pcDNA3 (white bars) or expression vector pcDNA3-BCL6 (black bars). Luciferase activity was measured and firefly luciferase was normalized to Renilla luciferase. Data are reported as the fold increase over pGL3-Enhancer and presented as mean \pm S.E.M.; $\mathrm{n}=4 ; *$ : $\mathrm{p}<0.05 ; * *$ : $<<0.01 ; * * *$ : $\mathrm{p}<0.001$, significantly different from control (pcDNA3) using the unpaired two-tailed $t$-test.

The potential involvement of the three suggested BCL6 binding sites, located at -222 to -206 $\mathrm{bp},-241$ to $-225 \mathrm{bp}$, and -1494 to $-1478 \mathrm{bp}$ in the OAT1 promoter was investigated (figure 3.17). Five to six point mutations in every predicted BCL6 binding site were introduced into the OAT1 $(-1982 /+88)$ promoter construct, resulting to the complete deficiency within in silico analyses. In this experiment, three different predicted BCL6 binding sites were mutated, leading to seven OAT1 $(-1982 /+88)$ mutated promoter constructs, all varying in the combination of mutated binding sites (figure 3.17A and B). Promoter construct OAT1 $(-1982 /+88)$ mut 1 contained mutations in the first BCL6 binding site, and OAT1 $(-1982 /+88)$ mut 2 included the second mutated BCL6 binding site. Both promoter constructs were activated by BCL6 (figure 3.17B). OAT1 (-1982/+88) mut 1+2 included mutations in the first and second BCL6 binding site and showed also an activation by BCL6. After comparison of the ratios between the fold increase of pcDNA3-BCL6 and pcDNA3 for these three promoter 
constructs no significant differences in BCL6-dependent activation between wild type and mutated constructs were observed (figure 3.17C). The OAT1 (-1982/+88) mut 3, which contained the third BCL6 binding site being mutated, also showed an activation by BCL6 (figure 3.17B), which was comparable to that observed by wild type (figure 3.17C). The remaining three promoter constructs OAT1 (-1982/+88) mut 1+3, OAT1 (-1982/+88) mut $2+3$, and OAT1 $(-1982 /+88)$ mut $1+2+3$, containing all previously described mutations in the indicated combinations, were still activated in a BCL6-dependent manner (figure 3.17B). Comparing their ratios between the fold increase of pcDNA3-BCL6 and pcDNA3 for every promoter construct, no significant differences between wild type and mutated constructs were observed (figure $3.17 \mathrm{C}$ ).

A

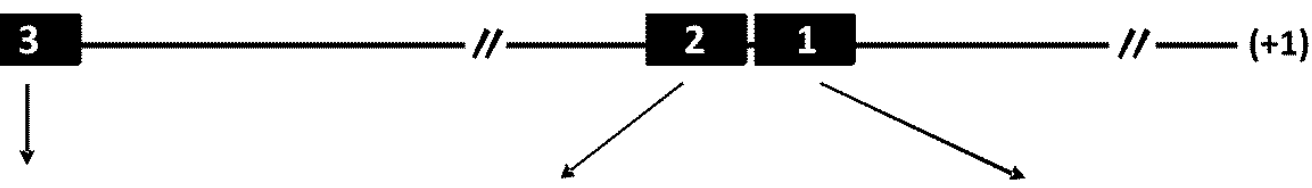

BCL6 binding site 3 (-1.494 to -1478)

BCL6 binding site 2 (-241 to -225)

BCL6 binding site $1(-222$ to -206$)$

WT 3'-GAATTCCTCCAACAGAG - $5^{\prime}$

WT 5'-CACTTCCCAGAGCCCAG -3'

WT 5'-TCCTICCTAAAAGGAAG-3'

Mut $3^{\prime}$-GAAGGACGCCGACAGAG-5' Mut 5'-CACTGAACCTCGCCCAG-3'

Mut 5'-TCCGGACTCACCGGAG-3'

B

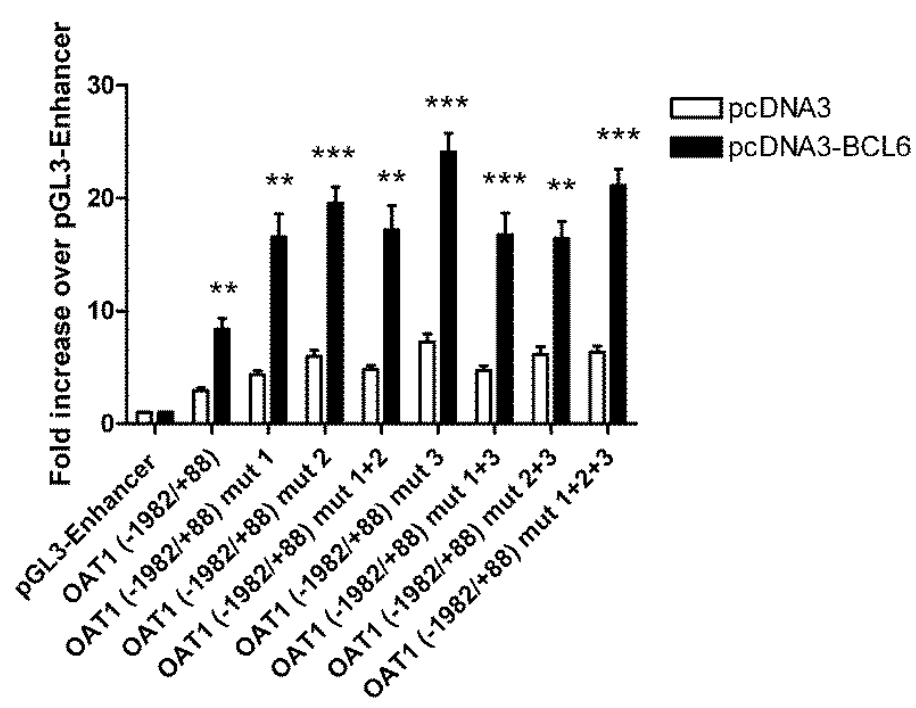

C

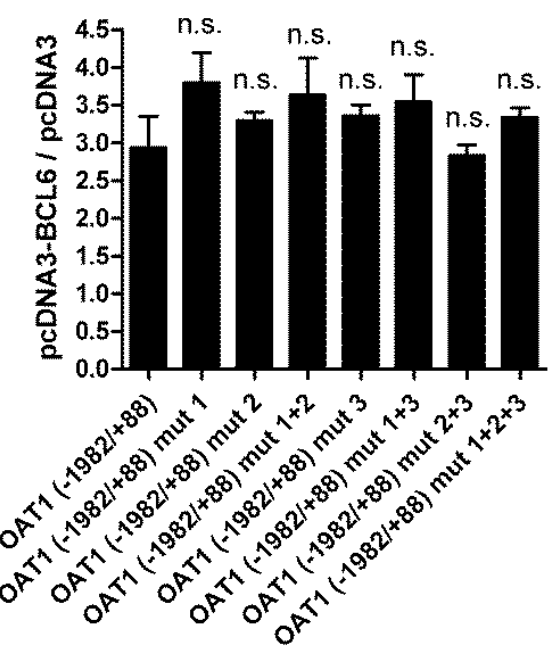

Figure 3.17: BCL6-induced human OAT1 promoter activity after mutation of BCL6 binding sites.

A: All three predicted BCL6 binding sites in the promoter of OAT1 were mutated; +1 : transcriptional start site. Bold typed and underlined nucleotides indicate the differences between wild type (WT) and mutated (Mut) BCL6 binding site. B: Promoter constructs with or without indicated mutated BCL6 binding sites and pcDNA3 control vector (white bars) or BCL6 expression vector pcDNA3-BCL6 (black bars) were transiently transfected into OK cells. Luciferase activity was measured and firefly luciferase was normalized to Renilla luciferase. Data are reported as the fold increase over pGL3-Enhancer and presented as mean \pm S.E.M.; $\mathrm{n}=4$; **: $\mathrm{p}<0.01$; ***: $\mathrm{p}<0.001$, significantly different from control (pcDNA3) using the unpaired two-tailed $t$-test. C: The ratio between the fold increase of pcDNA3-BCL6, and pcDNA3 transfected cells was estimated for each promoter construct. Data are presented as mean \pm S.E.M.; $\mathrm{n}=4$, n.s. not significant compared to wild type OAT1 (-1982/+88), by using one-way ANOVA with Dunnett's multiple comparison test. 
Results

In summary, all tested OAT1 (-1982/+88) promoter constructs showed an equal BCL6dependent activation, unaffected by mutated BCL6 binding sites.

Focusing on the minimal OAT1 promoter region, required for BCL6-dependent promoter activation, two different truncated OAT1 promoter constructs, OAT1 $(-63 /+88)$ and OAT1 $(-198 /+88)$ were generated. The promoter construct OAT1 $(-342 /+88)$ was again utilized due to its established BCL6-dependent activation (see figure 3.16). Promoter constructs were transiently transfected into OK cells and their BCL6-dependent activity was measured by luciferase assay. Localization of predicted BCL6 binding sites of investigated promoter constructs is shown in figure 3.18A. Truncated constructs OAT1 $(-63 /+88)$ and OAT1 $(-198 /+88)$ contained no predicted BCL6 binding site, whereas OAT1 $(-342 /+88)$ contained two predicted BCL6 binding sites. The first truncated OAT1 (-198/+88), without predicted BCL6 binding site, showed an activation by BCL6 (figure 3.18B), which was not significantly different from that of OAT1 $(-342 /+88)$ (figure 3.18C). The second truncated OAT1 $(-63 /+88)$ promoter construct, which also contained no predicted BCL6 binding site, was activated by BCL6 (figure 3.18B), with a smaller increase as it was estimated for OAT1 (-342/+88) (figure 3.18C). Taken together, these data revealed that promoter region -63 to +1 bp of OAT1 seems to be the minimal promoter region responsible for BCL6-dependent OAT1 promoter activation. 
A

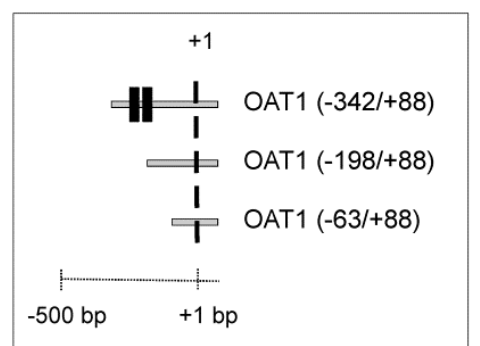

B

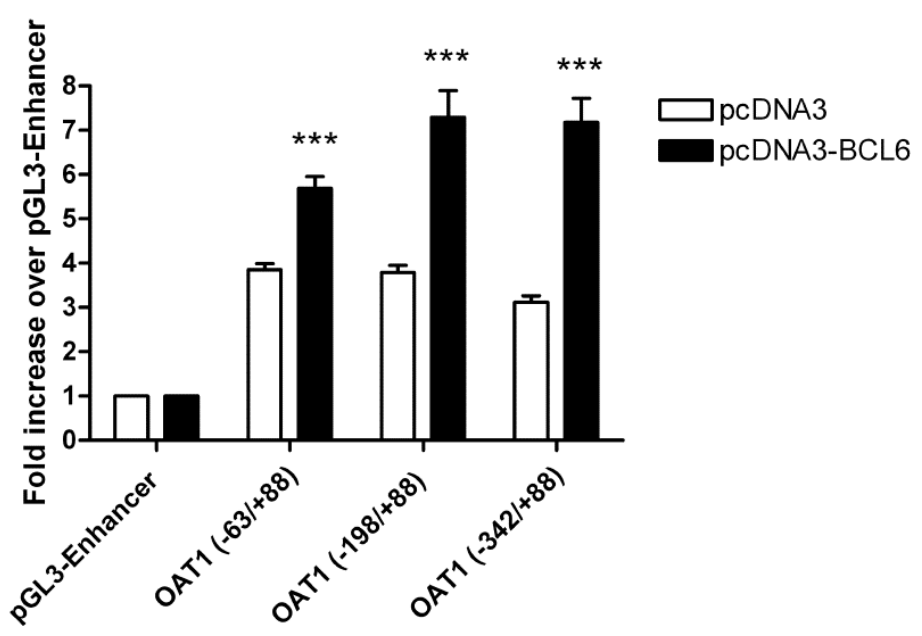

C

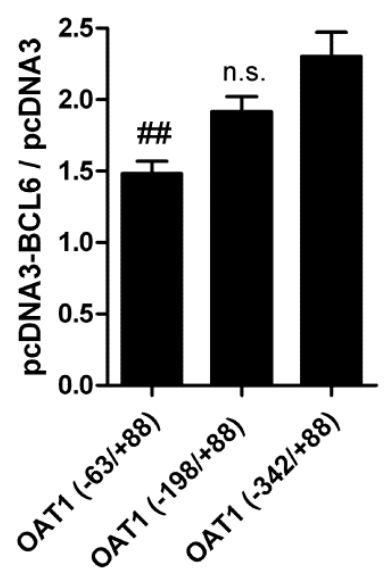

Figure 3.18: Effect of BCL6 on truncated human OAT1 promoter constructs.

A: Localization of BCL6 binding sites (indicated as black bars) in different OAT1 promoter constructs; +1 : transcriptional start site. B: Truncated OAT1 promoter constructs and pcDNA3 control vector (white bars) or BCL6 expression vector pcDNA3-BCL6 (black bars) were transiently transfected into OK cells. Luciferase activity was measured and firefly luciferase was normalized to Renilla luciferase. Data are reported as the fold increase over pGL3-Enhancer and presented as mean \pm S.E.M.; $\mathrm{n}=4$; ***: $\mathrm{p}<0.001$, significantly different from control (pcDNA3) using the unpaired two-tailed $t$-test. C: The ratio between the fold increase of pcDNA3BCL6 and pcDNA3 transfected cells was estimated for each promoter construct. Data are presented as mean \pm S.E.M.; $n=4$; n.s.: not significant, between OAT1 $(-342 /+88)$ and respectively promoter constructs by using one-way ANOVA with Dunnett's multiple comparison test.

Similar to human OAT1 promoter, the involvement of BCL6 on the promoter activity of OAT3 was investigated.

Three OAT3 promoter constructs with different lengths, OAT3 (-214/+21), OAT3 (-323/+21), and OAT3 $(-1499 /+21)$, were transiently transfected into OK cells, and their BCL6 dependency was examined by measuring luciferase activity. Promoter construct OAT3 $(-214 /+21)$ contained no predicted BCL6 binding sites, OAT3 $(-323 /+21)$ contained one, and OAT3 $(-3048 /+21)$ included two predicted BCL6 binding sites (figure 3.19A). All three promoter constructs were significantly activated by BCL6, although OAT3 (-214/+21) contained no predicted BCL6 binding sites (figure 3.19B). The ratios of the fold induction of pcDNA3-BCL6 and control pcDNA3 transfected promoter constructs were not significantly different between OAT3 (-214/+21) and respectively promoter constructs (figure 3.19C). 
A

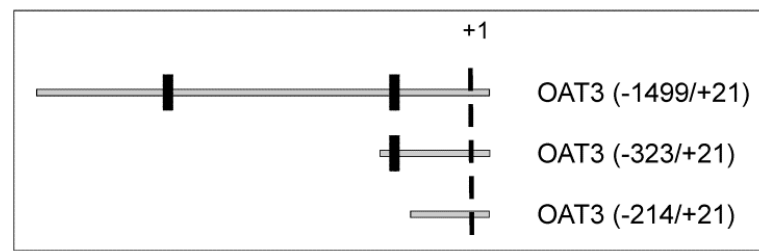

B

C
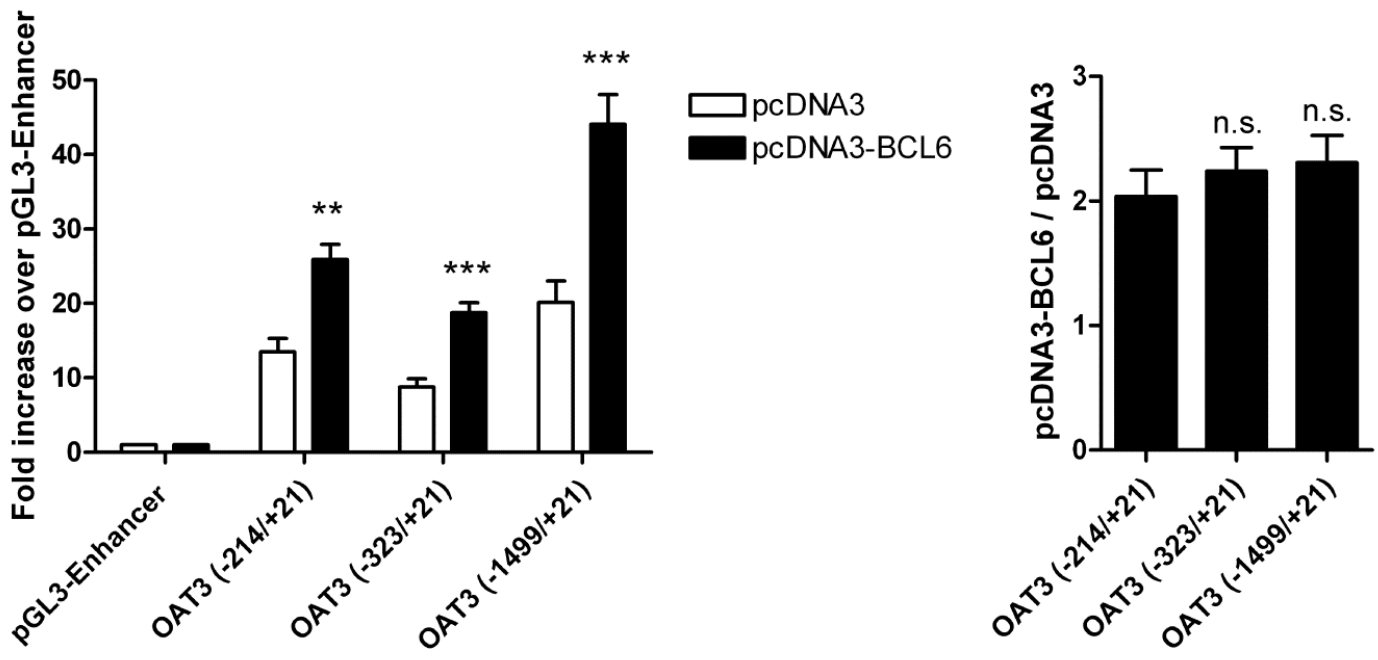

Figure 3.19: Involvement of BCL6 on human OAT3 promoter activity.

A: Localization of BCL6 binding sites (indicated as black bars) in different OAT3 promoter constructs; +1 : transcriptional start site. B: OK cells were transiently transfected with indicated promoter constructs of OAT3, and with control vector pcDNA3 (white bars) or expression vector pcDNA3-BCL6 (black bars). Luciferase activity was measured and firefly luciferase was normalized to Renilla luciferase. Data are reported as the fold increase over pGL3-Enhancer and presented as mean \pm S.E.M.; $\mathrm{n}=6$; **: $\mathrm{p}<0.01 ; * * *$ : $\mathrm{p}<0.001$, significantly different from control (pcDNA3) using the unpaired two-tailed $t$-test. $\mathbf{C}$ : The ratio between the fold increase of pcDNA3-BCL6 and pcDNA3 transfected cells was estimated for each promoter construct. Data are presented as mean \pm S.E.M.; $\mathrm{n}=6$; n.s.: not significant; between OAT3 (-214/+21) and respectively promoter constructs by using one-way ANOVA with Dunnett's multiple comparison test.

These data showed that all OAT3 promoter constructs were activated by BCL6. However, this activation was not due to the predicted BCL6 binding sites.

Next, the minimal promoter region for BCL6-dependent activation of OAT3 promoter was elucidated (figure 3.20). Promoter constructs OAT3 $(-214 /+21)$, OAT3 $(-112 /+21)$ and OAT3 (-59/+21), all without predicted BCL6 binding sites, were transiently transfected into OK cells and their BCL6-dependent luciferase activity was measured (figure 3.20B). Promoter construct OAT3 $(-112 /+21)$ and OAT3 $(-214 /+21)$ were activated by BCL6 in a comparable manner, whereas promoter construct OAT3 $(-59 /+21)$ showed no significant activation by BCL6 (figure 3.20B and C). Furthermore, OAT3 (-59/+21) showed no basal promoter activity at all. 
A

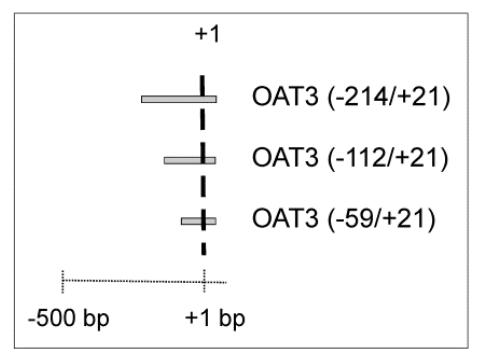

B

C
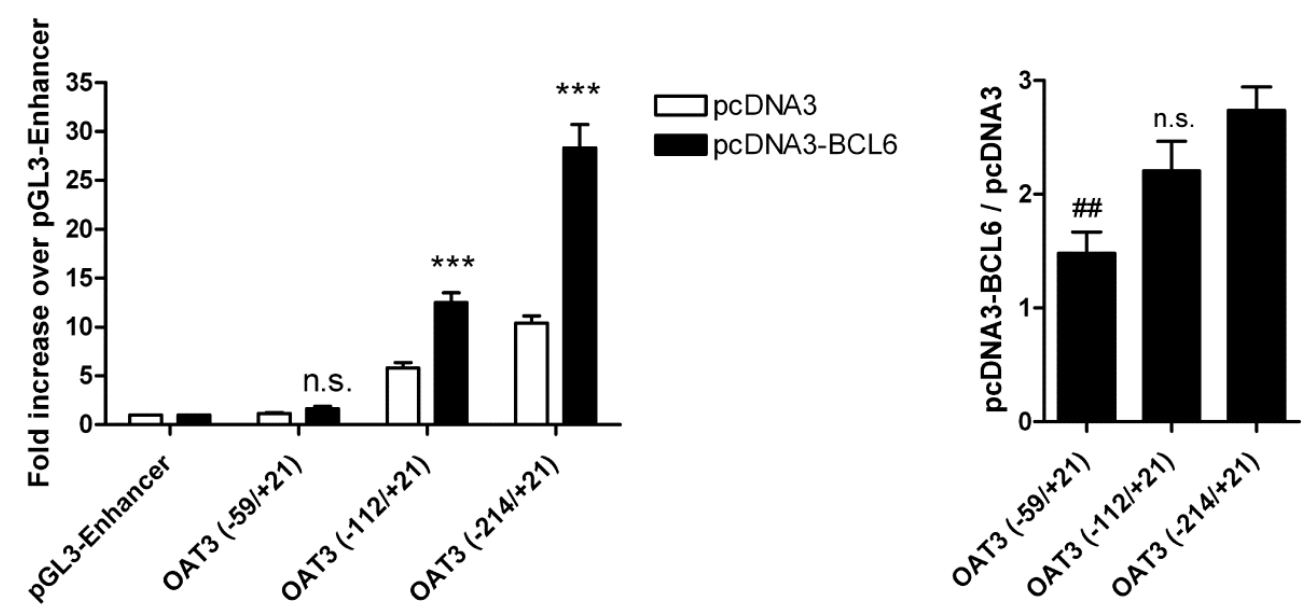

Figure 3.20: Impact of BCL6 on truncated human OAT3 promoter constructs.

A: Overview of transfected OAT3 promoter constructs without BCL6 binding site; +1 : transcriptional start site. B: Truncated OAT3 promoter constructs and pcDNA3 control vector (white bars) or BCL6 expression vector pcDNA3-BCL6 (black bars) were transiently transfected into OK cells. Luciferase activity was measured and firefly luciferase was normalized to Renilla luciferase. Data are reported as the fold increase over pGL3Enhancer and presented as mean \pm S.E.M.; $\mathrm{n}=4$; $\mathrm{n}$.s.: not significant; $* * * \mathrm{p}<0.001$, significantly different from control (pcDNA3) (20B). C: The ratio between the fold increase of pcDNA3-BCL6 and pcDNA3 transfected cells was estimated for each promoter construct. Data are presented as mean \pm S.E.M.; $n=4$; n.s.: not significant; \#\#: p < 0.01, between OAT3 $(-214 /+21)$ and respectively promoter constructs by using one-way ANOVA with Dunnett's multiple comparison test.

These data strongly indicated that the promoter region -59 to -112 is essential for basal promoter activity of OAT3 and moreover for its BCL6-dependent promoter activation.

The minimal promoter regions, required for BCL6 activation, +88 to $-63 \mathrm{bp}$ for OAT1 (figure 3.18), and -59 to -112 bp for OAT3 (figure 3.20) were again analyzed by the MatInspector software (table 3.5). Predicted binding sites were filtered for transcription factors which were expected to regulate both promoters, OAT1 as well as OAT3. Four different possible interacting partners of BCL6 were found: BCDF (bicoid-like homeodomain transcription factor), CREB (cAMP-responsive element binding protein), HNF1 (hepatic nuclear factor 1), and MYBL (cellular and viral myb-like transcriptional regulator).

OAT1 promoter region -63 to +88 bp included seven predicted binding sites whereas different transcription factors have overlapping binding sequences: BCDF and HNF1 at -57 to $-41 \mathrm{bp}$, 
CREB and HNF1 at -32 to $-16 \mathrm{bp}$, and BCDF, HNF1 and MYBL at -1 to +4 bp (table 3.5). OAT3 promoter region of at -112 to $-59 \mathrm{bp}$ included also seven predicted binding sites, with in part overlapping sequences. HNF1, CREB and MYBL share predicted binding sequences located at -91 to $-85 \mathrm{bp}$ (table 3.5 ).

Table 3.5: In silico analyses of OAT1 (-63/+88) and OAT3 (-112/-59). Date of analyses: November 13, 2012.

\begin{tabular}{|c|c|c|c|}
\hline Promoter & Binding site & Sequence & Position (bp) \\
\hline \multirow[t]{7}{*}{ ב्OAT1 (-63 to +88 bp) } & $\overline{\mathrm{BCDF}}$ & "5'-agggttaatccttctga-3' & -59 to -43 \\
\hline & $\mathrm{HNF}^{\mathrm{a}}{ }^{\mathrm{a}}$ & $5^{\prime}$-ggttaatccttctgata-3' & -57 to -41 \\
\hline & CREB & $5^{\prime}$-acactttaactcattccetcc-3' & -33 to -13 \\
\hline & HNF1 & $3^{\prime}$-gggaatgagttaaagtg-5' & -32 to -16 \\
\hline & HNF1 & $3^{\prime}$-ttttaatcettggcetg-5 & -13 to +4 \\
\hline & $\mathrm{BCDF}$ & $3^{\prime}-\mathrm{gtttttaatccttggcc}-5^{\prime}$ & -11 to +6 \\
\hline & MYBL & $5^{\prime}$-taaaaactgcccatg-3' & -1 to +14 \\
\hline \multirow[t]{7}{*}{ OAT3 (-112 to $-59 \mathrm{bp})$} & HNF1 & $5^{\prime}$-cagcactctccetgccagtga- $3^{\prime}$ & -105 to -85 \\
\hline & CREB $^{\text {b) }}$ & 5-'ccctgecagtgacgttaatcc-3' & -96 to -76 \\
\hline & CREB $^{\text {b) }}$ & $3^{\prime}-$ gcggattaacgtcactggcag- $-5^{\prime}$ & -94 to -76 \\
\hline & CREB & $3^{\prime}$-tgccagtgacgttaatccgca-5 $5^{\prime}$ & -93 to -73 \\
\hline & MYBL & $3^{\prime}$-gattaacgtcactgg-5' & -91 to -77 \\
\hline & $\mathrm{BCDF}$ & $5^{\prime}$-gacgttaatccgcaaaa-3' & -86 to -70 \\
\hline & $\mathrm{HNF}^{\mathrm{c}}{ }^{\mathrm{f}}$ & $3^{\prime}$-ggctaatgtttgacttt- $5^{\prime}$ & -68 to -52 \\
\hline
\end{tabular}

OAT: organic anion transporter; BCDF: bicoid-like homeodomain transcription factors; CREB: cAMPresponsive element binding proteins; HNF1: hepatic nuclear factor 1; MYBL: cellular and viral myb-like transcriptional regulators. Binding sites marked with a-c were functional characterized by a) Saji et al., 2007 b) Ogasawara et al., 2006, and c) Kikuchi et al., 2006.

The BCL6-dependent activation of OAT1 and OAT3 minimal promoter regions, which contained no predicted BCL6 binding sites, might be due to protein-protein interactions between BCL6 and other proteins. Binding sites for BCDF, CREB, HNF1, and MYBL were predicted in the minimal promoter region of OAT1 and OAT3, and these transcription factors were therefore assumed to be interacting partners of BCL6. 


\section{Discussion}

Sex-differences in the Oats/OATs dependent transport of endogenous and exogenous substrates, including often prescribed drugs, has been described [reviewed in: (Morris et al., 2003; Franconi et al., 2007; Sabolic et al., 2007)]. In rats, and often used preclinical animal model, a male-dominant and testosterone-dependent expression of Oat1 and Oat3 has been shown (Ljubojevic et al., 2004).

Therefore the aim of my thesis was to identify the molecular mechanism by which testosterone influences the transcriptional regulation of rat renal Oat1 and Oat3 and, moreover, to localize the functional androgen response elements (AREs) within their promoters.

\subsection{Involvement of testosterone in the regulation of rat and human Oat1/OAT1 and Oat3/OAT3}

Although no sex-dependent expression of human OAT1 and OAT3 has been published, the effect of testosterone on their promoter activity was additionally investigated. Due to a similar HNF1-dependnet regulation of mouse and human Oat1/OAT1 and a generally high proximal promoter sequence homology ( -300 to $+1 \mathrm{bp}$ ) between rodent and human Oat1/OAT1 and Oat3/OAT3, a comparable transcriptional regulation between rats and humans was assumed, but not mandatory (Kikuchi et al., 2006; Saji et al., 2008).

In silico analyses of approximately three $\mathrm{kb}$ of rat and human Oat1/OAT1 and Oat3/OAT3 promoter revealed two to three predicted androgen response elements (AREs), respectively. AREs are part of the androgen receptor activation cascade and they are responsible for the direct binding of testosterone-activated AR to the promoter, leading to the regulation of gene expression. The involvement of testosterone in rat and human Oat1/OAT1 and Oat3/OAT3 promoter activity was investigated in two different proximal tubules cell lines. Results obtained in OK cells were further confirmed within the second cell system LLC-PK1 cells. OK cells are an often used model for OAT promoter activation studies (Ogasawara et al., 2006; Ogasawara et al., 2007). Moreover, OK cells show many characteristics of renal proximal tubule cells, including their morphology, and an organic anion transporter system (Koyama et al., 1978; Hori et al., 1993; Nagai et al., 1995). The porcine kidney cell line LLC-PK1 was used as a second cell system because of the published functional androgen 


\section{Discussion}

receptor activation cascade of organic cation transporter 2 (Oct2) promoter within these cells (Asaka et al., 2006). LLC-PK1 cells were also widely used in promoter activation studies (Holtzman et al., 1993; Yan et al., 1994; Tanaka et al., 2004; Asaka et al., 2006). To ensure that our cell systems fulfill all requirements for testosterone-dependent promoter activation, both cell lines were transiently transfected with a rat or human AR expression vector. Immunofluorescence investigations of OK and LLC-PK1 cells revealed that co-transfected AR was exclusively expressed in the nucleus, with the typical homogenous distribution for AR, including the absence in nucleoli (Tyagi et al., 2000; Farla et al., 2005). Nucleoli are non-membrane bound structures which are composed of nucleic acids and proteins (appearing as dark areas in the nucleus) (Shaw and Brown, 2012). Their main function is the transcription of three ribosomal RNAs (s-rRNA, 5.8S-rRNA, and 1-rRNA) and in addition the assembly and maturation of ribosomes (Shaw and Brown, 2012). AR in its unbound form is localized in the cytoplasm (Tyagi et al., 2000). After binding of androgen to its receptor, the activated AR is rapidly (15-60 $\mathrm{min}$ ) translocated into the nucleus (Tyagi et al., 2000). Our data confirm the exclusively nuclear staining and the existence of an active AR, which is activated by endogenous testosterone, a component of the growth medium supplement fetal bovine serum (FBS). Moreover, the previously published androgen dependency of the minimal promoter of rat probasin ( $\mathrm{rPb}-\mathrm{Luc})$ and rat Oct2 promoter were checked, and used as positive controls (Rennie et al., 1993; Asaka et al., 2006). The rPb-Luc and Oct2 were highly activated by testosterone in OK and LLC-PK1 cells, reflecting a functional androgen receptor activation cascade within both cell systems. The positive control $\mathrm{rPb}$-Luc was only significantly activated by testosterone in the presence of transfected AR, confirming the need of transiently transfected AR expression vector to complete the testosterone-dependent androgen receptor activation cascade.

Investigated rat and human Oat1/OAT1 and Oat3/OAT3 promoter constructs were, however, not activated by the testosterone/androgen receptor complex. These results were rather unexpected. At least rat Oat 1 and Oat 3 were suggested to be activated by testosterone, because the positive involvement of testosterone in the transport rate of their prototypical substrate PAH (Huang and McIntosh, 1955; Kleinman et al., 1966; Reyes et al., 1998). Furthermore, testosterone has also been reported to enhance rat Oat1 and Oat3 expression (Ljubojevic et al., 2004). Early in 1955 and 1966, it was shown that the transport rate of PAH in rat renal cortical kidney slices is higher in males compared to females (Huang and McIntosh, 1955; Kleinman et al., 1966). Furthermore pretreatment of rats with testosterone increased the transport rate (Huang and McIntosh, 1955; Kleinman et al., 1966). After cloning 82 
and functional characterization of rat Oat1 and Oat3, both transporters have been shown to be responsible for the renal PAH transport with comparable $K_{\mathrm{M}}$ values (Sweet et al., 1997; Kusuhara et al., 1999). By investigating PAH kinetics in anesthetized rats of both sexes, Reyes indicated that male rats exhibit a significantly shorter elimination half-time of PAH than females (Reyes et al., 1998). Moreover, females, which received a testosterone treatment for 7 days, showed equal PAH elimination half-times than those obtained from untreated intact male rats (Reyes et al., 1998). Within additional experiments, it was demonstrated that the main effect of testosterone is the enhancement of functional renal PAH transporters, without any evident changes in turnover (Reyes et al., 1998). Concerning the abundance of rat renal sex-dependent Oat1 and Oat3 expression, some controversial literature exists. In two independent studies Oat1 has been shown to be not sex-dependently expressed (Urakami et al., 1999; Kobayashi et al., 2002). In contrast, in four other independent publications a maledominant Oat1 expression was described (Cerrutti et al., 2002; Buist et al., 2003; Ljubojevic et al., 2004; Hazelhoff et al., 2012). Regarding the Oat3 expression, Hazelhoff and Ljubojevic revealed a strong male-dominant expression, Buist a weak (with only an approximately 1.3 fold difference between males and females), whereas Kobayashi did not identify any differences between male and female rats (Kobayashi et al., 2002, Buist and Klaassen, 2004; Ljubojevic et al., 2004; Hazelhoff et al., 2012). The reasons for these discrepancies are not entirely clear, but can be due to the usage of different rat strains or detection methods. The groups of Urakami, Kobayashi, Cerrutti, Ljubojevic, and Hazelhoff used Wistar rats, whereas Buist analyzed Sprague-Dawley rats (Urakami et al., 1999; Cerrutti et al., 2002; Kobayashi et al., 2002; Buist and Klaassen, 2004; Ljubojevic et al., 2004; Hazelhoff et al., 2012). With regard to the utilized methods, Urakami, Kobayashi, and Buist investigated Oat1 and Oat3 expression at the mRNA level by using Northern blot analyses or branched DNA assays focusing on different nucleotide sequences (Urakami et al., 1999; Kobayashi et al., 2002; Buist and Klaassen, 2004). Cerrutti, Ljubojevic, and Hazellhoff examined the expression at the protein level by using Western blot analyses and immunostaining with diverse Oat1 and Oat3 antibodies (Cerrutti et al., 2002; Ljubojevic et al., 2004; Hazelhoff et al., 2012). Within my thesis, by using established TaqMan ${ }^{\circledR}$ probes, the findings by Cerrutti, Buist, Ljubojevic and Hazelhoff, showing the male-dominant Oat1 and Oat3 expression in Wistar rats, were confirmed.

In summary, although the OK and LLC-PK1 cell system possessed a functional androgen receptor activation cascade, promoters of rat and human Oat1/OAT1 and Oat3/OAT3 were not activated by testosterone. These data revealed that each predicted ARE within the investigated 


\section{Discussion}

promoter constructs was not functional. Moreover, we suggest that the expression of rat and human Oat1/OAT1 and Oat3/OAT3 are not directly regulated via the testosterone-dependent androgen receptor activation cascade. Indeed, functional AREs which are involved in the testosterone-dependent activation could be either located even more distant from the transcription start site, or furthermore, downstream of the transcription start site than the investigated three $\mathrm{kb}$ of promoter region. But for a multitude of androgen responsive genes, like the $\alpha$-subunit of the epithelial sodium channel $(\alpha \mathrm{EnaC})$, the cyclin-dependent kinase inhibitor $\mathrm{p} 21$, the prostate specific antigen (PSA), the rat prostatic protein, and the proteaseactivated receptor-1 (PAR-1), functional and therefore responsible AREs for the testosteronedependent activation have been shown to be located within three $\mathrm{kb}$ of their promoter region (Rennie et al., 1993; Lu et al., 1999b; Kim and Coetzee, 2004; Quinkler et al., 2005; Salah et al., 2005). Furthermore, the basolateral located SLC22 family member Oct2 has been demonstrated to be male-dominantly and testosterone-dependent expressed in rat kidneys (Urakami et al., 1999; Urakami et al., 2000). Two out of five predicted AREs within three kb upstream of the transcription start site have been shown to be responsible for the Oct2 sexdependent expression (Asaka et al., 2006). In our experiments, Oct2 served as positive control and was activated under the same conditions as they were used for the non-activated rat and human Oat1/OAT1 and Oat3/OAT3 promoters. These results demonstrated that the maledominant and testosterone-dependent expression of different SLC22 family members could be regulated by a variety of testosterone-dependent mechanisms. One possible alternative mechanism was shown in Sertoli cells, where testosterone stimulated the phosphorylation of the MAP kinases ERK1/2, and CREB (Fix et al., 2004). Regarding rat and human Oat1/OAT1 and Oat3/OAT3, testosterone probably phosphorylates a so far unknown transcription factor, which than induces their male-dominant expression. This transcription factor might be CREB, because CREB has been shown to be involved in the activation of human OAT3 promoter (Ogasawara et al., 2006).

\subsection{Identification of sex-dependently expressed genes in rat proximal tubule cells}

Microarray analyses were perforemd to identify genes responsible for the sex-dependent expression of Oat 1 and Oat 3 in rats.

Out of 17,406 genes, 335 showed a sex-dependent expression in rat renal cortical slices. Cortical kidney slices used for microarray analyses could contain beside proximal tubules 
cells, several other cell types like distal convoluted tubule cells, podocytes, and endothelial cells. Therefore, the alignment with the transcription database was necessary to focus on genes expressed in the rat proximal tubules. Comparison between our microarray data with those from the "Rat Proximal Tubule Transcription Database", revealed 56 genes sexdifferently expressed.

Microarrays are known to have a decreased sensitivity compared to real-time PCR. Therefore, verification of selected candidate genes and the known Oats/OATs transcriptional regulators HNF1 $\alpha$, HNF1 $\beta$, and HNF4 $\alpha$ were investigated by TaqMan® real-time PCR. HNF1 $\alpha$ and HNF1 $\beta$ are known to activate transcription by binding as homo- or heterodimers to their response elements (Mendel and Crabtree, 1991; Mendel et al., 1991; Kikuchi et al., 2006; Saji et al., 2008; Jin et al., 2011). HNF1 $\alpha$ expression is restricted to the proximal and distal tubules of the kidneys, whereas HNF1 $\beta$ is also expressed in the collecting duct (Lazzaro et al., 1992; Pontoglio et al., 1996). The promoters of human OAT1/OAT3 and mouse Oat1 have been shown to be activated by HNF1 $\alpha / \beta$ (Kikuchi et al., 2006; Saji et al., 2008). In support of its physiological role, the involvement of HNF1 $\alpha$ in organic anion transporter expression was confirmed by HNF1 $\alpha$ knockout mice, which showed reduced renal expression of Oat1 and Oat3 (Maher et al., 2006). HNF4 $\alpha$ is predominantly expressed in the proximal tubules (Jiang et al., 2003) and activates the transcription of human OAT1 (Ogasawara et al., 2007). Microarray analyses and real-time PCR revealed that all three hepatocyte nuclear factors HNF1 $\alpha$, HNF1 $\beta$, and HNF4 $\alpha$ are expressed in the proximal tubules but revealed no sexdifferences. In contrast, POLR3G, HSD17B1, and BCL6, demonstrate a male-dominant expression in microarray analyses and in real-time PCR, and were therefore considered to be promising candidate genes for the sex-dependent regulation of Oat1 and Oat3.

POLR3G is a subunit of the dissociable RNA polymerase (pol) III subcomplex, comprising the subunits POLR3C (RPC62 or RPC3), POLR3F (RPC39 or RPC6), and POLR3G (RPC32 or RPC7) (Wang and Roeder, 1997; Kenneth et al., 2008). This subcomplex interacts with the transcription factor IIIB (TFIIIB) which in turn recruits Pol III to its target genes, leading to the initiation of transcription (Wang and Roeder, 1997; Kenneth et al., 2008; White, 2011). Pol III is specialized for the transcription of short non-coding transcripts, for example tRNAs, 5S RNA, and 7SK RNA which regulate Pol II activity (Kenneth et al., 2008; White, 2011). The male-dominant expression of POLR3G could enhance the initiation of Pol III transcription, leading to a rather indirect higher expression of Oat 1 and Oat 3 in male rats.

The second promising candidate gene, HSD17B1, is a member of the $17 \beta$-hydroxysteroid dehydrogenase (HSDs) family whose members play an exclusive role in the estrogen and 


\section{Discussion}

androgen steroid biosynthesis (Martel et al., 1992; Luu-The, 2001; Marchais-Oberwinkler et al., 2011). Human HSD17B1 selectively converts estrone to estradiol (Luu-The, 2001), whereas rat HSD17B1 mediates the reduction of androstenedione to testosterone as efficiently as the analogous reduction from estrone to estradiol (Puranen et al., 1997). Male-dominantly expressed HSD17B1 could be responsible for the higher levels of testosterone in male rats by catalyzing the reduction from androstenedione to testosterone (Puranen et al., 1997). An elevated concentration of testosterone could, therefore, activate the transcription of rat Oat1 and Oat3 by a so far unknown mechanism, leading to the sex-dependent expression and transport rate of both transporters. Our previously discussed results revealed no direct activation of Oat1/OAT1 and Oat3/OAT3 expression by the testosterone/androgen receptor complex.

The third promising candidate gene was the transcription factor BCL6, which showed great potential to be a transcriptional regulator of rat Oat1 and Oat3 expression. BCL6 demonstrated a significantly high male-dominant expression in our microarray and real-time PCR data, is a known transcription factor, and in silico analyses of each rat and human Oat1/OAT1 and Oat3/OAT3 promoter revealed several predicted BCL6 binding sites, including highly conserved sites with only one to two nucleotides differing from the consensus sequence ttcct(a/c)gaa (Dent et al., 2002).

\subsection{Transcription factor BCL6}

The transcription factor BCL6 has been reported to be mainly involved in lymphocyte differentiation, immune response, inflammation, and cell cycle control (Staudt et al., 1999; Shaffer et al., 2000; Dent et al., 2002; Wagner et al., 2011; Basso and Dalla-Favera, 2012). Based on its modular organization, BCL6 is classified as a POZ/BTB/zinc finger transcription factor (Chang et al., 1996; Miles et al., 2005; Basso and Dalla-Favera, 2012) (figure 4.1). The amino terminal Poxviruses Zinc-finger (POZ), or Broad complex, Tramtrack, and Bric à brac (BTB) domain is an evolutionary highly conserved domain, which is responsible for proteinprotein interaction and dimerization of BCL6 (Costoya, 2007; Basso and Dalla-Favera, 2012). The middle part, between POZ/BTB and zinc finger domain, has a rather unknown function, but is involved in the modulation of BCL6 protein stability and activity (Bereshchenko et al., 2002; Basso and Dalla-Favera, 2012).Within this middle part, the co-activator p300 binds and acetylates BCL6, leading to an inactivation of its function (Bereshchenko et al., 2002). The 
zinc finger domain consists of six Krüppel-like zinc fingers and is located at the C-terminus. It is responsible for nuclear targeting and protein-protein interaction of BCL6 (Mascle et al., 2003; Miles et al., 2005). Moreover, the zinc fingers enable BCL6 to interact with DNA in a sequence-specific manner (Mascle et al., 2003; Costoya, 2007). BCL6 has been shown to regulate the transcription of different genes, like the programmed cell death 2 (PDCD2) (Baron et al., 2007), the interleukine-18 (IL-18) (Takeda et al., 2003), and the monocyte chemoattractant protein-1 (MCP-1) (Toney et al., 2000), via binding to these so called BCL6binding sites within their promoters.

Sex-differences in the expression of BCL6 have been published for rat liver, where BCL6 was higher expressed in males compared to females (Meyer et al., 2009). In general, BCL6, formerly named BCL5, is widely expressed in human and mouse, including heart, brain, spleen, lung, liver, skeletal muscle, and kidneys (Miki et al., 1994a; Miki et al., 1994b; Allman et al., 1996; Bajalica-Lagercrantz et al., 1998). To our knowledge, this is the first time that BCL6 was shown to be sex-dependently expressed in the kidneys, with a higher expression in male compared to female rats.

The known male-dominant hepatic BCL6 expression was due to a growth hormone (GH) induced block of transcriptional elongation in females (Meyer et al., 2009). GH activates the expression of transcription factor STAT5, which then binds to responsive elements in the BCL6 promoter of male and female liver (Meyer et al., 2009). Due to the continuous GH level in females, BCL6 expression was suppressed by a block of transcriptional elongation early in intron 4 and in exon 5 (Meyer et al., 2009). In general, GH is known to determine sex-dependent expression of $>1000$ genes in rat liver (Zhang et al., 2011). Regarding the sexdependent expression of rat Oat1 and Oat3 in the kidneys, so far no data are available concerning the involvement of BCL6 alone, or in combination with GH.

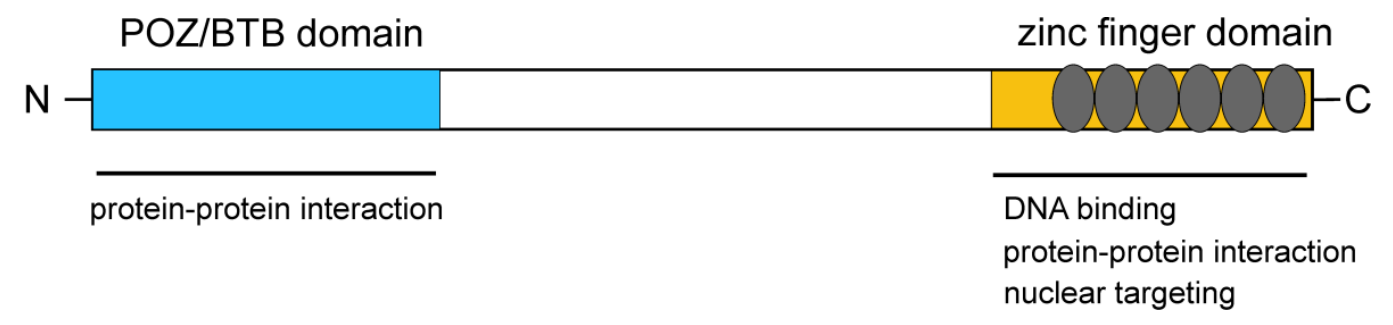

Figure 4.1: Modular organization of BCL6.

BCL6 consists of two major regions. First, the N-terminal highly conserved Poxviruses Zinc-finger (POZ), or Broad complex, Tramtrack, and Bric à brac (BTB) domain, which is responsible for protein-protein interaction, and second the highly conserved zinc finger domain, which is located at the $\mathrm{C}$-terminus. The zinc finger domain consist of six Krüppel-like zinc fingers and is responsible for sequence-specific DNA binding, protein-protein interaction, and nuclear targeting of BCL6. 


\section{Discussion}

\subsubsection{Establishment of a cell system for BCL6-dependent promoter regulation}

Predicted BCL6 binding sites in the promoters of rat and human Oat1/OAT1 and Oat3/OAT3 are supposed to be functional sites, at which BCL6 binds via its DNA-binding domain thereby regulating their expression. The impact of BCL6 on the transcriptional regulation was investigated by using luciferase activity assays. First a suitable cell system with good transfection efficiency was established. Only four out of nine investigated cell lines, OK, LLC-PK1, HEK-293, and TK-173, showed sufficient transfection efficiencies (over 15\%). Furthermore, OK cells showed a high basal activity for all rat and human Oat1/OAT1 and Oat3/OAT3 promoters. LLC-PK1 cells behaved similarly, except for rat Oat1, exhibiting only low basal promoter activity. To keep within species, promoters of human OAT1 and OAT3 were also tested in the human kidney cell lines, HEK-293 and TK-173. The OAT3 promoter demonstrated a high basal activity in both cell lines, whereas the basal promoter activity of OAT1 was low in HEK-293, and absent in TK-173 cells. Therefore OK cells were used in the subsequent experiments.

For the evaluation of BCL6-dependent promoter activity, OK cells were transiently transfected with the human BCL6 expression vector pcDNA3-BCL6. At the protein level, rat and human BCL6 showed about 95\% homology. Therefore all experiments with human and rat promoters were carried out by using the human BCL6 expression vector.

BCL6-transfected OK cells showed an exclusively nuclear localization of BCL6 as it has been reported previously (Cattoretti et al., 1995; Lemercier et al., 2002; Dean et al., 2009). Moreover, a nuclear diffuse BCL6 staining indicated cells which were in the $\mathrm{G}_{1}$-phase of cell cycle, whereas punctuated nuclear BCL6 distribution specify cells which are currently in the S-phase of cell cycle (Albagli et al., 2000).

Within the literature, contradictory data with respect to the involvement of BCL6 in apoptosis exist. BCL6 was published to either trigger apoptosis (Albagli et al., 1999; Yamochi et al., 1999), or to inhibit it (Baron et al., 2002; Kurosu et al., 2003; Baron et al., 2010). In OK cells, BCL6 induced neither a reduction nor an enhancement of apoptosis.

\subsubsection{BCL6-dependent rat and human Oat1/OAT1 and Oat3/OAT3 promoter activation}

The impact of BCL6 on rat and human Oat1/OAT1 and Oat3/OAT3 promoter activity was examined. All investigated Oat1/OAT1 and Oat3/OAT3 promoter constructs were activated by 88 
BCL6, with the exception of OAT3 (-59/+21). This construct was not activated, moreover, it showed no basal promoter activity, although it contains the TATA box, which is involved in the formation of basal transcription complex leading to the initiation of transcription (Kikuchi et al., 2006; Baumann et al., 2010). The absent promoter activity was in accordance with the results reported by Ogasawara, who identified the promoter region -214 to -77 required for basal promoter activity of OAT3 (Ogasawara et al., 2006).

Surprisingly, mutations of several BCL6-binding sites revealed a lack of their functionality and, consequently, implicated that they are not responsible for the BCL6-dependent activation of rat and human Oat1/OAT1 and Oat3/OAT3 promoters. Except for our findings, BCL6 has always been reported to inhibit the transcription of several genes via binding to BCL6 binding sites within their promoters (Toney et al., 2000; Takeda et al., 2003; Baron et al., 2007). Therefore, BCL6 was only described as a transcriptional repressor (Chang et al., 1996; Yoshida et al., 1999; Shaffer et al., 2000; Toney et al., 2000; Lemercier et al., 2002). It is known to interact via its POZ/BTB domain with many co-repressors such as the silencing mediator of retinoid and thyroid receptors (SMRT), the nuclear receptor co-repressor (NCoR), and the BCL6 interacting co-repressor (BCoR) (Dhordain et al., 1997; Huynh and Bardwell, 1998; Wong and Privalsky, 1998; Huynh et al., 2000). Moreover, members of the histone deacetylase (HDAC) family can either directly bind to BCL6, or are recruited by the corepressors SMRT and BCoR (Dhordain et al., 1997; Huynh et al., 2000; Lemercier et al., 2002). This so far published repressing function is in contrast to our data, which clearly showed a transcriptional activation of rat and human Oat1/OAT1 and Oat3/OAT3 promoters by BCL6. The hitherto unrecognized activator function might be due to the major research fields of BCL6. The majority of investigations were carried out in B and T cells and their developmental stages (Allman et al., 1996; Staudt et al., 1999; Shaffer et al., 2000; Ichii et al., 2002; Wagner et al., 2011; Basso and Dalla-Favera, 2012), although BCL6 expression has also been reported in pulmonary epithelium, hepatocytes, and adipocytes (Chen et al., 2009; Meyer et al., 2009; Seto et al., 2011). Above all, most transcription factors are known to act as activators or repressors [summarized in (Whitington et al., 2011)]. One example is the nuclear transcription factor $\mathrm{Y}$ (NFY). NFY has been shown to function as an activator or as a repressor, depending on its DNA binding site (Bertagna and Jahroudi, 2001; Peng and Jahroudi, 2002). As an activator, NFY binds to its well-known consensus sequence CCAAT (Mantovani, 1998) but, as an repressor, NFY interacts with the binding site CCGNNNCCC (Peng and Jahroudi, 2002). Similar to NFY, BCL6 can possibly act as an activator for Oat1/OAT1 and Oat3/OAT3 transcription, due to so far unknown and therefore not predicted 


\section{Discussion}

DNA-binding sites (figure 4.2A). As a reason of periodically matrix updates of MatInspector software, additional BCL6 binding sites could be predicted, which also have to be investigated.

Due to its N-terminal protein binding domain or, additionally, via its C-terminal DNA-binding domain, BCL6 is able to interact with other proteins (Lemercier et al., 2002; Mascle et al., 2003; Costoya, 2007). Therefore protein-protein interaction between BCL6 and a second transcription factor, which is directly bound to the respectively promoters, is suggested to be involved in the BCL6-dependent activation of rat and human Oat1/OAT1 and Oat3/OAT3 transcription. In this connection, BCL6 could either interact and enhance a transcriptional activator, or inhibit a transcriptional repressor (figure 4.2B and $\mathrm{C}$ ). One possible interacting factor might be the nuclear factor kappa-light-chain-enhancer of activated B-cells (NFkB). At the posttranscriptional level, BCL6 has been shown to repress NFאB activity due to a proteinprotein interaction (Perez-Rosado et al., 2008). In renal ischemic rats, expression of renal Oat1 and Oat3 was decreased (Schneider et al., 2007), and the renal expression of NFkB was increased (Gabr et al., 2011). Hence, it is possible that male-dominant BCL6 inactivates NFkB, leading indirectly to the higher Oat1 and Oat3 expression in males compared to females. Similar to rats, human kidneys and especially proximal tubule cells showed endogenous NFкB expression (Miki et al., 1994a; Miki et al., 1994b; Broadbelt et al., 2009), leading NFאB to a potential BCL6-interacting partner in the regulation of rat and human Oat1/OAT1 and Oat3/OAT3 transcription.

Additionally, the transcription factors HNF1 and CREB are promising interaction partners in the BCL6-dependent activation of rat and human Oat1/OAT1 and Oat3/OAT3 transcription. In silico analyses of determined minimal promoter regions of OAT1 and OAT3, which contained no BCL6-binding site, predicted several binding sites for HNF1 and CREB in both promoters. HNF1 and CREB are known to be involved in the regulation of Oats/OATs expression. The mouse and human Oat1/OAT1 promoter was shown to be activated by HNF1 with the functional response element located at -56 to $-44 \mathrm{bp}$ (Saji et al., 2008). This functional HNF1 binding site lies within our determined minimal promoter region ( -63 to $+1 \mathrm{bp}$ ) for BCL6dependent OAT1 activation. The promoter of human OAT3 is activated via a functional cAMP-response element located at -87 to -80 bp (Ogasawara et al., 2006), and by HNF1 with the active response element located at -65 to -53 bp (Kikuchi et al., 2006). Binding sites for both transcription factors are positioned within our identified minimal promoter region of OAT3 (-112 to -59 bp). Furthermore, analysis of BCL6 interacting proteins by tandem mass spectrometry in a BCL6 expressing human B-cell lymphoma cell line, revealed HNF1 as a 90 
direct interacting partner of BCL6 (Miles et al., 2005). Except for HNF1 and CREB, also binding sites for BCDF (bicoid-like homeodomain transcription factor), and MYBL (cellular and viral myb-like transcriptional regulator) were predicted within both, the OAT1 and OAT3 minimal promoter region. So far BCDF and MYLB have not been linked to transcriptional regulation of Oats/OATs, but their possible involvement cannot be generally excluded. Interestingly, to strengthen our suggestion of a common transcription factor which interacts with BCL6 and is therefore involved in the BCL6-dependent activation of rat and human Oat1/OAT1 and Oat3/OAT3, binding sites for HNF1 and CREB were also predicted in the promoters of rat Oat1 (-1226/-1) and Oat3 (-444/-1) (data not shown).

Focusing on the involvement of a second transcription factor in the BCL6-dependent activation of rat and human Oat1/OAT1 and Oat3/OAT3 promoters, one additional mechanism is assumed. BCL6 binds and activates the promoter of a certain activator, such as HNF1 or CREB, which then itself binds to their respectively promoters, thereby initiating the transcription of Oat1/OAT1 and Oat3/OAT3 (figure 4.2D). In addition, BCL6 can also bind to a certain promoter, thereby inhibiting the expression of a repressor, which is then no longer able to bind to the rat and human Oat1/OAT1 and Oat3/OAT3 promoters, resulting in an increased transcription (figure 4.2E). In both cases, BCL6 does not directly bind to the Oat1/OAT1 and Oat3/OAT3 promoters, but indirectly regulates their expression. One possible involved repressor might be the liver $\mathrm{X}$ receptor (LXR), which is a ligand activated transcription factor, consisting of the two isoforms $\operatorname{LXR} \alpha$ and $\operatorname{LXR} \beta$, both expressed in the kidneys (Willy et al., 1995; Morello et al., 2005; Wang et al., 2005; Baranowski, 2008; Kittayaruksakul et al., 2011). Upon ligand binding, LXR forms heterodimers with the retinoic $\mathrm{X}$ receptors (RXRs), and subsequently binds to their respective promoter response elements, regulating target gene transcription (Morello et al., 2005; Baranowski, 2008). For the human OAT1 expression a down regulation by the activated liver $\mathrm{X}$ receptor has been published (Kittayaruksakul et al., 2011). 
A)

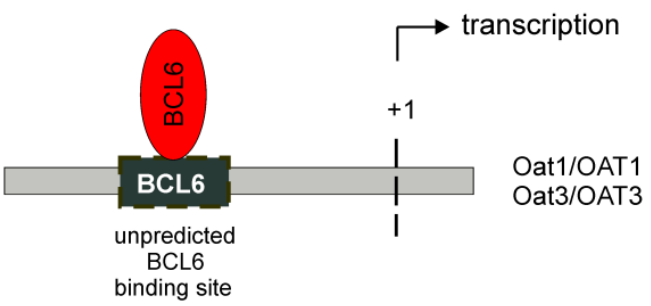

B)

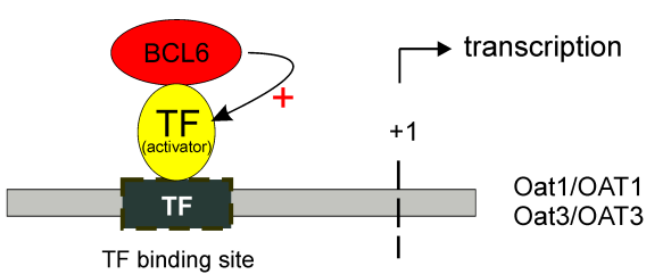

D)

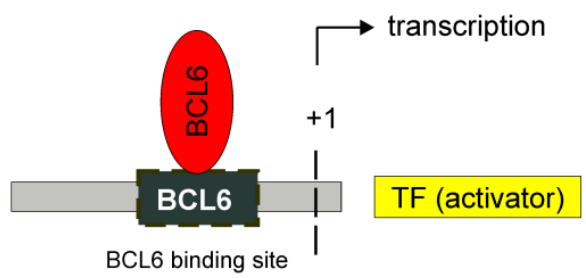

E)

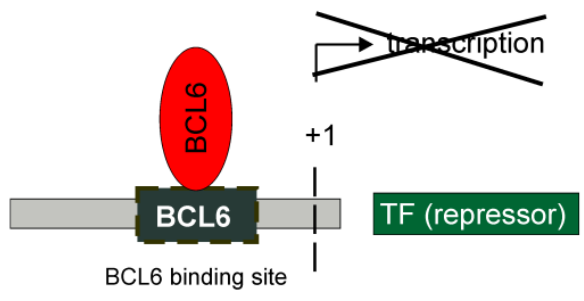

C)
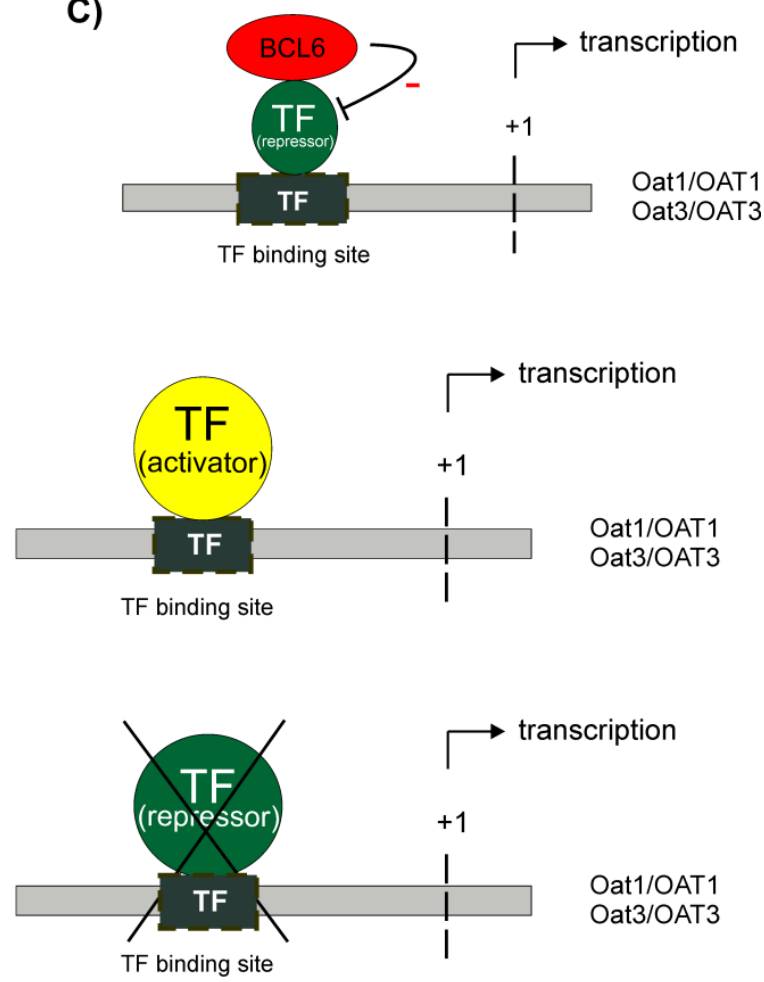

Figure 4.2: Mechanism by which BCL6 possibly activates the transcription of rat and human Oat1/OAT1 and Oat3/OAT3. A: BCL6 activates the transcription via binding to so far not predicted BCL6 binding sites. B: Transcription factor BCL6 binds to a hitherto unknown transcriptional factor (TF), which is an activator and enhance its function, leading to the activation of transcription C: BCL6 binds to an unknown suppressor and block its function, resulting in the expression of Oats/OATs D: BCL6 activates the expression of an activator, which then binds to the promoter of Oat1/OAT1 and Oat3/OAT3, and initiates their expression. C: BCL6 represses the transcription of a certain repressor, which then is no longer able to bind the promoter of Oat1/OAT1 and Oat3/OAT3, thereby leading to their transcription.

In summary, rat and human Oat1/OAT1 and Oat3/OAT3 promoters were shown to be activated by BCL6, however this activation was not mediated via so far predicted BCL6 binding sites. At least in rats, BCL6 was demonstrated to be involved in the regulation of male-dominantly expressed Oat1 and Oat3. Beside our identified male-dominant BCL6 expression in rat proximal tubule cells, similar sex-dependent expression has been reported in rat hepatocytes (Meyer et al., 2009). Due to the fact, that BCL6 is also expressed in heart, brain, spleen, lung, skeletal, and muscle (Miki et al., 1994a; Miki et al., 1994b; Allman et al., 1996; Bajalica-Lagercrantz et al., 1998) sex-dependent expression in other organs except for 92 
liver and kidneys might be possible. In some of these organs such as liver, brain, and skeletal muscle, Oat1/OAT1 and Oat3/OAT3 expression has been reported (Cihlar et al., 1999; Hosoyamada et al., 1999; Kusuhara et al., 1999; Sweet et al., 1999; Cha et al., 2001; Buist and Klaassen, 2004; Nishimura and Naito, 2005; Bleasby et al., 2006). Therefore, the impact of BCL6 in the regulation of Oats/OTAs is supposed to be not restricted to the kidneys. Moreover, beside the Oats/OATs, BCL6 might be involved in the transcriptional regulation of other members of the SLC22 family. 


\section{Conclusions and Outlook}

The results of my thesis revealed that the known male-dominant and testosterone-dependent expression of rat renal Oat1 and Oat3 was not regulated via the testosterone/androgen receptor mediated transcriptional pathway. Furthermore, predicted androgen response elements localized in the promoter regions of human OAT1 and OAT3 were not functional, indicating the absence of a direct testosterone/androgen receptor complex involvement in their promoter activation.

This work was the first report of sex-dependent BCL6 expression in rat proximal tubule cells, demonstrating a clearly higher expression in males compared to females. BCL6 activated the promoters of rat and human Oat1/OAT1 and Oat3/OAT3 assumed to regulate their sexdependent expression. BCL6-dependent promoter activation was not mediated via so far predicted BCL6 binding sites. The previously described Oats/OATs transcriptional regulators HNF1 $\alpha, \mathrm{HNF} 1 \beta$, and HNF4 $\alpha$ showed not sex-dependent expression. After the alignment of functional characterized response elements with our identified minimal promoter regions of rat and human Oat1/OAT1 and Oat3/OAT3 promoters, the transcription factors HNF1 and CREB were identified as promising BCL6-interacting partners in the activation of rat and human Oat1/OAT1 and Oat3/OAT3 transcription.

In future, to elucidate the exact mechanism by which BCL6 activates the promoters of rat and human Oat1/OAT1 and Oat3/OAT3, closer consideration of the supposed protein-protein interaction by tandem mass spectrometry will provide more information. Mutation of the suggested HNF1 and CREB binding sites and their impact in the BCL6-dependet promoter activation of rat and human Oat1/OAT1 and Oat3/OAT3 will be needed to closer examine their involvement. Beside the more precisely defined research of rat and human Oat1/OAT1 and Oat3/OAT3 transcriptional regulation, the investigation/confirmation of sex-dependent OAT1 and OAT3 expression in humans is urgently required. 


\section{Bibliography}

Ahn SY and Nigam SK (2009) Toward a systems level understanding of organic anion and other multispecific drug transporters: a remote sensing and signaling hypothesis. Mol Pharmacol 76:481-490.

Aktories K, Förstermann U, Hofmann F and Starke K (2010) Allgemeine und spezielle Pharmakologie und Toxikologie, Elservier GmbH, Urban \& Fischer Verlag, 10. Auflage

Albagli O, Lantoine D, Quief S, Quignon F, Englert C, Kerckaert JP, Montarras D, Pinset C and Lindon C (1999) Overexpressed BCL6 (LAZ3) oncoprotein triggers apoptosis, delays $\mathrm{S}$ phase progression and associates with replication foci. Oncogene 18:50635075 .

Albagli O, Lindon C, Lantoine D, Quief S, Puvion E, Pinset C and Puvion-Dutilleul F (2000) DNA replication progresses on the periphery of nuclear aggregates formed by the BCL6 transcription factor. Mol Cell Biol 20:8560-8570.

Allman D, Jain A, Dent A, Maile RR, Selvaggi T, Kehry MR and Staudt LM (1996) BCL-6 expression during B-cell activation. Blood 87:5257-5268.

Andersson S, Bishop RW and Russell DW (1989) Expression cloning and regulation of steroid 5 alpha-reductase, an enzyme essential for male sexual differentiation. $J$ Biol Chem 264:16249-16255.

Asaka J, Terada T, Okuda M, Katsura T and Inui K (2006) Androgen receptor is responsible for rat organic cation transporter 2 gene regulation but not for rOCT1 and rOCT3. Pharm Res 23:697-704.

Asif AR, Steffgen J, Metten M, Grunewald RW, Muller GA, Bahn A, Burckhardt G and Hagos Y (2005) Presence of organic anion transporters 3 (OAT3) and 4 (OAT4) in human adrenocortical cells. Pflugers Arch 450:88-95.

Askew EB, Gampe RT, Jr., Stanley TB, Faggart JL and Wilson EM (2007) Modulation of androgen receptor activation function 2 by testosterone and dihydrotestosterone. $\mathrm{J}$ Biol Chem 282:25801-25816.

Augustine LM, Markelewicz RJ, Jr., Boekelheide K and Cherrington NJ (2005) Xenobiotic and endobiotic transporter mRNA expression in the blood-testis barrier. Drug Metab Dispos 33:182-189.

Bahn A, Ebbinghaus C, Ebbinghaus D, Ponimaskin EG, Fuzesi L, Burckhardt G and Hagos Y (2004) Expression studies and functional characterization of renal human organic anion transporter 1 isoforms. Drug Metab Dispos 32:424-430.

Bahn A, Knabe M, Hagos Y, Rodiger M, Godehardt S, Graber-Neufeld DS, Evans KK, Burckhardt $\mathrm{G}$ and Wright SH (2002) Interaction of the metal chelator 2,3-dimercapto- 
1-propanesulfonate with the rabbit multispecific organic anion transporter 1 (rbOAT1). Mol Pharmacol 62:1128-1136.

Bahn A, Prawitt D, Buttler D, Reid G, Enklaar T, Wolff NA, Ebbinghaus C, Hillemann A, Schulten HJ, Gunawan B, Fuzesi L, Zabel B and Burckhardt G (2000) Genomic structure and in vivo expression of the human organic anion transporter 1 (hOAT1) gene. Biochem Biophys Res Commun 275:623-630.

Bain DL, Heneghan AF, Connaghan-Jones KD and Miura MT (2007) Nuclear receptor structure: implications for function. Annu Rev Physiol 69:201-220.

Bajalica-Lagercrantz S, Piehl F, Farnebo F, Larsson C and Lagercrantz J (1998) Expression of the BCL6 gene in the pre- and postnatal mouse. Biochem Biophys Res Commun 247:357-360.

Bakhiya A, Bahn A, Burckhardt G and Wolff N (2003) Human organic anion transporter 3 (hOAT3) can operate as an exchanger and mediate secretory urate flux. Cell Physiol Biochem 13:249-256.

Baranowski M (2008) Biological role of liver X receptors. J Physiol Pharmacol 59 Suppl $7: 31-55$.

Baron BW, Anastasi J, Thirman MJ, Furukawa Y, Fears S, Kim DC, Simone F, Birkenbach M, Montag A, Sadhu A, Zeleznik-Le N and McKeithan TW (2002) The human programmed cell death-2 (PDCD2) gene is a target of BCL6 repression: implications for a role of BCL6 in the down-regulation of apoptosis. Proc Natl Acad Sci U S A 99:2860-2865.

Baron BW, Hyjek E, Gladstone B, Thirman MJ and Baron JM (2010) PDCD2, a protein whose expression is repressed by BCL6, induces apoptosis in human cells by activation of the caspase cascade. Blood Cells Mol Dis 45:169-175.

Baron BW, Zeleznik-Le N, Baron MJ, Theisler C, Huo D, Krasowski MD, Thirman MJ, Baron RM and Baron JM (2007) Repression of the PDCD2 gene by BCL6 and the implications for the pathogenesis of human B and T cell lymphomas. Proc Natl Acad Sci U S A 104:7449-7454.

Barros SA, Srimaroeng C, Perry JL, Walden R, Dembla-Rajpal N, Sweet DH and Pritchard JB (2009) Activation of protein kinase Czeta increases OAT1 (SLC22A6)- and OAT3 (SLC22A8)-mediated transport. J Biol Chem 284:2672-2679.

Basso K and Dalla-Favera R (2012) Roles of BCL6 in normal and transformed germinal center B cells. Immunol Rev 247:172-183.

Baumann M, Pontiller J and Ernst W (2010) Structure and basal transcription complex of RNA polymerase II core promoters in the mammalian genome: an overview. Mol Biotechnol 45:241-247.

Beato M (1989) Gene regulation by steroid hormones. Cell 56:335-344. 
Benjamini Y and Hochberg Y (1995) Controlling the false discovery rate: A practical and powerful approach to multiple testing. Journal of the Royal Statistical Society B 57:289-300.

Bereshchenko OR, Gu W and Dalla-Favera R (2002) Acetylation inactivates the transcriptional repressor BCL6. Nat Genet 32:606-613.

Bertagna A and Jahroudi N (2001) The NFY transcription factor mediates induction of the von Willebrand factor promoter by irradiation. Thromb Haemost 85:837-844.

Bleasby K, Castle JC, Roberts CJ, Cheng C, Bailey WJ, Sina JF, Kulkarni AV, Hafey MJ, Evers R, Johnson JM, Ulrich RG and Slatter JG (2006) Expression profiles of 50 xenobiotic transporter genes in humans and pre-clinical species: a resource for investigations into drug disposition. Xenobiotica 36:963-988.

Bradford MM (1976) A rapid and sensitive method for the quantitation of microgram quantities of protein utilizing the principle of protein-dye binding. Anal Biochem $72: 248-254$.

Brady KP, Dushkin H, Fornzler D, Koike T, Magner F, Her H, Gullans S, Segre GV, Green RM and Beier DR (1999) A novel putative transporter maps to the osteosclerosis (oc) mutation and is not expressed in the oc mutant mouse. Genomics 56:254-261.

Breithaupt H (2012) The science of sex. EMBO Rep 13:394.

Broadbelt NV, Chen J, Silver RB, Poppas DP and Felsen D (2009) Pressure activates epidermal growth factor receptor leading to the induction of iNOS via NFkappaB and STAT3 in human proximal tubule cells. Am J Physiol Renal Physiol 297:F114-124.

Buist SC, Cherrington NJ, Choudhuri S, Hartley DP and Klaassen CD (2002) Gender-specific and developmental influences on the expression of rat organic anion transporters. J Pharmacol Exp Ther 301:145-151.

Buist SC, Cherrington NJ and Klaassen CD (2003) Endocrine regulation of rat organic anion transporters. Drug Metab Dispos 31:559-564.

Buist SC and Klaassen CD (2004) Rat and mouse differences in gender-predominant expression of organic anion transporter (Oat1-3; Slc22a6-8) mRNA levels. Drug Metab Dispos 32:620-625.

Burckhardt BC and Burckhardt G (2003) Transport of organic anions across the basolateral membrane of proximal tubule cells. Rev Physiol Biochem Pharmacol 146:95-158.

Burckhardt G (2012) Drug transport by Organic Anion Transporters (OATs). Pharmacol Ther 136:106-130.

Burckhardt G and Burckhardt BC (2011) In vitro and in vivo evidence of the importance of organic anion transporters (OATs) in drug therapy, in: Drug Transporters (Fromm MF, Kim RB and SpringerLink (Online service) eds), pp 29-104, Springer-Verlag Berlin Heidelberg, Berlin, Heidelberg. 
Bibliography

Carson C, 3rd and Rittmaster R (2003) The role of dihydrotestosterone in benign prostatic hyperplasia. Urology 61:2-7.

Cattoretti G, Chang CC, Cechova K, Zhang J, Ye BH, Falini B, Louie DC, Offit K, Chaganti RS and Dalla-Favera R (1995) BCL-6 protein is expressed in germinal-center B cells. Blood 86:45-53.

Cerrutti JA, Brandoni A, Quaglia NB and Torres AM (2002) Sex differences in p-aminohippuric acid transport in rat kidney: role of membrane fluidity and expression of OAT1. Mol Cell Biochem 233:175-179.

Cha SH, Sekine T, Fukushima JI, Kanai Y, Kobayashi Y, Goya T and Endou H (2001) Identification and characterization of human organic anion transporter 3 expressing predominantly in the kidney. Mol Pharmacol 59:1277-1286.

Cha SH, Sekine T, Kusuhara H, Yu E, Kim JY, Kim DK, Sugiyama Y, Kanai Y and Endou H (2000) Molecular cloning and characterization of multispecific organic anion transporter 4 expressed in the placenta. J Biol Chem 275:4507-4512.

Chabardes-Garonne D, Mejean A, Aude JC, Cheval L, Di Stefano A, Gaillard MC, ImbertTeboul M, Wittner M, Balian C, Anthouard V, Robert C, Segurens B, Wincker P, Weissenbach J, Doucet A and Elalouf JM (2003) A panoramic view of gene expression in the human kidney. Proc Natl Acad Sci U S A 100:13710-13715.

Chamberlain NL, Whitacre DC and Miesfeld RL (1996) Delineation of two distinct type 1 activation functions in the androgen receptor amino-terminal domain. $J$ Biol Chem 271:26772-26778.

Chang CC, Ye BH, Chaganti RS and Dalla-Favera R (1996) BCL-6, a POZ/zinc-finger protein, is a sequence-specific transcriptional repressor. Proc Natl Acad Sci U $S$ 93:6947-6952.

Chen CD, Welsbie DS, Tran C, Baek SH, Chen R, Vessella R, Rosenfeld MG and Sawyers CL (2004) Molecular determinants of resistance to antiandrogen therapy. Nat Med 10:33-39.

Chen J, Terada T, Ogasawara K, Katsura T and Inui K (2008) Adaptive responses of renal organic anion transporter 3 (OAT3) during cholestasis. Am J Physiol Renal Physiol 295:F247-252.

Chen Y, Lin G, Huo JS, Barney D, Wang Z, Livshiz T, States DJ, Qin ZS and Schwartz J (2009) Computational and functional analysis of growth hormone $(\mathrm{GH})$-regulated genes identifies the transcriptional repressor B-cell lymphoma 6 (Bc16) as a participant in GH-regulated transcription. Endocrinology 150:3645-3654.

Cihlar T, Lin DC, Pritchard JB, Fuller MD, Mendel DB and Sweet DH (1999) The antiviral nucleotide analogs cidofovir and adefovir are novel substrates for human and rat renal organic anion transporter 1. Mol Pharmacol 56:570-580. 
Claessens F, Denayer S, Van Tilborgh N, Kerkhofs S, Helsen C and Haelens A (2008) Diverse roles of androgen receptor (AR) domains in AR-mediated signaling. $\mathrm{Nucl}$ Recept Signal 6:e008.

Cleutjens KB, van Eekelen CC, van der Korput HA, Brinkmann AO and Trapman J (1996) Two androgen response regions cooperate in steroid hormone regulated activity of the prostate-specific antigen promoter. J Biol Chem 271:6379-6388.

Costoya JA (2007) Functional analysis of the role of POK transcriptional repressors. Brief Funct Genomic Proteomic 6:8-18.

Danielian PS, White R, Lees JA and Parker MG (1992) Identification of a conserved region required for hormone dependent transcriptional activation by steroid hormone receptors. EMBO J 11:1025-1033.

Dantzler WH (2002) Renal organic anion transport: a comparative and cellular perspective. Biochim Biophys Acta 1566:169-181.

Dean J, Hashimoto K, Tsuji T, Gautier V, Hall WW and Sheehy N (2009) Functional interaction of HTLV-1 tax protein with the POZ domain of the transcriptional repressor BCL6. Oncogene 28:3723-3734.

Denayer S, Helsen C, Thorrez L, Haelens A and Claessens F (2010) The rules of DNA recognition by the androgen receptor. Mol Endocrinol 24:898-913.

Dent AL, Vasanwala FH and Toney LM (2002) Regulation of gene expression by the protooncogene BCL-6. Crit Rev Oncol Hematol 41:1-9.

Dhordain P, Albagli O, Lin RJ, Ansieau S, Quief S, Leutz A, Kerckaert JP, Evans RM and Leprince D (1997) Corepressor SMRT binds the BTB/POZ repressing domain of the LAZ3/BCL6 oncoprotein. Proc Natl Acad Sci U S A 94:10762-10767.

Duan P, Li S and You G (2009) Angiotensin II inhibits activity of human organic anion transporter 3 through activation of protein kinase Calpha: accelerating endocytosis of the transporter. Eur J Pharmacol 627:49-55.

Ekaratanawong S, Anzai N, Jutabha P, Miyazaki H, Noshiro R, Takeda M, Kanai Y, Sophasan S and Endou H (2004) Human organic anion transporter 4 is a renal apical organic anion/dicarboxylate exchanger in the proximal tubules. J Pharmacol Sci 94:297-304.

Enomoto A, Kimura H, Chairoungdua A, Shigeta Y, Jutabha P, Cha SH, Hosoyamada M, Takeda M, Sekine T, Igarashi T, Matsuo H, Kikuchi Y, Oda T, Ichida K, Hosoya T, Shimokata K, Niwa T, Kanai Y and Endou H (2002a) Molecular identification of a renal urate anion exchanger that regulates blood urate levels. Nature 417:447-452.

Enomoto A, Takeda M, Shimoda M, Narikawa S, Kobayashi Y, Yamamoto T, Sekine T, Cha SH, Niwa T and Endou H (2002b) Interaction of human organic anion transporters 2 and 4 with organic anion transport inhibitors. J Pharmacol Exp Ther 301:797-802. 
Eraly SA, Vallon V, Vaughn DA, Gangoiti JA, Richter K, Nagle M, Monte JC, Rieg T, Truong DM, Long JM, Barshop BA, Kaler G and Nigam SK (2006) Decreased renal organic anion secretion and plasma accumulation of endogenous organic anions in OAT1 knock-out mice. J Biol Chem 281:5072-5083.

Farla P, Hersmus R, Trapman J and Houtsmuller AB (2005) Antiandrogens prevent stable DNA-binding of the androgen receptor. J Cell Sci 118:4187-4198.

FDA (homepage) http://www.fda.gov/.

Feng B, Dresser MJ, Shu Y, Johns SJ and Giacomini KM (2001) Arginine 454 and lysine 370 are essential for the anion specificity of the organic anion transporter, rOAT3. Biochemistry 40:5511-5520.

Fix C, Jordan C, Cano P and Walker WH (2004) Testosterone activates mitogen-activated protein kinase and the cAMP response element binding protein transcription factor in Sertoli cells. Proc Natl Acad Sci U S A 101:10919-10924.

Franconi F, Brunelleschi S, Steardo L and Cuomo V (2007) Gender differences in drug responses. Pharmacol Res 55:81-95.

Gabr MM, Hussein AM, Sherif IO, Ali SI and Mohamed HE (2011) Renal ischemia /reperfusion injury in type II DM: Possible role of proinflammatory cytokines, apoptosis, and nitric oxide. J Physiol Pathophysiol 2:6-17.

Gandhi M, Aweeka F, Greenblatt RM and Blaschke TF (2004) Sex differences in pharmacokinetics and pharmacodynamics. Annu Rev Pharmacol Toxicol 44:499-523.

Garcia JF, Maestre L, Lucas E, Sanchez-Verde L, Romero-Chala S, Piris MA and Roncador G (2006) Genetic immunization: a new monoclonal antibody for the detection of BCL-6 protein in paraffin sections. J Histochem Cytochem 54:31-38.

Gelmann EP (2002) Molecular biology of the androgen receptor. J Clin Oncol 20:3001-3015.

Genestie I, Morin JP, Vannier B and Lorenzon G (1995) Polarity and transport properties of rabbit kidney proximal tubule cells on collagen IV-coated porous membranes. Am J Physiol 269:F22-30.

George RL, Wu X, Huang W, Fei YJ, Leibach FH and Ganapathy V (1999) Molecular cloning and functional characterization of a polyspecific organic anion transporter from Caenorhabditis elegans. J Pharmacol Exp Ther 291:596-603.

Giacomini KM, Huang SM, Tweedie DJ, Benet LZ, Brouwer KL, Chu X, Dahlin A, Evers R, Fischer V, Hillgren KM, Hoffmaster KA, Ishikawa T, Keppler D, Kim RB, Lee CA, Niemi M, Polli JW, Sugiyama Y, Swaan PW, Ware JA, Wright SH, Yee SW, ZamekGliszczynski MJ and Zhang L (2010) Membrane transporters in drug development. Nat Rev Drug Discov 9:215-236.

Hagos Y, Bahn A, Asif AR, Krick W, Sendler M and Burckhardt G (2002) Cloning of the pig renal organic anion transporter 1 (pOAT1). Biochimie 84:1221-1224. 
Hagos Y, Braun IM, Krick W, Burckhardt G and Bahn A (2005) Functional expression of pig renal organic anion transporter 3 (pOAT3). Biochimie 87:421-424.

Hagos Y and Wolff NA (2010) Assessment of the role of renal organic anion transporters in drug-induced nephrotoxicity. Toxins (Basel) 2:2055-2082.

Hasannejad H, Takeda M, Taki K, Shin HJ, Babu E, Jutabha P, Khamdang S, Aleboyeh M, Onozato ML, Tojo A, Enomoto A, Anzai N, Narikawa S, Huang XL, Niwa T and Endou H (2004) Interactions of human organic anion transporters with diuretics. J Pharmacol Exp Ther 308:1021-1029.

Hasegawa M, Kusuhara H, Endou H and Sugiyama Y (2003) Contribution of organic anion transporters to the renal uptake of anionic compounds and nucleoside derivatives in rat. J Pharmacol Exp Ther 305:1087-1097.

Hasegawa M, Kusuhara H, Sugiyama D, Ito K, Ueda S, Endou H and Sugiyama Y (2002) Functional involvement of rat organic anion transporter 3 (rOat3; Slc22a8) in the renal uptake of organic anions. J Pharmacol Exp Ther 300:746-753.

Hazelhoff MH, Bulacio RP and Torres AM (2012) Gender related differences in kidney injury induced by mercury. Int J Mol Sci 13:10523-10536.

Hediger MA, Romero MF, Peng JB, Rolfs A, Takanaga H and Bruford EA (2004) The ABCs of solute carriers: physiological, pathological and therapeutic implications of human membrane transport proteinsIntroduction. Pflugers Arch 447:465-468.

Heemers HV and Tindall DJ (2007) Androgen receptor (AR) coregulators: a diversity of functions converging on and regulating the AR transcriptional complex. Endocr Rev 28:778-808.

Heidenhain R (1874) Versuche über den Vorgang der Harnabsonderung. Plügers Arch 9:1-27.

Heidrich HG, Kinne R, Kinne-Saffran E and Hannig K (1972) The polarity of the proximal tubule cell in rat kidney. Different surface charges for the brush-border microvilli and plasma membranes from the basal infoldings. J Cell Biol 54:232-245.

Henshall SM, Quinn DI, Lee CS, Head DR, Golovsky D, Brenner PC, Delprado W, Stricker PD, Grygiel JJ and Sutherland RL (2001) Altered expression of androgen receptor in the malignant epithelium and adjacent stroma is associated with early relapse in prostate cancer. Cancer Res 61:423-427.

Hering-Smith KS, Schiro FR, Pajor AM and Hamm LL (2011) Calcium sensitivity of dicarboxylate transport in cultured proximal tubule cells. Am J Physiol Renal Physiol 300:F425-432.

Hilgendorf C, Ahlin G, Seithel A, Artursson P, Ungell AL and Karlsson J (2007) Expression of thirty-six drug transporter genes in human intestine, liver, kidney, and organotypic cell lines. Drug Metab Dispos 35:1333-1340. 
Ho ES, Lin DC, Mendel DB and Cihlar T (2000) Cytotoxicity of antiviral nucleotides adefovir and cidofovir is induced by the expression of human renal organic anion transporter 1. J Am Soc Nephrol 11:383-393.

Hohmann B, Frohnert PP, Kinne R and Baumann K (1974) Proximal tubular lactate transport in rat kidney: a micropuncture study. Kidney Int 5:261-270.

Holtzman EJ, Kinane TB, West K, Soper BW, Karga H, Ausiello DA and Ercolani L (1993) Transcriptional regulation of G-protein alpha i subunit genes in LLC-PK1 renal cells and characterization of the porcine G alpha 1-3 gene promoter. J Biol Chem 268:39643975 .

Hori R, Okamura M, Takayama A, Hirozane K and Takano M (1993) Transport of organic anion in the OK kidney epithelial cell line. Am J Physiol 264:F975-980.

Hosoyamada M, Sekine T, Kanai Y and Endou H (1999) Molecular cloning and functional expression of a multispecific organic anion transporter from human kidney. Am J Physiol 276:F122-128.

Huang KC and McIntosh BJ (1955) Effect of sex hormones on renal transport of p-aminohippuric acid. Am J Physiol 183:387-390.

Huynh KD and Bardwell VJ (1998) The BCL-6 POZ domain and other POZ domains interact with the co-repressors N-CoR and SMRT. Oncogene 17:2473-2484.

Huynh KD, Fischle W, Verdin E and Bardwell VJ (2000) BCoR, a novel corepressor involved in BCL-6 repression. Genes Dev 14:1810-1823.

Ichida K, Hosoyamada M, Kimura H, Takeda M, Utsunomiya $\mathrm{Y}$, Hosoya $\mathrm{T}$ and Endou $\mathrm{H}$ (2003) Urate transport via human PAH transporter hOAT1 and its gene structure. Kidney Int 63:143-155.

Ichii H, Sakamoto A, Hatano M, Okada S, Toyama H, Taki S, Arima M, Kuroda Y and Tokuhisa T (2002) Role for Bcl-6 in the generation and maintenance of memory CD8+ T cells. Nat Immunol 3:558-563.

Jacobsson JA, Haitina T, Lindblom J and Fredriksson R (2007) Identification of six putative human transporters with structural similarity to the drug transporter SLC22 family. Genomics 90:595-609.

Jariyawat S, Sekine T, Takeda M, Apiwattanakul N, Kanai Y, Sophasan S and Endou H (1999) The interaction and transport of beta-lactam antibiotics with the cloned rat renal organic anion transporter 1. J Pharmacol Exp Ther 290:672-677.

Jenkins EP, Andersson S, Imperato-McGinley J, Wilson JD and Russell DW (1992) Genetic and pharmacological evidence for more than one human steroid 5 alpha-reductase. J Clin Invest 89:293-300. 
Jenster G, van der Korput HA, Trapman J and Brinkmann AO (1995) Identification of two transcription activation units in the $\mathrm{N}$-terminal domain of the human androgen receptor. J Biol Chem 270:7341-7346.

Jiang S, Tanaka T, Iwanari H, Hotta H, Yamashita H, Kumakura J, Watanabe Y, Uchiyama Y, Aburatani H, Hamakubo T, Kodama T and Naito M (2003) Expression and localization of P1 promoter-driven hepatocyte nuclear factor-4alpha (HNF4alpha) isoforms in human and rats. Nucl Recept 1:5.

Jin L, Kikuchi R, Saji T, Kusuhara H and Sugiyama Y (2011) Regulation of tissue-specific expression of renal organic anion transporters by hepatocyte nuclear factor 1 alpha/beta and DNA methylation. J Pharmacol Exp Ther 340:648-655.

Jørgensen PL (1980) Sodium and potassium ion pump in kidney tubules. Physiol Rev 60:864917.

Jung KY, Takeda M, Kim DK, Tojo A, Narikawa S, Yoo BS, Hosoyamada M, Cha SH, Sekine T and Endou H (2001) Characterization of ochratoxin A transport by human organic anion transporters. Life Sci 69:2123-2135.

Jung KY, Takeda M, Shimoda M, Narikawa S, Tojo A, Kim DK, Chairoungdua A, Choi BK, Kusuhara H, Sugiyama Y, Sekine T and Endou H (2002) Involvement of rat organic anion transporter 3 (rOAT3) in cephaloridine-induced nephrotoxicity: in comparison with rOAT1. Life Sci 70:1861-1874.

Kashgarian M, Biemesderfer D, Caplan M and Forbush B, 3rd (1985) Monoclonal antibody to $\mathrm{Na}, \mathrm{K}-\mathrm{ATPase}$ immunocytochemical localization along nephron segments. Kidney Int 28:899-913.

Kato Y, Kuge K, Kusuhara H, Meier PJ and Sugiyama Y (2002) Gender difference in the urinary excretion of organic anions in rats. J Pharmacol Exp Ther 302:483-489.

Kaufhold M, Schulz K, Breljak D, Gupta S, Henjakovic M, Krick W, Hagos Y, Sabolic I, Burckhardt BC and Burckhardt G (2011) Differential interaction of dicarboxylates with human sodium-dicarboxylate cotransporter 3 and organic anion transporters 1 and 3. Am J Physiol Renal Physiol 301:F1026-1034.

Kaulfuss S, Grzmil M, Hemmerlein B, Thelen P, Schweyer S, Neesen J, Bubendorf L, Glass AG, Jarry H, Auber B and Burfeind P (2008) Leupaxin, a novel coactivator of the androgen receptor, is expressed in prostate cancer and plays a role in adhesion and invasion of prostate carcinoma cells. Mol Endocrinol 22:1606-1621.

Kenneth NS, Marshall L and White RJ (2008) Recruitment of RNA polymerase III in vivo. Nucleic Acids Res 36:3757-3764.

Keppler D (2011) Multidrug resistance proteins (MRPs, ABCCs): importance for pathophysiology and drug therapy, in: Drug Transporters (Fromm MF and Kim RB eds), pp 299-323, Springer-Verlag Berlin Heidelberg, Berlin, Heidelberg. 
Bibliography

Khamdang S, Takeda M, Noshiro R, Narikawa S, Enomoto A, Anzai N, Piyachaturawat P and Endou H (2002) Interactions of human organic anion transporters and human organic cation transporters with nonsteroidal anti-inflammatory drugs. J Pharmacol Exp Ther 303:534-539.

Kikuchi R, Kusuhara H, Hattori N, Shiota K, Kim I, Gonzalez FJ and Sugiyama Y (2006) Regulation of the expression of human organic anion transporter 3 by hepatocyte nuclear factor $1 \alpha / \beta$ and DNA methylation. Mol Pharmacol 70:887-896.

Kim J and Coetzee GA (2004) Prostate specific antigen gene regulation by androgen receptor. J Cell Biochem 93:233-241.

Kimura H, Takeda M, Narikawa S, Enomoto A, Ichida K and Endou H (2002) Human organic anion transporters and human organic cation transporters mediate renal transport of prostaglandins. J Pharmacol Exp Ther 301:293-298.

Kittayaruksakul S, Soodvilai S, Asavapanumas N, Muanprasat C and Chatsudthipong V (2011) Liver X receptor activation downregulates organic anion transporter 1 (OAT1) in the renal proximal tubule. Am J Physiol Renal Physiol 302:F552-560.

Kleinman LI, Loewenstein MS and Goldstein L (1966) Sex difference in the transport of p-aminohippurate by the rat kidney. Endocrinology 78:403-406.

Klinke R, Pape H-C, Kurtz A and Silbernagel S (2010) Physiologie, Gerorg Thieme Verlag Stuttgart New York, 6. Auflage.

Kobayashi Y, Hirokawa N, Ohshiro N, Sekine T, Sasaki T, Tokuyama S, Endou H and Yamamoto T (2002) Differential gene expression of organic anion transporters in male and female rats. Biochem Biophys Res Commun 290:482-487.

Koepsell H and Endou H (2004) The SLC22 drug transporter family. Pflugers Arch 447:666676.

Koepsell H, Lips K and Volk C (2007) Polyspecific organic cation transporters: structure, function, physiological roles, and biopharmaceutical implications. Pharm Res 24:1227-1251.

Kojima R, Sekine T, Kawachi M, Cha SH, Suzuki Y and Endou H (2002) Immunolocalization of multispecific organic anion transporters, OAT1, OAT2, and OAT3, in rat kidney. J Am Soc Nephrol 13:848-857.

Koyama H, Goodpasture C, Miller MM, Teplitz RL and Riggs AD (1978) Establishment and characterization of a cell line from the American opossum (Didelphys virginiana). In Vitro 14:239-246.

Kurosu T, Fukuda T, Miki T and Miura O (2003) BCL6 overexpression prevents increase in reactive oxygen species and inhibits apoptosis induced by chemotherapeutic reagents in B-cell lymphoma cells. Oncogene 22:4459-4468. 
Kusuhara H, Sekine T, Utsunomiya-Tate N, Tsuda M, Kojima R, Cha SH, Sugiyama Y, Kanai Y and Endou H (1999) Molecular cloning and characterization of a new multispecific organic anion transporter from rat brain. J Biol Chem 274:13675-13680.

Lazzaro D, De Simone V, De Magistris L, Lehtonen E and Cortese R (1992) LFB1 and LFB3 homeoproteins are sequentially expressed during kidney development. Development 114:469-479.

Leazer TM and Klaassen CD (2003) The presence of xenobiotic transporters in rat placenta. Drug Metab Dispos 31:153-167.

Lee HJ and Chang C (2003) Recent advances in androgen receptor action. Cell Mol Life Sci 60:1613-1622.

Lemercier C, Brocard MP, Puvion-Dutilleul F, Kao HY, Albagli O and Khochbin S (2002) Class II histone deacetylases are directly recruited by BCL6 transcriptional repressor. J Biol Chem 277:22045-22052.

Li S, Duan P and You G (2010) Regulation of human organic anion transporter 3 by peptide hormone bradykinin. J Pharmacol Exp Ther 333:970-975.

Litvinov IV, Chang C and Isaacs JT (2004) Molecular characterization of the commonly used human androgen receptor expression vector, pSG5-AR. Prostate 58:319-324.

Livak KJ and Schmittgen TD (2001) Analysis of relative gene expression data using real-time quantitative PCR and the 2(-Delta Delta C(T)) Method. Methods 25:402-408.

Ljubojevic M, Herak-Kramberger CM, Hagos Y, Bahn A, Endou H, Burckhardt G and Sabolic I (2004) Rat renal cortical OAT1 and OAT3 exhibit gender differences determined by both androgen stimulation and estrogen inhibition. Am J Physiol Renal Physiol 287:F124-138.

Lonergan PE and Tindall DJ (2011) Androgen receptor signaling in prostate cancer development and progression. J Carcinog 10:20.

Lopez-Nieto CE, You G, Bush KT, Barros EJ, Beier DR and Nigam SK (1997) Molecular cloning and characterization of NKT, a gene product related to the organic cation transporter family that is almost exclusively expressed in the kidney. J Biol Chem 272:6471-6478.

Lu R, Chan BS and Schuster VL (1999a) Cloning of the human kidney PAH transporter: narrow substrate specificity and regulation by protein kinase C. Am J Physiol 276:F295-303.

Lu S, Liu M, Epner DE, Tsai SY and Tsai MJ (1999b) Androgen regulation of the cyclindependent kinase inhibitor p21 gene through an androgen response element in the proximal promoter. Mol Endocrinol 13:376-384.

Luu-The V (2001) Analysis and characteristics of multiple types of human 17betahydroxysteroid dehydrogenase. J Steroid Biochem Mol Biol 76:143-151. 
Bibliography

Maher JM, Slitt AL, Callaghan TN, Cheng X, Cheung C, Gonzalez FJ and Klaassen CD (2006) Alterations in transporter expression in liver, kidney, and duodenum after targeted disruption of the transcription factor HNF1alpha. Biochem Pharmacol 72:512-522.

Mantovani R (1998) A survey of 178 NF-Y binding CCAAT boxes. Nucleic Acids Res 26:1135-1143.

Marchais-Oberwinkler S, Henn C, Moller G, Klein T, Negri M, Oster A, Spadaro A, Werth R, Wetzel M, Xu K, Frotscher M, Hartmann RW and Adamski J (2011) 17betaHydroxysteroid dehydrogenases (17beta-HSDs) as therapeutic targets: protein structures, functions, and recent progress in inhibitor development. J Steroid Biochem Mol Biol 125:66-82.

Martel C, Rheaume E, Takahashi M, Trudel C, Couet J, Luu-The V, Simard J and Labrie F (1992) Distribution of 17 beta-hydroxysteroid dehydrogenase gene expression and activity in rat and human tissues. J Steroid Biochem Mol Biol 41:597-603.

Martin RM, Biswas PN, Freemantle SN, Pearce GL and Mann RD (1998) Age and sex distribution of suspected adverse drug reactions to newly marketed drugs in general practice in England: analysis of 48 cohort studies. Br J Clin Pharmacol 46:505-511.

Mascle X, Albagli O and Lemercier C (2003) Point mutations in BCL6 DNA-binding domain reveal distinct roles for the six zinc fingers. Biochem Biophys Res Commun 300:391396.

McKenna NJ, Lanz RB and O'Malley BW (1999a) Nuclear receptor coregulators: cellular and molecular biology. Endocr Rev 20:321-344.

McKenna NJ, Xu J, Nawaz Z, Tsai SY, Tsai MJ and O'Malley BW (1999b) Nuclear receptor coactivators: multiple enzymes, multiple complexes, multiple functions. J Steroid Biochem Mol Biol 69:3-12.

Mendel DB and Crabtree GR (1991) HNF-1, a member of a novel class of dimerizing homeodomain proteins. J Biol Chem 266:677-680.

Mendel DB, Hansen LP, Graves MK, Conley PB and Crabtree GR (1991) HNF-1 alpha and HNF-1 beta (vHNF-1) share dimerization and homeo domains, but not activation domains, and form heterodimers in vitro. Genes Dev 5:1042-1056.

Meyer RD, Laz EV, Su T and Waxman DJ (2009) Male-specific hepatic Bcl6: growth hormone-induced block of transcription elongation in females and binding to target genes inversely coordinated with STAT5. Mol Endocrinol 23:1914-1926.

Miki T, Kawamata N, Arai A, Ohashi K, Nakamura Y, Kato A, Hirosawa S and Aoki N (1994a) Molecular cloning of the breakpoint for 3q27 translocation in B-cell lymphomas and leukemias. Blood 83:217-222. 
Miki T, Kawamata N, Hirosawa S and Aoki N (1994b) Gene involved in the 3q27 translocation associated with B-cell lymphoma, BCL5, encodes a Kruppel-like zincfinger protein. Blood 83:26-32.

Miles RR, Crockett DK, Lim MS and Elenitoba-Johnson KS (2005) Analysis of BCL6interacting proteins by tandem mass spectrometry. Mol Cell Proteomics 4:1898-1909.

Miller VM (2012) In pursuit of scientific excellence: sex matters. Am J Physiol Renal Physiol 302:F1067-1068.

Morello F, de Boer RA, Steffensen KR, Gnecchi M, Chisholm JW, Boomsma F, Anderson LM, Lawn RM, Gustafsson JA, Lopez-Ilasaca M, Pratt RE and Dzau VJ (2005) Liver $\mathrm{X}$ receptors alpha and beta regulate renin expression in vivo. J Clin Invest 115:19131922.

Morris ME, Lee HJ and Predko LM (2003) Gender differences in the membrane transport of endogenous and exogenous compounds. Pharmacol Rev 55:229-240.

Motohashi H, Sakurai Y, Saito H, Masuda S, Urakami Y, Goto M, Fukatsu A, Ogawa O and Inui K (2002) Gene expression levels and immunolocalization of organic ion transporters in the human kidney. J Am Soc Nephrol 13:866-874.

Nagai J, Takano M, Hirozane K, Yasuhara M and Inui K (1995) Specificity of p-aminohippurate transport system in the OK kidney epithelial cell line. J Pharmacol Exp Ther 274:1161-1166.

Nieuwenhoven L and Klinge I (2010) Scientific excellence in applying sex- and gendersensitive methods in biomedical and health research. $J$ Womens Health (Larchmt) 19:313-321.

Nishimura M and Naito S (2005) Tissue-specific mRNA expression profiles of human ATPbinding cassette and solute carrier transporter superfamilies. Drug Metab Pharmacokinet 20:452-477.

Nozaki Y, Kusuhara H, Kondo T, Hasegawa M, Shiroyanagi Y, Nakazawa H, Okano T and Sugiyama Y (2007) Characterization of the uptake of organic anion transporter (OAT) 1 and OAT3 substrates by human kidney slices. J Pharmacol Exp Ther 321:362-369.

Ogasawara K, Terada T, Asaka J, Katsura T and Inui K (2006) Human organic anion transporter 3 gene is regulated constitutively and inducibly via a cAMP-response element. J Pharmacol Exp Ther 319:317-322.

Ogasawara K, Terada T, Asaka J, Katsura T and Inui K (2007) Hepatocyte nuclear factor-4 $\alpha$ regulates the human organic anion transporter 1 gene in the kidney. Am J Physiol Renal Physiol 292:F1819-1826.

Opitz L, Salinas-Riester G, Grade M, Jung K, Jo P, Emons G, Ghadimi BM, Beissbarth T and Gaedcke J (2010) Impact of RNA degradation on gene expression profiling. BMC Med Genomics 3:36. 
Oren I, Fleishman SJ, Kessel A and Ben-Tal N (2004) Free diffusion of steroid hormones across biomembranes: a simplex search with implicit solvent model calculations. Biophys J 87:768-779.

Ozanne DM, Brady ME, Cook S, Gaughan L, Neal DE and Robson CN (2000) Androgen receptor nuclear translocation is facilitated by the f-actin cross-linking protein filamin. Mol Endocrinol 14:1618-1626.

Pajor AM (1996) Molecular cloning and functional expression of a sodium-dicarboxylate cotransporter from human kidney. Am J Physiol 270:F642-648.

Pajor AM and Sun NN (2010) Single nucleotide polymorphisms in the human $\mathrm{Na}$-dicarboxylate cotransporter affect transport activity and protein expression. Am J Physiol Renal Physiol 299:F704-711.

Palvimo JJ, Kallio PJ, Ikonen T, Mehto M and Janne OA (1993) Dominant negative regulation of trans-activation by the rat androgen receptor: roles of the $\mathrm{N}$-terminal domain and heterodimer formation. Mol Endocrinol 7:1399-1407.

Peng Y and Jahroudi N (2002) The NFY transcription factor functions as a repressor and activator of the von Willebrand factor promoter. Blood 99:2408-2417.

Perez-Rosado A, Artiga M, Vargiu P, Sanchez-Aguilera A, Alvarez-Barrientos A and Piris M (2008) BCL6 represses NFkappaB activity in diffuse large B-cell lymphomas. J Pathol 214:498-507.

Phillips AO, Steadman R, Morrisey K and Williams JD (1997) Polarity of stimulation and secretion of transforming growth factor-beta 1 by cultured proximal tubular cells. $\mathrm{Am}$ J Pathol 150:1101-1111.

Pontoglio M, Barra J, Hadchouel M, Doyen A, Kress C, Bach JP, Babinet C and Yaniv M (1996) Hepatocyte nuclear factor 1 inactivation results in hepatic dysfunction, phenylketonuria, and renal Fanconi syndrome. Cell 84:575-585.

Pritchard JB (1988) Coupled transport of p-aminohippurate by rat kidney basolateral membrane vesicles. Am J Physiol 255:F597-604.

Pritchard JB (1995) Intracellular alpha-ketoglutarate controls the efficacy of renal organic anion transport. J Pharmacol Exp Ther 274:1278-1284.

Puranen T, Poutanen M, Ghosh D, Vihko R and Vihko P (1997) Origin of substrate specificity of human and rat 17beta-hydroxysteroid dehydrogenase type 1, using chimeric enzymes and site-directed substitutions. Endocrinology 138:3532-3539.

Quinkler M, Bujalska IJ, Kaur K, Onyimba CU, Buhner S, Allolio B, Hughes SV, Hewison M and Stewart PM (2005) Androgen receptor-mediated regulation of the alpha-subunit of the epithelial sodium channel in human kidney. Hypertension 46:787-798. 
Race JE, Grassl SM, Williams WJ and Holtzman EJ (1999) Molecular cloning and characterization of two novel human renal organic anion transporters (hOAT1 and hOAT3). Biochem Biophys Res Commun 255:508-514.

Reid G, Wolff NA, Dautzenberg FM and Burckhardt G (1998) Cloning of a human renal p-aminohippurate transporter, hROAT1. Kidney Blood Press Res 21:233-237.

Rennie PS, Bruchovsky N, Leco KJ, Sheppard PC, McQueen SA, Cheng H, Snoek R, Hamel A, Bock ME, MacDonald BS and et al. (1993) Characterization of two cis-acting DNA elements involved in the androgen regulation of the probasin gene. Mol Endocrinol 7:23-36.

Reyes JL, Melendez E, Alegria A and Jaramillo-Juarez F (1998) Influence of sex differences on the renal secretion of organic anions. Endocrinology 139:1581-1587.

Ricciardelli C, Choong CS, Buchanan G, Vivekanandan S, Neufing P, Stahl J, Marshall VR, Horsfall DJ and Tilley WD (2005) Androgen receptor levels in prostate cancer epithelial and peritumoral stromal cells identify non-organ confined disease. Prostate 63:19-28.

Riedmaier AE, Nies AT, Schaeffeler E and Schwab M (2012) Organic anion transporters and their implications in pharmacotherapy. Pharmacol Rev 64:421-449.

Rizwan AN and Burckhardt G (2007) Organic anion transporters of the SLC22 family: biopharmaceutical, physiological, and pathological roles. Pharm Res 24:450-470.

Roch-Ramel F, Guisan B and Schild L (1996) Indirect coupling of urate and p-aminohippurate transport to sodium in human brush-border membrane vesicles. Am J Physiol 270:F61-68.

Sabolic I, Asif AR, Budach WE, Wanke C, Bahn A and Burckhardt G (2007) Gender differences in kidney function. Pflugers Arch 455:397-429.

Sack JS, Kish KF, Wang C, Attar RM, Kiefer SE, An Y, Wu GY, Scheffler JE, Salvati ME, Krystek SR, Jr., Weinmann R and Einspahr HM (2001) Crystallographic structures of the ligand-binding domains of the androgen receptor and its T877A mutant complexed with the natural agonist dihydrotestosterone. Proc Natl Acad Sci U S A 98:4904-4909.

Saji T, Kikuchi R, Kusuhara H, Kim I, Gonzalez FJ and Sugiyama Y (2008) Transcriptional regulation of human and mouse organic anion transporter 1 by hepatocyte nuclear factor $1 \alpha / \beta$. J Pharmacol Exp Ther 324:784-790.

Sakurai Y, Motohashi H, Ueo H, Masuda S, Saito H, Okuda M, Mori N, Matsuura M, Doi T, Fukatsu A, Ogawa O and Inui K (2004) Expression levels of renal organic anion transporters (OATs) and their correlation with anionic drug excretion in patients with renal diseases. Pharm Res 21:61-67.

Salah Z, Maoz M, Cohen I, Pizov G, Pode D, Runge MS and Bar-Shavit R (2005) Identification of a novel functional androgen response element within hPar1 promoter: implications to prostate cancer progression. FASEB J 19:62-72. 
Sanger F, Nicklen S and Coulson AR (1977) DNA sequencing with chain-terminating inhibitors. Proc Natl Acad Sci U S A 74:5463-5467.

Sato M, Suzaka H and Miyazaki H (2000) Sex-related differences in urinary excretion of egualen sodium in rats. Drug Metab Dispos 28:21-27.

Sauvant C, Hesse D, Holzinger H, Evans KK, Dantzler WH and Gekle M (2004) Action of EGF and PGE2 on basolateral organic anion uptake in rabbit proximal renal tubules and hOAT1 expressed in human kidney epithelial cells. Am J Physiol Renal Physiol 286:F774-783.

Sauvant C, Holzinger H and Gekle M (2003) Short-term regulation of basolateral organic anion uptake in proximal tubular opossum kidney cells: prostaglandin E2 acts via receptor-mediated activation of protein kinase A. J Am Soc Nephrol 14:3017-3026.

Schmidt R, Lang F and Heckmann M (2010) Physiologie des Menschen mit Pathophysiologie, Springer Medizin Verlag Heidelberg, 31. Auflage.

Schneider R, Sauvant C, Betz B, Otremba M, Fischer D, Holzinger H, Wanner C, Galle J and Gekle M (2007) Downregulation of organic anion transporters OAT1 and OAT3 correlates with impaired secretion of para-aminohippurate after ischemic acute renal failure in rats. Am J Physiol Renal Physiol 292:F1599-1605.

Sekine T, Cha SH, Hosoyamada M, Kanai Y, Watanabe N, Furuta Y, Fukuda K, Igarashi T and Endou H (1998) Cloning, functional characterization, and localization of a rat renal Na+-dicarboxylate transporter. Am J Physiol 275:F298-305.

Sekine T, Miyazaki H and Endou H (2006) Molecular physiology of renal organic anion transporters. Am J Physiol Renal Physiol 290:F251-261.

Sekine T, Watanabe N, Hosoyamada M, Kanai Y and Endou H (1997) Expression cloning and characterization of a novel multispecific organic anion transporter. J Biol Chem 272:18526-18529.

Seto T, Yoshitake M, Ogasawara T, Ikari J, Sakamoto A, Hatano M, Hirata H, Fukuda T, Kuriyama T, Tatsumi K, Tokuhisa T and Arima M (2011) Bcl6 in pulmonary epithelium coordinately controls the expression of the CC-type chemokine genes and attenuates allergic airway inflammation. Clin Exp Allergy 41:1568-1578.

Shaffer AL, Yu X, He Y, Boldrick J, Chan EP and Staudt LM (2000) BCL-6 represses genes that function in lymphocyte differentiation, inflammation, and cell cycle control. Immunity 13:199-212.

Shaffer PL, Jivan A, Dollins DE, Claessens F and Gewirth DT (2004) Structural basis of androgen receptor binding to selective androgen response elements. Proc Natl Acad Sci U S A 101:4758-4763.

Shaw P and Brown J (2012) Nucleoli: composition, function, and dynamics. Plant Physiol 158:44-51. 
Shimada H, Moewes B and Burckhardt G (1987) Indirect coupling to Na+ of p-aminohippuric acid uptake into rat renal basolateral membrane vesicles. Am J Physiol 253:F795-801.

Smith DF and Toft DO (2008) Minireview: the intersection of steroid receptors with molecular chaperones: observations and questions. Mol Endocrinol 22:2229-2240.

Srimaroeng C, Perry JL and Pritchard JB (2008) Physiology, structure, and regulation of the cloned organic anion transporters. Xenobiotica 38:889-935.

Staudt LM, Dent AL, Shaffer AL and Yu X (1999) Regulation of lymphocyte cell fate decisions and lymphomagenesis by BCL-6. Int Rev Immunol 18:381-403.

Sugiyama D, Kusuhara H, Shitara Y, Abe T, Meier PJ, Sekine T, Endou H, Suzuki H and Sugiyama Y (2001) Characterization of the efflux transport of 17beta-estradiol-D17beta-glucuronide from the brain across the blood-brain barrier. J Pharmacol Exp Ther 298:316-322.

Sweet DH, Bush KT and Nigam SK (2001) The organic anion transporter family: from physiology to ontogeny and the clinic. Am J Physiol Renal Physiol 281:F197-205.

Sweet DH, Chan LM, Walden R, Yang XP, Miller DS and Pritchard JB (2003) Organic anion transporter 3 (Slc22a8) is a dicarboxylate exchanger indirectly coupled to the $\mathrm{Na}+$ gradient. Am J Physiol Renal Physiol 284:F763-769.

Sweet DH, Miller DS and Pritchard JB (1999) Localization of an organic anion transporterGFP fusion construct (rROAT1-GFP) in intact proximal tubules. Am J Physiol 276:F864-873.

Sweet DH, Miller DS, Pritchard JB, Fujiwara Y, Beier DR and Nigam SK (2002) Impaired organic anion transport in kidney and choroid plexus of organic anion transporter 3 (Oat3 (Slc22a8)) knockout mice. J Biol Chem 277:26934-26943.

Sweet DH, Wolff NA and Pritchard JB (1997) Expression cloning and characterization of ROAT1. The basolateral organic anion transporter in rat kidney. J Biol Chem 272:30088-30095.

Tahara H, Shono M, Kusuhara H, Kinoshita H, Fuse E, Takadate A, Otagiri M and Sugiyama Y (2005) Molecular cloning and functional analyses of OAT1 and OAT3 from cynomolgus monkey kidney. Pharm Res 22:647-660.

Takeda N, Arima M, Tsuruoka N, Okada S, Hatano M, Sakamoto A, Kohno Y and Tokuhisa $\mathrm{T}$ (2003) Bcl6 is a transcriptional repressor for the IL-18 gene. J Immunol 171:426431.

Tanaka H, Terada Y, Kobayashi T, Okado T, Inoshita S, Kuwahara M, Seth A, Sato Y and Sasaki S (2004) Expression and function of Ets-1 during experimental acute renal failure in rats. J Am Soc Nephrol 15:3083-3092. 
Bibliography

Tojo A, Sekine T, Nakajima N, Hosoyamada M, Kanai Y, Kimura K and Endou H (1999) Immunohistochemical localization of multispecific renal organic anion transporter 1 in rat kidney. J Am Soc Nephrol 10:464-471.

Toney LM, Cattoretti G, Graf JA, Merghoub T, Pandolfi PP, Dalla-Favera R, Ye BH and Dent AL (2000) BCL-6 regulates chemokine gene transcription in macrophages. Nat Immunol 1:214-220.

Torres AM, Dnyanmote AV, Bush KT, Wu W and Nigam SK (2011) Deletion of multispecific organic anion transporter Oat1/Slc22a6 protects against mercury-induced kidney injury. J Biol Chem 286:26391-26395.

Tyagi RK, Lavrovsky Y, Ahn SC, Song CS, Chatterjee B and Roy AK (2000) Dynamics of intracellular movement and nucleocytoplasmic recycling of the ligand-activated androgen receptor in living cells. Mol Endocrinol 14:1162-1174.

Ueo H, Motohashi H, Katsura T and Inui K (2005) Human organic anion transporter hOAT3 is a potent transporter of cephalosporin antibiotics, in comparison with hOAT1. Biochem Pharmacol 70:1104-1113.

Ueo H, Motohashi H, Katsura T and Inui K (2007) Cl- -dependent upregulation of human organic anion transporters: different effects on transport kinetics between hOAT1 and hOAT3. Am J Physiol Renal Physiol 293:F391-397.

Urakami Y, Nakamura N, Takahashi K, Okuda M, Saito H, Hashimoto Y and Inui K (1999) Gender differences in expression of organic cation transporter OCT2 in rat kidney. FEBS Lett 461:339-342.

Urakami Y, Okuda M, Saito H and Inui K (2000) Hormonal regulation of organic cation transporter OCT2 expression in rat kidney. FEBS Lett 473:173-176.

Uwai Y, Saito H, Hashimoto Y and Inui KI (2000) Interaction and transport of thiazide diuretics, loop diuretics, and acetazolamide via rat renal organic anion transporter rOAT1. J Pharmacol Exp Ther 295:261-265.

Vallon V, Eraly SA, Rao SR, Gerasimova M, Rose M, Nagle M, Anzai N, Smith T, Sharma K, Nigam SK and Rieg T (2012) A role for the organic anion transporter OAT3 in renal creatinine secretion in mice. Am J Physiol Renal Physiol 302:F1293-1299.

VanWert AL, Bailey RM and Sweet DH (2007) Organic anion transporter 3 (Oat3/Slc22a8) knockout mice exhibit altered clearance and distribution of penicillin G. Am J Physiol Renal Physiol 293:F1332-1341.

VanWert AL, Gionfriddo MR and Sweet DH (2010) Organic anion transporters: discovery, pharmacology, regulation and roles in pathophysiology. Biopharm Drug Dispos 31:171.

Wagner SD, Ahearne M and Ferrigno PK (2011) The role of BCL6 in lymphomas and routes to therapy. Br J Haematol 152:3-12. 
Wang Y, Moser AH, Shigenaga JK, Grunfeld C and Feingold KR (2005) Downregulation of liver $\mathrm{X}$ receptor-alpha in mouse kidney and HK-2 proximal tubular cells by LPS and cytokines. J Lipid Res 46:2377-2387.

Wang Z and Roeder RG (1997) Three human RNA polymerase III-specific subunits form a subcomplex with a selective function in specific transcription initiation. Genes Dev 11:1315-1326.

Wegner W, Burckhardt BC, Burckhardt G and Henjakovic M (2012) Male-dominant activation of rat renal organic anion transporter 1 (Oat1) and 3 (Oat3) expression by transcription factor BCL6. PLoS One 7:e35556.

White RJ (2011) Transcription by RNA polymerase III: more complex than we thought. Nat Rev Genet 12:459-463.

Whitington T, Jolma A and Taipale J (2011) Beyond the balance of activator and repressor. Sci Signal 4:pe29.

Wickert L and Selbig J (2002) Structural analysis of the DNA-binding domain of alternatively spliced steroid receptors. J Endocrinol 173:429-436.

Willy PJ, Umesono K, Ong ES, Evans RM, Heyman RA and Mangelsdorf DJ (1995) LXR, a nuclear receptor that defines a distinct retinoid response pathway. Genes Dev 9:10331045.

Wilson EM and French FS (1976) Binding properties of androgen receptors. Evidence for identical receptors in rat testis, epididymis, and prostate. J Biol Chem 251:5620-5629.

Wolff NA, Thies K, Kuhnke N, Reid G, Friedrich B, Lang F and Burckhardt G (2003) Protein kinase $\mathrm{C}$ activation downregulates human organic anion transporter 1-mediated transport through carrier internalization. J Am Soc Nephrol 14:1959-1968.

Wolff NA, Werner A, Burkhardt S and Burckhardt G (1997) Expression cloning and characterization of a renal organic anion transporter from winter flounder. FEBS Lett 417:287-291.

Wong CW and Privalsky ML (1998) Components of the SMRT corepressor complex exhibit distinctive interactions with the POZ domain oncoproteins PLZF, PLZF-RARalpha, and BCL-6. J Biol Chem 273:27695-27702.

Wright EM (2001) Renal Na(+)-glucose cotransporters. Am J Physiol Renal Physiol 280:F1018.

Wu W, Baker ME, Eraly SA, Bush KT and Nigam SK (2009) Analysis of a large cluster of SLC22 transporter genes, including novel USTs, reveals species-specific amplification of subsets of family members. Physiol Genomics 38:116-124.

Yamochi T, Kaneita Y, Akiyama T, Mori S and Moriyama M (1999) Adenovirus-mediated high expression of BCL-6 in CV-1 cells induces apoptotic cell death accompanied by down-regulation of BCL-2 and BCL-X(L). Oncogene 18:487-494. 
Yan N, Mosckovitz R, Gerber LD, Mathew S, Murty VV, Tate SS and Udenfriend S (1994) Characterization of the promoter region of the gene for the rat neutral and basic amino acid transporter and chromosomal localization of the human gene. Proc Natl Acad Sci U S A 91:7548-7552.

Yoshida T, Fukuda T, Hatano M, Koseki H, Okabe S, Ishibashi K, Kojima S, Arima M, Komuro I, Ishii G, Miki T, Hirosawa S, Miyasaka N, Taniguchi M, Ochiai T, Isono K and Tokuhisa T (1999) The role of Bcl6 in mature cardiac myocytes. Cardiovasc Res 42:670-679.

Yu MJ, Miller RL, Uawithya P, Rinschen MM, Khositseth S, Braucht DW, Chou CL, Pisitkun T, Nelson RD and Knepper MA (2009) Systems-level analysis of cell-specific AQP2 gene expression in renal collecting duct. Proc Natl Acad Sci U S A 106:24412446.

Yuan H, Feng B, Yu Y, Chupka J, Zheng JY, Heath TG and Bond BR (2009) Renal organic anion transporter-mediated drug-drug interaction between gemcabene and quinapril. J Pharmacol Exp Ther 330:191-197.

Zhang Q, Hong M, Duan P, Pan Z, Ma J and You G (2008) Organic anion transporter OAT1 undergoes constitutive and protein kinase $\mathrm{C}$-regulated trafficking through a dynaminand clathrin-dependent pathway. J Biol Chem 283:32570-32579.

Zhang X, Groves CE, Bahn A, Barendt WM, Prado MD, Rodiger M, Chatsudthipong V, Burckhardt $G$ and Wright SH (2004) Relative contribution of OAT and OCT transporters to organic electrolyte transport in rabbit proximal tubule. Am J Physiol Renal Physiol 287:F999-1010.

Zhang Y, Laz EV and Waxman DJ (2011) Dynamic, sex-differential STAT5 and BCL6 binding to sex-biased, growth hormone-regulated genes in adult mouse liver. Mol Cell Biol 32:880-896.

Zhou ZX, Sar M, Simental JA, Lane MV and Wilson EM (1994) A ligand-dependent bipartite nuclear targeting signal in the human androgen receptor. Requirement for the DNAbinding domain and modulation by $\mathrm{NH} 2$-terminal and carboxyl-terminal sequences. J Biol Chem 269:13115-13123.

Zopf Y, Rabe C, Neubert A, Janson C, Brune K, Hahn EG and Dormann H (2009) Genderbased differences in drug prescription: relation to adverse drug reactions. Pharmacology 84:333-339. 
Appendix

7. Appendix

7.1 Curriculum vitae 


\section{Appendix}

\subsection{Table S1}

Table S1: Sex-dependently expressed genes in rat cortical kidney slices.

\begin{tabular}{|c|c|c|c|c|}
\hline Symbol & Description & $\begin{array}{c}\log 2 \mathrm{FC} \\
(\mathrm{m}-\mathrm{f})\end{array}$ & $\begin{array}{l}\text { P.Value } \\
(\mathbf{m}-\mathbf{f})\end{array}$ & $\begin{array}{l}\text { FDR } \\
(\mathbf{m}-\mathbf{f})\end{array}$ \\
\hline $\mathrm{A} 2 \mathrm{~m}$ & alpha-2-macroglobulin & -2.20 & $2.40 \mathrm{E}-03$ & $3.51 \%$ \\
\hline Abca7 & ATP-binding cassette, sub-family A (ABC1), member 7 & -1.35 & $1.40 \mathrm{E}-05$ & $0.19 \%$ \\
\hline Abcb1b & ATP-binding cassette, sub-family B (MDR/TAP), member 1B & -2.66 & $3.96 \mathrm{E}-03$ & $4.65 \%$ \\
\hline Abra & actin-binding Rho activating protein & -1.17 & $3.08 \mathrm{E}-03$ & $4.02 \%$ \\
\hline Acox 2 & acyl-Coenzyme A oxidase 2, branched chain & -1.98 & $7.71 \mathrm{E}-05$ & $0.47 \%$ \\
\hline Acvr1c & activin A receptor, type IC & -2.34 & $1.77 \mathrm{E}-06$ & $0.07 \%$ \\
\hline Acvr1c & activin A receptor, type IC & -2.29 & $2.77 \mathrm{E}-06$ & $0.08 \%$ \\
\hline Adamts3 & ADAM metallopeptidase with thrombospondin type 1 , motif 3 & -1.32 & $2.11 \mathrm{E}-04$ & $0.85 \%$ \\
\hline Adh6 & alcohol dehydrogenase 6 (class V) & -6.29 & $5.80 \mathrm{E}-06$ & $0.12 \%$ \\
\hline Adh6a & alcohol dehydrogenase $6 \mathrm{~A}$ (class $\mathrm{V}$ ) & -1.09 & $1.83 \mathrm{E}-04$ & $0.79 \%$ \\
\hline Aebp2 & AE binding protein 2 & -3.12 & $3.82 \mathrm{E}-06$ & $0.09 \%$ \\
\hline Afp & alpha-fetoprotein & -2.41 & $1.20 \mathrm{E}-03$ & $2.38 \%$ \\
\hline Akr1b7 & aldo-keto reductase family 1 , member B7 & -8.16 & $1.13 \mathrm{E}-04$ & $0.58 \%$ \\
\hline Akr1c21 & aldo-keto reductase family 1 , member $\mathrm{C} 21$ & -1.35 & $1.33 \mathrm{E}-04$ & $0.65 \%$ \\
\hline Angpt2 & angiopoietin 2 & -1.32 & $3.14 \mathrm{E}-05$ & $0.28 \%$ \\
\hline Ankrd5 & ankyrin repeat domain 5 & -1.86 & $3.20 \mathrm{E}-03$ & $4.09 \%$ \\
\hline Aqp4 & aquaporin 4 & -1.17 & $1.37 \mathrm{E}-03$ & $2.58 \%$ \\
\hline Arid3b & AT rich interactive domain 3B (Bright like) & -1.48 & $1.65 \mathrm{E}-04$ & $0.73 \%$ \\
\hline Azgp1 & alpha-2-glycoprotein 1, zinc-binding & -1.61 & $6.24 \mathrm{E}-04$ & $1.63 \%$ \\
\hline Baat & $\begin{array}{l}\text { bile acid Coenzyme A: amino acid N-acyltransferase (glycine N- } \\
\text { choloyltransferase) }\end{array}$ & -1.24 & $1.22 \mathrm{E}-03$ & $2.40 \%$ \\
\hline Btbd11 & BTB (POZ) domain containing 11 & -1.01 & $1.30 \mathrm{E}-03$ & $2.50 \%$ \\
\hline Btbd17 & BTB (POZ) domain containing 17 & -2.00 & $1.88 \mathrm{E}-04$ & $0.79 \%$ \\
\hline Cbr1 & carbonyl reductase 1 & -1.60 & $2.33 \mathrm{E}-04$ & $0.90 \%$ \\
\hline Cd1d1 & CD1d1 molecule & -1.14 & $7.03 \mathrm{E}-04$ & $1.74 \%$ \\
\hline Cda & cytidine deaminase & -2.86 & $5.59 \mathrm{E}-05$ & $0.40 \%$ \\
\hline Cgref1 & cell growth regulator with EF hand domain 1 & -1.83 & $8.46 \mathrm{E}-05$ & $0.49 \%$ \\
\hline Cited 1 & $\begin{array}{l}\text { Cbp/p300-interacting transactivator with Glu/Asp-rich carboxy-terminal } \\
\text { domain } 1\end{array}$ & -1.04 & $1.47 \mathrm{E}-03$ & $2.67 \%$ \\
\hline Cklf & chemokine-like factor & -1.11 & $6.62 \mathrm{E}-05$ & $0.43 \%$ \\
\hline Cklf & chemokine-like factor & -1.03 & $6.79 \mathrm{E}-05$ & $0.44 \%$ \\
\hline Cldn1 & claudin 1 & -1.54 & $5.66 \mathrm{E}-07$ & $0.04 \%$ \\
\hline Cldn14 & claudin 14 & -1.45 & $2.42 \mathrm{E}-03$ & $3.51 \%$ \\
\hline Cldn20 & claudin 20 & -1.03 & $3.09 \mathrm{E}-04$ & $1.06 \%$ \\
\hline Cldn23 & claudin 23 & -1.71 & $3.96 \mathrm{E}-04$ & $1.21 \%$ \\
\hline $\mathrm{Cmtm} 2 \mathrm{a}$ & CKLF-like MARVEL transmembrane domain containing 2A & -4.00 & $9.04 \mathrm{E}-07$ & $0.05 \%$ \\
\hline $\mathrm{Cmtm} 3$ & CKLF-like MARVEL transmembrane domain containing 3 & -1.31 & $7.80 \mathrm{E}-06$ & $0.14 \%$ \\
\hline Cnr1 & cannabinoid receptor 1 (brain) & -3.91 & $1.10 \mathrm{E}-05$ & $0.17 \%$ \\
\hline Cnr1 & cannabinoid receptor 1 (brain) & -3.52 & $1.09 \mathrm{E}-06$ & $0.05 \%$ \\
\hline Col17a1 & collagen, type XVII, alpha 1 & -4.09 & $2.63 \mathrm{E}-05$ & $0.27 \%$ \\
\hline Col17a1 & collagen, type XVII, alpha 1 & -2.19 & $2.24 \mathrm{E}-04$ & $0.88 \%$ \\
\hline Col24a1 & collagen, type XXIV, alpha 1 & -5.17 & $1.85 \mathrm{E}-06$ & $0.07 \%$ \\
\hline Cpe & carboxypeptidase E & -2.39 & $5.99 \mathrm{E}-07$ & $0.04 \%$ \\
\hline
\end{tabular}




\begin{tabular}{|c|c|c|c|c|}
\hline Crtac1 & cartilage acidic protein 1 & -1.82 & $2.04 \mathrm{E}-07$ & $0.03 \%$ \\
\hline Cryab & crystallin, alpha B & -1.50 & $6.65 \mathrm{E}-05$ & $0.44 \%$ \\
\hline Cst11 & cystatin 11 & -1.33 & $1.17 \mathrm{E}-05$ & $0.18 \%$ \\
\hline Cth & cystathionase (cystathionine gamma-lyase) & -1.01 & $1.24 \mathrm{E}-04$ & $0.61 \%$ \\
\hline Cyp1a1 & cytochrome P450, family 1 , subfamily a, polypeptide 1 & -5.50 & $1.78 \mathrm{E}-06$ & $0.07 \%$ \\
\hline Cyp4b1 & cytochrome P450, family 4 , subfamily b, polypeptide 1 & -1.15 & $1.17 \mathrm{E}-03$ & $2.34 \%$ \\
\hline Cyp4f4 & cytochrome P450, family 4 , subfamily f, polypeptide 4 & -2.67 & $3.46 \mathrm{E}-05$ & $0.30 \%$ \\
\hline Ddit41 & DNA-damage-inducible transcript 4-like & -1.76 & $3.62 \mathrm{E}-03$ & $4.40 \%$ \\
\hline Dio3 & deiodinase, iodothyronine, type III & -1.56 & 4.19E-05 & $0.33 \%$ \\
\hline Dock5 & dedicator of cytokinesis 5 & -1.58 & $1.75 \mathrm{E}-03$ & $2.93 \%$ \\
\hline Dpt & dermatopontin & -1.07 & $2.91 \mathrm{E}-04$ & $1.01 \%$ \\
\hline Efcab10 & EF-hand calcium binding domain 10 & -1.15 & $3.80 \mathrm{E}-04$ & $1.18 \%$ \\
\hline Epha8 & Eph receptor A8 & -1.38 & 2.37E-03 & $3.47 \%$ \\
\hline Ephb1 & Eph receptor B1 & -1.18 & $2.30 \mathrm{E}-04$ & $0.89 \%$ \\
\hline Fgb & fibrinogen beta chain & -1.32 & $1.07 \mathrm{E}-06$ & $0.05 \%$ \\
\hline Fgg & fibrinogen gamma chain & -1.33 & $4.39 \mathrm{E}-03$ & $4.94 \%$ \\
\hline Foxa1 & forkhead box A1 & -4.41 & $2.48 \mathrm{E}-06$ & $0.08 \%$ \\
\hline Foxq1 & forkhead box Q1 & -2.23 & $2.06 \mathrm{E}-05$ & $0.23 \%$ \\
\hline Gjb5 & gap junction protein, beta 5 & -2.70 & $1.09 \mathrm{E}-05$ & $0.17 \%$ \\
\hline Gng13 & guanine nucleotide binding protein ( $\mathrm{G}$ protein), gamma 13 & -1.32 & $2.26 \mathrm{E}-04$ & $0.88 \%$ \\
\hline Gng13 & guanine nucleotide binding protein ( $\mathrm{G}$ protein), gamma 13 & -1.26 & $5.14 \mathrm{E}-04$ & $1.43 \%$ \\
\hline Gpt & glutamic-pyruvate transaminase (alanine aminotransferase) & -1.00 & $8.84 \mathrm{E}-05$ & $0.50 \%$ \\
\hline Gsbs & G substrate & -1.46 & $4.10 \mathrm{E}-04$ & $1.24 \%$ \\
\hline Hfe2 & hemochromatosis type 2 (juvenile) (human homolog) & -1.24 & $6.91 \mathrm{E}-04$ & $1.72 \%$ \\
\hline Igfbpl1 & insulin-like growth factor binding protein-like 1 & -2.54 & $5.84 \mathrm{E}-06$ & $0.12 \%$ \\
\hline Itpka & inositol 1,4,5-trisphosphate 3-kinase A & -1.15 & $9.18 \mathrm{E}-04$ & $2.03 \%$ \\
\hline Klhl14 & kelch-like 14 (Drosophila) & -1.32 & $5.28 \mathrm{E}-05$ & $0.39 \%$ \\
\hline Klhl14 & kelch-like 14 (Drosophila) & -1.31 & $2.68 \mathrm{E}-05$ & $0.27 \%$ \\
\hline Kng2 & kininogen 2 & -1.43 & $1.03 \mathrm{E}-03$ & $2.17 \%$ \\
\hline Len11 & lipocalin 11 & -1.86 & $1.04 \mathrm{E}-03$ & $2.17 \%$ \\
\hline Lifr & leukemia inhibitory factor receptor alpha & -1.00 & $3.88 \mathrm{E}-06$ & $0.09 \%$ \\
\hline LOC100192205 & heat shock factor binding protein 1-like & -1.10 & 4.04E-05 & $0.32 \%$ \\
\hline LOC291863 & carboxylesterase-like & -1.09 & $2.13 \mathrm{E}-04$ & $0.85 \%$ \\
\hline LOC305806 & similar to glutaredoxin 1 (thioltransferase); glutaredoxin & -1.41 & $4.03 \mathrm{E}-04$ & $1.22 \%$ \\
\hline LOC310902 & similar to Alcohol dehydrogenase 1A (Alcohol dehydrogenase alpha subunit) & -3.51 & $2.48 \mathrm{E}-06$ & $0.08 \%$ \\
\hline LOC316935 & similar to Spetex-2D protein & -3.23 & $9.69 \mathrm{E}-05$ & $0.53 \%$ \\
\hline LOC361914 & $\begin{array}{l}\text { similar to solute carrier family } 7 \text { (cationic amino acid transporter, } \mathrm{y}+\text { system), } \\
\text { member } 12\end{array}$ & -3.87 & $3.17 \mathrm{E}-06$ & $0.09 \%$ \\
\hline LOC498565 & hypothetical LOC498565 & -3.33 & $7.29 \mathrm{E}-05$ & $0.46 \%$ \\
\hline LOC500148 & similar to 40S ribosomal protein S7 (S8) & -1.74 & $3.79 \mathrm{E}-05$ & $0.31 \%$ \\
\hline LOC501369 & similar to spermatogenesis associated glutamate $(E)$-rich protein $4 d$ & -2.68 & $1.89 \mathrm{E}-03$ & $3.05 \%$ \\
\hline LOC679817 & similar to carboxylesterase 1 isoform c precursor & -1.29 & $2.74 \mathrm{E}-04$ & $0.99 \%$ \\
\hline LOC680666 & hypothetical protein LOC680666 & -3.03 & $1.29 \mathrm{E}-05$ & $0.19 \%$ \\
\hline LOC682546 & hypothetical protein LOC682546 & -1.18 & $1.07 \mathrm{E}-04$ & $0.56 \%$ \\
\hline LOC685904 & similar to Spetex-2F protein & -3.61 & $1.94 \mathrm{E}-04$ & $0.81 \%$ \\
\hline LOC688585 & hypothetical protein LOC688585 & -1.31 & $2.73 \mathrm{E}-03$ & $3.77 \%$ \\
\hline LOC689709 & similar to FERM domain containing 1 & -2.12 & $4.80 \mathrm{E}-04$ & $1.37 \%$ \\
\hline LOC690776 & hypothetical protein LOC690776 & -1.32 & $6.21 \mathrm{E}-05$ & $0.42 \%$ \\
\hline LOC691429 & hypothetical protein LOC691429 & -2.56 & $6.71 \mathrm{E}-04$ & $1.70 \%$ \\
\hline
\end{tabular}




\section{Appendix}

\begin{tabular}{|c|c|c|c|c|}
\hline Lrrc17 & leucine rich repeat containing 17 & -1.00 & $2.85 \mathrm{E}-05$ & $0.27 \%$ \\
\hline Mcoln2 & mucolipin 2 & -2.41 & $1.00 \mathrm{E}-04$ & $0.54 \%$ \\
\hline Meox2 & mesenchyme homeobox 2 & -1.17 & $1.54 \mathrm{E}-04$ & $0.70 \%$ \\
\hline Mep1b & meprin 1 beta & -1.48 & $2.52 \mathrm{E}-04$ & $0.94 \%$ \\
\hline Mlana & melan-A & -1.60 & $1.68 \mathrm{E}-05$ & $0.21 \%$ \\
\hline $\mathrm{Nmb}$ & neuromedin B & -2.32 & $1.86 \mathrm{E}-03$ & $3.03 \%$ \\
\hline Nxf7 & nuclear RNA export factor 7 & -2.26 & $5.45 \mathrm{E}-04$ & $1.48 \%$ \\
\hline Oat & ornithine aminotransferase (gyrate atrophy) & -1.36 & 3.03E-05 & $0.28 \%$ \\
\hline Olr1592 & olfactory receptor 1592 & -2.01 & $6.40 \mathrm{E}-04$ & $1.64 \%$ \\
\hline Osgin 1 & oxidative stress induced growth inhibitor 1 & -1.11 & $2.51 \mathrm{E}-03$ & $3.60 \%$ \\
\hline Otor & otoraplin & -1.13 & $1.12 \mathrm{E}-04$ & $0.57 \%$ \\
\hline Pacrg & Park2 co-regulated & -1.75 & $3.56 \mathrm{E}-06$ & $0.09 \%$ \\
\hline Pcsk6 & proprotein convertase subtilisin/kexin type 6 & -1.21 & $1.86 \mathrm{E}-03$ & $3.03 \%$ \\
\hline Pebp4 & phosphatidylethanolamine binding protein 4 & -1.02 & 7.90E-05 & $0.47 \%$ \\
\hline $\operatorname{Pkd} 212$ & polycystic kidney disease 2 -like 2 & -2.15 & $2.42 \mathrm{E}-05$ & $0.25 \%$ \\
\hline Pld1 & phospholipase D1 & -1.93 & 1.37E-04 & $0.66 \%$ \\
\hline Pld1 & phospholipase D1 & -1.63 & 4.58E-04 & $1.33 \%$ \\
\hline Pnoc & prepronociceptin & -1.93 & $1.63 \mathrm{E}-04$ & $0.73 \%$ \\
\hline Prss 35 & protease, serine, 35 & -4.06 & $2.54 \mathrm{E}-06$ & $0.08 \%$ \\
\hline Pstpip1 & proline-serine-threonine phosphatase-interacting protein 1 & -2.49 & $1.56 \mathrm{E}-05$ & $0.21 \%$ \\
\hline RGD1304731 & similar to RIKEN cDNA 5330437I02 gene & -2.50 & 8.87E-06 & $0.15 \%$ \\
\hline RGD1304731 & similar to RIKEN cDNA 5330437102 gene & -2.43 & 2.09E-05 & $0.23 \%$ \\
\hline RGD1305807 & hypothetical LOC298077 & -3.29 & $2.68 \mathrm{E}-05$ & $0.27 \%$ \\
\hline RGD1305939 & hypothetical LOC300074 & -1.17 & $1.46 \mathrm{E}-03$ & $2.66 \%$ \\
\hline RGD1306344 & similar to $\mathrm{Ab} 1-133$ & -1.39 & $8.59 \mathrm{E}-07$ & $0.05 \%$ \\
\hline RGD1311940 & similar to bA305P22.2.1 (novel protein, isoform 1) & -1.44 & $9.27 \mathrm{E}-05$ & $0.52 \%$ \\
\hline RGD1560166 & similar to Probable G-protein coupled receptor 62 (hGPCR8) & -1.28 & $6.38 \mathrm{E}-06$ & $0.13 \%$ \\
\hline RGD1560846 & similar to hypothetical protein MGC40178 & -2.01 & $1.00 \mathrm{E}-03$ & $2.14 \%$ \\
\hline RGD1561530 & similar to Tle6 protein & -1.12 & $1.98 \mathrm{E}-03$ & $3.14 \%$ \\
\hline RGD1562107 & similar to class-alpha glutathione S-transferase & -4.02 & $3.80 \mathrm{E}-06$ & $0.09 \%$ \\
\hline RGD1562146 & RGD1562146 & -1.22 & 5.89E-05 & $0.41 \%$ \\
\hline RGD1563516 & similar to histone protein Hist $2 \mathrm{~h} 3 \mathrm{c} 1$ & -1.02 & 4.13E-03 & $4.77 \%$ \\
\hline RGD1564053 & similar to hypothetical protein & -4.28 & $1.15 \mathrm{E}-06$ & $0.05 \%$ \\
\hline RGD1564937 & similar to RIKEN cDNA $1110032 \mathrm{~A} 03$ & -2.30 & 3.93E-05 & $0.32 \%$ \\
\hline RGD1565052 & similar to hypothetical protein MGC27085 & -1.39 & $1.40 \mathrm{E}-03$ & $2.61 \%$ \\
\hline RGD1565480 & similar to hypothetical protein MGC35130 & -1.49 & $6.31 \mathrm{E}-04$ & $1.63 \%$ \\
\hline RGD1566180 & RGD1566180 & -1.34 & $2.22 \mathrm{E}-03$ & $3.33 \%$ \\
\hline Ribc2 & RIB43A domain with coiled-coils 2 & -3.45 & 4.15E-03 & $4.79 \%$ \\
\hline $\mathrm{R} \ln 1$ & relaxin 1 & -1.72 & $2.82 \mathrm{E}-05$ & $0.27 \%$ \\
\hline Scgb3a2 & secretoglobin, family $3 \mathrm{~A}$, member 2 & -1.28 & 2.69E-04 & $0.98 \%$ \\
\hline Sds & serine dehydratase & -3.32 & $2.68 \mathrm{E}-05$ & $0.27 \%$ \\
\hline Sept 4 & septin 4 & -1.14 & $7.68 \mathrm{E}-05$ & $0.47 \%$ \\
\hline Serpina10 & $\begin{array}{l}\text { serine (or cysteine) peptidase inhibitor, clade A (alpha-1 antiproteinase, } \\
\text { antitrypsin), }\end{array}$ & -5.04 & $1.06 \mathrm{E}-06$ & $0.05 \%$ \\
\hline Slc13a5 & solute carrier family 13 (sodium-dependent citrate transporter), member 5 & -1.00 & $5.00 \mathrm{E}-06$ & $0.11 \%$ \\
\hline Slc22a13 & solute carrier family 22 (organic anion transporter), member 13 & -5.59 & $6.10 \mathrm{E}-07$ & $0.04 \%$ \\
\hline Slc22a13 & solute carrier family 22 (organic anion transporter), member 13 & -3.38 & 1.04E-07 & $0.02 \%$ \\
\hline Slc22a7 & solute carrier family 22 (organic anion transporter), member 7 & -5.08 & 2.34E-07 & $0.03 \%$ \\
\hline Slc22a9 & solute carrier family 22 (organic anion transporter), member 9 & -2.32 & $1.59 \mathrm{E}-05$ & $0.21 \%$ \\
\hline
\end{tabular}




\begin{tabular}{|c|c|c|c|c|}
\hline Slc23a3 & solute carrier family 23 (nucleobase transporters), member 3 & -1.53 & $5.97 \mathrm{E}-04$ & $1.58 \%$ \\
\hline Slc24a5 & solute carrier family 24 , member 5 & -1.52 & $6.92 \mathrm{E}-04$ & $1.72 \%$ \\
\hline Slc5a10 & solute carrier family 5 (sodium/glucose cotransporter), member 10 & -1.47 & $3.33 \mathrm{E}-04$ & $1.09 \%$ \\
\hline Slc7a12 & $\begin{array}{l}\text { solute carrier family } 7 \text { (cationic amino acid transporter, } y+\text { system), member } \\
12\end{array}$ & -4.54 & $1.12 \mathrm{E}-06$ & $0.05 \%$ \\
\hline Slcola6 & solute carrier organic anion transporter family, member 1a6 & -2.14 & 2.37E-04 & $0.91 \%$ \\
\hline Smoc2 & SPARC related modular calcium binding 2 & -3.23 & $3.30 \mathrm{E}-06$ & $0.09 \%$ \\
\hline Smoc2 & SPARC related modular calcium binding 2 & -3.01 & 4.32E-06 & $0.10 \%$ \\
\hline Socs 2 & suppressor of cytokine signaling 2 & -1.03 & $2.88 \mathrm{E}-04$ & $1.01 \%$ \\
\hline Spetex-2A & Spetex-2A protein & -3.29 & 4.49E-05 & $0.35 \%$ \\
\hline Spetex-2F & Spetex-2F protein & -1.85 & $1.55 \mathrm{E}-04$ & $0.70 \%$ \\
\hline Spetex-2G & Spetex- $2 \mathrm{G}$ protein & -2.91 & $1.39 \mathrm{E}-04$ & $0.66 \%$ \\
\hline Spink8 & serine peptidase inhibitor, Kazal type 8 & -1.30 & $7.75 \mathrm{E}-05$ & $0.47 \%$ \\
\hline Spta1 & spectrin, alpha, erythrocytic 1 (elliptocytosis 2) & -1.58 & $2.62 \mathrm{E}-06$ & $0.08 \%$ \\
\hline St6gall & ST6 beta-galactosamide alpha-2,6-sialyltranferase 1 & -1.52 & $2.48 \mathrm{E}-04$ & $0.93 \%$ \\
\hline St6gal1 & ST6 beta-galactosamide alpha-2,6-sialyltranferase 1 & -1.06 & $2.31 \mathrm{E}-04$ & $0.89 \%$ \\
\hline Stc2 & stanniocalcin 2 & -4.35 & 8.77E-05 & $0.50 \%$ \\
\hline Stra6 & stimulated by retinoic acid gene 6 & -1.16 & $9.07 \mathrm{E}-06$ & $0.16 \%$ \\
\hline Tle2 & transducin-like enhancer of split 2 (E(sp1) homolog, Drosophila) & -1.39 & $2.34 \mathrm{E}-05$ & $0.25 \%$ \\
\hline Tnfrsf11b & tumor necrosis factor receptor superfamily, member $11 \mathrm{~b}$ & -1.82 & $1.28 \mathrm{E}-03$ & $2.46 \%$ \\
\hline Tspan8 & tetraspanin 8 & -1.13 & $2.24 \mathrm{E}-04$ & $0.88 \%$ \\
\hline Ttc39a & tetratricopeptide repeat domain 39A & -2.23 & 4.34E-05 & $0.34 \%$ \\
\hline Ttr & transthyretin & -5.39 & $4.34 \mathrm{E}-06$ & $0.10 \%$ \\
\hline Ugt1a9 & UDP glucuronosyltransferase 1 family, polypeptide A9 & -1.93 & 4.54E-06 & $0.10 \%$ \\
\hline Abcb11 & ATP-binding cassette, sub-family B (MDR/TAP), member 11 & 2.11 & $1.01 \mathrm{E}-04$ & $0.54 \%$ \\
\hline Abcc 8 & ATP-binding cassette, sub-family C (CFTR/MRP), member 8 & 2.25 & $9.26 \mathrm{E}-06$ & $0.16 \%$ \\
\hline Acot5 & acyl-CoA thioesterase 5 & 1.23 & 7.48E-04 & $1.80 \%$ \\
\hline Adcy1 & adenylate cyclase 1 (brain) & 1.69 & 4.98E-06 & $0.11 \%$ \\
\hline Agt & angiotensinogen (serpin peptidase inhibitor, clade A, member 8) & 3.14 & $3.43 \mathrm{E}-06$ & $0.09 \%$ \\
\hline Ahrr & aryl-hydrocarbon receptor repressor & 3.32 & $7.84 \mathrm{E}-06$ & $0.14 \%$ \\
\hline Akr1c1211 & aldo-keto reductase family 1 , member C12-like 1 & 4.82 & $1.56 \mathrm{E}-10$ & $0.00 \%$ \\
\hline Aldh1a1 & aldehyde dehydrogenase 1 family, member A1 & 1.01 & $3.85 \mathrm{E}-06$ & $0.09 \%$ \\
\hline Anxa13 & annexin $\mathrm{A} 13$ & 2.92 & $9.30 \mathrm{E}-07$ & $0.05 \%$ \\
\hline Apoa4 & apolipoprotein A-IV & 1.02 & $3.59 \mathrm{E}-04$ & $1.13 \%$ \\
\hline Apoh & apolipoprotein H (beta-2-glycoprotein I) & 2.95 & 4.33E-08 & $0.02 \%$ \\
\hline Asgr1 & asialoglycoprotein receptor 1 & 1.49 & $3.35 \mathrm{E}-05$ & $0.29 \%$ \\
\hline B4galt5 & UDP-Gal:betaGlcNAc beta 1,4-galactosyltransferase, polypeptide 5 & 1.00 & $1.23 \mathrm{E}-05$ & $0.18 \%$ \\
\hline Bc16 & B-cell CLL/lymphoma 6 & 2.18 & $1.61 \mathrm{E}-05$ & $0.21 \%$ \\
\hline Ccdc67 & coiled-coil domain containing 67 & 1.58 & $5.23 \mathrm{E}-04$ & $1.45 \%$ \\
\hline Ccdc88a & coiled coil domain containing $88 \mathrm{~A}$ & 1.12 & $1.15 \mathrm{E}-04$ & $0.58 \%$ \\
\hline $\mathrm{Cd} 28$ & Cd28 molecule & 1.92 & $3.36 \mathrm{E}-04$ & $1.09 \%$ \\
\hline $\operatorname{Cdh} 22$ & cadherin 22 & 1.10 & $2.01 \mathrm{E}-03$ & $3.16 \%$ \\
\hline Cks2 & CDC28 protein kinase regulatory subunit 2 & 1.06 & $3.81 \mathrm{E}-03$ & $4.55 \%$ \\
\hline Cldn22 & claudin 22 & 1.12 & $7.24 \mathrm{E}-05$ & $0.45 \%$ \\
\hline Cndp1 & carnosine dipeptidase 1 (metallopeptidase M20 family) & 1.45 & 4.23E-04 & $1.27 \%$ \\
\hline Cnnm1 & cyclin M1 & 2.26 & $1.93 \mathrm{E}-05$ & $0.23 \%$ \\
\hline Cpne4 & copine IV & 2.41 & $1.65 \mathrm{E}-03$ & $2.86 \%$ \\
\hline Cpne4 & copine IV & 3.23 & $1.94 \mathrm{E}-04$ & $0.81 \%$ \\
\hline Crb1 & crumbs homolog 1 (Drosophila) & 1.27 & $1.56 \mathrm{E}-03$ & $2.76 \%$ \\
\hline
\end{tabular}




\section{Appendix}

\begin{tabular}{|c|c|c|c|c|}
\hline Csmd1 & CUB and Sushi multiple domains 1 & 1.18 & 4.33E-04 & $1.28 \%$ \\
\hline Сур2c & cytochrome P450, subfamily IIC (mephenytoin 4-hydroxylase) & 5.90 & $3.71 \mathrm{E}-07$ & $0.04 \%$ \\
\hline Cyp2d4v1 & cytochrome P450, family 2 , subfamily d, polypeptide 4 & 1.11 & 4.39E-06 & $0.10 \%$ \\
\hline Сур4a2 & cytochrome P450, family 4, subfamily a, polypeptide 2 & 3.03 & $9.25 \mathrm{E}-04$ & $2.04 \%$ \\
\hline Ddx19a & DEAD (Asp-Glu-Ala-Asp) box polypeptide 19a & 1.05 & $6.57 \mathrm{E}-05$ & $0.43 \%$ \\
\hline Dhrs7 & dehydrogenase/reductase (SDR family) member 7 & 7.34 & $6.24 \mathrm{E}-07$ & $0.04 \%$ \\
\hline Dnajc5b & DnaJ (Hsp40) homolog, subfamily C, member 5 beta & 2.48 & $2.30 \mathrm{E}-04$ & $0.89 \%$ \\
\hline Dnm3 & dynamin 3 & 2.64 & $2.16 \mathrm{E}-07$ & $0.03 \%$ \\
\hline Dpp6 & dipeptidylpeptidase 6 & 1.26 & 2.24E-05 & $0.24 \%$ \\
\hline Dtx4 & deltex homolog 4 (Drosophila) & 1.03 & $2.89 \mathrm{E}-03$ & $3.90 \%$ \\
\hline Eepd1 & endonuclease/exonuclease/phosphatase family domain containing 1 & 1.02 & $2.67 \mathrm{E}-04$ & $0.98 \%$ \\
\hline Epha4 & Eph receptor A4 & 1.06 & 2.99E-05 & $0.28 \%$ \\
\hline Epha4 & Eph receptor A4 & 1.10 & $1.82 \mathrm{E}-04$ & $0.78 \%$ \\
\hline Es22 & esterase 22 & 2.02 & $3.16 \mathrm{E}-07$ & $0.03 \%$ \\
\hline Espn & espin & 1.21 & $1.31 \mathrm{E}-03$ & $2.51 \%$ \\
\hline Esr1 & estrogen receptor 1 & 1.55 & 1.32E-04 & $0.64 \%$ \\
\hline $\mathrm{F} 2$ & coagulation factor II (thrombin) & 1.71 & 2.65E-06 & $0.08 \%$ \\
\hline F3 & coagulation factor III (thromboplastin, tissue factor) & 1.10 & $2.80 \mathrm{E}-05$ & $0.27 \%$ \\
\hline Fabp12 & fatty acid binding protein 12 & 1.04 & $3.32 \mathrm{E}-03$ & $4.17 \%$ \\
\hline Fam132a & family with sequence similarity 132 , member A & 1.62 & 4.97E-04 & $1.40 \%$ \\
\hline Fam186b & family with sequence similarity 186 , member B & 1.11 & $1.26 \mathrm{E}-03$ & $2.45 \%$ \\
\hline Fgf13 & fibroblast growth factor 13 & 1.12 & $3.32 \mathrm{E}-06$ & $0.09 \%$ \\
\hline Fgf13 & fibroblast growth factor 13 & 1.19 & $5.45 \mathrm{E}-06$ & $0.12 \%$ \\
\hline Fibcd1 & fibrinogen $\mathrm{C}$ domain containing 1 & 1.01 & $1.48 \mathrm{E}-03$ & $2.68 \%$ \\
\hline Fitm1 & fat storage-inducing transmembrane protein 1 & 1.75 & $1.99 \mathrm{E}-05$ & $0.23 \%$ \\
\hline Frmpd1 & FERM and PDZ domain containing 1 & 1.33 & $5.38 \mathrm{E}-05$ & $0.39 \%$ \\
\hline Gabbr2 & gamma-aminobutyric acid (GABA) B receptor 2 & 1.32 & $2.96 \mathrm{E}-05$ & $0.28 \%$ \\
\hline Gabrb3 & gamma-aminobutyric acid (GABA) A receptor, beta 3 & 2.60 & 4.38E-07 & $0.04 \%$ \\
\hline Gas2 & growth arrest-specific 2 & 1.40 & 5.73E-07 & $0.04 \%$ \\
\hline Gc & group specific component & 3.94 & 9.47E-06 & $0.16 \%$ \\
\hline Gent1 & glucosaminyl (N-acetyl) transferase 1 , core 2 & 1.41 & $1.65 \mathrm{E}-04$ & $0.73 \%$ \\
\hline Gdf15 & growth differentiation factor 15 & 1.17 & 3.13E-04 & $1.06 \%$ \\
\hline Glp1r & glucagon-like peptide 1 receptor & 1.02 & $3.16 \mathrm{E}-03$ & $4.06 \%$ \\
\hline Gpr1 & G protein-coupled receptor 1 & 1.80 & 4.29E-03 & $4.88 \%$ \\
\hline Gpr77 & G protein-coupled receptor 77 & 1.35 & 1.10E-04 & $0.57 \%$ \\
\hline Gpr83 & G protein-coupled receptor 83 & 3.48 & $6.16 \mathrm{E}-04$ & $1.61 \%$ \\
\hline Grid2ip & glutamate receptor, ionotropic, delta 2 (Grid2) interacting protein & 1.26 & $1.15 \mathrm{E}-03$ & $2.32 \%$ \\
\hline Grpr & gastrin releasing peptide receptor & 1.53 & 2.84E-04 & $1.00 \%$ \\
\hline Gucy1b2 & guanylate cyclase 1 , soluble, beta 2 & 1.87 & $3.45 \mathrm{E}-05$ & $0.30 \%$ \\
\hline Haol & hydroxyacid oxidase (glycolate oxidase) 1 & 1.88 & 1.24E-04 & $0.61 \%$ \\
\hline Hhat & hedgehog acyltransferase & 1.91 & $1.54 \mathrm{E}-04$ & $0.70 \%$ \\
\hline Hmgcs2 & 3-hydroxy-3-methylglutaryl-Coenzyme A synthase 2 (mitochondrial) & 3.30 & 9.19E-06 & $0.16 \%$ \\
\hline Hoxd4 & homeo box D4 & 1.49 & $9.80 \mathrm{E}-08$ & $0.02 \%$ \\
\hline Hsd17b1 & hydroxysteroid (17-beta) dehydrogenase 1 & 1.52 & $1.93 \mathrm{E}-05$ & $0.23 \%$ \\
\hline Jakmip2 & janus kinase and microtubule interacting protein 2 & 1.76 & $2.15 \mathrm{E}-04$ & $0.85 \%$ \\
\hline Kifc1 & kinesin family member $\mathrm{C} 1$ & 1.37 & $3.41 \mathrm{E}-05$ & $0.29 \%$ \\
\hline L1td1 & LINE-1 type transposase domain containing 1 & 1.51 & $3.34 \mathrm{E}-05$ & $0.29 \%$ \\
\hline LOC286989 & UDP-glucuronosyltransferase & 3.84 & $6.17 \mathrm{E}-06$ & $0.12 \%$ \\
\hline
\end{tabular}




\begin{tabular}{|c|c|c|c|c|}
\hline LOC290876 & similar to RIKEN cDNA $1700029 \mathrm{H} 14$ & 1.21 & $2.40 \mathrm{E}-03$ & $3.51 \%$ \\
\hline LOC299312 & similar to $\mathrm{G}$ protein-binding protein CRFG & 1.20 & $1.44 \mathrm{E}-04$ & $0.67 \%$ \\
\hline LOC367975 & similar to B-cell translocation gene 1 & 4.92 & $1.96 \mathrm{E}-06$ & $0.07 \%$ \\
\hline LOC497796 & hypothetical protein LOC497796 & 1.31 & $2.81 \mathrm{E}-04$ & $1.00 \%$ \\
\hline LOC498672 & similar to F40G12.3 & 1.01 & $1.67 \mathrm{E}-03$ & $2.88 \%$ \\
\hline LOC500118 & similar to RIKEN cDNA D330028D13 & 1.14 & 7.09E-05 & $0.45 \%$ \\
\hline LOC501110 & $\begin{array}{l}\text { similar to Glutathione S-transferase A1 (GTH1) (HA subunit 1) (GST-epsilon) } \\
\text { (GSTA1-1) (GST class-alpha) }\end{array}$ & 1.20 & $2.00 \mathrm{E}-05$ & $0.23 \%$ \\
\hline LOC501283 & similar to lipid droplet associated protein & 1.06 & $1.95 \mathrm{E}-06$ & $0.07 \%$ \\
\hline LOC502372 & hypothetical protein LOC502372 & 2.76 & $4.26 \mathrm{E}-05$ & $0.34 \%$ \\
\hline LOC685001 & $\begin{array}{l}\text { similar to MIR-interacting saposin-like protein precursor (Transmembrane } \\
\text { protein 4) (Putative secreted protein ZSIG9) }\end{array}$ & 1.33 & $6.31 \mathrm{E}-05$ & $0.43 \%$ \\
\hline LOC687842 & similar to Cytochrome P450 2C24 (CYPIIC24) (P450-PROS2) & 5.61 & 1.34E-07 & $0.02 \%$ \\
\hline LOC688832 & hypothetical protein LOC688832 & 3.65 & $1.02 \mathrm{E}-06$ & $0.05 \%$ \\
\hline LOC689316 & hypothetical protein LOC689316 & 1.36 & $1.99 \mathrm{E}-03$ & $3.15 \%$ \\
\hline LOC689842 & $\begin{array}{l}\text { similar to Nucleolar GTP-binding protein } 1 \text { (Chronic renal failure gene } \\
\text { protein) (GTP-binding protein NGB) }\end{array}$ & 1.13 & $1.96 \mathrm{E}-05$ & $0.23 \%$ \\
\hline LOC690226 & similar to dehydrogenase/reductase (SDR family) member 7 & 5.45 & 4.06E-10 & $0.00 \%$ \\
\hline LOC691416 & hypothetical protein LOC691416 & 1.26 & $6.55 \mathrm{E}-06$ & $0.13 \%$ \\
\hline LOC691416 & hypothetical protein LOC691416 & 1.53 & 9.86E-06 & $0.16 \%$ \\
\hline Masp2 & mannan-binding lectin serine peptidase 2 & 1.21 & 2.02E-04 & $0.83 \%$ \\
\hline Mbl1 & mannose-binding lectin (protein A) 1 & 2.63 & $1.60 \mathrm{E}-05$ & $0.21 \%$ \\
\hline Melk & maternal embryonic leucine zipper kinase & 3.61 & $1.78 \mathrm{E}-09$ & $0.00 \%$ \\
\hline Mlc1 & $\begin{array}{l}\text { megalencephalic leukoencephalopathy with subcortical cysts } 1 \text { homolog } \\
\text { (human) }\end{array}$ & 3.88 & 7.65E-08 & $0.02 \%$ \\
\hline Mlph & melanophilin & 1.91 & $1.53 \mathrm{E}-06$ & $0.06 \%$ \\
\hline Mmp12 & matrix metallopeptidase 12 & 1.14 & 4.43E-03 & $4.96 \%$ \\
\hline Mpped1 & metallophosphoesterase domain containing 1 & 6.17 & $1.39 \mathrm{E}-07$ & $0.02 \%$ \\
\hline Mybl1 & myeloblastosis oncogene-like 1 & 2.47 & $3.66 \mathrm{E}-06$ & $0.09 \%$ \\
\hline $\mathrm{Nefm}$ & neurofilament, medium polypeptide & 3.03 & $3.59 \mathrm{E}-08$ & $0.02 \%$ \\
\hline Nrep & neuronal regeneration related protein & 1.16 & 2.97E-04 & $1.02 \%$ \\
\hline Obfc2a & oligonucleotide/oligosaccharide-binding fold containing $2 \mathrm{~A}$ & 1.17 & $2.45 \mathrm{E}-05$ & $0.26 \%$ \\
\hline Olr857 & olfactory receptor 857 & 2.42 & $2.89 \mathrm{E}-03$ & $3.90 \%$ \\
\hline Ostalpha & organic solute transporter alpha & 1.13 & $3.06 \mathrm{E}-05$ & $0.28 \%$ \\
\hline Panx2 & pannexin 2 & 1.04 & 4.01E-05 & $0.32 \%$ \\
\hline Pecr & peroxisomal trans-2-enoyl-CoA reductase & 1.15 & $9.75 \mathrm{E}-05$ & $0.53 \%$ \\
\hline Picalm & phosphatidylinositol binding clathrin assembly protein & 1.14 & $2.96 \mathrm{E}-06$ & $0.08 \%$ \\
\hline Pipox & pipecolic acid oxidase & 1.94 & 4.92E-04 & $1.39 \%$ \\
\hline Plc12 & phospholipase C-like 2 & 1.54 & $1.34 \mathrm{E}-05$ & $0.19 \%$ \\
\hline Polr3g & polymerase (RNA) III (DNA directed) polypeptide G (32kD) & 1.34 & $3.14 \mathrm{E}-05$ & $0.28 \%$ \\
\hline Polr3g & polymerase (RNA) III (DNA directed) polypeptide G (32kD) & 1.40 & $8.02 \mathrm{E}-06$ & $0.14 \%$ \\
\hline Ppm1j & protein phosphatase $1 \mathrm{~J}$ & 1.57 & 2.96E-05 & $0.28 \%$ \\
\hline Prima1 & proline rich membrane anchor 1 & 3.00 & 5.37E-06 & $0.12 \%$ \\
\hline Prlr & prolactin receptor & 1.14 & 1.82E-04 & $0.78 \%$ \\
\hline Proc & protein $\mathrm{C}$ & 1.01 & 2.22E-07 & $0.03 \%$ \\
\hline Ptgds & prostaglandin D2 synthase (brain) & 2.19 & $2.46 \mathrm{E}-06$ & $0.08 \%$ \\
\hline Ptpn22 & protein tyrosine phosphatase, non-receptor type 22 (lymphoid) & 2.21 & $2.00 \mathrm{E}-06$ & $0.07 \%$ \\
\hline Rarres1 & retinoic acid receptor responder (tazarotene induced) 1 & 2.57 & $2.24 \mathrm{E}-05$ & $0.24 \%$ \\
\hline Rasa2 & RAS p21 protein activator 2 & 1.04 & 5.92E-05 & $0.41 \%$ \\
\hline Rasl12 & RAS-like, family 12 & 2.18 & $2.12 \mathrm{E}-05$ & $0.24 \%$ \\
\hline Rdh2 & retinol dehydrogenase 2 & 1.56 & 4.49E-04 & $1.31 \%$ \\
\hline
\end{tabular}




\section{Appendix}

\begin{tabular}{|c|c|c|c|c|}
\hline $\operatorname{Rdh} 2$ & retinol dehydrogenase 2 & 1.85 & $1.14 \mathrm{E}-03$ & $2.30 \%$ \\
\hline Reep6 & receptor accessory protein 6 & 1.20 & $1.78 \mathrm{E}-06$ & $0.07 \%$ \\
\hline RGD1304605 & hypothetical LOC299944 & 6.56 & 1.63E-08 & $0.01 \%$ \\
\hline RGD1305412 & similar to exonuclease NEF-sp & 1.35 & $8.70 \mathrm{E}-05$ & $0.50 \%$ \\
\hline RGD1305733 & similar to RIKEN cDNA 2900011008 & 2.03 & 5.91E-05 & $0.41 \%$ \\
\hline RGD1305733 & similar to RIKEN cDNA 2900011008 & 2.32 & 7.52E-05 & $0.46 \%$ \\
\hline RGD1309170 & similar to hypothetical protein DKFZp434G072 & 1.48 & $2.36 \mathrm{E}-03$ & $3.47 \%$ \\
\hline RGD1310641 & similar to hypothetical protein & 2.55 & $1.11 \mathrm{E}-03$ & $2.26 \%$ \\
\hline RGD1311575 & hypothetical LOC289568 & 1.38 & $4.58 \mathrm{E}-04$ & $1.33 \%$ \\
\hline RGD1561849 & similar to RIKEN cDNA 3110035E14 & 1.21 & $1.22 \mathrm{E}-03$ & $2.41 \%$ \\
\hline RGD1561849 & similar to RIKEN cDNA 3110035E14 & 2.63 & $1.64 \mathrm{E}-04$ & $0.73 \%$ \\
\hline RGD1562024 & RGD1562024 & 1.37 & $8.63 \mathrm{E}-05$ & $0.50 \%$ \\
\hline RGD1562043 & similar to Claudin-22 & 2.20 & $9.74 \mathrm{E}-04$ & $2.11 \%$ \\
\hline RGD1562344 & similar to Gm566 protein & 2.28 & $7.26 \mathrm{E}-07$ & $0.04 \%$ \\
\hline RGD1563748 & similar to ankyrin-like protein & 1.84 & $5.69 \mathrm{E}-04$ & $1.53 \%$ \\
\hline RGD1563821 & RGD1563821 & 2.43 & 3.54E-04 & $1.12 \%$ \\
\hline RGD1563825 & similar to ENSANGP00000020885 & 4.17 & $4.46 \mathrm{E}-06$ & $0.10 \%$ \\
\hline RGD1563825 & similar to ENSANGP00000020885 & 4.78 & $9.00 \mathrm{E}-07$ & $0.05 \%$ \\
\hline RGD1564391 & RGD1564391 & 1.73 & 3.17E-07 & $0.03 \%$ \\
\hline RGD1565166 & similar to MGC45438 protein & 1.47 & $2.40 \mathrm{E}-05$ & $0.25 \%$ \\
\hline Rgn & regucalcin (senescence marker protein-30) & 1.45 & $6.74 \mathrm{E}-04$ & $1.70 \%$ \\
\hline Rpp25 & ribonuclease P 25 subunit (human) & 1.77 & 4.64E-05 & $0.35 \%$ \\
\hline Rufy3 & RUN and FYVE domain containing 3 & 1.06 & $2.06 \mathrm{E}-03$ & $3.20 \%$ \\
\hline Scgb1c1 & secretoglobin, family $1 \mathrm{C}$, member 1 & 1.20 & $1.70 \mathrm{E}-04$ & $0.75 \%$ \\
\hline Sectm $1 b$ & secreted and transmembrane $1 \mathrm{~B}$ & 1.21 & 5.43E-05 & $0.40 \%$ \\
\hline Sema5a & $\begin{array}{l}\text { sema domain, seven thrombospondin repeats (type } 1 \text { and type 1-like), } \\
\text { transmembrane domain (TM) and short cytoplasmic domain, (semaphorin) 5A }\end{array}$ & 1.00 & $7.60 \mathrm{E}-05$ & $0.46 \%$ \\
\hline Sema5a & $\begin{array}{l}\text { sema domain, seven thrombospondin repeats (type } 1 \text { and type 1-like), } \\
\text { transmembrane domain (TM) and short cytoplasmic domain, (semaphorin) } 5 \mathrm{~A}\end{array}$ & 1.25 & $1.00 \mathrm{E}-06$ & $0.05 \%$ \\
\hline Sept3 & septin 3 & 1.00 & 9.82E-06 & $0.16 \%$ \\
\hline Slc10a1 & solute carrier family 10 (sodium/bile acid cotransporter family), member 1 & 1.12 & $3.98 \mathrm{E}-04$ & $1.21 \%$ \\
\hline Slc24a2 & solute carrier family 24 (sodium/potassium/calcium exchanger), member 2 & 1.05 & $1.52 \mathrm{E}-04$ & $0.69 \%$ \\
\hline Slc30a2 & solute carrier family 30 (zinc transporter), member 2 & 1.26 & 7.12E-06 & $0.13 \%$ \\
\hline Slc35f1 & solute carrier family 35 , member F1 & 1.04 & $6.59 \mathrm{E}-04$ & $1.68 \%$ \\
\hline Slc39a41 & solute carrier family 39 (zinc transporter), member 4-like & 1.09 & 1.59E-05 & $0.21 \%$ \\
\hline Slc6a4 & solute carrier family 6 (neurotransmitter transporter, serotonin), member 4 & 1.08 & $1.36 \mathrm{E}-05$ & $0.19 \%$ \\
\hline Slco1a1 & solute carrier organic anion transporter family, member 1a1 & 7.42 & 1.99E-06 & $0.07 \%$ \\
\hline Sntg2 & syntrophin, gamma 2 & 1.83 & $2.32 \mathrm{E}-05$ & $0.25 \%$ \\
\hline Spc25 & SPC25, NDC80 kinetochore complex component, homolog (S. cerevisiae) & 1.02 & $1.73 \mathrm{E}-03$ & $2.92 \%$ \\
\hline Spns3 & spinster homolog 3 (Drosophila) & 1.41 & $2.75 \mathrm{E}-03$ & $3.79 \%$ \\
\hline Stom & stomatin & 1.12 & $1.19 \mathrm{E}-03$ & $2.36 \%$ \\
\hline Tff3 & trefoil factor 3, intestinal & 1.39 & $9.23 \mathrm{E}-04$ & $2.04 \%$ \\
\hline Tm4sf20 & transmembrane $4 \mathrm{~L}$ six family member 20 & 3.47 & $1.56 \mathrm{E}-06$ & $0.06 \%$ \\
\hline Tmem144 & transmembrane protein 144 & 1.02 & $3.89 \mathrm{E}-05$ & $0.32 \%$ \\
\hline Tmem144 & transmembrane protein 144 & 1.09 & $1.85 \mathrm{E}-04$ & $0.79 \%$ \\
\hline Tmem169 & transmembrane protein 169 & 1.25 & $1.71 \mathrm{E}-03$ & $2.92 \%$ \\
\hline Tmod1 & tropomodulin 1 & 1.27 & $2.94 \mathrm{E}-04$ & $1.02 \%$ \\
\hline Tmprss4 & transmembrane protease, serine 4 & 1.77 & 7.99E-04 & $1.89 \%$ \\
\hline Tox & thymocyte selection-associated high mobility group box & 1.07 & $1.81 \mathrm{E}-05$ & $0.22 \%$ \\
\hline Tph1 & tryptophan hydroxylase 1 & 1.41 & $1.17 \mathrm{E}-07$ & $0.02 \%$ \\
\hline
\end{tabular}


Appendix

\begin{tabular}{|l|l|c|c|c|}
\hline Tpx2 & TPX2, microtubule-associated, homolog (Xenopus laevis) & 1.30 & $5.76 \mathrm{E}-05$ & $0.41 \%$ \\
\hline Trim59 & tripartite motif-containing 59 & 1.02 & $5.78 \mathrm{E}-06$ & $0.12 \%$ \\
\hline Trpm8 & transient receptor potential cation channel, subfamily M, member 8 & 1.42 & $5.97 \mathrm{E}-04$ & $1.58 \%$ \\
\hline Usp9x & ubiquitin specific peptidase 9, X-linked & 2.35 & $2.53 \mathrm{E}-03$ & $3.60 \%$ \\
\hline Ust5r & integral membrane transport protein UST5r & 1.07 & $1.85 \mathrm{E}-04$ & $0.79 \%$ \\
\hline Vom2r36 & vomeronasal 2 receptor, 36 & 1.58 & $1.54 \mathrm{E}-03$ & $2.74 \%$ \\
\hline Zfp93 & zinc finger protein 64 & 1.29 & $1.14 \mathrm{E}-05$ & $0.17 \%$ \\
\hline
\end{tabular}

FC: $\log 2$ fold-change $(F C) \leq-1$ or $\geq 1$, FDR: false discovery rate, (m-f): male-female. Genes are displayed in an alphabetical order, starting with negative $\log 2 \mathrm{FC}$ representing genes higher expressed in females, followed by genes with a positive $\log 2 \mathrm{FC}$ representing higher expression in males. Probes with a FDR $>5 \%$ and probes with no Gene ID are excluded in this list (Wegner et al. 2012). 